Departamento \& medicina

Facultad \& medicina

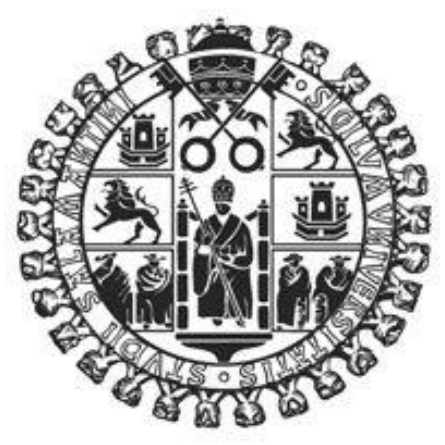

Universidad \& salamanca

\title{
Estudio de polimorfismos de genes reparadores del ADN en cáncer de mama
}

Autor:

Elena Castro Marcos

Directores:

Prof. Juan Jesús Cruz Hernández

Prof. Rogelio Gonzalez Sarmiento

Salamanca, $22 \&$ octubre 2010 
A mis padres, que han hecho todo por mí.

A mis abuelos, que no pudieron estudiar y siempre me insistieron en la importancia de que yo lo hiciera.

A David, sin quien nada sería lo mismo.

Agradezco a mis supervisores de tesis, así como a mis compañeros del Servicio de Oncología y del laboratorio, la ayuda prestada en la realización de este trabajo. 
Los resultados de este trabajo han sido presentados en los siguientes congresos científicos:

- 2010 ASCO Annual Meeting (American Society of Clinical Oncology) 4-8 Junio 2010, Chicago, Illinois (EEUU)

General Poster Session, Breast Cancer, Adjuvant therapy.

Póster. Abstract: 619

Título: Germline single nucleotide polymorphisms (SNPS) in XRCC3, XRCC1, and XPD, and survival outcomes after adjuvant chemotherapy (CT) in early breast cancer (EBC) patients (pts).

Publicado en: Journal of Clinical Oncology 28:15s, 2010 (abst r619)

- IMPAKT 2010 Breast Cancer Conference (European Society of Medical Oncology) 6-8 Mayo, 2010, Bruselas (Bélgica)

Póster. Adjuvant Medical Therapy Session.

Abstract: 67

Título: Germline single nucleotide polymorphisms in XRCC3, XRCC1, and XPD, and survival outcomes after adjuvant chemotherapy in early breast cancer patients.

Publicado en: Annals of Oncology, 21: 4s, 2010 (suppl, abstr 67)

- XI congreso ASEICA, 2007 (Asociación Española para la Investigación del Cáncer) 10-12 Mayo, 2007, Las Palmas de Gran Canaria (España)

Póster. Breast Cancer

Abstract: 104

Título: Polymorphisms in DNA repiar genes, risk of breast cancer and longevity.

Publicado en: Clinical and Translational Oncology, vol 9, extraordinary 1, May 2007 (abstract 104)

Premios:

- El trabajo presentado en IMPAKT 2010 Breast Cancer Conference fue merecedor de Travel Grant/Merit Award 


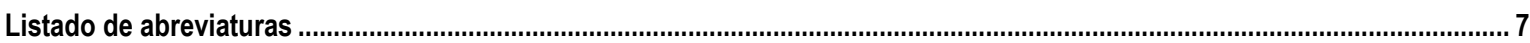

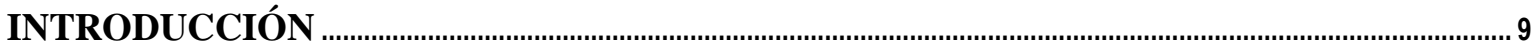

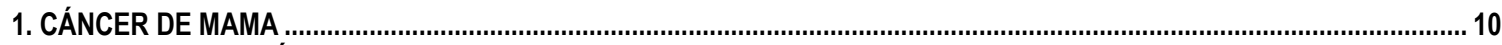

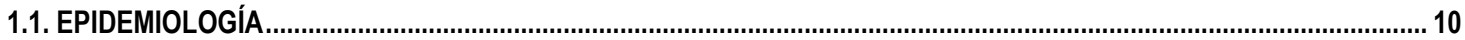

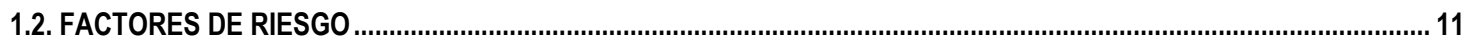

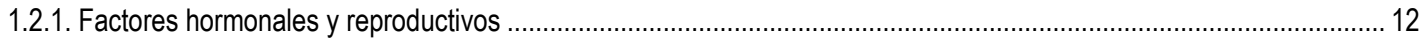

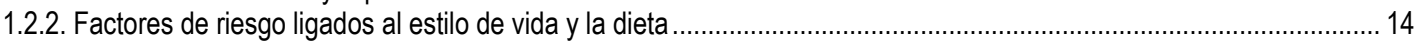

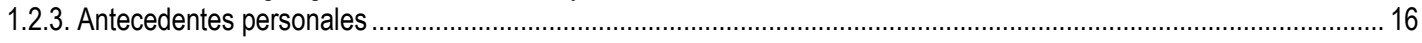

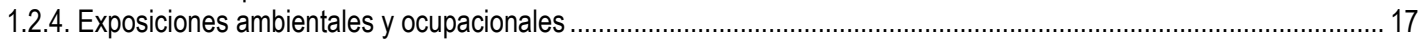

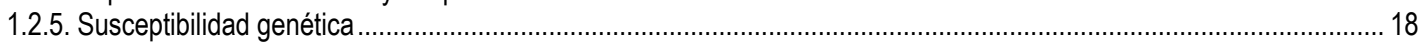

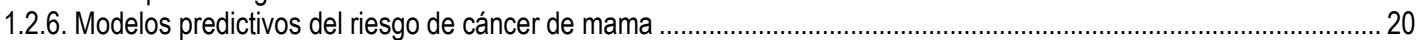

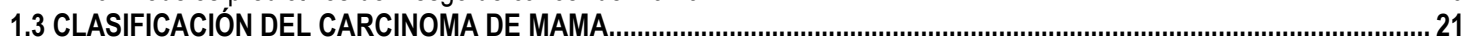

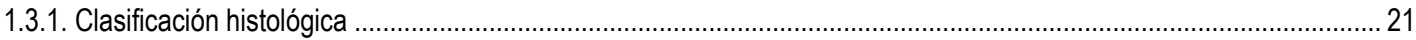

1.3.2. Clasificación del cáncer de mama según patrones de expresión génica ................................................................. 22

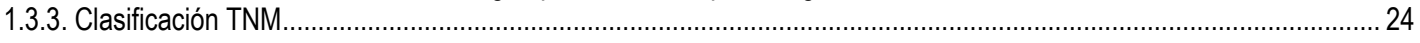

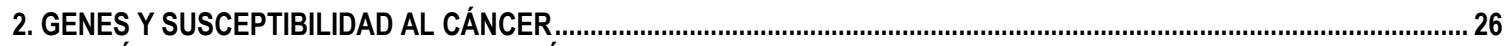

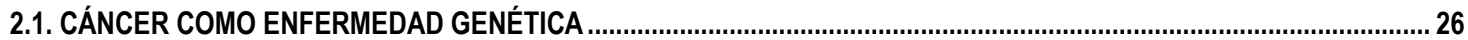

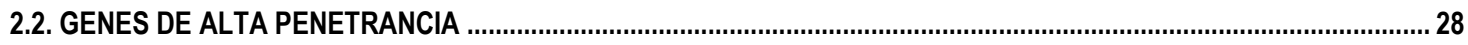

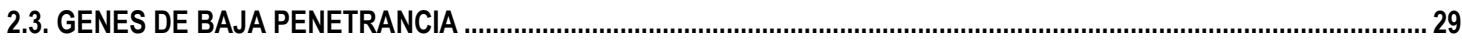

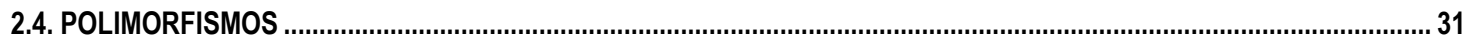

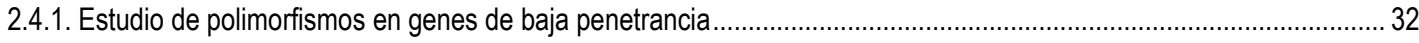

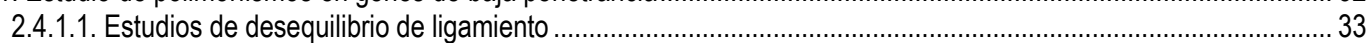

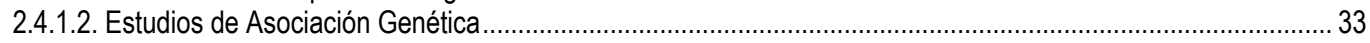

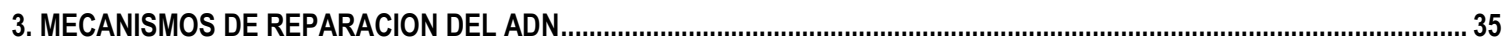

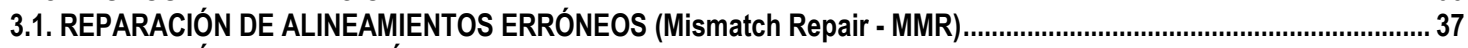

3.2. REPARACIÓN POR ESCISIÓN DE BASES (Base Escisión Repair-BER) ...............................................................4 40

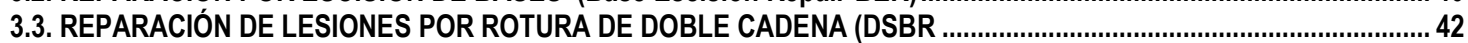

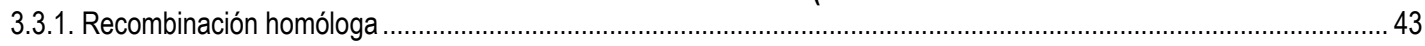

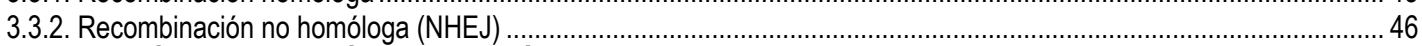

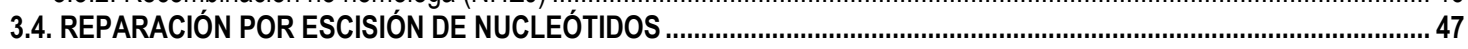

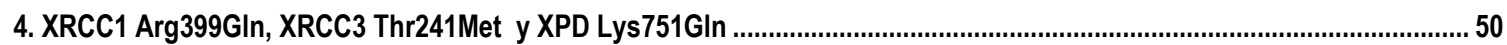

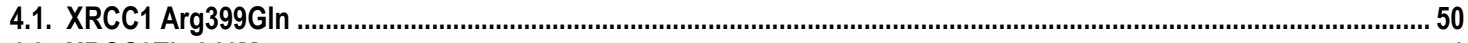

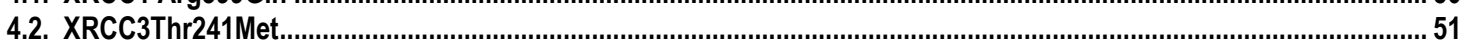

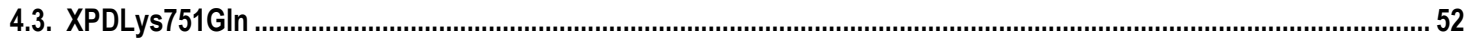

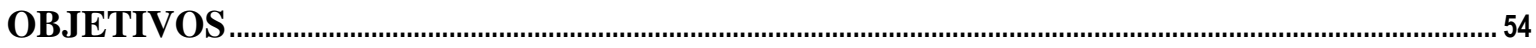

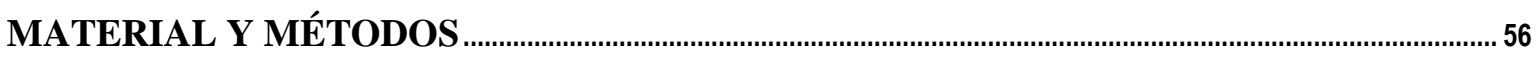

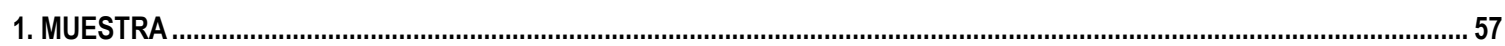

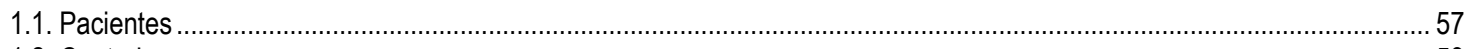

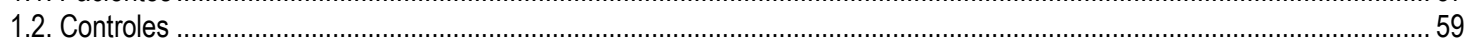

2. AISLAMIENTO DE ADN GENÓMICO

3. ESTUDIO DE LOS POLIMORFISMOS XRCC3Thr241Met, XPD Lys751GIn y XRCC1 Arg399GIn ....................................62

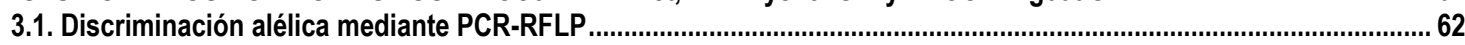

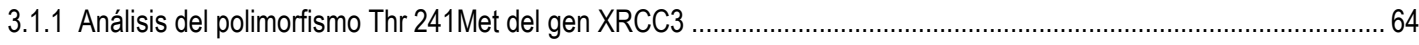

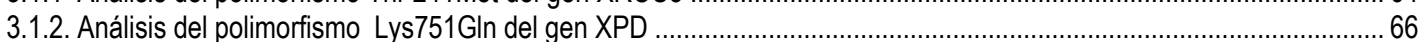

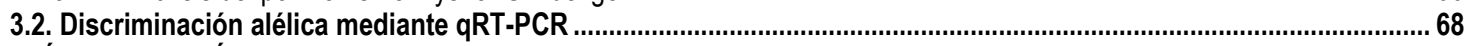

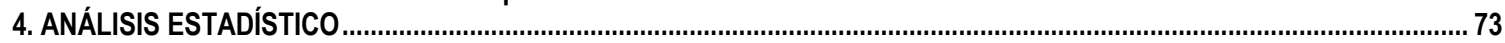


RESULTADOS

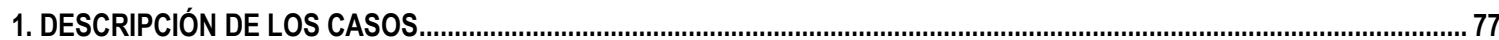

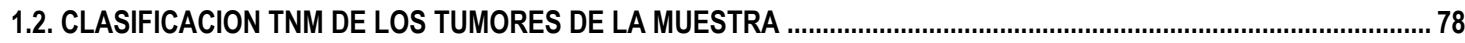

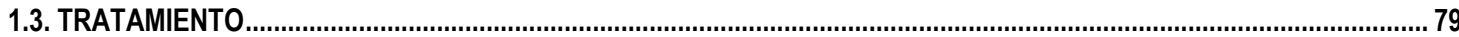

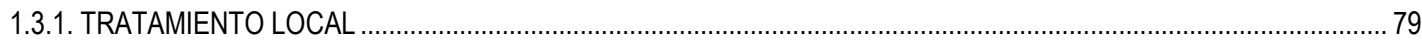

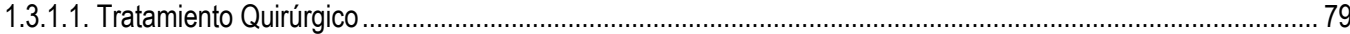

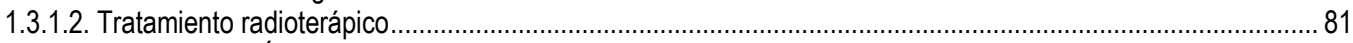

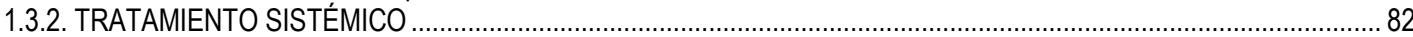

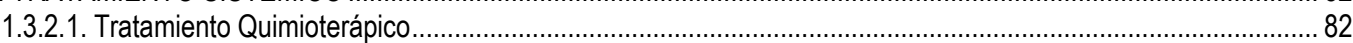

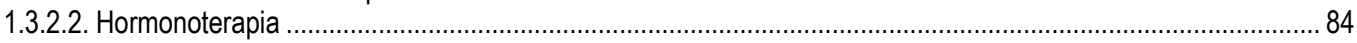

2. ESTUDIO DE XPDLys751GIn, XRCC1Arg399GIn y XRCC3Thr241Met ............................................................................86

2.1. Estudio de XPDLys751Gln, XRCC1Arg399Gln y XRCC3Thr241Met en casos y controles .......................................... 86

2.2. Estudio de XPDLys751GIn, XRCC1Arg399GIn y XRCC3Thr241Met en relación con la edad en los grupos caso y control

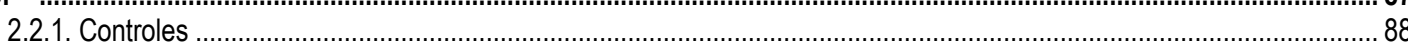

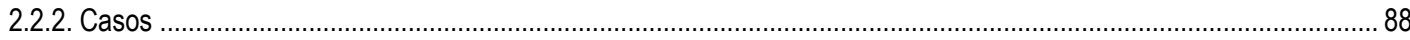

2.3. Estudio de XPDLys751GIn, XRCC1Arg399GIn y XRCC3Thr241Met en relación con el tratamiento radioterápico .... 90

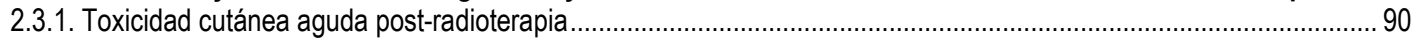

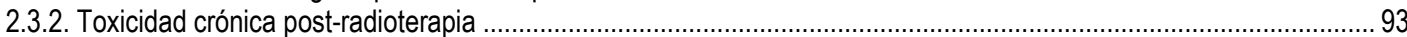

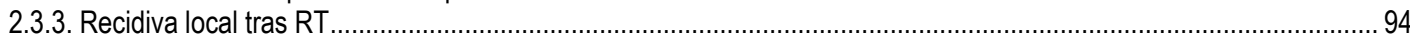

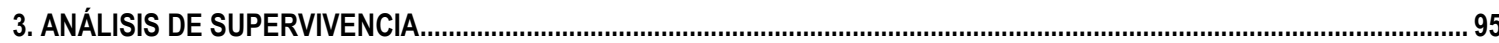

3.1. PACIENTES CON ENFERMEDAD LOCAL

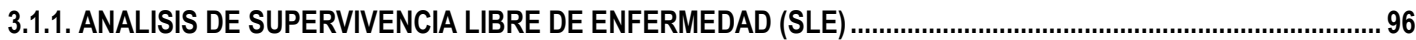

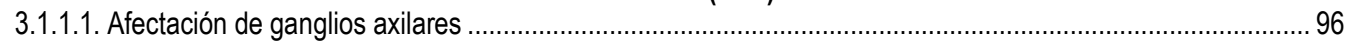

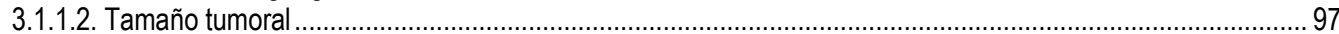

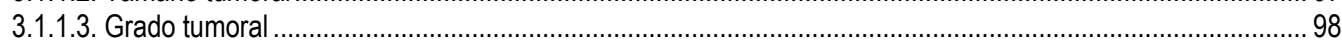

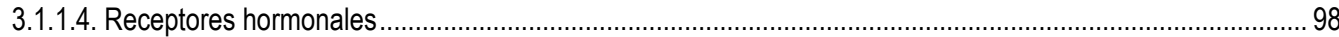

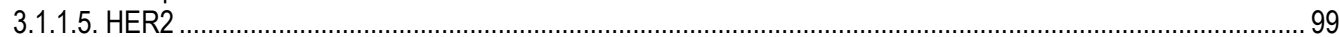

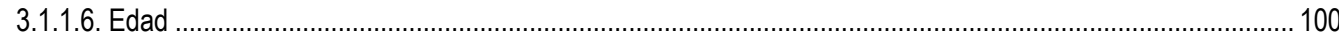

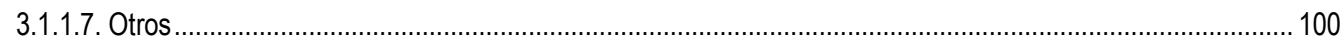

3.1.1.8. Análisis de XRCC3Thr241Met, XRCC1Arg399GIn y XPDLys751Gln en relación con SLE

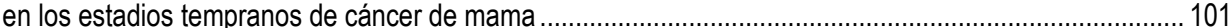

3.1.2. SUPERVIVENCIA GLOBAL

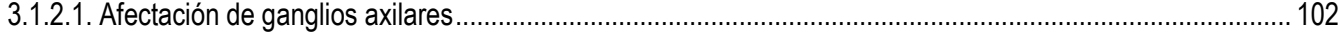

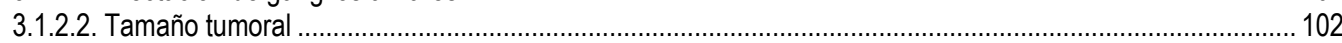

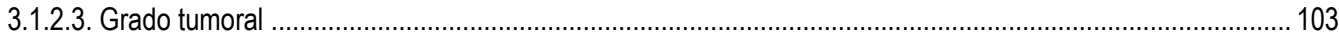

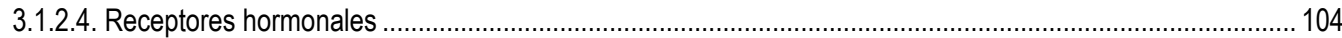

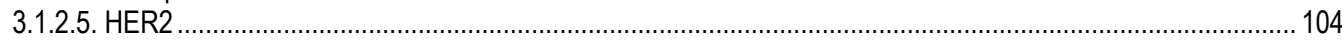

3.1.2.6. XRCC3Thr241Met, XRCC1Arg399GIn y XPDLys751GIn en relación con SG ......................................... 105

3.1.3. ANALISIS DE SUPERVIVENCIA EN PACIENTES TRATADAS CON ANTRACICLINAS EN ADYUVANCIA $O$

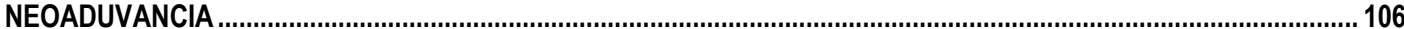

3.1.3.1. SLE en pacientes tratadas con antraciclinas en adyuvancia o neoadyuvancia ....................................... 108

3.1.3.2. SG en las pacientes tratadas con antracilinas en adyuvancia o neoadyuvancia ...................................... 111

3.1.3.3. Pacientes tratadas con antraciclinas en adyuvancia y neoadyuvancia excluyendo las que recibieron taxanos.......................................................... 114

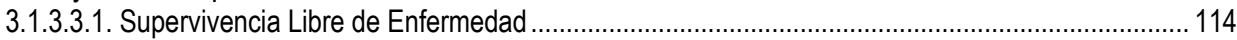

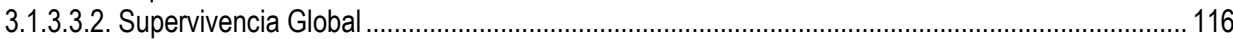

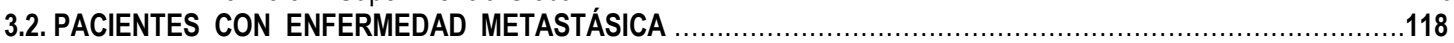

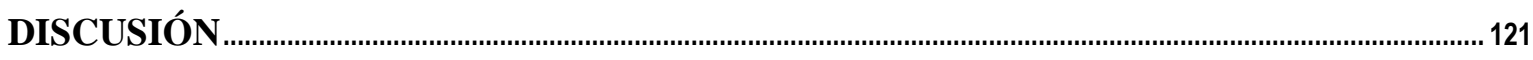

1. ESTUDIOS DE ASOCIACIÓN EN CASOS Y CONTROLES..........................................................................................123

1.1. XRCC3 Thr241Met, XRCC1 Arg399GIn, XPDLys751GIn como modificadores del riesgo de cáncer de mama ............ 125

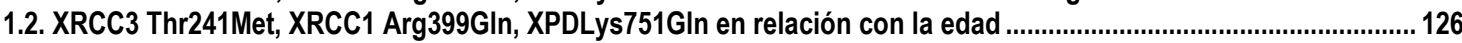

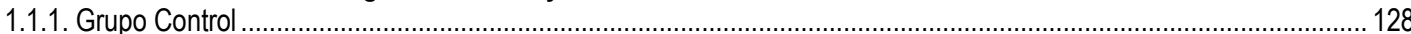

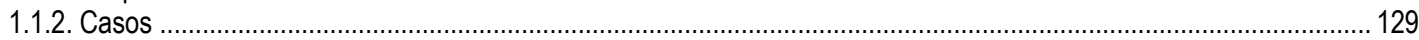

2. ANALISIS RADIO Y FARMACOGENÓMICO DE LAS VARIANTES XRCC3Thr241Met, XRCC1Arg399GIn, XPDLys751Gln EN CÁNCER DE MAMA 
2.1. XRCC3Thr241Met, XRCC1Arg399GIn y XPDLys751GIn y radioterapia

2.2. XRCC3Thr241Met, XRCC1Arg399GIn XPDLys751GIn en relación con el tratamiento con antraciclinas en pacientes con cáncer de mama temprano.

CONCLUSIONES 143

SUMMARY 145

BIBLIOGRAFÍA 171 


\section{Listado de abreviaturas}

5-FU: 5-Fluoruracilo

A: adenina

ADN: Ácido desoxirribonucleico

AJCC: American Joint Committee on Cancer

Arg: Arginina

ARN: Ácido ribonucleico

ATM: Ataxia-teleangiectasia mutated

ATP: Adenosín trifosfoato

BER: Reparación por escisión de bases

BGC: Biopsia del Ganglio Centinela

BRCA1, 2: Breast Cancer 1, 2

BRCT: Extremo C-terminal de BRCA

C: Citosina

Ca. Mama: Cáncer de mama

CDI: Carcinoma Ductal Infiltrante

CLI: Carcinoma Lobulillar Infiltrante

CS: Síndrome de Cockayne

Des. Stand: Desviación estándar de la media

DL: Desequilibrio de ligamiento

dNTP: Desoxinucleotido trifosfato

DSBR: Reparación de roturas de doble cadena

E2F1: E2F transcription factor 1

EGFR: Receptor del factor de crecimiento epidérmico

EX011: Exonucleasa 11

G: Guanina

GG-NER: Global Genomic Repair

Gln: Glutamina

GWAs: Genome Wide Association studies

Gy: Gray

HER2: Human Epidermal Receptor 2

HNPCC: Cáncer de colon hereditario no polipósico

HR: Hazard Ratio

HR: Recombinación Homóloga
IGF-1: Insulin Growth Factor 1

LHRH: Hormona Liberadora de gonadotropina

LIG I, III: Ligasa I y III

LKB1/STK11: Serin -Treonin kinase11

Lys: Lisina

M: Metástasis

Met: Metionina

Min: minutos

MLH1: MutL homolog 1

MMR: Mismatch Repair

MRN : Complejo NBS1/Mre11/RAD50

MSH2: MutS homolog 2

MSH6: MutS homolog 6

MSI: inestabilidad de microsatélites

Mut:: Mutación

$\mathrm{N}$ : Ganglios

NER: Reparación por escisión de nucleótidos

NHEJ: Non-homologous end joining

NSB1: Nibrina

PARP: Poli ADP ribose polymerase

$\mathrm{Pb}$ : pares de bases

$\mathrm{Pb}$ : Pares de bases

PCNA: proliferating cell nuclear antigen

PCR: Reacción en cadena de la polimerasa

PK: Proteína kinasa

PMS2: Postmeiotic segregation increased 2

PNK: Polinucleotide Kinase

POL $\beta, \delta, \lambda, \mu$ : Polimerasa $\beta, \delta, \lambda, \mu$

PTEN: Phosphatase and Tensin homolog

RAD51: RecA homolog

$\mathrm{RE}:$ Receptor de estrógenos

RFC: Replication factor $C$

RFLP: Fragmentos de restricción de longitud polimórfica

RH: Receptores Hormonales 
RP: Receptor de progestagenos

RT: Radioterapia

RTOG: Radiation Therapy Oncology Group

RT-PCR: PCR en tiempo real

SDSA: Synthesis Depending Strand Annealing

Sec: Segundos

SG: Supervivencia global

$S G_{M}$ : Supervivencia Global desde la Metástasis

SLE: Supervivencia Libre de Enfermedad

SNP: Single nucleotide polymorphisms

ssADN: ADN de cadena sencilla

T: Tamaño tumoral

$\mathrm{T}$ : timina

TASPE: Transplante autólogo de progenitores hematopoyéticos de sangre periférica

TCR-NER: Transcription coupled nucleotide excision repair

Tdp1: Tyrosil-DNA phosphodiesterase

TFIIH: Transcription Factor IIH

Thr: Treonina

Topo II: Topoisomerasa II

TTD: Tricotiodistrofia

UICC: Union Internationale Contre le Cancer

UNG: Uracil-N-glicosilasa

UV: ultravioleta

Wrn: Werner syndrome

XP: Xeroderma Pigmentoso

XPD: Xeroderma Pigmentoso D

XRCC: $X$-ray repair cross complementation group 
INTRODUCCIÓN 


\section{CÁNCER DE MAMA}

\subsection{EPIDEMIOLOGÍA}

El cáncer de mama es el tumor más frecuente entre las mujeres occidentales y se estima que representa el $25-20 \%$ de todos los nuevos casos de cáncer diagnosticados en mujeres. La incidencia y mortalidad por esta patología presentan una gran variabilidad geográfica, observándose una mayor incidencia en Norte América, Australia, Países Nórdicos, Europa occidental y Argentina1,2. En la Unión Europea, según los datos presentados en 2010 por la Dirección General para la Salud y los Consumidores, el cáncer de mama es el cáncer más frecuente entre las europeas, ya que supone el $30 \%$ de todos los nuevos casos de neoplasias en mujeres, y la principal causa de muerte por cáncer antes de los 75 años en todos los países miembros de la Unión ${ }^{3}$. En España, afecta a una de cada trece mujeres, se diagnostican entorno a 16000 casos al año y produce anualmente la muerte de unas 6000 mujeres $^{4}$. El cáncer de mama constituye, sin ninguna duda, un importante problema de salud pública.

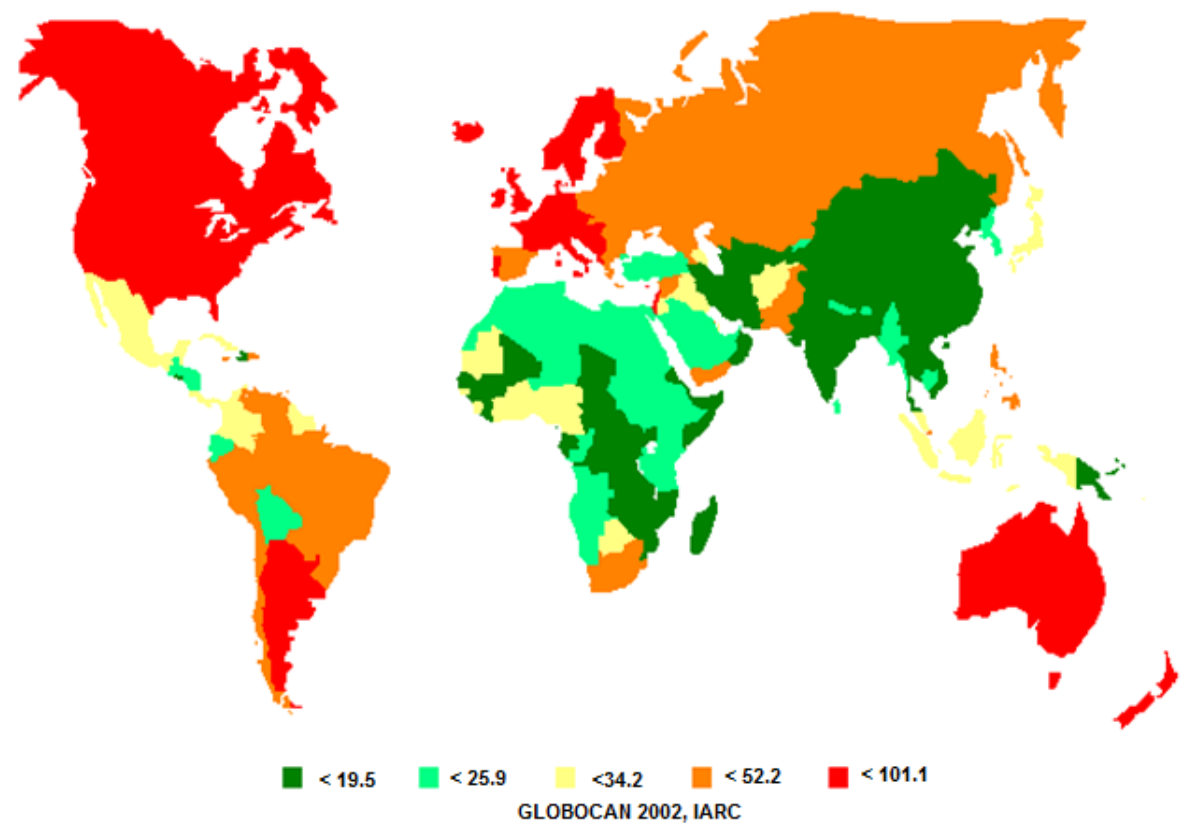

Figura 1:Tasas de incidencia de cáncer de mama estandarizadas por edad en el mundo. Estimación de los casos anuales por cada /10000 mujeres-año en el $2002^{5}$ 
A lo largo del siglo XX se produjo un paulatino incremento de la incidencia, motivado tanto por los cambios en los hábitos de vida, como por el aumento de los diagnósticos debido a la introducción de los programas de cribado y a la mejora de las técnicas diagnósticas. En las últimas décadas del siglo asistimos un aumento en países que tradicionalmente mostraban las tasas más bajas y una estabilización en aquellos en los que las tasas de incidencia habían sido mayores en los años previos, atenuándose las diferencias geográficas observadas hasta entonces 6 .

La mortalidad también ha tenido una evolución llamativa. En la mayoría de los países desarrollados, sufrió un importante aumento desde los años 50 hasta la década de los $80^{6}$, sin embargo, los programas de diagnóstico precoz y el éxito de los nuevos tratamientos han hecho que esta tendencia comenzara a invertirse desde los años 90. En Europa, la supervivencia a 5 años aumentó entre 1992 y 2002 en un 1,6\% anual, situándose actualmente entorno al 83\%, si bien aún existen diferencias entre los países de la Unión Europea, oscilando entre el 73\% de Polonia y el $85 \%$ de Suecia $3,7,8$.

La evolución de los datos de incidencia y mortalidad por cáncer de mama en España ha sido paralela a la del resto de países desarrollados y actualmente, supone casi el $25 \%$ de todas las neoplasias malignas diagnosticadas en mujeres españolas. Mientras que la incidencia aumenta a un ritmo del 2-3\% anual, la tasa de mortalidad comenzó a descender en 1992 en torno al 1.8-2\% anual. Este descenso, aunque se produce en todos los grupos de edad, es más acusado en las menores de 45 años. La tasa ajustada de mortalidad en 2006 se situaba en 18.6 casos por 100.000 mujeres/año, inferior a la estimada para el conjunto de Europa. Al mismo tiempo, la supervivencia a los 5 años es del 83\%, entre las más altas de la Unión Europea4.

\subsection{FACTORES DE RIESGO}

El incremento en riesgo de desarrollar cáncer de mama, se ha asociado a múltiples factores como la edad, la historia familiar o la dieta, aunque los principales son aquellos que guardan relación con el carácter hormonodependiente de este tumor, y la mayoría de los factores conllevan un riesgo de pequeño a moderado de desarrollar esta patología 9 . Habitualmente no es 
posible señalar una única causa como origen del cáncer de mama en una determinada paciente, ni siquiera en aquellas que portan mutaciones en genes de alta penetrancia rantica (p.e. BRCA1 y BRCA2) y debemos entender que éste es debido a la interacción de una serie de factores hormonales, dietéticos, de hábitos de vida y genéticos (Tabla 1).

Tabla 1. Magnitud del riesgo relativo de cancer de mama estimado para diferentes factores 9

\begin{tabular}{|c|c|c|}
\hline Riesgo Relativo <2 & Riesgo Relativo 2-4 & Riesgo Relativo $\geq 4$ \\
\hline $\begin{array}{l}\text { Menarquía temprana } \\
\text { Menopausia tardía } \\
\text { Nuliparidad } \\
\text { Terapia Hormonal Sustitutiva } \\
\text { Alcohol } \\
\text { Tabaco } \\
\text { Obesidad } \\
\text { Edad }>55 \text { años } \\
\text { Variantes genes de susceptibilidad }\end{array}$ & $\begin{array}{l}\text { Familiares de } 1 \text { er grado con ca. mama } \\
\text { Primípara }>35 \text { años } \\
\text { Hiperplasia sin atipia } \\
\text { Mamas mamográficamente densas } \\
\text { Variantes genes de baja penetrancia }\end{array}$ & $\begin{array}{l}\text { Mutación en BRCA1 y } 2 \\
\text { Mut. otros genes de alta penetrancia } \\
\text { Carcinoma Lobulillar in situ } \\
\text { Hiperplasia atípica de la mama } \\
\text { Radiaciones ionizantes } \\
\text { Varios familiares con ca. mama }\end{array}$ \\
\hline
\end{tabular}

\subsubsection{Factores hormonales y reproductivos}

El cáncer de mama es 150 veces más frecuente en las mujeres que en los hombres y su incidencia aumenta exponencialmente con la edad, elevándose de forma gradual desde los 30 años hasta los 50-60, en que alcanza su máxima incidencia y se estabiliza, posiblemente debido a la caída de los niveles de estrógeno circulantes en las mujeres ${ }^{9}$. Los datos epidemiológicos, junto con las evidencias experimentales involucran claramente a estas hormonas en la etiopatogenia de la enfermedad. El mecanismo por el que los estrógenos ejercen su función en los tejidos hormonsensibles no se conoce por completo. Juegan un importante papel en la carcinogénesis, clásicamente atribuido a la promoción de la división celular que tiene lugar tras la unión de estas hormonas a sus receptores ${ }^{10}$. Sin embargo, este no es el único mecanismo, dado que la metabolización de los estrógenos origina quinonas, semiquinonas, y radicales libres, que a su vez, inducen la formación de aductos y otras mutaciones en el $\mathrm{ADN}^{11}$, que si no son correctamente reparadas, pueden conducir a una proliferación y diferenciación celular no reguladas ${ }^{10}$.. 
Los factores reproductivos son factores de riesgo bien establecidos, debido a que condicionan la exposición a estrógenos a lo largo de la vida y la estimulación estrogénica prolongada incrementa el riesgo de cáncer de mama ${ }^{10,12}$. La actividad hormonal endógena es, con mucho, la más importante desde el punto de vista patogénico, si bien, la implicación de las fuentes exógenas, es ampliamente reconocida. En relación a las fuentes hormonales endógenas, destacan tres fenómenos: la duración del periodo fértil, el número de embarazos a término así como la edad a la que se producen y la lactancia.

La duración del periodo fértil está directamente relacionada con el riesgo de cáncer de mama, de modo que la menarquia temprana, sobre todo antes de los 12 años aumenta el riesgo 1 '5 veces mientras que cada año de retraso de la menarquia, lo reduce un $4 \%{ }^{13}$. La menopausia tardía duplica el riesgo respecto a la menopausia precoz, mientras que la deprivación estrogénica prematura, como se ha observado en las mujeres sometidas a ooforectomía, lo reduce ${ }^{12,13}$.

En cuanto a la relación entre el embarazo a término y el desarrollo de cáncer de mama, se ha demostrado que las mujeres nulíparas presentan un riesgo 1'5 a 3 veces mayor, si bien, parece que las primíparas de más de 35 años tendría un riesgo igual o mayor que aquellas mujeres que no tienen descendencia ${ }^{13,14}$. El embarazo tiene un efecto doble, a corto y largo plazo, ya que se asocia un incremento del riesgo inicial ligado al aumento de las hormonas circulantes, pero a la larga constituye un factor de protección, debido a la maduración del tejido mamario ${ }^{14}$. La mama puberal y la de las mujeres nulíparas están constituidas principalmente por estructuras lobulares y conductos indiferenciados. Los estudios con modelos animales han demostrado que las células epiteliales mamarias indiferenciadas tienen mayor susceptibilidad a la transformación neoplásica por acción de los carcinógenos que las células bien diferenciadas ${ }^{10,11}$. Por tanto, un embarazo a término es un factor de protección frente al cáncer de mama porque provoca la diferenciación final del tejido mamario ${ }^{10,12}$. Esta maduración se produce muy tardíamente en el caso de las primíparas mayores de 35 años, lo que sumado al incremento de los niveles circulantes de estrógenos propio de la gestación, hace que estas mujeres no se beneficien del efecto protector del embarazo a corto plazo. 
En relación con la lactancia, se ha visto que está asociada a un menor riesgo de cáncer de mama antes de la menopausia y que la magnitud del efecto protector guarda relación con la duración del período de lactancia15,16.

La implicación de los estrógenos exógenos ha sido muy discutida, si bien en la actualidad es ampliamente aceptada. La relación entre la terapia hormonal sustitutiva y el desarrollo de cáncer de mama ha sido objeto de gran controversia. Actualmente se acepta que este tipo de tratamiento conlleva un pequeño pero significativo incremento del riesgo, cuya magnitud estaría en relación con el tipo de terapia, la duración y la dosis de la misma9,13,17,18. En cuanto al papel de los anticonceptivos hormonales se han publicado datos en uno y otro sentido, si bien parece que estos preparados confieren un moderado incremento del riesgo de desarrollar cáncer de mama que desciende progresivamente al suspender su uso y que desaparece a los 10 años de finalizado el tratamiento $9,12,13,15,19$.

Otra hormona, en este caso no esteroidea, que se ha relacionado con el cáncer mama es la somatomedina o IGF-I (Insulin Growth Factor I), que estimula la proliferación de las células mamarias. La relación entre los niveles plasmáticos de IGF-I, su proteína trasportadora IGFBP-3 y el cáncer de mama ha sido evaluada en estudios recientes, con resultados positivos en mujeres premenopáusicas ${ }^{20,21 .}$

\subsubsection{Factores de riesgo ligados al estilo de vida y la dieta}

El estilo de vida desempeña un papel, si no más, al menos tan importante como los factores genéticos.

Debido a que la dieta supone la exposición a una gran variedad de compuestos cancerígenos y anticancerígenos, los factores dietéticos han sido ampliamente estudiados. La asociación entre la elevada ingesta de grasas y el riesgo de cáncer de mama fue sugerido por varios estudios epidemiológicos que describieron una mayor incidencia de cáncer de mama en los países con elevado consumo de grasas ${ }^{15,22,23}$, si bien algunos trabajos posteriores no han podido confirmar esta observación ${ }^{23,24}$. Mediante estudios con modelos animales se ha demsotrado que el 
consumo excesivo de grasas poliinsaturadas se asocia a la elevación de los niveles circulantes de estrógenos y progestágenos ${ }^{12}$. Esta discordancia puede deberse a la dificultad para evaluar la exposición individual a los factores dietéticos. No queda claro si el incremento del riesgo se debe únicamente al consumo total de grasas o a una ingesta calórica excesiva, casos en los que se ha observado una resistencia a la insulina debido a unos niveles permanentemente elevados de la hormona y de IGFs, que favorecen el recambio celular en la mayoría de los tejidos, y que se ha asociado con el desarrollo de cáncer de mama20. También se ha propuesto que el consumo de frutas y verduras sería beneficioso debido a que la fibra inhibe la reabsorción de estrógenos en el tracto digestivo ${ }^{2526}$, si bien no hay estudios concluyentes ${ }^{9,23}$.

Los estudios epidemiológicos y experimentales en relación con los alimentos que contienen fitoestrógenos son contradictorios y sus resultados no permiten obtener conclusiones firmes. Estos compuestos, de débil actividad estrogénica pueden interferir con la acción y el metabolismo de los estrógenos endógenos. De hecho, existen distintos mecanismos de acción que harían preveer un efecto protector de estas sustancias. En cambio, estudios con animales muestran un efecto proliferativo sobre tumores homonosensibles ${ }^{23}$.

La obesidad se asocia al cáncer de mama principalmente en mujeres postmenopáusicas ${ }^{13}$ debido a que en ellas la grasa periférica es la principal fuente de estrógenos ${ }^{12,15,20,23}$. El aumento de peso que tiene lugar durante el período reproductivo de la edad adulta también se ha asociado con el desarrollo de cáncer de mama en la menopausia ${ }^{27}$, sin que haya podido demostrarse claramente que la obesidad en el periodo infantil se asocie con esta patología20,23.

El ejercicio físico moderado y regular disminuye el riesgo de cáncer de mama en todas las edades, mediante mecanismos como el retraso de la menarquía, la reducción del número de ciclos ovulatorios, el descenso en la concentración de insulina, la disminución de la producción ovárica de estrógenos, el peso y la grasa corporal20.

La ingesta excesiva de alcohol aumenta la frecuencia de cáncer de mama, en función de la dosis ${ }^{28}$. Entre los mecanismos propuestos se incluyen la influencia que ejerce sobre las concentraciones de estrógenos, la producción de radicales libres y metabolitos tóxicos como el acetaldehído y la alteración de la capacidad de reparación del ADN. Los polimorfismos de genes 
implicados en su metabolización, como GST (glutation-S-transferasas), también parecen estar implicados ${ }^{12,20}$.

Los estudio epidemiológicos que han tratado de evaluar la asociación entre el hábito tabáquico y el cáncer de mama han vertido resultados contradictorios, probablemente debidos a la variabilidad en el diseño de los estudios, de la población incluida y de la evaluación de la exposición ${ }^{12}$. Sin embargo, parece que el tabaco produce un incremento del riesgo en aquellas mujeres que empezaron a fumar en los cinco años siguientes a la menarquia, debido a que los carcinógenos del tabaco actuarían sobre la mama en desarrollo, pero no en aquellas que comienzan a fumar tras el parto, puesto que la mama habría completado su formación. No se ha demostrado ninguna asociación en el caso de las mujeres postmenopáusicas ${ }^{29}$.

\subsubsection{Antecedentes personales}

Las lesiones benignas de la mama sin un componente proliferativo no parecen asociarse a una mayor incidencia de cáncer de mama. De este modo, la enfermedad fibroquísitica conlleva un aumento del riesgo de cáncer de mama bilateral únicamente en los casos en que se acompaña de hiperplasia ductal atípica. ${ }^{9}$

El carcinoma ductal in situ es considerado el paso previo del carcinoma invasivo, transformación que precisa una media de 6 a 10 años. En cambio, el carcinoma lobulillar in situ suele ser multicéntrico y bilateral y no se considera estrictamente un lesión precancerosa, sino un marcador de riesgo de padecer cáncer de mama ${ }^{30}$.

Tras haber desarrollado un cáncer de mama, el riesgo de afectación contralateral se incrementa hasta 10 veces $^{9}$.

La presencia de un patrón mamográfico de alta densidad es un factor de riesgo al que se le concede una importancia creciente. Varios estudios epidemiológicos describen un aumento del riesgo de entre 1'8 a 6 veces en las mujeres con patrones mamográficos más densos ${ }^{31-33}$. Este incremento del riesgo se ha relacionado con el hecho de que las mamas más densas 
desarrollarían con más frecuencia lesiones premalignas del tipo hiperplasia ductal atípica, y con la presencia de una aromatasa hiperactiva en la mama que incrementaría la producción local de estrógenos ${ }^{31,32}$. Esta densidad mamaria depende de los niveles hormonales, por lo que varía en función de las variables reproductivas y de otros factores ambientales como la dieta, pero por otro lado, tiene también un fuerte componente genético, como demuestran los estudios en gemelos homo y heterocigotos 34 .

Una historia familiar de cáncer de mama, aumenta la probabilidad individual de padecerlo, si bien la magnitud del riesgo varía dependiendo del grado de parentesco con el familiar afecto, de su estado hormonal y de si la enfermedad es 0 no bilatera| ${ }^{35}$. Así en mujeres cuya madre 0 hermana han padecido cáncer de mama, la probabilidad de padecerlo ellas mismas se incrementa hasta 3 veces, aumentando hasta 9 veces en el caso de que el familiar de primer grado sea una mujer premenopáusica con afectación bilateral30.

\subsubsection{Exposiciones ambientales y ocupacionales}

La exposición a radiaciones ionizantes, antes de los 40 años, principalmente durante la infancia y la adolescencia, cuando las glándulas mamarias no han alcanzado aún su madurez, es un importante factor de riesgo. Se ha establecido una relación lineal entre la dosis total recibida y el incremento del riesgo9,36.

Mediante modelos animales se han identificado más de 200 sustancias que actúan como carcinógenos mamarios y unas 250 que mimetizan o interfieren con la actividad de los estrógenos. Las sustancias más estudiadas han sido los compuestos orgánicos persistentes, principalmente los PCBs (Policloruro de Bifenilo), donde se incluyen el DDT (Dicloro Difenil Tricloroetano) y sus metabolitos. Aunque los resultados de los estudio epidemiológicos son poco consistentes sugieren que la exposición al PCB podría incrementar hasta en un 10-15\% el riesgo de desarrollar un cáncer de mama en las mujeres portadoras de algunas variantes genéticas responsables de su metabolización ${ }^{37} 38$. 
Otras exposiciones ocupacionales de riesgo incluyen el estireno, los solventes orgánicos, el óxido de etileno, y los campos electromagnéticos ${ }^{37,38}$.

\subsubsection{Susceptibilidad genética}

Como se apuntó anteriormente, una historia familiar de cáncer de mama es uno de los factores de riesgo más importantes para desarrollar la enfermedad. Ya en 1866 el anatomista francés Pierre Paul Broca publicó el caso de la familia de su esposa en la que 10 de sus miembros, a lo largo de cuatro generaciones, habían fallecido a consecuencia de un cáncer de mama ${ }^{39}$. Desde entonces, se han realizado numerosos trabajos para tratar de estimar el riesgo de una mujer de padecer este tipo de cáncer, en función del número de familiares afectas, del grado de parentesco y de la edad al diagnóstico. Así, hoy sabemos que si una mujer tiene un cáncer de mama, el riesgo de sus familiares de primer grado es el doble de la población general, mientras que si hay tres o más familiares de primer grado diagnosticados de cáncer de mama, el riesgo relativo es de cuatro 35,40 . Factores como la juventud al diagnóstico o la bilateralidad, incrementan aún más el riesgo, que puede ser hasta 9 veces más alto que el de una mujer sin antecedentes familiares de cáncer de mama 41,42 (Figura 2.)

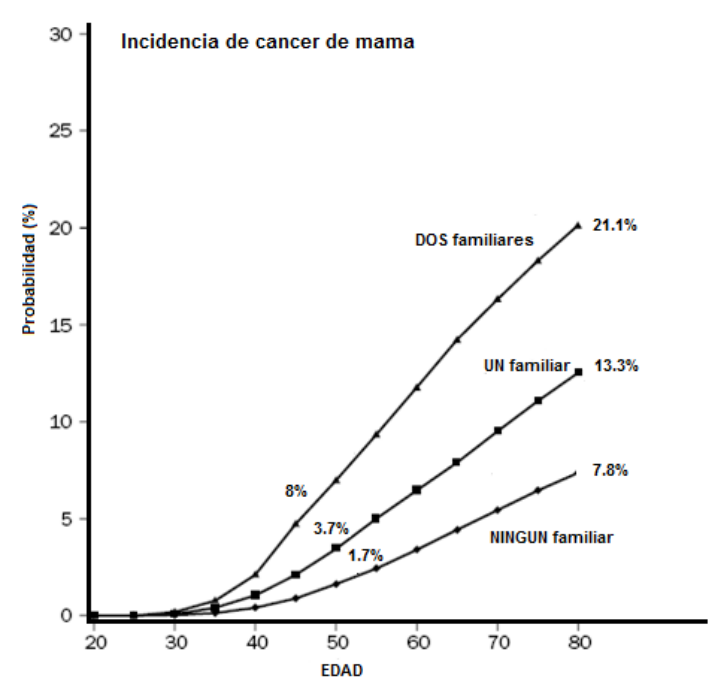

Figura 2: Probabilidad de que una mujer desarrolle cáncer de mama a lo largo de su vida según el número de familiares afectos 35 
Observaciones similares llevaron a Penrose en 1948 a plantearse la existencia de una posible alteración genética heredable como responsable de la agregación familiar ${ }^{43}$, hecho que en parte se confirmó cuando a mediados de los años 90, se descubrió que mutaciones en los genes BRCA 1 y 2 (Breast Cancer 1 y 2) eran responsables del síndrome de cáncer de mama y ovario hereditarios 4445 . Actualmente se considera que sólo el 5-10\% de los cánceres de mama son hereditarios y que las mutaciones en BRCA 1 y BRCA 2 únicamente explican el 15-20\% de todos los casos. Otros genes alterados en síndromes de cáncer familiar son p53, PTEN (Phosphatase and Tensin homolog) y AMT (Ataxia-Teleangiectasia Mutated) que explicarían menos de un 10\% de los cánceres de mama familiares ${ }^{41,46}$. Existe, por tanto, un gran porcentaje de familias con historia de cáncer de mama en varios de sus miembros en los que no se encuentra mutación en ninguno de los genes de alta penetrancia descritos. Esta agregación podría deberse a tanto a factores genéticos como ambientales, si bien los estudios en gemelos, la incidencia de afectación contralateral en las pacientes con cáncer de mama y el patrón de herencia familiar, resaltan el papel de los genes ${ }^{47}$, que podría deberse a la existencia de un hipotético "BRCA X" no identificado hasta la fecha ${ }^{41}$, si bien esta hipótesis parece cada vez menos probable ${ }^{48}$.

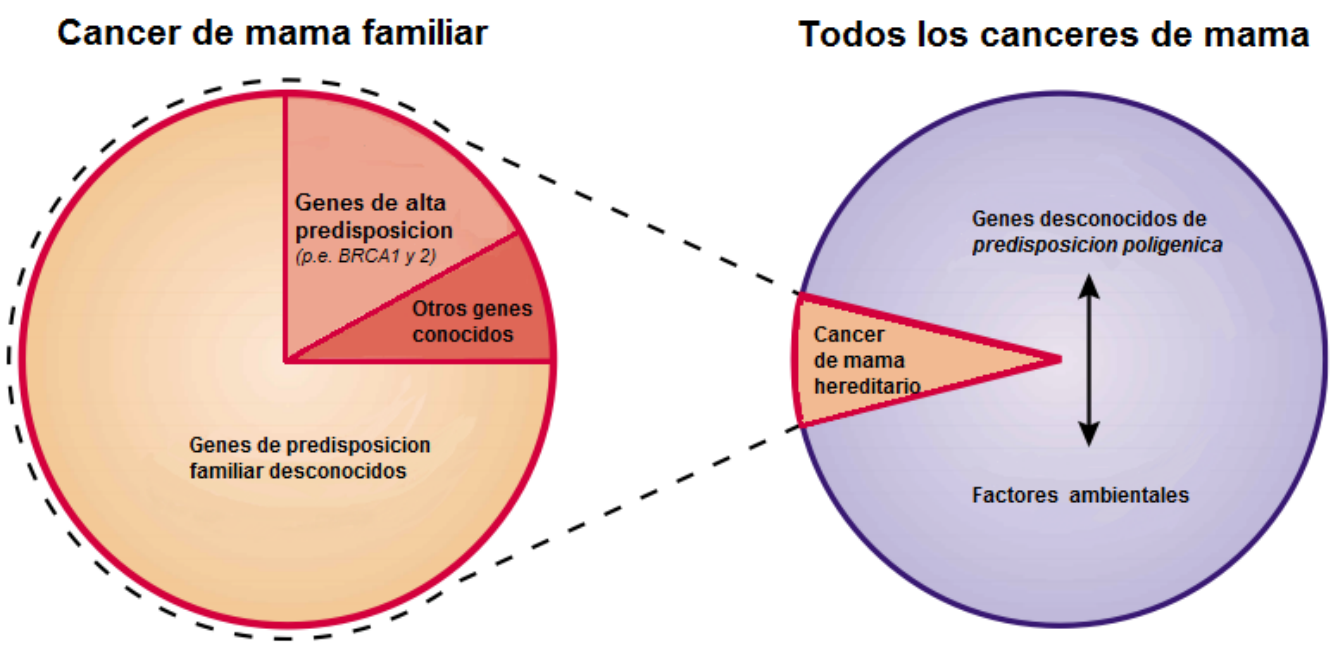

Figura 3: Susceptibilidad genética al cáncer de mama ${ }^{46}$ 
Pero la explicación más ampliamente aceptada para esta agregación familiar y para la gran mayoría de los casos esporádico se encuentra en el Modelo Poligénico de susceptibilidad al cáncer, según el cual, la susceptibilidad heredada al cáncer de mama de un individuo no dependería de un único gen de alta predisposición sino que estaría determinada por la herencia de un conjunto de variantes alélicas de múltiples genes de baja predisposición 48,49 . Este modelo se discute con mayor detalle en el apartado 2 de la Introdución (Genes y susceptibilidad al cáncer).

\subsubsection{Modelos predictivos del riesgo de cáncer de mama}

Con la intención de establecer las medidas de prevención primaria más adecuadas a cada caso, en las últimas décadas se han desarrollado varios modelos, tanto estadísticos como empíricos, que permiten estratificar a las mujeres según su riesgo de padecer cáncer de mama a lo largo de la vida.

La mayoría de ellos sólo tienen en cuenta los antecedentes familiares, y únicamente los modelos de Gail50 y Tyrer-Cuziack ${ }^{51}$ incluyen otros factores de riesgo no hereditarios para el cálculo. El hecho de que el riesgo estimado por unos y otros modelos sea en ocasiones discordante, y la necesidad de programas de cálculo complejos, ha limitado el uso de estos algoritmos en la práctica clínica diaria.

El primero de estos modelos lo publicó Michelle Gail en 198950. Gail analizó el riesgo de que una mujer de una determinada edad, desarrollara un carcinoma invasor o in situ a lo largo de la vida. En su estudio sólo incluyó mujeres caucásicas que participaban en un programa de cribado del cáncer de mama mediante mamografía anual. Encontró que los mejores predictores del riesgo de cáncer de mama en esta población eran: el número de familiares de primer grado con antecedentes de cáncer de mama, la edad de la menarquía y del primer embarazo a término y la realización de biopsias previas de la mama ${ }^{52}$. Validaciones posteriores de este algoritmo en otras poblaciones encontraron que el modelo era muy bueno para predecir la probabilidad de cáncer de mama al estratificar para un determinado factor de riesgo, pero su capacidad de predecir el riesgo de una mujer en particular era mucho más modesto ${ }^{53}$. Con intención de mejorar la capacidad predictiva del modelo, Gail añadió recientemente la información del genotipado de siete y 
posteriormente de diez polimorfismos en diferentes genes que previamente habían sido asociados con el cáncer de mama, pero estó no se tradujo en un aumento significativo de la capacidad predictora del modelo ${ }^{54,55}$, probablemente debido a que los datos de incidencia y prevalencia de cáncer de mama que utiliza son los de los años ochenta y noventa ${ }^{56}$.

El modelo de Claus, publicado en $1990^{57}$ y modificado en $1994^{40}$, estima el riesgo de cáncer de mama en función del número de familiares de primer grado afectas y de la edad de diagnóstico, pero no incluye ningún de los factores no hereditarios.

BRCAPRO58 se desarrolló tras el descubrimiento de BRCA1 y 2 y estima la probabilidad de encontrar una mutación en estos genes en una determinada familia, pero no icluye ningún otro factor. BOADICEA 59 tampoco incluye ningún factor no hereditario, pero en cambio añade el efecto de un componente poligénico, que explicaría los casos de agregación familiar que no se deben a mutaciones en BRCA.

El modelo más reciente es el denominado Tyrer-Cuzick ${ }^{51}$ en el que se integran factores genéticos tales como la historia familiar y la prevalencia de mutaciones de BRCA en la población y otros genes de baja penetrancia, marcadores surrogados de la exposición endógena a estrógenos (edad de la menarquía y menopausia, paridad y edad del primer embarazo a término), el Indice de Masa Corporal y la presencia de lesiones benignas en la mama. Los estudios de validación sugieren que en general, éste es el modelo que mejor predice el riesgo de cáncer de mama ${ }^{56}$, sin embargo, sobreestima el riesgo en las mujeres con hiperplasia atípica de la mama60.

\subsection{CLASIFICACIÓN DEL CARCINOMA DE MAMA}

\subsubsection{Clasificación histológica}

Atendiendo a exclusivamente a características morfológicas, el cáncer de mama se ha clasificado en los grupos histológicos que se muestran en la Tabla 2. El tipo más frecuente es el Carcinoma Ductal Infiltrante, que supone entorno al $70 \%$ de todos los casos, pero se distinguen hasta 20 tipos, algunos con muy baja incidencia. Los carcinomas tubulares, cribiformes y coloides, 
se caracterizan por tener un buen pronóstico, mientras que en el caso de los carcinomas inflamatorio o metaplásico éste es bastante peor ${ }^{9}$.

Tabla 2: Clasificación histológica del carcinoma de mama ${ }^{9}$.

\begin{tabular}{|l|c|}
\hline \multicolumn{1}{|c|}{ Tipos histológicos } & Frecuencia \\
\hline Ductal & $75 \%$ \\
Lobulillar & $5-10 \%$ \\
Mucinoso (Coloide) & $3-5 \%$ \\
Tubular & $5 \%$ \\
Medular & $5-7 \%$ \\
Inflamatorio & $1-3 \%$ \\
Metaplásico & $<1 \%$ \\
Paget & $<1 \%$ \\
Tumores derivados de & $1 \%$ \\
estructuras no glandulares: & \\
sarcomas, cutáneos, linfomas & $<1 \%$ \\
Metástasis de otros tumores & \\
\hline
\end{tabular}

\subsubsection{Clasificación del cáncer de mama según patrones de expresión génica}

Tradicionalmente, el cáncer de mama se clasificaba únicamente en función de la morfología celular, de la determinación inmunohistoquímica de los receptores de estrógenos (RE) y progesterona (RP), así como de la amplificación del Human Epidermal Receptor 2 (HER2) y de parámetros clínicos como el tamaño tumoral, la afectación de ganglios linfáticos y la presencia de metástasis. En base a esto, se obtenían grupos con implicaciones pronósticas y terapéuticas, observándose que pacientes de un mismo grupo y tratadas de igual modo, presentaban distinta evolución, sin que pudieran establecerse las causas de tan diferente comportamiento.

Aunque la caracterización de los tumores de mama que expresan marcadores propios de célula basal y sus implicaciones pronósticas fueron descritas hace más de veinte años ${ }^{8,61}$,la clasificación de los carcinomas invasivos de la mama según patrones de expresión molecular no ha recibido atención por parte de la comunidad científica hasta su re-descubrimiento en los estudios de microarrays, cuando Perou et al62 propusieron que la variedad fenotípica y de comportamiento de los tumores de la mama podría correlacionarse con diferencias en los patrones de expresión génica, de modo que una vez determinados éstos, los tumores pudiesen ser 
clasificados en subgrupos más homogéneos. Así, los tumores de la mama se clasifican actualmente en cuatro categorías principales atendiendo al patrón de expresión génica: Basal Like, Her2, Luminal A y Luminal B (Tabla 3).

Tabla 3: Clasificación del cáncer de mama según los grupos de expresión génica63

\begin{tabular}{|c|l|}
\hline SUBGRUPOS & \multicolumn{1}{c|}{ EXPRESIÓN GÉNICA } \\
\hline Basal- Like & $\begin{array}{l}\text { RE-, RP-, HER2-, CK 5/6+, CK17+ C-KIT+/-, EGFR+/-, } \\
\text { integrina } \beta 4, \text { laminina, moesina, vimentina, P-cadherina, CAV1 y 2 }\end{array}$ \\
\hline HER2+ & $\begin{array}{l}\text { RE-, HER2+, } \\
\text { (importante expresión de genes próximos a HER2) }\end{array}$ \\
\hline Luminal A & $\begin{array}{l}\text { RE++, RP +/-, HER2- } \\
\text { CK 8+, CK 18+ }\end{array}$ \\
\hline Luminal B & $\begin{array}{l}\text { RE+, RP +/-, HER2+/-, alta expresión de Ki67 } \\
\text { (Expresión moderada/baja de genes específicos del patrón luminal) }\end{array}$ \\
\hline
\end{tabular}

Los tumores luminales, reciben este nombre por su similitud con las células epiteliales que recubren la luz de los conductos mamarios. El patrón de expresión génica de los tumores de fenotipo basal-like remeda al de las células mioepiteliales del epitelio basal mamario normal, por lo que se supone que su origen se encuentra precisamente en tales células. En el trabajo inicial de Perou ya se constató que los tumores basalioides expresaban RE, RP y HER2 con mucha menor frecuencia que el resto de tumores no seleccionados y que lo inverso sucedía con EGFR, cKIT62,64-67. Nielsen ${ }^{68}$ demostró que es posible distinguir los grupos luminales, basales y HER2 utilizando técnicas inmunohistoquímicas en vez de perfiles de expresión génica.

Estudios posteriores han corroborado los resultados de Perou68-70, han aumentado la lista de genes con expresión diferencial en los distintos grupos ${ }^{71-74}$, han establecidos las diferencias pronósticas de estos subgrupos y han evaluado su respuesta a las diferentes opciones terapéuticas actualmente disponibles ${ }^{75-78}$. 
Introducción

\subsubsection{Clasificación TNM}

En la Tabla 4 se muestra la clasificación TNM (UICC-AJCC), que atendiendo al tamaño tumoral $(\mathrm{T})$, las metástasis en ganglios regionales $(\mathrm{N})$ y la existencia 0 no de metástasis a distancia, establece diferentes grupos con significación pronóstica (Tabla 5).

Tabla 4: Clasificación TNM del cáncer mama. 6ª edición, 2003. (www.UICC.org)

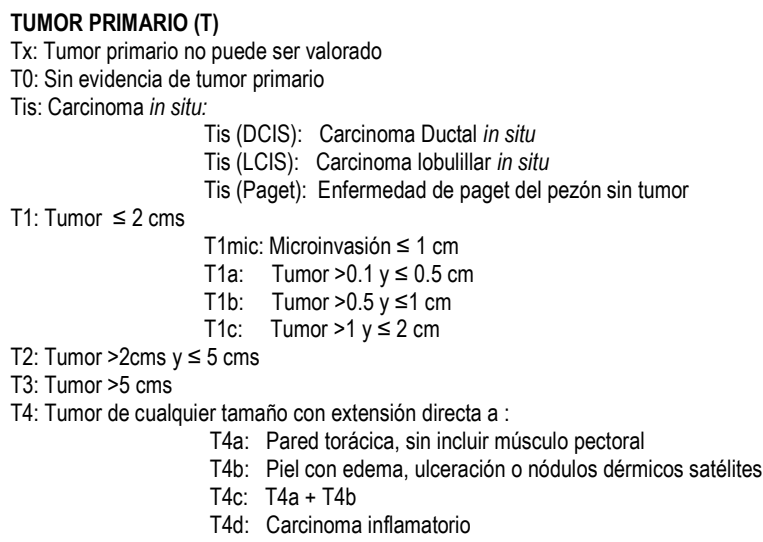

GANGLIOS LINFÁTICOS (pN)

$\mathrm{pNx}$ : Los ganglios no pueden ser evaluados (extirpados previamente)

pNO: No metástasis histológicas en ganglios

pN1: Metástasis en 1 a $3 \mathrm{gl}$ axilares y/o en gl de la mamaria interna con enfermedad microscópica en el ganglio centinela (GC), clínicamente no aparente:

pN1mic: Micrometástasis $(>0.2 \mathrm{~mm}$ y $\leq 2.0 \mathrm{~mm})$

pN1a: Metástasis de 1 a 3 ganglios axilares

pN1b: Mts en gl de la mamaria interna con enfermedad microscópica en el GC extirpado

pN1c: Mts en 1-3 gl axilares y en gl de la mamaria interna con enfermedad microscópica en el GC

pN2: Metástasis de 4 a 9 ganglios axilares o ganglios de la mamaria interna aparentes clínicamente,

en ausencia de ganglios axilares metastáticos:

pN2a: $\quad$ Mts en 4 a 9 ganglios axilares (uno al menos con tumor $>2 \mathrm{~mm}$ )

pN2b: Mts en gl de la mamaria interna clínicamente aparentes, en ausencia de mts en gl axilares.

pN3: Mts en 10 o más gl axilares, o en gl infraclaviculares, o en gl de la mamaria interna clínicamente aparentes en presencia de 1 o más gl axilares, o más de $3 \mathrm{gl}$ axilares con gl de la mamaria interna microscopicamente negativos, o con gl supraclaviculares ipsilaterales:

pN3a: Mts en 10 o más gl axilares, o mts en gl infraclaviculares.

pN3b: Mts en gl ipsilaterales de la mamaria interna clínicamente aparentes en presencia de $\geq 1$ $\mathrm{gl}$ axilares positivos, $0>3 \mathrm{gl}$ axilares con gl de la mamaria interna con enfermedad microscópica en el GC extirpado, no aparente clínicamente.

pN3c: Mts en gl supraclaviculares ipsilaterales

\section{METÁSTASIS}

Mx: La metástasis no pueden ser evaluadas

M0: No existen metástasis a distancia

M1: Presencia de metástasis a distancia 
Introducción

Tabla 5: Supervivencia Libre de Enfermedad (SLE) a 5 años según el Estadio TNM ${ }^{30}$

\begin{tabular}{|c|c|c|}
\hline ESTADIO & TNM & $\%$ SLE a 5 años \\
\hline Estadio I & T1N0M0 (incl T1mic) & 80 \\
\hline Estadio IIA & $\begin{array}{l}\text { TON1M0 } \\
\text { T1N1M0 } \\
\text { T2NOM0 }\end{array}$ & 75 \\
\hline Estadio IIB & $\begin{array}{l}\text { T2N1M0 } \\
\text { T3NOM0 }\end{array}$ & 75 \\
\hline Estadio IIIA & $\begin{array}{l}\text { TON2M0 } \\
\text { T1N2M0 } \\
\text { T2N2M0 } \\
\text { T3N1M0 } \\
\text { T3N2M0 }\end{array}$ & 55 \\
\hline Estadio IIIB & $\begin{array}{l}\text { T4NOM0 } \\
\text { T4N1M0 }\end{array}$ & 35 \\
\hline Estadio IIIC & T4N2M0 & 25 \\
\hline Estadio IV & Cualquier T, N3M0 & 10 \\
\hline Global & Cualquier M1 & 65 \\
\hline
\end{tabular}




\section{GENES Y SUSCEPTIBILIDAD AL CÁNCER}

\subsection{Cáncer como enfermedad genética}

El cáncer es una enfermedad compleja y heterogénea que surge por las interacciones de factores genéticos y ambientales tras los cuales una célula escapa de los controles sobre su división y diferenciación. Durante el proceso, la célula adquiere nuevas características que le conducirán a proliferar muy rápidamente, evadiendo las señales de apoptosis. Así mismo, inicia un proceso de desdiferenciación y adquiere la capacidad de dividirse de forma indefinida, al tiempo que es capaz de alcanzar nuevos tejidos y órganos e invadirlos. Algunas de estas células tumorales, son capaces de inducir la formación de nuevos vasos sanguíneos, abandonar el tumor primario y atravesar la matriz extracelular que las rodea, alcanzar el torrente circulatorio, sobrevivir en él y posteriormente abandonarlo atravesando las paredes de los capilares localizadas en lugares distantes del organismo, invadiendo nuevamente la matriz extracelular e iniciando en la nueva localización, un tumor secundario 79 .

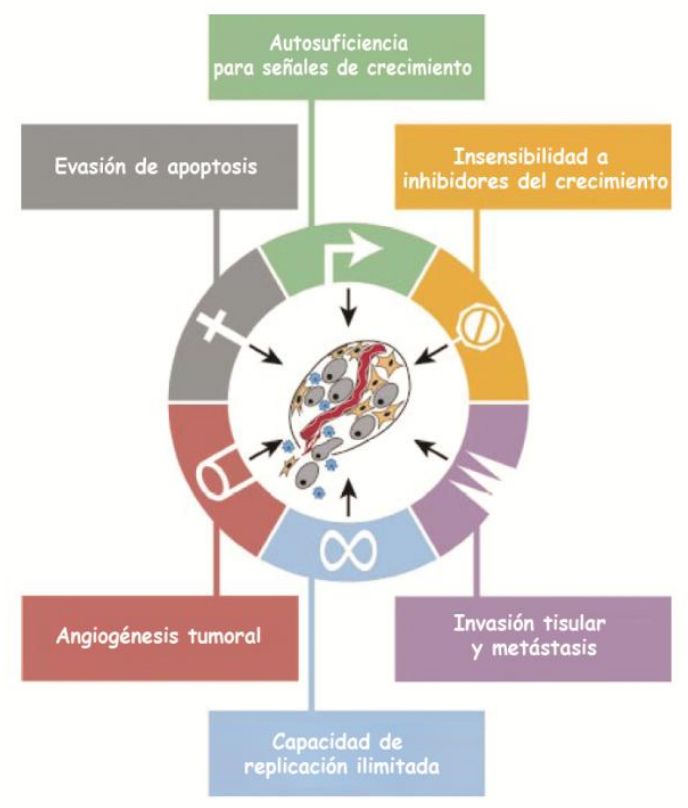

Figura 4: Propiedades que adquieren las células durante la transformación tumoral 79 
Finalmente, esta metástasis, inicialmente microscópica, continuará su división ilimitada hasta formar una nueva masa tumoral. Para ello, requerirá la formación de nuevos vasos que le permitan crecer y diseminar sus células para dar lugar a la aparición de nuevas metástasis a distancia. (Figura 4) 79 .

El proceso de la transformación tumoral de una célula, puede iniciarse por la alteración de los genes que conocemos como Oncogenes y genes Supresores, pero rara vez un único defecto es suficiente para el desarrollo de un tumor. Para que las células adquieran todas las capacidades anteriormente descritas necesitan de la adición sucesiva de numerosas alteraciones genéticas y epigenéticas que aún no han sido bien caracterizadas. Estas alteraciones afectan tanto a diferentes funciones de la célula tumoral como a las células de su entorno 79 .

Los Proto-oncogenes son genes que, en las células normales, promueven el crecimiento y la proliferación celular o inhiben la muerte celular programada (apoptosis). En un sentido más amplio, podrían incluirse a todos aquellos genes que inhiben procesos de diferenciación y los que promueven procesos como la angiogénesis, invasividad, metástasis, etc. Las mutaciones en ellos producen una ganancia en su actividad, pasando a denominarse oncogenes ${ }^{80,81}$.

Los genes supresores son aquellos que frenan la proliferación celular, ya que regulan de forma negativa la división y el crecimiento de las células. Para que favorezcan el desarrollo tumoral es necesario que las proteínas codificadas por ellos no sean funcionales lo que supone que o bien se alteren los dos alelos o que la mutación de uno de uno de ellos dé lugar a una proteína que inactive la del alelo normal, por lo que las alteraciones de estos genes se consideran recesivas. A su vez, se dividen en "gatekeepers" y "caretakers". Los primeros, están directamente implicados en la regulación de la proliferación, diferenciación y apoptosis celular. Cuando se produce la pérdida de función, fallan los mecanismos de control y la célula adquiere una ventaja proliferativa respecto al resto. Los genes "caretakers" en cambio, controlan la replicación del ADN, la transcripción, la reparación del ADN y los chekpoints del ciclo celular. Estos genes son por tanto, los encargados de mantener la integridad del genoma ${ }^{80-82}$. 


\subsection{Genes de alta penetrancia}

De forma general, las células de un tumor se originan mediante la expansión clonal de una única célula, y las células hijas heredan las mutaciones de la madre. Pero estas alteraciones genéticas no son transmitidas por un progenitor a sus hijos, a menos que estén presentes en las células germinales, en cuyo caso estaríamos ante un síndrome hereditario de predisposición al cáncer83.

Por otro lado, el hecho de heredar una mutación patogénica en uno de los genes críticos del cáncer, ya sea un oncogen o un gen supresor, no implica que el individuo vaya a desarrollar de un tumor. Se define como penetrancia genética la proporción de individuos de una población que, presentando un determinado genotipo (mutación en un alelo), expresa un determinado fenotipo (en este caso cáncer). Cuando todos los portadores de la mutación desarrollan cáncer, se dice que la penetrancia es completa, y en caso contrario incompleta, pudiendo ser más alta o más baja.

Si bien la mayoría de los síndromes de cáncer familiar se deben a mutaciones en genes de alta penetrancia, principalmente genes supresores, solamente las mutaciones de p53 (Sindrome de Li-Fraumeni) y del gen APC (Síndrome de Poliposis Adenomatosa Familiar) presentan una penetrancia completa. Las mutaciones de BRCA, en cambio, tienen una penetrancia entrorno al $60-80 \%$ dependiendo de las poblaciones ${ }^{84}$.

BRCA1 y BRCA2 fueron los dos primeros genes de alta penetrancia relacionados con el cáncer de mama hereditario y aunque en un principio se pensó que sería posible encontrar mutaciones de estos genes en todos los casos de cáncer de mama familiar, hoy sabemos que sólo son responsables del $15-20 \%$ de los casos $^{44,85,86}$. La probabilidad de encontrar una mutación en estos genes en una familia aumenta con el número de miembros afectos, de manera que se han encontrado en el $80 \%$ de las familias con más de 6 casos de cáncer de mama y en un tercio de las familias con $405 \operatorname{casos}^{87}$. Los primeros estudios sobre la incidencia de cáncer de mama en las portadoras de mutación en los genes BRCA 1 y 2, estimaban entorno al 75-80\% la probabilidad de desarrollar la enfermedad a lo largo de la vida, mientras que en trabajos posteriores, este porcentaje varía ostensiblemente ${ }^{41}$. En población española, la probabilidad de desarrollar cáncer 
de mama de las mujeres portadoras de mutaciones en BRCA1, se ha estimado entorno al $52 \%$ y al $48 \%$ si el gen alterado es BRCA2 ${ }^{88}$. Por tanto, aunque la penetrancia de estos genes es muy alta, no es completa y a pesar de que se ha sugerido podría estar modulada por diferentes genes como NAT2, CYP1A1, GSTT1 o por la presencia de polimorfismos en diferentes genes, el mecanismo que regula la penetrancia de los genes BRCA no ha sido aún establecido41,89.

Se han descrito otros genes de alta penetrancia responsables de diferentes síndromes hereditarios que cursan con cáncer de mama como son p53, PTEN y AMT (Tabla 5) que explicarían en conjunto otro $10 \%$ de los casos de cáncer de mama familiar 41,46 .

Tabla 5. Síndromes de cáncer hereditario que presentan cáncer de mama ${ }^{42}$

\begin{tabular}{|c|c|c|}
\hline Síndrome & Gen & Otras neoplasias asociadas \\
\hline Cáncer de mama y & BRCA1 y 2 & Ovario, próstata, páncreas, vía biliar, SNC. \\
\hline Li-Fraumeni & P53 & $\begin{array}{l}\text { Sarcomas óseos y de partes blandas, leucemia, SNC y } \\
\text { adrenocorticales }\end{array}$ \\
\hline Cowden & PTEN & Tiroides, ovario, trichilemoma facial y papilomas orales \\
\hline Muir-Torre & MSH2, MLH1 & Colorrectal, Genitourinario. \\
\hline Peutz-Jeghers & STK1, LKB1 & $\begin{array}{l}\text { Pólipos hamartomatosos, colon, estómago, páncreas, } \\
\text { tiroides, pulmón, útero y ovario }\end{array}$ \\
\hline Ataxia-Teleangiectasia & ATM & Leucemia y linfoma. \\
\hline
\end{tabular}

\subsection{Genes de baja penetrancia}

Los estudios en cáncer familiar y la identificación de genes de alta susceptibilidad han contribuido a un mayor entendimiento de los mecanismos de carcinogénesis y de la biología tumoral, pero solamente el $5-10 \%$ de los tumores tiene un componente hereditario, de modo que las variante alélicas implicadas en estos casos tienen un gran impacto para el individuo, pero su contribución a la incidencia del cáncer a nivel poblacional es muy pequeña. Los estudios realizados en gemelos homo y heterocigotos demostraron que la agregación familiar que se 
observa en el cáncer de mama se debe principalmente a factores genéticos heredados, más que a factores ambientales 0 al estilo de vida ${ }^{47}$, y se sugirió que debía existir otro grupo de genes que, predisponiendo al cáncer, presentasen una baja penetrancia.

Para explicar la incidencia de los tumores esporádicos, estos genes deberían presentar variaciones estructurales que alterasen su función con una frecuencia mucho mayor que las mutaciones patogénicas de los genes de alta penetrancia. El análisis de estas variantes polimórficas ha sido, y sigue siendo, la única estrategia viable para identificar estos genes de baja penetrancia90. Así, mediante diferentes tipos de estudios de asociación y en menor medida mediante estudios de ligamiento, se han identificado multitud de polimorfismos, principalmente en genes que intervienen en funciones celulares como la reparación del ADN o el metabolismo de carcinógenos tanto endógenos como exógeno, aunque también en genes supresores de tumores e incluso en oncogenes, si bien son mucho menos frecuentes ${ }^{91}$. Cada una de estos genes de baja penetrancia confiere un riesgo individual $\leq 1.3$, pero su efecto podría ser aditivo 0 incluso multiplicativo ${ }^{92}$, de modo que cada vez parece es más aceptado que la principal fuente de predisposición heredada al cáncer se debe al efecto de la combinación de diferentes variantes genéticas en múltiples loci, lo que se conoce como Modelo Poligénico de susceptibilidad al cáncer $48,93,94$.

Por otro lado, cada vez hay más estudios que analizan el efecto de estos genes sobre la incidencia de cáncer en relación con la exposición a diferentes factores ambientales como el tabaco o la radiación ultravioleta, corroborados mediante modelos animales ${ }^{91,94}$. La susceptibilidad del individuo a desarrollar cáncer tras la exposición a diferentes carcinógenos del ambiente, estaría condicionada, por ejemplo, por la capacidad de reparar el ADN que tenga la combinación de genes reparadores que haya heredado de sus padres ${ }^{93}$, lo que explicaría por qué no todos los individuos expuestos a un factor de riesgo asociado con un determinado tipo de tumor lo desarrollan.

En relación con el cáncer de mama, puede que la respuesta a por qué ni todas las nulíparas obesas, ni todas las fumadoras con terapia hormonal sustitutiva (THS) desarrollan cáncer de mama a pesar de que la nuliparidad, la obesidad, el hábito tabáquico y la THS son 
conocidos factores de riesgo, esté en las variantes funcionales de los genes modificadores, lo que se conoce como.

La mayoría de estas variantes confieren un riesgo individual $\leq 1.3$, pero su efecto podría ser aditivo o incluso multiplicativo ${ }^{92}$ y su interés radica en el hecho de que combinados, podrían utilizarse para establecer modelos que estimen el riesgo individual, y adecuar a cada caso las medidas de prevención primarias y secundarias ${ }^{95-97}$. De hecho, la predisposición al cáncer debida a la combinación de estas variantes podría ser de mayor interés para la salud pública que la predisposición debida a los genes de alta penetrancia94.

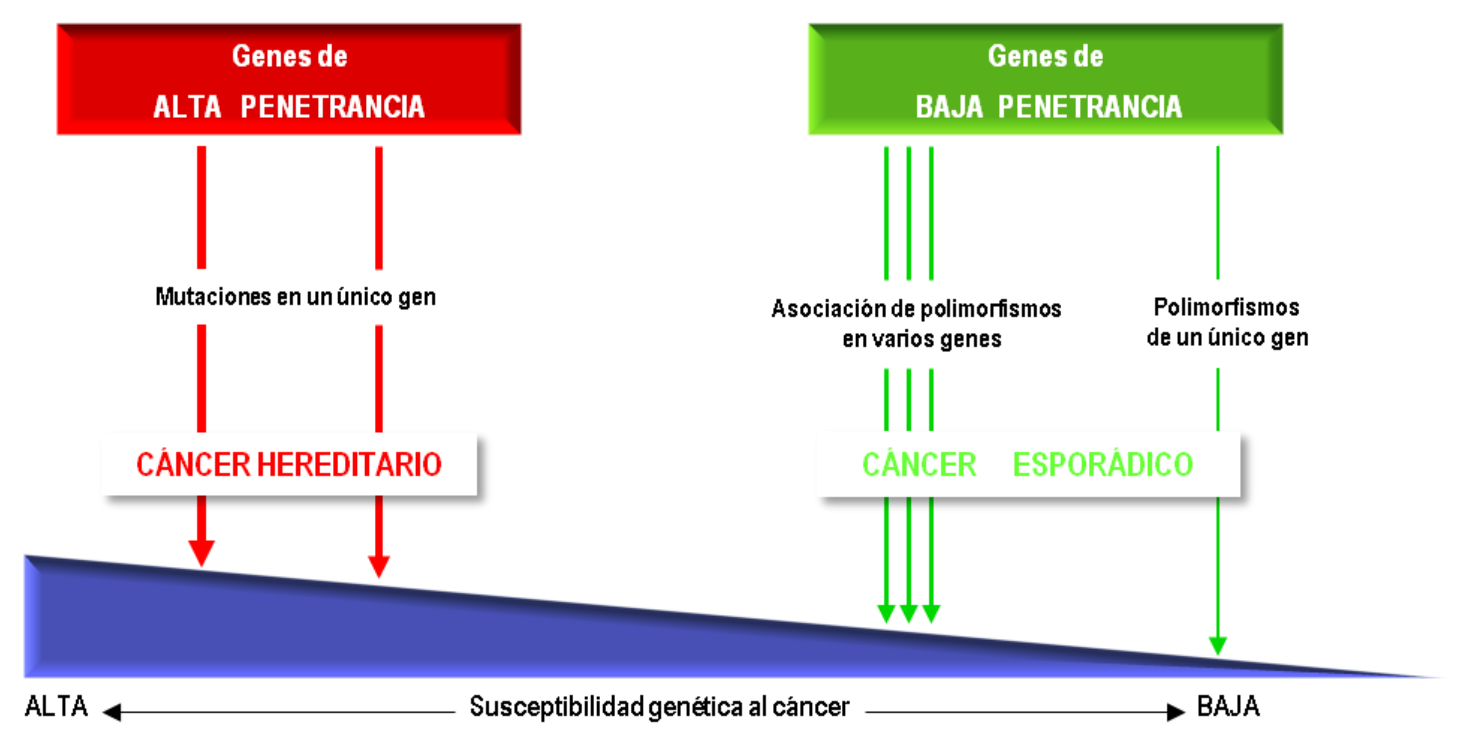

Figura 5: Esquema de la susceptibilidad heredada al cáncer

\subsection{Polimorfismos}

Un polimorfismo se define como la existencia de dos o más formas alternativas de un gen en una población, de modo que la variante menos frecuente no pueda ser explicada por una mutación patogénica recurrente, para lo cual, debe estar presente en más del $1 \%$ de los individuos ${ }^{98}$. 
Se estima que existen más de 10 millones de polimorfismos en el genoma humano, que aparecen con una frecuencia relativamente alta en la población, y a diferencia de las mutaciones patogénicas, conllevan un escaso o nulo incremento del riesgo de cáncer por sí mismas. Es necesaria la concurrencia de varios polimorfismos que actúen de forma sinérgica o de mutaciones patogénicas en otros genes 0 de determinadas circunstancias ambientales, (p.e. exposición a carcinógenos) para que estos modificadores tengan algún efecto sobre el desarrollo de cáncer, sobre la agresividad del fenotipo o sobre la respuesta al tratamiento quimioterápico ${ }^{46}$.

Los polimorfismos, al igual que las mutaciones, pueden consistir en la sustitución de un nucleótido por otro, en la inserción de uno o varios nuevos o en la delección de nucleotidos previamente existentes. Estos procesos pueden afectar a un número variable de bases, pero lo más frecuente es que sólo se afecte uno, lo que se denomina Single Nucleotide Polymorphism o SNP99.

Los polimorfismos pueden localizarse en regiones codificantes o no codificantes del ADN. A aquellos que en las regiones codificantes producen un cambio de aminoácido se les denomina no sinónimos. Si este cambio introduce un codón de parada, se llama entonces polimorfismo nonsense, mientras que si codifica un nuevo aminoácido, será un polimorfismo de cambio de sentido (missense). Si el polimorfismo al traducirse no produce ninguna alteración en la secuencia aminoacídica se dice que es sinónimo o silente. Los polimorfismos de las zonas no codificantes son también muy importantes porque pueden producir una alteración del splicing, o impedir la unión de factores de transcripción ${ }^{99}$.

Los polimorfismos no sinónimos que inducen un cambio de aminoácido son los que más fácilmente alteran la función de la proteína, y en consecuencia, son los más estudiados.

\subsubsection{Estudio de polimorfismos en genes de baja penetrancia}

Como se señaló anteriormente, la mejor forma de identificar los genes de baja penetrancia es mediante el estudio de sus polimorfismos, que puede llevarse a cabo mediante dos tipos de análisis: el estudio del desequilibrio de ligamiento (DL) o estudios de asociación en casos y controles. 


\subsubsection{Estudios de desequilibrio de ligamiento:}

En el genoma existen genes separados por cientos o incluso miles de bases en la cadena del ADN que se segregan de forma conjunta durante la meiosis, lo que se conoce como desequilibrio de ligamiento. Lo mismo sucede con algunos polimorfismos. Cuando estas variantes aparecen en los individuos que padecen una determinada enfermedad con más frecuencia que en aquellos que no la padecen, pensaremos que de uno u otro modo esos polimorfismos están implicados en dicha patología. Si las variantes no implican un cambio funcional del gen que pueda explicar la aparición de la enfermedad, cabe pensar que la causa sea algún otro gen de los que se encuentran en el espacio que separa los dos polimorfismos que se segregan conjuntamente ${ }^{100}$.

Los estudios de DL se realizan mediante el análisis del ADN en familias con varios casos de la enfermedad o en parejas de gemelos donde uno está afecto y el otro no y tienen gran capacidad para detectar alelos poco frecuentes pero de alta predisposición con un mecanismo de herencia mendeliano. Pero para detectar el efecto de alelos comunes con escasa influencia sobre la enfermedad se precisa de muestras mucho mayores, de tamaño casi prohibitivo. Por ello, han sido muy utilizados para encontrar genes implicados en enfermedades monogénicas, pero han tenido menos éxito en el estudio de enfermedades multigénicas como el cáncer, a excepción de los síndromes de cáncer hereditario, donde permitieron la caracterización de BRCA1 y 291,101.

\subsubsection{Estudios de Asociación Genética:}

Los estudios de asociación buscan establecer la relación estadística entre variables genéticas poblacionales y un fenotipo determinado. Se trata generalmente de estudios de cohortes prospectivas o de casos-controles en los que se establece el peso relativo del componente genético con respecto a otros factores como puede ser el ambiente en el riesgo de desarrollar la enfermedad.

Estos estudios buscan relacionar un marcador genético particular con una enfermedad a través de una población, más que dentro de una familia. Precisan de muestras más pequeñas que 
los estudios de DL y su poder estadístico para detectar los efectos de las variantes comunes es bastante mayor.

Existen dos acercamientos para establecer la asociación entre variantes genéticas y el riesgo de enfermedad: El estudio del "SNP candidato" y la "asociación indirecta".

El primero es un test directo de asociación entre una variante potencialmente funcional y el riesgo de padecer una enfermedad. Se establece por tanto un gen candidato de antemano en base a estudios previos o de evidencia experimental biológica ${ }^{100}$. Los SNP's son elegidos fundamentalmente en base a cuatro criterios: 1) el conocimiento previo de que son funcionales, 2) las variaciones de tipo missense, 3) que exista DL con las variables causales y 4) que exista un tecnología que permita el estudio. ${ }^{100}$ Los polimorfismos missense son los que tienen más posibilidades de representar un cambio funcional, ya sea de pérdida o ganancia, por lo que la mayoría de los estudios se centran en ellos. Las variantes que no causan cambio de aminoácido pueden tener un impacto sobre la capacidad de reparación, si se sitúan en entrones reguladores de splicing o si causan inestabilidad del ARN, pero el uso de variantes no codificantes para determinar cambios en la función es mucho más complejo por el limitado conocimiento que tenemos sobre las secuencias reguladoras ${ }^{102}$.

En cambio, la asociación indirecta consiste en testar un mapa denso de SNP's bajo la suposición de que si existe un polimorfismo de riesgo este será o bien tipificado directamente o se encontrará en fuerte DL con uno de los SNP's estudiados. La ventaja de este último método es que no precisa la determinación de qué SNP's pueden ser funcionalmente importantes. La desventaja es que precisa el estudio de un número mucho mayor de SNP's Los estudios de genotipado masivo (GWAs, Wide Genome Association studies) permiten el screening extenso y de alta densidad del genoma completo, para lo que utilizan cientos de miles de SNPs marcadores, de modo que inicialmente se genotipan entorno a 250.000 polimorfismos en miles de individuos (fase I). Después se seleccionan únicamente los SNP's que demuestran ser más significativos (unas decenas de miles) estudiándolos en nuevas cohortes (fase II) y finalmente se realiza un mapeo fino de los polimorfismos adyacentes a los validados, si se considera que estos no son los implicados en la patología pero que pudiera existir un DL (fase III)92,96,100,103,104. 


\section{MECANISMOS DE REPARACION DEL ADN}

La supervivencia a largo plazo de una especie puede aumentar gracias a cambios genéticos favorables en el proceso de selección natural, pero la supervivencia de cada individuo en particular requiere una estabilidad genética que le salvaguarde del desarrollo de tumores. La exposición a diferentes factores del medio ambiente o incluso del medio intracelular puede originar daños al $A D N$, pero sin duda, la principal fuente de mutaciones proviene de errores espontáneos durante la replicación del material genético. Para evitarlo, junto a mecanismos extremadamente precisos de replicación del ADN son necesarios otros que reparen las lesiones que se producen en él constantemente. Así, al igual que los genomas de otras especies, el humano codifica sistemas que le permiten mantener su propia integridad. Las enzimas reparadoras de ADN supervisan continuamente los cromosomas para corregir los daños en los nucleótidos producidos por factores ambientales como la radiación solar ultravioleta, radiaciones ionizantes o el humo del tabaco; productos del metabolismo celular normal como el agua oxigenada, las moléculas de oxigeno reactivas y ciertos metabolitos que actúan como agentes alquilantes; o la desaminación espontánea 0 inducida de citosina, adenina y guanina. Se estima que cada día se alteran unas 25000 bases por célula del total de $3 \times 10^{9}$ que contiene el genoma humano. Estos sistemas de reparación consiguen que menos de 1/1000 alteraciones accidentales se transformen en mutación que se transmita a las células hijas $61,90,99,105$.

Se han descrito cuatro mecanismos principales de reparación del ADN: Mismatch Repair (MMR), Reparación por escisión de bases (BER), Reparación de rotura de doble cadena (DSBR), y Reparación por excisión de nucleótidos (NER). Son más de 130 los genes implicados en estos procesos, en los que se han identificado un gran número de polimorfismos, muchos de ellos con implicaciones funcionales ${ }^{102,106,107 .}$

Los genes que codifican las proteínas que reconocen el daño en el genoma y los encargados de repararlo, interactúan con los responsables del control del ciclo celular, de manera que la replicación y división de la célula se posterga hasta que las lesiones se hayan reparado. Si esto no se logra, se induce la apoptosis celular, evitando la transmisión del error a las células 


\section{Introducción}

hijas. Cuando estos mecanismos fallan y el daño permanece sin que la célula muera, ésta la transmitirá a sus células descendientes, pudiendo iniciarse la transformación tumoral108. Los genes que intervienen en los diferentes mecanismos de reparación se comportan como "caretakers", y su pérdida de función puede afectar directamente a la estabilidad de otros genes, incluidos los "gatekeepers", ya que si se produce una mutación en un gen supresor que no es correctamente reparada, puede llevar a la pérdida de función supresora y a la carcinogénesis.

a

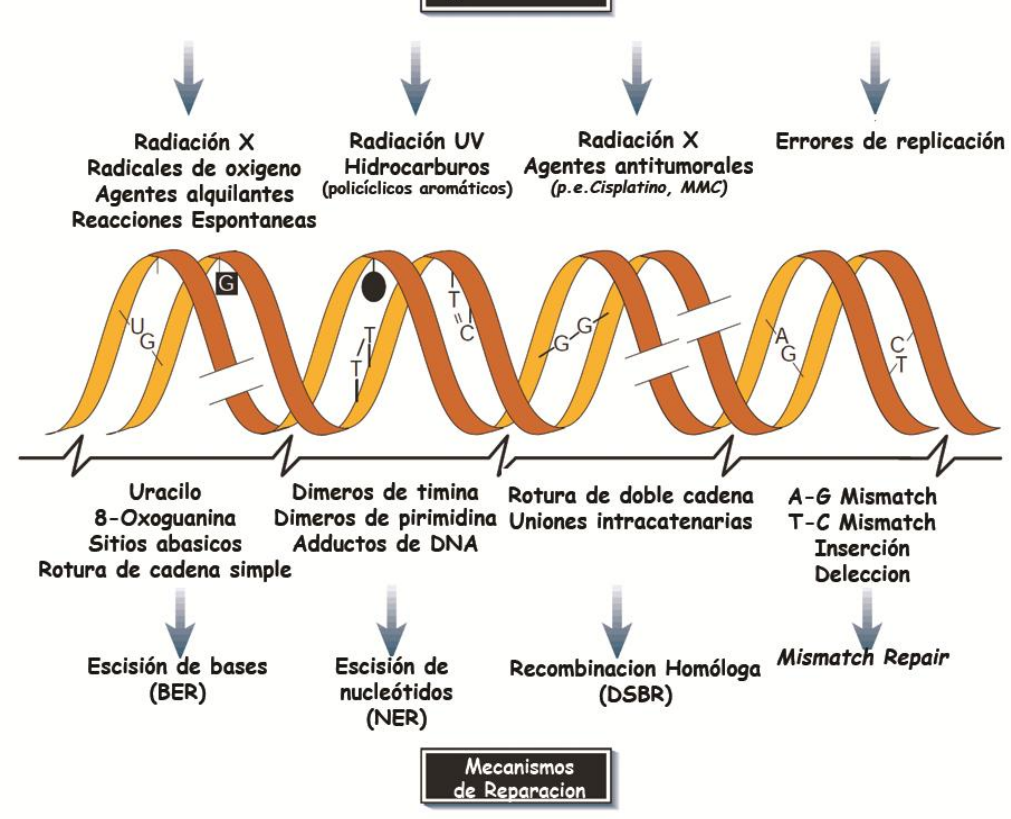

b CONSECUENCIAS

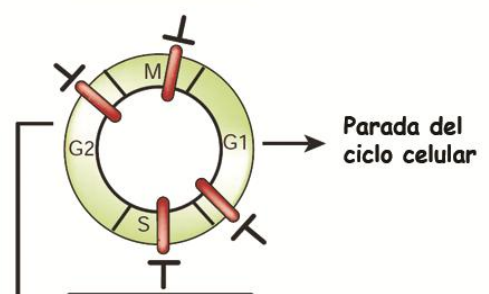

Figura 6: Diferentes mecanismos de reparación del ADN

La funcionalidad de cada una de estas vías en un individuo determinado es independiente, y se han caracterizado varios síndromes hereditarios con una alta predisposición al cáncer debidos a defectos en los genes que participan en estas vías (Tabla 6). Ahora bien, la gran mayoría de los tumores son esporádicos y tal y como se comentó en el punto 2.4. al explicar el modelo poligénico, lo que cada persona hereda es un conjunto de variantes en los genes reparadores de ADN que explicarían la susceptibilidad individual a desarrollar un determinado tipo de cáncer al exponerse a diferentes carcinógenos ${ }^{46}$. 
Tabla 6: Síndromes hereditarios por defectos en los mecanismos de reparación del ADN 46

\begin{tabular}{|lccc|}
\hline \multicolumn{1}{|c}{ SínDROME } & $\begin{array}{c}\text { Mecanismo de } \\
\text { reparación afectado }\end{array}$ & $\begin{array}{c}\text { Alteración genómica } \\
\text { observada }\end{array}$ & $\begin{array}{c}\text { Tipos de cáncer } \\
\text { más frecuentes }\end{array}$ \\
\hline Xeroderma Pigmentoso & NER & Mut. Puntuales & Cutáneos \\
Cockayne & TCR & Mut. Puntuales & Ninguno \\
Tricotiodistrofia & NER/TCR & Mut. Puntuales & Ninguno \\
Ataxia-Teleangiectasia & DSB & Alt. Cromosómicas & Linfomas \\
Nijmegen & DSB & Alt. Cromosómicas & Linfomas \\
BRCA1/BRCA2 & HR & Alt. Cromosómicas & Mama y Ovario \\
Werner & HR & Alt. Cromosómicas & Varios \\
Bloom & HR & Alt. Cromosómicas & Leucemia, linfoma \\
Rothmund-Thomsom & HR & Alt. Cromosómicas & Osteosarcoma \\
HNPCC & MMR & Mut. Puntuales & Colorrectal \\
\hline
\end{tabular}

MMR: Mismatch Repair; DSB: rotura de doble cadena; NER: Reparación por escisión de nucleótidos; HR: Recombinación Homóloga; TCR: Transcription-coupled repair; HNPCC: Cáncer de colon hereditario no polipósico

\subsection{REPARACIÓN DE ALINEAMIENTOS ERRÓNEOS (Mismatch Repair - MMR)}

La importancia del sistema MMR para mantener la estabilidad del genoma bacteriano se demostró hace más de 30 años con la observación de que defectos en estas vías se asociaban a una alta tasa de mutaciones espontáneas. Poco después se comprobó que los defectos en MMR en células humanas producían un aumento de la inestabilidad de todo el genoma, incluyendo unas regiones altamente repetitivas denominadas microsatélites, y que ésto se asocia con el desarrollo de tumores tanto hereditarios como esporádicos ${ }^{109}$. La capacidad de este sistema para mantener la estabilidad genómica se ha asociado con la corrección de emparejamientos que se producen de forma errónea durante la replicación del ADN y el bloqueo de la recombinación entre secuencias similares pero no idénticas (Recombinación no Homóloga). Se ha visto que el sistema MMR 
interviene también en los puntos de control del ciclo celular y en la muerte celular programada en respuesta a ciertos daños en el ADN110.

Este sistema de reparación, en el que intervienen una docena de genes, se inicia con el reconocimiento por parte del complejo hMutS, de los pequeños bucles generados por la inserción, delección e incorporación errónea de bases y nucleótidos durante la replicación. La unión de hMSH2 con MSH6 forma hMutS $\alpha$, que reconoce bucles de 1 o 2 nucleótidos, mientras que la unión de hMSH2 con MSH3, forma hMutS $\beta$, que identifica estructuras más complejas, si bien, existe cierta redundancia entre las funciones de ambos heterodímeros ${ }^{111-113}$. hMLH1 interactúa con hPMS2, hMLH3, hPMS1 para formar tres posibles heterodímeros, denominados hMutL $\alpha$, hMutL $\beta$ y hMutL $\gamma$, respectivamente. Estos Thrs complejos tienen actividad ATPasa y actúan como nexo con las proteínas responsables de la escisión y síntesis.

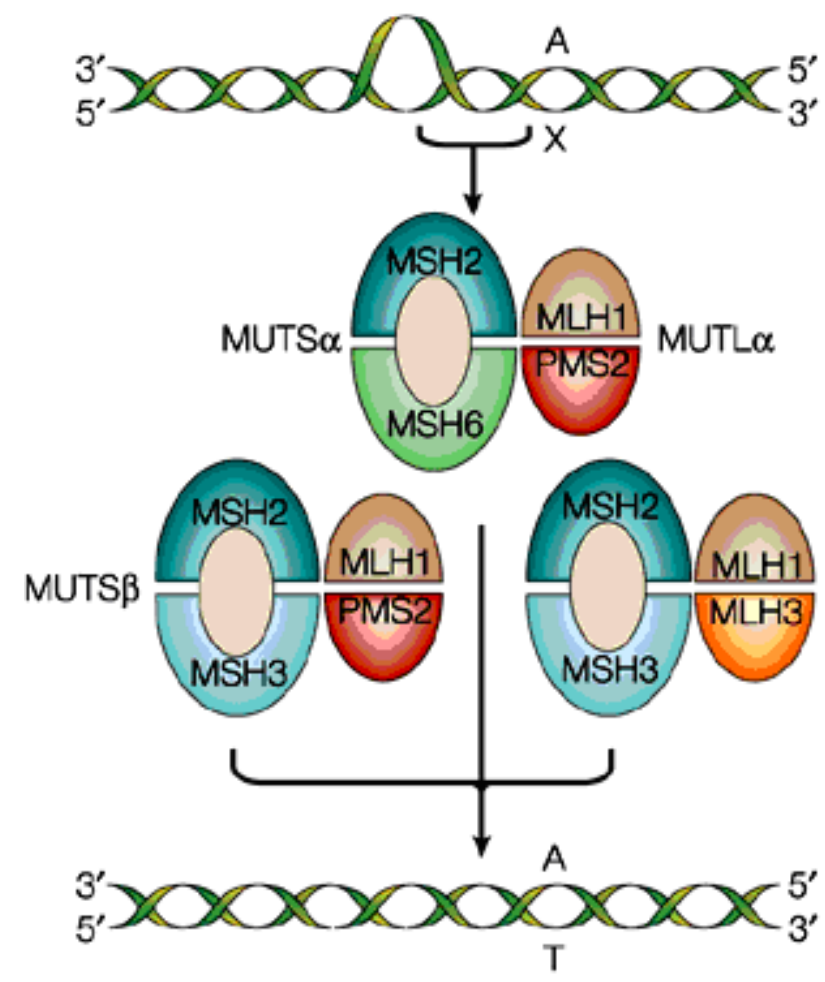

Figura 7. Principales genes implicados en el mecanismo MMR de reparación de ADN105

PCNA (proliferating cell nuclear antigen) favorece la unión de hMutS $\alpha$ y hMutS $\beta$ al lugar del daño. Además interviene como enlace entre estos complejos y la ADN polimerasa en la horquilla de replicación, posiblemente facilitando el reconocimiento y reparación de la nueva 
cadena. Para ello precisa de RFC (Replication Factor C), que facilita su unión al ADN 105. La exonucleasa EXO1 escinde las secuencias erróneas, tras lo que las ADN polimerasas $\delta$, a y $\varepsilon$, sintetizan la nueva cadena ${ }^{112}$. Las ADN ligasas que finalizan el proceso no han sido bien caracterizadas hasta el momento.

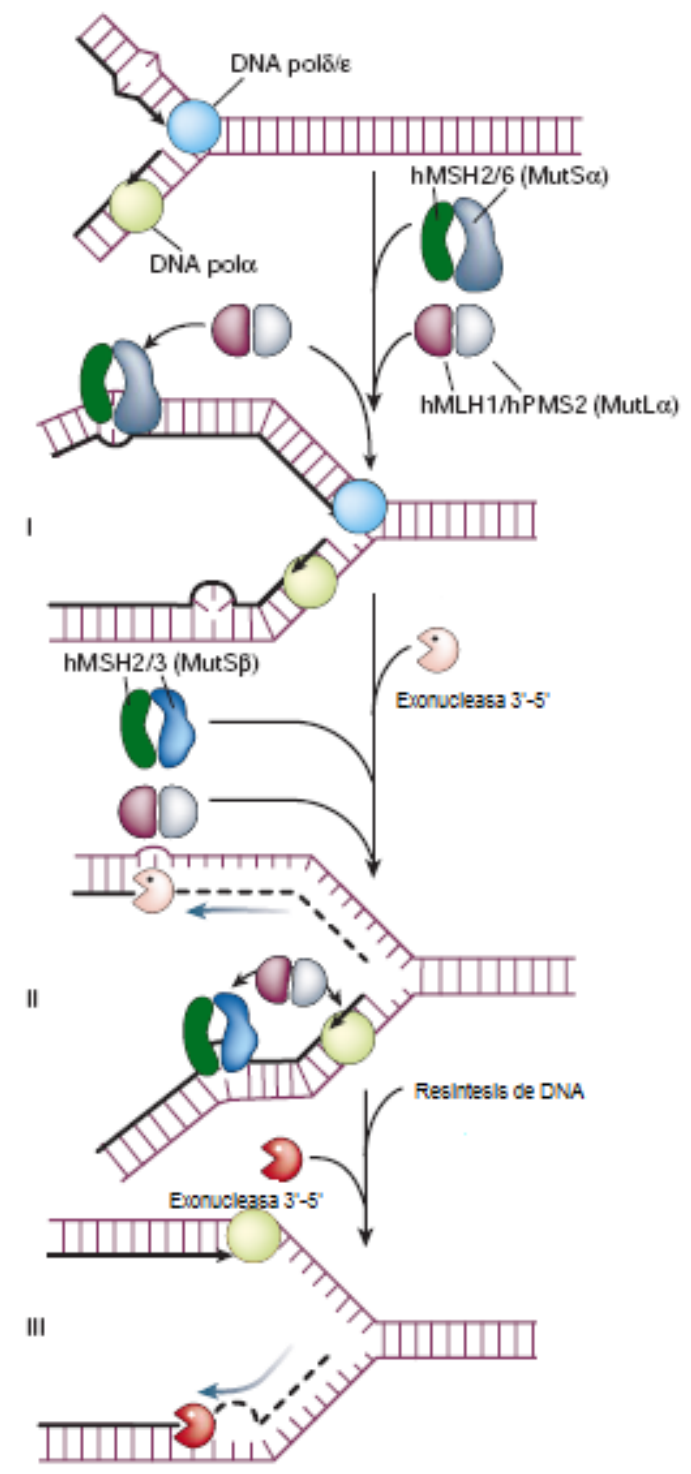

Figura 8: Esquema que representa la reparación por la vía MMR 108 
Los primeros estudios de inestabilidad genética, observaron que cuando el sistema MMR no funcionaba adecuadamente, se producía un aumento, una alteración en el número de repeticiones de los microsatélites. Dicha inestabilidad (MSI), se asoció inicialmente con el desarrollo de cáncer colorrectal hereditario no polipósico (HNPCC) debido a la presencia de una mutación inactivante en los genes MLH1, MSH2, MLH3, MSH6 y más rara vez en PMS2 ${ }^{114}$. Trabajos posteriores demostraron que las formas esporádicas de cáncer de colon presentaban con cierta frecuencia alteraciones estructurales ${ }^{112} 0$ inactivaciones epigenéticas ${ }^{113}$ en estos mismos genes. Esta pérdida de MMR se ha observado también en tumores de endometrio, ovario, gástrico, cérvix, piel, pulmón, próstata, vejiga, mama y linfomas ${ }^{115}$. Por otro lado, se han publicado varios estudios que demuestran la importancia de MMR en la resistencia a quimioterápicos como temozolamida, cisplatino o 5 -fluoruracilo ${ }^{116}$.

\subsection{REPARACIÓN POR ESCISIÓN DE BASES (Base Escisión Repair-BER)}

Algunos productos del metabolismo celular normal suponen una amenaza constante para la integridad del genoma, entre los que se incluyen las especies reactivas de oxígeno (aniones superóxido, radicales hidroxilo y peróxido de hidrógeno) derivados de la respiración oxidativa y de la peroxidación de los lípidos. Además, algunas uniones químicas pueden romperse de forma espontánea en condiciones fisiológicas, como sucede con la hidrólisis de nucleótidos a $37^{\circ} \mathrm{C} 107,117$.

La escisión de bases (BER) es el principal mecanismo de eliminación de bases alteradas o añadidas erróneamente. El reconocimiento de la lesión y la rotura del enlace $\mathrm{N}$-glicosil entre la base nitrogenada y la desoxirribosa-fosfato se realizan a través de un conjunto de glicosilasas, encimas clave de este proceso. Presentan gran especificidad de sustrato, aunque se ha descrito cierta redundancia. La más abundante es UNG, que elimina los residuos de uracilo que han sido incorporados en vez de timina. Poseen un dominio catalítico de hasta 250 residuos y utilizan las regiones amino y carboxilo terminales para realizar interacciones adicionales con la cadena complementaria. La eliminación de las bases nitrogenadas, puede suceder también de forma espontánea108 (Figura 9). 


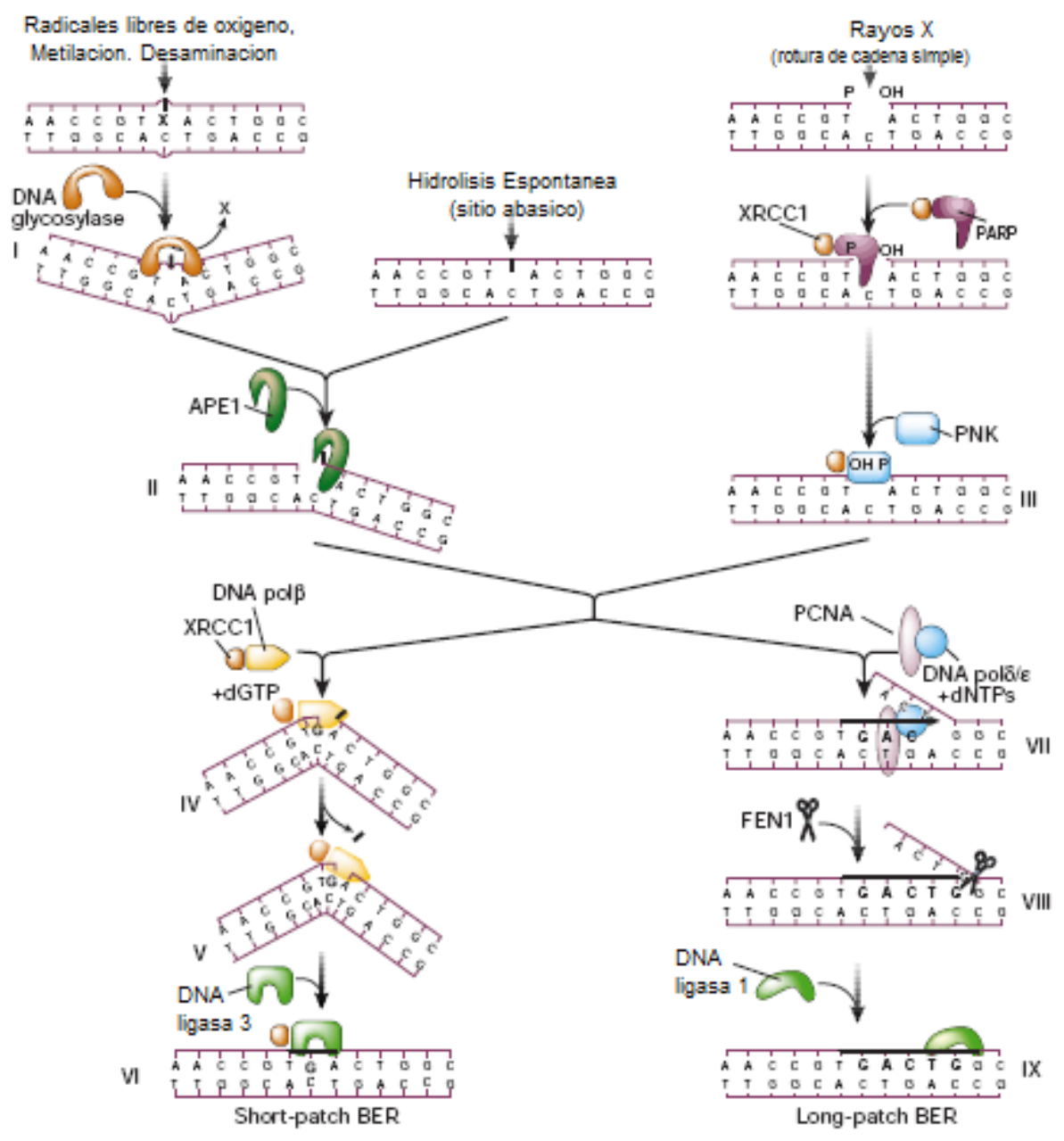

Figura 9: Mecanismo de reparación por Escisión de Bases 108

La endonucleasa APE1 rompe el enlace fosfodiester en el lugar donde se ha eliminado la base. E el caso de que la lesión sea una rotura de cadena simple inducida, por ejemplo, por radiación ionizante, PARP y PNK se unen a los exThrmos de la cadena de ADN a fin de protegerlos.

A partir de aquí, se conocen dos posibles vías de reparación: Long-patch, cuando se afectan varios nucleótidos y Short-patch, cuando solo se implica uno. Short-patch es el mecanismo 
más frecuente, y en ella interviene POL $\beta$, que posee dos dominios que le confieren funciones diferentes: un pequeño dominio terminal $\mathrm{NH}_{2}$ con actividad $\mathrm{AP}$ liasa y que sustrae el residuo de azúcar-fosfato abásico y otro dominio polimerasa propiamente dicho, con el que añade el nucleótido correcto. Además, interactúa con el complejo formado por XRCC1 y ADN ligasa III. XRCC1 actúa como proteína estabilizadora permitiendo la unión de la polimerasa y la ligasa al sitio de reparación, al tiempo que se une al ADN por su región amino-terminal ${ }^{108}$

En los casos en los que el residuo de azúcar-fosfato es estructuralmente más complejo y por tanto resistente a la actividad liasa de POL $\beta$, se emplea el mecanismo Long-patch, en el que la exonucleasa FEN1 elimina la región desplazada, evitando la formación de bucles durante la subsiguiente síntesis de ADN y la polimerasa POL $\delta$ es la encargada de incorporar los nucleótidos que faltan. PCNA estimula estas reacciones estabilizando las diferentes proteínas al igual que XRCC1 lo hacía en la ruta anterior. Finalmente, intervendría la ADN ligasa I (LIGI) 108,118

Este mecanismo de reparación actúa a lo largo de todo el genoma, produciéndose en ocasiones el bloqueo de la transcripción, en cuyo caso se activa a la vez el mecanismo de TCRNER (Transcription Coupled-Nucleotide Escisión Repair). Actualmente, no se conoce ninguna patología humana causada por déficits en este mecanismo de reparación, en parte debido a la redundancia de función de algunas glicosilasas y al citado solapamiento con TCR-NER. En estudios con modelos animales, se ha visto que la inactivación de las proteínas que intervienen en BER es letal.

\subsection{REPARACIÓN DE LESIONES POR ROTURA DE DOBLE CADENA (DSBR)}

La rotura de doble cadena, que constituye una de las lesiones más nocivas para la célula, puede producirse por productos del metabolismo celular como las especies reactivas de oxígeno, las radiaciones ionizantes, la rotura espontánea de cromosomas durante la replicación del ADN y algunos quimioterápicos como los inhibidores de la topoisomerasa lla. Paradójicamente, también pueden ser secundarios a la actividad de otros mecanismos de reparación, como la Reparación por Escisión de Nucleótidos (NER) 108,119. 
La célula dispone de dos sistemas para reparar estas lesiones: Recombinación Homóloga (HR, homologous repair) y Recombinación no homóloga (NHEJ, Non-homologous end joining). HR requiere una secuencia de ADN homólogo como molde, generalmente la cromátida hermana, por lo que solo puede llevarse a cabo tras la replicación del ADN, en las fases S y G2 del ciclo celular ${ }^{120,121}$. En cambio mediante NHEJ, los exThrmos rotos son procesados por nucleasas y emparejados con otra secuencia de escasa o ninguna homología, por lo que es activa durante todo el ciclo, pero fundamentalmente durante $\mathrm{G} 1$, cuando no existe un cromosoma homólogo para que se produzca la recombinación ${ }^{122}$. La reparación mediante NHEJ es mucho más rápida, pero introduce errores, ya que se pierde la secuencia del lugar donde asienta la DSB y la unión de exThrmos de secuencias situadas en dos cromosomas diferentes, puede originar translocaciones 107,120,121,123. Que la célula elija uno u otro mecanismo depende por lo tanto de la fase del ciclo celular en que se encuentre, pero también del manejo inicial de la rotura de doble cadena. Si los exThrmos 5' son degradados por nucleasas para producir colas 3' de cadena sencilla, que son el substrato de RAD51, entonces, se iniciara el mecanismo de HR, inhibiéndose la NHEJ122.

\subsubsection{RECOMBINACIÓN HOMÓLOGA (HR)}

La recombinación homóloga $(H R)$ implica el intercambio de información entre regiones homólogas del genoma. Si el intercambio es recíproco, se denomina entrecruzamineto (crossover), mientras que no existe esta reprocidad se denomina conversión génica (non crossover). En algunos casos, se produce una combinación de ambos ${ }^{121}$. (Figura 10). Además de ser una forma de reparación de las roturas de doble cadena, es esencial durante la meiosis, ya que es el mecanismo a través del cual se produce el intercambio de información entre las dos cromátidas ${ }^{124}$. 


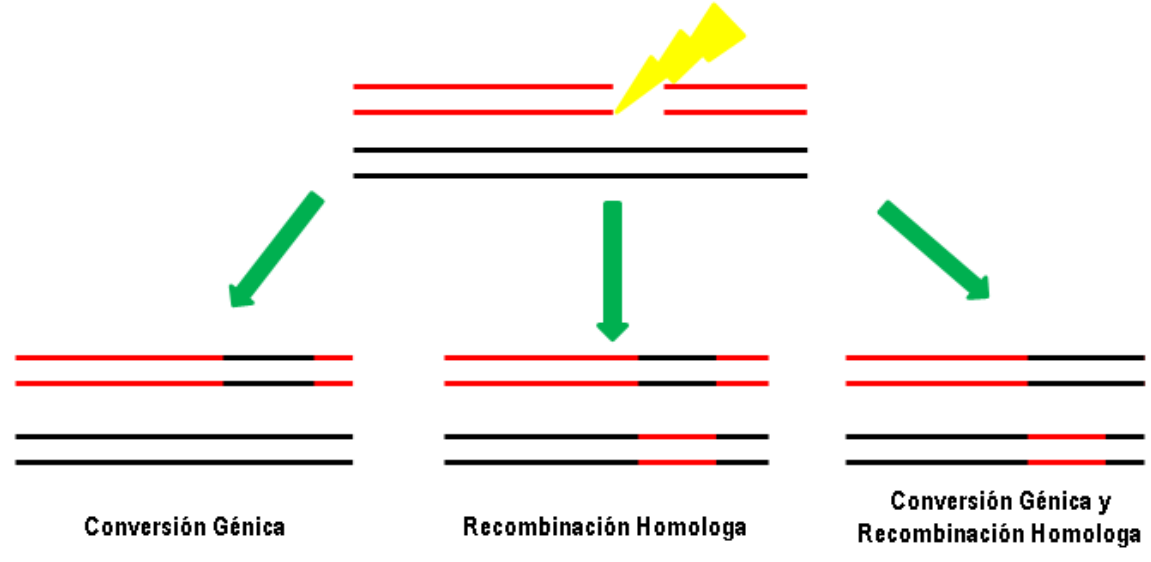

Figura 10: Posibles productos de la Recombinación Homóloga ${ }^{121}$

El proceso se inicia mediante la adhesión a los exThrmos de la cadena de ADN de varias proteínas, fundamentalmente el complejo MRN, formado por MRE11, RAD50 y NSB1, y con actividad exonucleasa, que expone los bordes y añade unas colas de cadena simple en sentido 3'. La recombinasa RAD51 induce entonces la unión a las moléculas de ADN homólogas. La unión de RAD51 a la cadena simple de ADN (SSADN) está favorecida y regulada por su interacción con BRCA2 y catalizada por múltiples proteínas, como XRCC2, XRCC3, y varias isoformas de RAD51 (RAD51B, RAD51C, RAD51D, y RAD52), capaces de encontrar secuencias homologas en todo el genoma y catalizar la reacción de intercambio formando un "loop" o anillo en la cadena de ADN. Si HR tiene lugar durante la mitosis, entonces el intercambio tendrá lugar con la cromátida homologa, pero si se produce durante la miosis, el ADN molde será similar, pero no necesariamente idéntico. Una vez que el intercambio se ha completado, el exThrmo 3' de la cadena invasora se alarga mediante una ADN polimerasa (Figura 11.a). A partir de aquí, el proceso puede proseguir por dos vías diferentes:

- SDSA (Synthesis-Dependent Strand Annealing): Una vez que la molécula de ADN rota ha unido a la hebra molde y se ha sintetizado uno de las cadenas, el anillo se rompe y la cadena nueva, sirve a su vez como molde para la cadena complementaria. (Figura 11.b)

- DSBR (Double Strand Break Repair): (Figura 11.c) Si en vez de una, son las dos cadenas rotas las que se unen al ADN molde, se forman dos anillos en vez de uno. De esta forma, se originan unas estructuras de forma cruciforme, denominadas Holliday Junctions, en las que concurren 
las hebras de las dos moléculas de ADN., Estos complejos son procesado por endonucleasas especializadas, que cortan las cadenas de maderas que generalemente mediante un mecanismo de crossover, si bien es cierto que según el punto de corte, puede no se produzca este entrecruzamiento sino una conversión génica120,121,123.

a

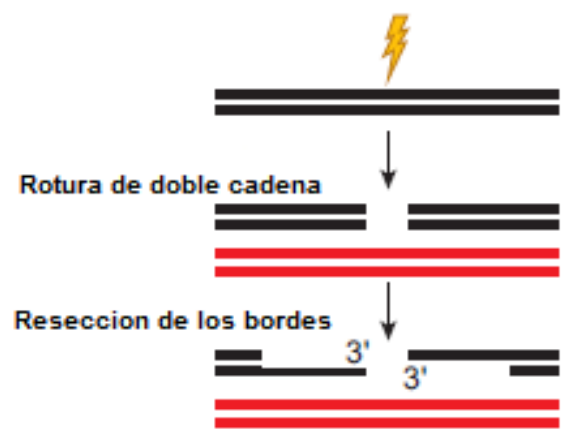

Invasion de la cadena Sintesis de DNA

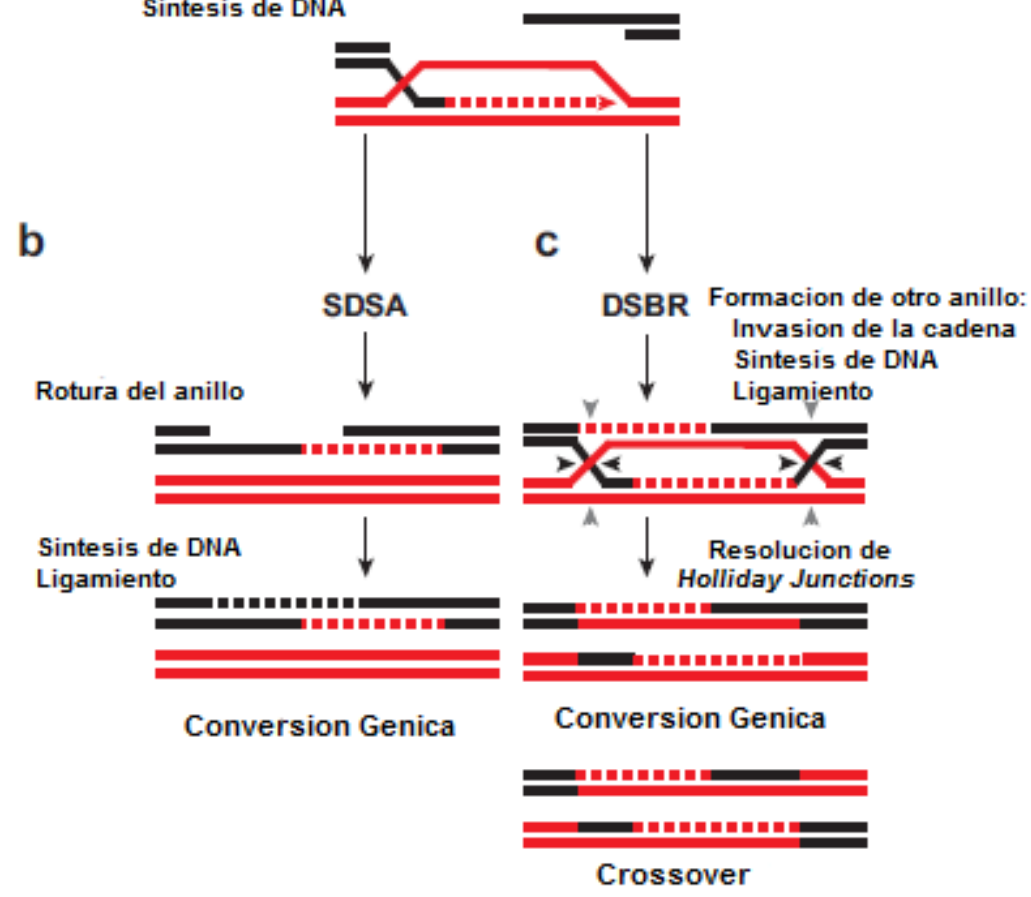

Figura 11: Reparación de Rotura de Doble Cadena por Recombinación Homóloga124 


\subsubsection{RECOMBINACIÓN NO HOMÓLOGA (NHEJ)}

Contrariamente a lo anterior, este mecanismo de reparación no precisa de homología en los extremos terminales del ADN, y es critica durante la recombinación somática $\mathrm{V}(\mathrm{D}) \mathrm{J}$, el mecanismo por el que se procesan los receptores de las células $B$ y $T$, y que origina la diversidad del sistema inmune ${ }^{120 .}$

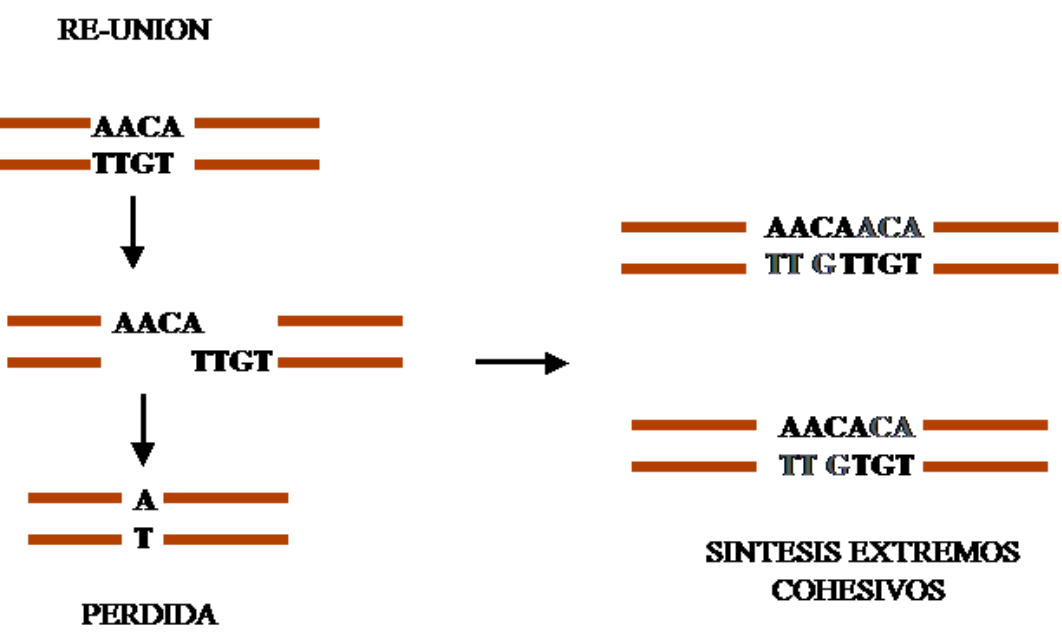

Figura 12. Mecanismos de recombinación no homóloga de las roturas de doble cadena ${ }^{119}$

El mecanismo se inicia por la unión a los exThrmos de un heterodímero formado por las proteínas Ku70 y Ku80. Esto activa la subunidad catalítica de la proteína ADN-PK (quinasa dependiente de $A D N$ ) que fosforila a otras proteínas y así misma, de forma que adquiere su forma activa y es capaz de activar a su vez a otras proteínas como Wrn, Artemis, Tdp1 y PNK, necesarias para eliminar los nucleótidos alterados y para el procesamiento de los exThrmos. Las polimerasas Pol $\lambda$ y Pol $\mu$ sintetizan la nueva cadena. El proceso concluye tras la ligación de los exThrmos por acción del complejo formado por la ADN ligasa IV y XRCC4 (Figura 12)119,120. 


\subsection{REPARACIÓN POR ESCISIÓN DE NUCLEÓTIDOS (NER)}

La mayoría de los organismos vivos dependen directa o indirectamente de la energía solar para su subsistencia, lo que por otro lado puede ocasionarle graves daños debido a la exposición al los rayos ultravioletas (UV). La reparación mediante escisión de nucleótidos (NER) es el mecanismo principal para resolver estas lesiones. Pero esta vía es muy versátil y a través de ella se reparan no solo los dímeros de pirimidinas inducidos por la radiación UV, sino también aductos de ADN debidos a sustancias químicas como cisplatino, N-acetil-acetoaminofluoreno o el tabaco. De hecho, se calcula que mediante la vía NER se reparan cerca del $70 \%$ de las lesiones en el ADN inducidas por el medio ambiente. Estas alteraciones distorsionan la estructura de la doble hélice e interfieren en la unión normal de las bases, alterando y bloqueando la replicación y la trascripción ${ }^{108 .}$

Se distinguen dos vías de reparación NER, según el mecanismo de reconocimiento de la lesión: GG-NER (Global Genomic Repair) reconoce lesiones que distorsionan la doble hélice a lo largo de todo el genoma. Este reconocimiento se realiza a través del complejo XPC-HHR23B, que atrae hacia ese lugar al heterodímero DDB (ADN damage binding), iniciándose la reparación. En cambio, TCR-NER (Transcription Coupled Repair) actúa únicamente en las regiones transcripcionalmente activas cuando existe una lesión que bloquea la actividad de la RNA polimerasa II. Las proteínas CSA y CSB son las encargadas de reclutar el resto de factores que intervienen en esta vía, por lo que su función es crítica.

Una vez que se ha producido el reconocimiento de la lesión, los pasos que siguen GGNER y TCR -NER son idénticos ${ }^{125}$ (Figura 13) y se inician con el desenrrollamiento de la hélice mediante el complejo TFIIH, constituído por nueve proteínas, entre ellas, XPD y XPB, con función helicasa. A continuación y de forma secuencial, las endonucleasas realizan dos incisiones a ambos lados de la lesión. La primera de ellas, a unas 6 bases en sentido 3', la realiza XPG, mientras que la segunda, a 22 bases en sentido $5^{\prime}$, la realizan un complejo que incluye a XPA, RPA y ERCC1-XPF. Se genera un oligonucleótido de $28 \mathrm{pb}$ que ha perdido las uniones covalentes con el resto de la cadena de ADN y únicamente se mantiene unida a sus bases complementarias mediante puentes de hidrógeno ${ }^{126}$. Durante este proceso, RPA ha permanecido 
unida a la cadena sana, protegiéndola y facilitando la posterior resíntesis del fragmento eliminado. Para ello atrae a PCNA, un factor de replicación que es capaz de reclutar a las ADN polimerasas $\delta$ ó $\varepsilon$. Finalmente, la ADN Ligasa I, une el exThrmo 5 'del nuevo fragmento a la secuencia original $105,110,127$.

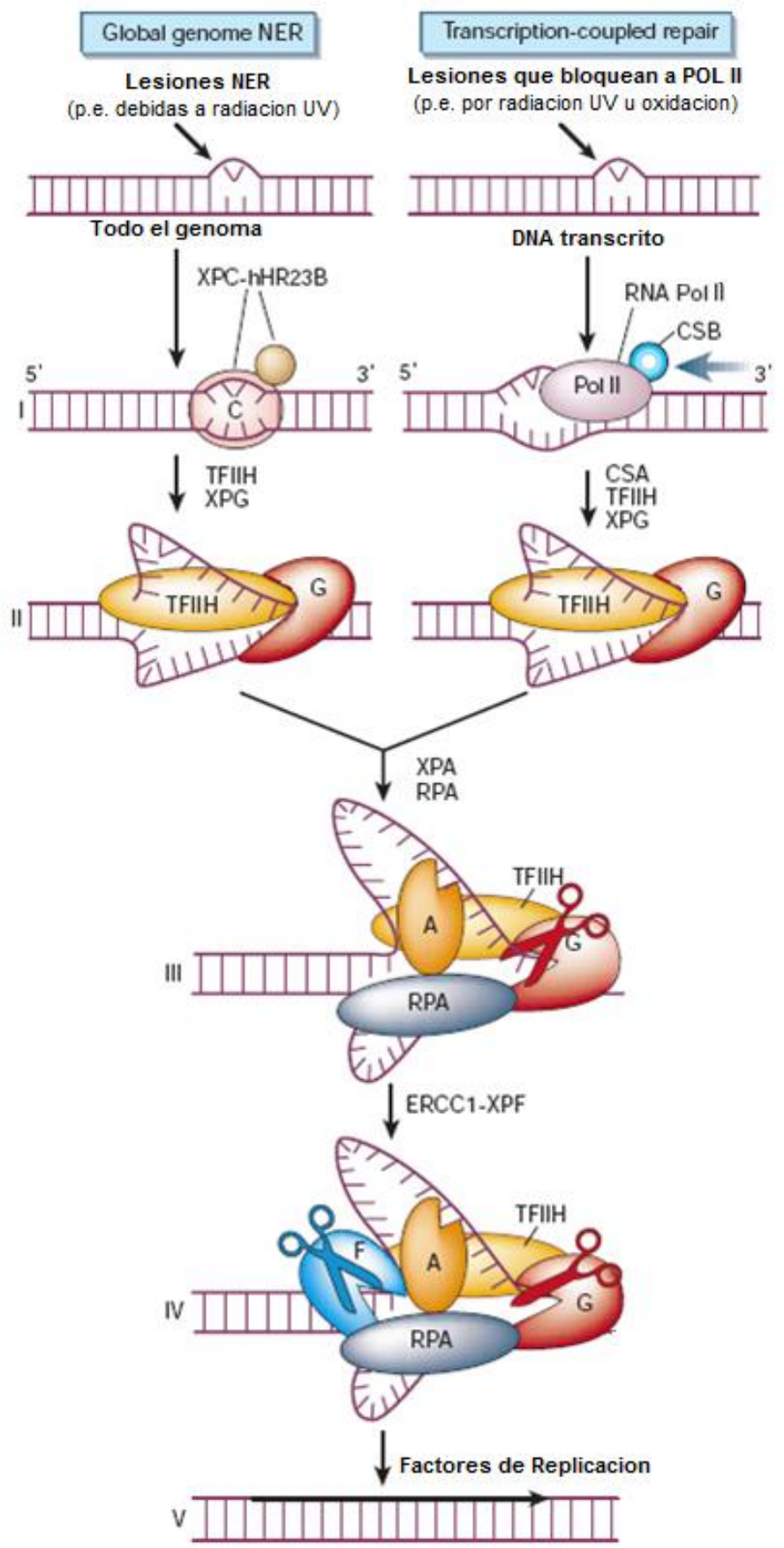

Figura 13: Mecanismo de reparación NER 108 
Al menos tres síndromes se han asociado con déficits congénitos en NER: Xeroderma Pigmentoso (XP), Síndrome de Cockayne (CS) y Tricotiodistrofia (TTD), todos ellos con una extraordinaria sensibilidad a la luz solar. XP se origina por mutaciones en uno de los siete genes XP (XPA-XPG) y es el prototipo de alteración de la reparación y conlleva un riesgo de cáncer de piel 1000 veces mayor que el de la población general. El Síndrome de Cockayne se debe a mutaciones en CSA y CSB lo que produce un fallo en TCR-NER. Esto hace que las células de estos individuos sean especialmente proclives a la apoptosis inducida por lesiones en el ADN, lo que les protege del desarrollo de tumores, pero cursa con un envejecimiento prematuro. La Tricotiodistrofia es forma de ictiosis laminar con un pelo con contenido anormalmente bajo en azufre, que a la luz polarizada, presenta bandas alternantes densas y claras que le dan el aspecto de "pelo en cola de tigre", además de compartir muchas de las alteraciones de CS. Mutaciones e XPD o XPB pueden originar cualquiera de estos tres síndromes. Esto se explica porque estos dos genes son subunidades de TFIIH, que interviene tanto en NER como en el inicio de la transcripción, por lo que alteraciones en estos genes, no solo comprometen la reparación, sino también la transcripción y con ello favorecen la aparición de tumores y de alteraciones del desarrollo 108,125,128.

Diferentes estudios sugieren que existen interacciones entre factores de unas y otras vías, como entre las ADN glicosilasas que intervienen en BER y factores de MMR y NER. También se relacionan a través de proteínas como PCNA y RPA, implicadas en la replicación que sigue a estos Thrs mecanismos de reparación 129.

Tanto la radioterapia, como diferentes quimioterápicos, entre los que se incluyen las antraciclinas y los platinos, pueden producir daño directo sobre el ADN a través de diferentes mecanismos como la peroxidación de los lípidos y la generación de radicales libres, la intercalación entre las bases del ADN o la formación de aductos. Estudios in vivo e in vitro han demostrado una asociación entre las alteraciones en los genes reparadores del ADN y la sensibilidad a diferentes citotóxicos. Se ha visto también que varios SNPs en estos genes alteran la capacidad funcional de los mismos y podrían condicionar la respuesta de los pacientes a los tratamientos quimio y radioterápicos. 


\section{XRCC1 Arg399GIn, XRCC3 Thr241Met y XPD Lys751GIn}

XRCC3 Thr241Met, XRCC1Arg399GIn, XPDLys751GIn son tres de los polimorfismos presentes en genes reparadores del ADN más ampliamente estudiados, debido a su elevada frecuencia en la población general y a que inducen un cambio en la funcionalidad de la proteína que ha podido ser caracterizado. Ademas, se han relacionado con el riesgo a desarrollar diferentes tipos de tumores sólidos así como con la respuesta de los pacientes al tratamiento.

\subsection{XRCC1 Arg399GIn}

El gen XRCC1 (X-ray repair cross complementation group 1), tiene un tamaño de $33 \mathrm{~kb}$ y se localiza en el cromosoma 19q13.2-13.3. Codifica una proteína de 663 aminoácidos a la que no se ha atribuido actividad enzimática, pero que posee Thrs dominios de interacción con otras proteínas, además de una señal de localización nuclear y un sitio de fosforilación por Ck2 ${ }^{130}$.

XRCC1 tiene un papel fundamental en la reparación del ADN por Escisión de Bases (BER). Interactúa con múltiples glicosilasas y forma complejos con la mayoría de las proteínas que intervienen en este proceso, como APE1, POL $\beta$, PARP1 y LIG3, lo que sugiere que es reclutado al lugar de la lesión por las glicosilasas y después coordina los siguientes pasos de BER, modulando la actividad del resto de factores implicados ${ }^{129}$.

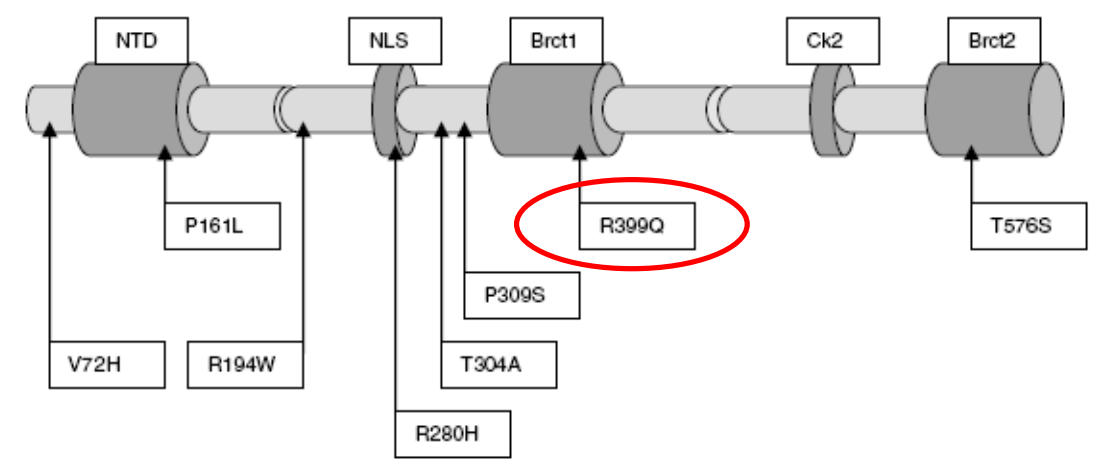

Figura 14: Dominios del gen XRCC1 (parte superior) y localización de los polimorfismos no sinónimos identificados 130 
El dominio N-terminal es el lugar de unión de POL $\beta$. Posee dos dominios BRCT, así denominados por su homología con el dominio C-terminal de BRCA1, que median la interacción con otras proteínas: BRCT1 es un sitio de interacción con PARP, mientras que BRCT2 es el lugar de interacción con LIG3 (Ligasa III). La zona de unión entre el exThrmo N-terminal y BRCT sirve de interacción con Apex, OGG1 y PCNA ${ }^{130}$. Recientemente se ha demostrado que la unión del factor de transcripción E2F1 regula la actividad de XRCC1 y promueve la reparación del ADN131.

Estudios en modelos animales han demostrado que la delección de XRCC1 en línea germinal es incompatible con la vida ${ }^{132}$, mientras que las líneas celulares con mutaciones inactivantes del gen presentan hipersensibilidad a las radiaciones ionizantes así como a los agentes alquilantes ${ }^{133}$.

Se han descrito más de 60 polimorfismos en este gen, de los que el más estudiado es Arg399GIn, localizado en el exón 10, en el dominio BRCT-1102. Consiste en el cambio de Guanina (G) por Adenosina (A) en la secuencia del ADN, lo que una vez transcrito supone la substitución de Arginina (Arg) por Glutamina (Gln) en la región BRCT-1. Esto determina un cambio en la conformación tridimensional de la proteína ${ }^{134}$, que determina la disminución de la capacidad reparadora del $A D N$, medida en estudios funcionales a través de la persistencia de aductos de $A D N$, aumento del número de mutaciones en p53, alteraciones cromosómicas y un retraso en ciclo celular cuando se somete a las células a radiación ionizante ${ }^{135-140}$. De acuerdo con los diferentes estudios, la variante Gln está presente en el $23-36 \%$ de la población general141, y se ha asociado con diferentes tipos de cáncer, principalmente en fumadores ${ }^{139}$.

\subsection{XRCC3Thr241Met}

El gen XRCC3 (X-ray repair cross complementation Group 3) se localiza en 14q32.3 y estructuralmente es similar a RAD51, con el que interactúa y junto al que juega un papel clave en la reparación de Roturas de Doble Cadena de ADN (DSB) a través del mecanismo de Recombinación Homóloga142-144. XRCC3 regula la activación de RAD51 y juntos coordinan la progresión de la horquilla de replicación durante la SDSA ${ }^{145,146}$. XRCC3, junto con otras proteínas de la familia de RAD51 coordina el proceso y resolución de la conversión génica ${ }^{146}$. 
Las células con mutaciones del gen XRCC3, presentan una gran sensibilidad a las radiaciones ionizantes así como a los agentes alquilantes ${ }^{147,148}$. Mediante cultivos celulares, se ha visto que la sola pérdida de XRCC3 induce una inestabilidad cromosómica que hace a la célula inviable, por lo que se ha sugerido que podría actuar como un gen supresor de tumores ${ }^{149,150 .}$

La sustitución de Citosina (C) por Timina (T) posición 18067 (exón 7) de XRCC3 se traduce en el cambio de Thronina (Thr) por Metionina (Met) en el codón 241. Este cambio elimina un sitio de fosforilación de la proteína, impidiendo la interacción de XRCC3 con otros elementos de la vía DSB y alterando la capacidad de reparación celular 121,136,151. Según los distintos estudios, la frecuencia del alelo Met en la población general oscila entre el 22 y el $44 \%$ de la población genera|152,153.

A pesar de que se han identificado varios polimorfismos en XRCC3, Thr241Met es probablemente el más estudiado de ellos, debido a su relativamente alta frecuencia en la población general y a que ha podido establecerse su significado biológico. Se han llevado a cabo múltiples estudios moleculares y epidemiológicos para evaluar el papel de esta variante en diferentes tipos tumorales ${ }^{153-155}$, así como en la sensibilidad y respuesta a diferentes fármacos, principalmente, agentes alquilantes ${ }^{156-158 .}$

\subsection{XPDLys751Gln}

El gen XPD (Xeroderma Pigmentoso D), también denominado ERCC2, es un gen de 54.3kb localizado 19q13.32. Codifica una helicasa de 760 a, evolutivamente muy conservada, que forma parte del complejo TFHIIH, esencial tanto para iniciar la transcripción mediada por la RNA polimerasa II, como para la reparación por escisión de nucleótidos (NER), 117,126,127. La proteína codificada, de 760 aminoácidos, es una helicasa dependiente de ATP que abre la hélice de ADN en sentido 5'-3' para que puedan iniciarse los procesos de transcripción y reparación ${ }^{159}$.

Mediante estudios de asociación, de función y modelos animales, se ha comprobado que la pérdida completa de la proteína XPD es incompatible con la vida, pero en cambio, el déficit 
parcial de su función que originan las diferentes mutaciones caracterizadas hasta la fecha en el gen XPD, pueden conducir tanto a síndromes con predisposición al cáncer como síndromes que cursan con progeria, como es el caso del Xeroderma Pigmentoso, el Síndrome de Cockayne o la Tricotiodistrofia $128,160,161$

Junto a estas mutaciones, se conocen múltiples SNP's en XPD. La mayoría de ellos se localizan en regiones intrónicas no codificantes, por lo que se consideran inocuos, si bien es posible que alguno altere el splicing de los transcritos primarios ${ }^{162}$. De los que se encuentran en las regiones exónicas, el cambio de Adenina (A) por Citosina (C) en la posición 2329163, es probablemente el más estudiado debido a que produce un cambio en la secuencia de aminoácidos y un cambio conformacional en la proteína ${ }^{164}$. El cambio de Lisina (Lys) por Glutamina (GIn) en el codón 751 introduce un cambio conformacional en el exThrmo carboxi-terminal de la proteína ${ }^{164}$, al que en condiciones normales se une p44, la proteína responsable de activar su función helicasa de XPD dentro del complejo TFIIH. Si bien esta alteración no elimina por completo la actividad de XPD, sí que la disminuye de manera importante, comprometiendo la reparación del ADN135,136, de forma que las células son más sensibles a las lesiones inducidas por exposición a las radiaciones X y UV154,165,166. La variante polimórfica está presente en aproximadamente el 30-40\% de la población general ${ }^{162}$.

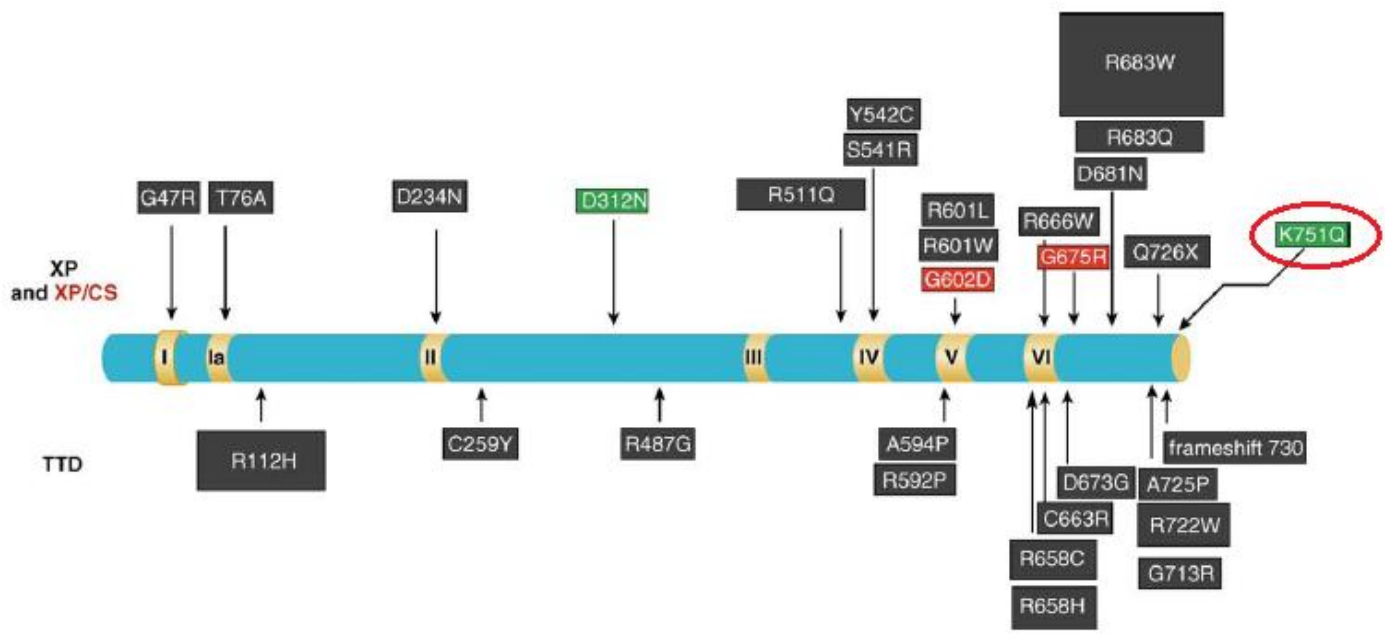

Figura 15: Estructura del gen XPD. En la parte superior del esquema, se muestran las mutaciones han sido asociadas sólo con XP (cuadros negros)y con XP y Sindrome de Cockayne (cuadros rojos). En la parte inferior, se muestran las mutaciones asociadas a TTD. Los cuadros verdes muestran los SNP's que implican cambios funcionales. Los números romanos I-VI señalan los siete dominios con actividad helicasa ${ }^{162}$. 


\section{OBJETIVOS}


En este trabajo pretendemos analizar la posible asociación entre polimorfismos de genes reparadores y el desarrollo de cáncer de mama no familiar, así como el papel de estas variantes genéticas en la sensibilidad a los esquemas terapéuticos habituales. Para ello, hemos planteando los siguientes objetivos:

1. Comparar las distribuciones alélicas y genotípicas de los polimorfismos Arg 399 Gln del gen XRCC1, Thre241Met del gen XRCC3 y Lys751GIn del gen XPD entre pacientes con cáncer de mama y mujeres sanas, con el fin de determinar una posible relación entre los diferentes genotipos y la predisposición al desarrollo de este tipo de tumores.

2. Estudiar la distribución de alelos y genotipos de los polimorfismos Arg $399 \mathrm{Gln}$ del gen XRCC1, Thr241Met del gen XRCC3 y Lys751GIn del gen XPD, en relación con la edad en los grupos caso y control.

3. Estudiar la distribución de alelos y genotipos de los polimorfismos Arg $399 \mathrm{Gln}$ del gen XRCC1, Thr241Met del gen XRCC3 y Lys751Gln del gen XPD en pacientes con cáncer de mama tratadas con radioterapia para analizar si existe relación en Thr estos y la aparición de toxicidad cutánea.

4. Analizar el posible papel pronóstico de XRCC1 Arg399GLn, XRCC3Thr241Met y XPDLys751GIn en las pacientes con cáncer de mama tanto en estadios tempranos como en la enfermedad diseminada. 
Material y Métodos 


\section{MUESTRA}

\subsection{Pacientes}

Las pacientes elegibles para el estudio eran mujeres mayores de 18 años diagnosticadas de cáncer de mama no familiar atendidas en las Consultas Externas del Servicio de Oncología del Hospital Universitario de Salamanca entre Enero y Abril de 2004. Se seleccionaron 200 pacientes que habían sido diagnosticadas entre 1990 y 2004. Para la obtención del ADN constitutivo, se les extrajo una muestra de $10 \mathrm{cc}$ de sangre periférica previo consentimiento, siguiendo las normas legales para los Estudios Clínicos de España y las del Comité de Ética del Hospital Universitario de Salamanca.

Se recogieron de forma retrospectiva los datos anatomopatológicos del tumor (Tipo histológico y grado de diferenciacion tumoral, receptores de estrógenos y progestagenos, HER2), TNM, (Tamaño tumoral, presencia de metástasis ganglionares o de metástasis en otras localizaciones), datos epidemiológicos de las pacientes (edad al diagnostico, y estado menstrual), datos sobre el tratmamiento recibido (Tipo de cirugía, tipo de radioterapia, hormonoterapia y esquemas de quimioterapia recibidos) y datos del seguimiento (recidiva local, metástasis a distancia, aparcicion de segundos tumores, tiempo de supervivencia desde el diagnóstico,y supervivencia libre de enferemdad, causa del fallecimiento).

Se revisaron los antecedentes familiares de las pacientes, comprobando que no existiese agregación familiar para cáncer de mama, o que en caso de existir, se hubiese realizado el estudio mutacional en los genes de alta penetrancia BRAC1 y 2. No se encontró mutación en estos genes en ninguna de las pacientes con dos o más casos de cáncer de mama en familiares de primer y segundo grado, pero 3 pacientes menores de 40 años fueron excluidas del estudio por encontrarse que eran portadoras de mutación en el gen BRCA1. 
Para homogeneizar la muestra, se descartaron otras 2 pacientes que habían recibido tratamiento con TASPE (trasplante autólogo de precursores hematopoyéticos obtenidos de sangre periférica). Se rechazaron otras 16 pacientes por no disponer de los informes anatomopatológicos o de los datos clínicos estudiados y 5 debido a que la cantidad de ADN obtenido era insuficiente y no permitía el estudio genético completo. El número final de casos analizados es de 174 (Figura 16). La mediana de edad en el momento del diagnóstico fue de 62 años, con un rango de 26.5 91.5 años y una media de 60.1 .

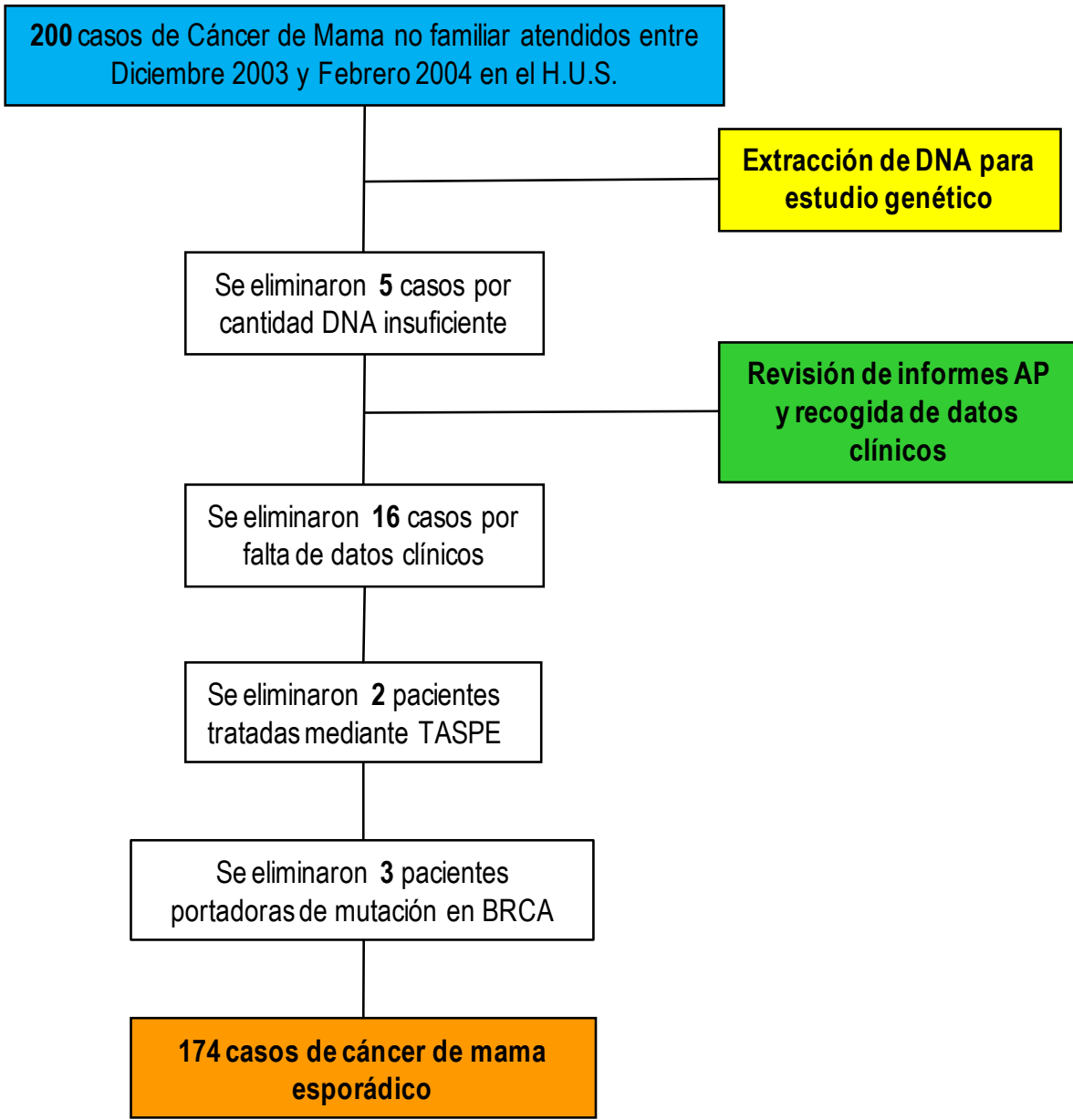

Figura 16: Diagrama de flujo de selección de los casos de la muestra 


\subsection{Controles}

Los individuos elegibles para el estudio como controles fueron mujeres mayores de 18 años que no hubiesen padecido ningún tipo de cáncer hasta el momento de ser reclutadas. Se seleccionaron un total de 310 mujeres atendidas en el Servicio de Urgencias del Hospital Universitario de Salamanca por diferentes dolencias entre Junio de 2004 y Junio de 2005, así como pacientes de varios Centros de Salud de la ciudad de Salamanca, a las que, previo consentimiento, se les extrajo una muestra de $10 \mathrm{cc}$ sangre periférica mediante venopunción antecubital. Finalmente, se excluyeron 10 controles debido a que la cantidad de ADN obtenido era insuficiente para el análisis genético.

Para cada uno de los casos se seleccionó como control una mujer sin antecedente de cáncer de la misma edad \pm 3 años. Este subgrupo control de 174 mujeres presenta una mediana de edad 61.5 años y la diferencia con el grupo de pacientes no es significativa $(p=0.996)$.

En el grupo control, se incluyeron otras 126 mujeres con rango de edad 20.5-98.5 años, para completar el análisis de la frecuencia de los polimorfismos XRCC3 Thr241Met, XRCC1 Arg399GIn y XPD Lys751GIn en relación con la edad. De este modo, la muestra final incluye 300 mujeres en el grupo control, de las cuales, 25 eran menores de 35 años (8.3\%), 55 eran mayores de 80 años (18.3\%) y el $73.3 \%$ restante (220) tenían entre 35 y 80 años. La tabla 7 recoge las características finales de la muestra.

Tabla 7: Distribución de la muestra por edades

\begin{tabular}{|r|c|c|c|c|}
\cline { 2 - 5 } \multicolumn{1}{c|}{} & $\mathrm{N}$ & Media Edad & Mediana Edad & Rango de edad $\mid$ \\
\hline CASOS & 174 & 60.1 & 62 & $26.5-91.5$ \\
\hline CONTROLES & 300 & 61.78 & 63.5 & $20.5-98.5$ \\
Pareados & 174 & 60.15 & 61.5 & $26.5-91.5$ \\
No pareados & 126 & 64 & 63.5 & $20.5-98.5$ \\
\hline
\end{tabular}




\section{AISLAMIENTO DE ADN GENÓMICO}

Se obtuvo el ADN genómico de cada individuo a partir de una muestra de $10 \mathrm{ml}$ de sangre periférica obtenida mediante venopunción en la región antecubital, previo consentimiento.

Las células nucleadas de la sangre se aislaron mediante centrifugación repetida y lisis eritrocitaria con solución hipotónica (centrifugación de la sangre total en $50 \mathrm{~mL}$ de $\mathrm{ddH}_{2} \mathrm{O}$ durante 30 minutos, $1500 \mathrm{rpm}$, a $4^{\circ} \mathrm{C}$ ). Tras la recuperación de la interfase creada y lisis de los glóbulos rojos con agua destilada, se lavaron las células mononucleadas en tampón Fornace $(0.25 \mathrm{M}$ Sacarosa; $50 \mathrm{mM}$ Tris- $\mathrm{HCl} \mathrm{pH} 7.5 ; 25 \mathrm{mM} \mathrm{KCl} ; 5 \mathrm{mM} \mathrm{MgCl}_{2}$ ) y se precipitaron mediante centrifugación a $580 \mathrm{~g}$ durante 20 minutos. El botón de células nucleadas de la sangre se resuspendió en tampón Fornace a una concentración estimada de $5 \times 10^{6}$ células $/ \mathrm{mL}$, tras lo cuál se añadió EDTA (ácido etilendiamino-tetraacético, concentración final 10 mM), SDS (Sodium Dodecyl Sulfate, concentración final $1 \%$ ) y Proteinasa $\mathrm{K}$ (concentración final $50 \mu \mathrm{g} / \mathrm{mL}$ ). La mezcla se incubó a $55^{\circ} \mathrm{C}$ durante 8 - 16 horas. Tras la incubación, se obtuvo el ADN por el método de extracción con fenol y cloroformo, anteriormente descrito.

La concentración y el grado de contaminación proteica del ADN así obtenidos se calcularon tras medir su absorbancia a 260 y $280 \mathrm{~nm}$ en un espectrofotómetro (GeneQuant, Pharmacia) por medio de la siguiente fórmula,

$\mu \mathrm{g}$ de $\mathrm{ADN} / \mathrm{mL}=\left(\mathrm{D} \mathrm{O}_{260}\right) \times($ factor de dilución $) \times(50)^{*}$

*: 50 es un factor de corrección introducido ya que una unidad de densidad óptica con una luz incidente de 260 nm es el valor de absorbancia que tienen $50 \mu \mathrm{g}$ de $\mathrm{ADN} / \mathrm{mL}$

El cociente $D . ._{260} / D . ._{280}$ se utiliza para determinar el grado de pureza, considerando como valores adecuados un cociente entre 1.7 y 2.0. Valores inferiores a los señalados indican 
contaminación por proteínas o por solventes orgánicos, realizándose en estos casos una nueva purificación del ADN. Valores superiores parecen indicar un exceso de RNA, el cual se eliminó tratando la solución de ADN con RNAsa y purificando nuevamente según el método antes descrito.

La muestra de ADN con una concentración aproximada entre 1 y $1,5 \mu \mathrm{g} / \mathrm{mL}$, se almacenó en tubos Eppendorf ${ }^{\circledR}$ a $-20^{\circ} \mathrm{C}$, con el fin de evitar tanto la degradación progresiva del ADN como su posible contaminación por microorganismos. 


\section{ESTUDIO DE LOS POLIMORFISMOS XRCC3Thr241Met, XPD Lys751Gln y XRCC1 Arg399GIn}

Los estudios de discriminación alélica se realizan fundamentalmente mediante dos métodos: el análisis de los polimorfismos en la longitud de los fragmentos de restricción (RFLP) y la PCR en tiempo real, (qQRT-PCR). En el momento en que se inició este trabajo, no disponíamos de la infraestructura necesaria para realizar qQRT-PCR, por lo que el estudio de XRCC3 Thr241Met, y de XPD Lys751Gln se inició mediante RFLP. Posteriormente, se adquirió StepOne System (Applied Biosystems, Foster City, CA), y se completo el estudio mediante qQRT-PCR (Tabla 8)

Tabla 8: Métodos de dicriminación alélica utilizados en el estudio de los SNPs

\begin{tabular}{|c|c|c|c|}
\cline { 2 - 4 } \multicolumn{1}{c|}{} & \multicolumn{1}{c}{$\begin{array}{c}\text { Mecanismo de } \\
\text { Reparación }\end{array}$} & \multicolumn{2}{c|}{$\begin{array}{c}\text { Técnica de } \\
\text { Polimorfismo } \\
\text { discriminación alélica }\end{array}$} \\
\hline XRCC3 & DSB-HR & Thr241Met & $\begin{array}{r}\text { PCR-RFLP } \\
\text { QRT-PCR }\end{array}$ \\
\hline XPD & GG-NER & Lys751Gln & $\begin{array}{r}\text { PCR-RFLP } \\
\text { QRT-PCR }\end{array}$ \\
\hline XRC1 & BER & Arg399GIn & QRT-PCR \\
\hline
\end{tabular}

\subsection{Discriminación alélica mediante PCR-RFLP}

El análisis de los fragmentos de restricción de longitud polimórfica (RFLP) se basa en la fragmentación de una molécula de ADN mediante encimas de restricción, las cuales solo actúan si está presente la secuencia nucleotídica especifica que cada una de ellas reconoce (diana de restricción). Cuando un polimorfismo altera una secuencia puede distorsionar una de estas dianas o generar una nueva, modificando el tamaño de los fragmentos de restricción. La electroforesis en gel de agarosa permite visualizar los frgmentos y saber así si una muestra presenta o no un determinado polimorfismo ${ }^{167}$. 
Previamente a la digestión con encimas de restricción es necesario aumentar el número de moléculas del ADN a estudio, para lo que se utiliza la reacción en cadena de la polimerasa o PCR. Mediante esta técnica se consigue la amplificación de forma logarítmica de secuencias de ADN de hasta $600 \mathrm{pb}$ de longitud ${ }^{168}$. Para ello, junto con la muestra de ADN a estudio, se precisan dos oligonucleótidos cebadores (o primers) de secuencia complementaria a las regiones que flanquean aquella que se quiere amplificar. Se necesita además una polimerasa resistente a altas temperaturas que generalemente se obtiene de la bacteria Thermus aquaticus, y se denomina Taq polimerasa. Esta enzima es capaz de sintetizar una nueva molécula de ADN a partir de los oligonucleótidos provistos, utilizando como molde la cadena de ADN que se desea amplificar. Para ello, es necesario añadir a la reacción los dNTPs (desoxirribonucleótidos trifosfato) que el enzima irá ensamblando y enriquecer el medio de la reacción con un tampón que proporcione el medio adecuado para la estabilización de la polimerasa, para lo que debe estar enriquecido en cloruro magnésico. La reacción tiene lugar mediante modificaciones cíclicas de la temperatura. Consiste en un primer paso de $3-5$ minutos a $92^{\circ} \mathrm{C}$ para favorecer la desnaturalización del material de partida, seguido de al menos 30 ciclos de temperatura variable durante los que se produce la síntesis de las nuevas cadenas de $\mathrm{ADN}$. Los ciclos se inician a $92^{\circ} \mathrm{C}$ para favorecer la separación de las hebras formadas en el ciclo anterior, otro paso a una teperatura variable entre 50 y $65^{\circ} \mathrm{C}$ a la que se favorece el anillaminto de los primers y por último, unos minutos a $72^{\circ} \mathrm{C}$ para favorecer la extensión por la polimerasa, que a partir de los primers va estendiendo la cadena. Una vez completados todos los ciclos, se hace un paso final de extensión, durante 5-7 minutos a $72^{\circ} \mathrm{C}$. La temperatura más variable es la que se emplea para el anillamiento, ya que debe modificarse según las características de los primers. Tras repetir estos ciclos de temperatura entre 30 y 40 veces, se obtienen millones de secuencia idénticas a la inicial169.

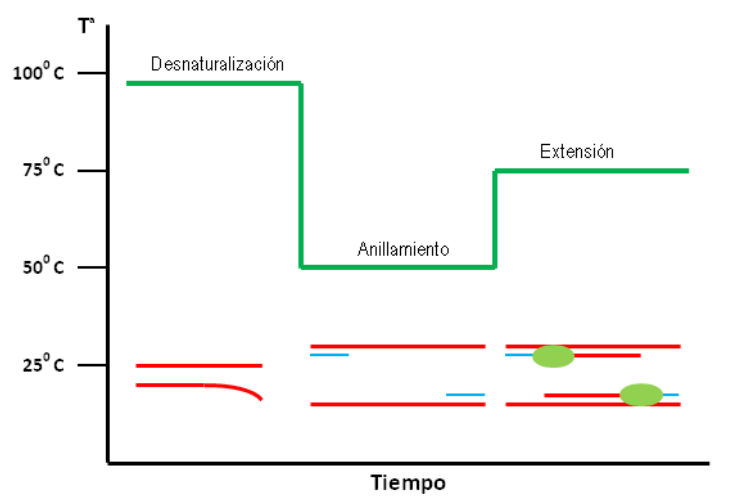

Figura 17: Esquema del ciclo de temperaturas durante una PCR 169 
En este trabajo, las reacciones de amplificación se realizaron con los productos comerciales para PCR Supermix ${ }^{\odot}$ (Gibco-BRL) y Master Mix ${ }^{\odot}$ (Promega), a los que se añadieron entre $1 \mu \mathrm{L}$ y $4 \mu \mathrm{L}$ de la mezcla de los dos oligonucleótidos flanqueantes y $1 \mathrm{LL}$ del ADN obtenido por el método anteriormente descrito (concentración $=0,1-0,2 \mu \mathrm{g} / \mathrm{mL}$ ).

Para asegurar que no existía contaminación y que las reacciones eran específicas para cada muestra de partida, se empleó como control una preparación que contenía todos los reactivos citados excepto ADN molde. Todas las reacciones de amplificación se llevaron a cabo en un termociclador automático y se incluyó siempre en paralelo un control negativo de la reacción. Para evitar la contaminación de las muestras con otros ADN, la manipulación post-PCR se realizó en un laboratorio distinto de donde habitualemente se realiza la extracción del ADN y de donde se prepararon las reacciones.

Los productos de PCR se visualizaron mediante luz ultravioleta tras realizar electroforesis en geles de agarosa al 2\% en tampón TBE 0,5X (TBE: 0,089 M Tris base/0,089 M ácido bórico) teñidos con bromuro de etidio $(0,5 \mu \mathrm{g} / \mathrm{mL})$

Una vez conseguida la amplificación de las muestras, se procedió al análisis de los polimorfismos empleando endonucleasas de restricción. El producto de PCR se incuba con estas encimas a una temperatura y tiempo característicos para cada una de ellas. Los fragmentos pueden después visualizarse realizando una nueva electroforesis en gel de agarosa teñido con bromuro de etidio.

\subsubsection{Análisis del polimorfismo Thr 241Met del gen XRCC3}

El polimorfismo Thr241Met del gen XRCC3, consiste en el cambio de una citosina (C) por una Timina (T) en la secuencia de ADN, lo que se traduce en el cambio del aminoácido Thronina por Meteonina en la posición 241. El fragmento que contiene el polimorfismo se amplificó con los oligonucleótidos 5'-GCC TGG TGG TCA TCG ACT C-3' (sentido) y 5'-ACA GGG CTC TGG AAG 
GCA CTG CTC AGC TCA CGC ACC-3' (antisentido, con una modificación en la base señalada para introducir un sitio de restricción en presencia del nucleótido T), en las siguientes condiciones:
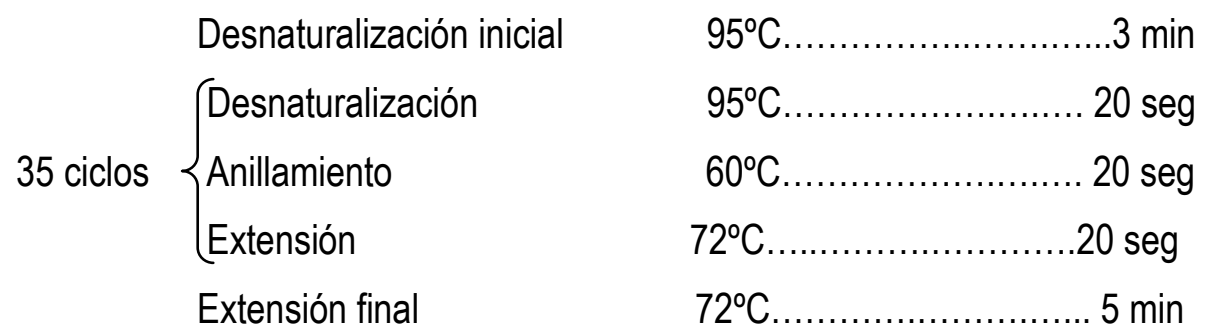

obteniendo un fragmento de 136 pb $^{136}$ (Figura 18):

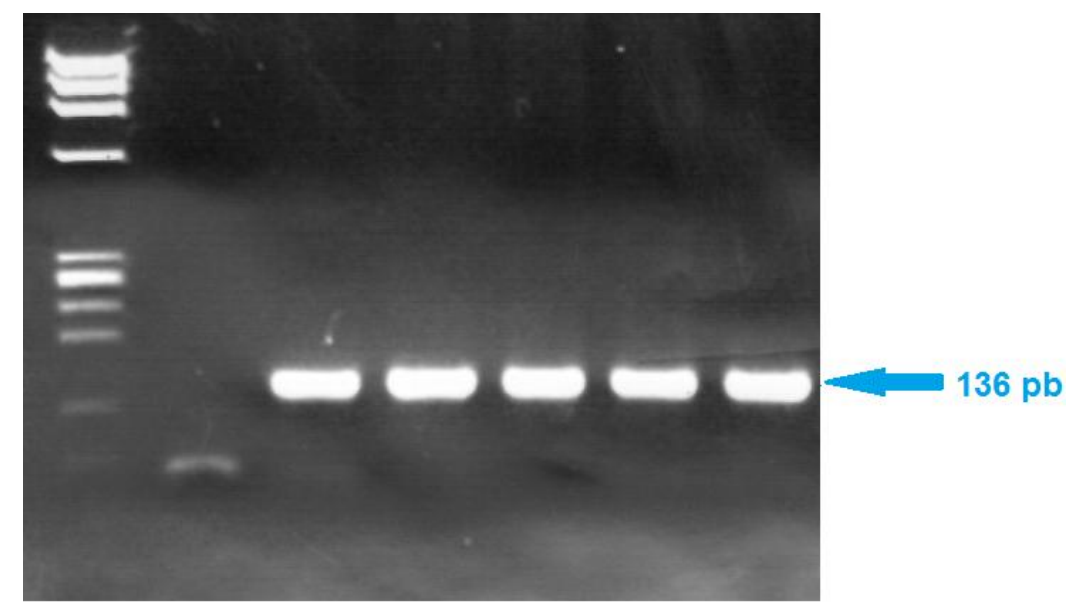

Figura 18. Amplificación por PCR del exón 7 de XRCC3

A continuación se digirieron $10 \mu \mathrm{L}$ de dicho producto con 10 unidades de la endonucleasa de restricción $\mathrm{Ncol}$ (Fermentas, Hanover, MD), a $37^{\circ} \mathrm{C}$ durante 5-6 horas. Este encima, que reconoce la secuencia $5^{\prime}$.... C CATGG...3' presente en el polimorfismo pero no en el alelo salvaje, genera dos fragmentos de $97 \mathrm{pb}$ y $39 \mathrm{pb}$, que fueron separados y visualizados tras realizar electroforesis en geles de agarosa al 3\%. (Figura 19)

Así, los genotipos generados son:

- Genotipo C/C (homocigoto Thronina): un fragmento de 136 pb

- Genotipo T/T (homocigoto Metionina): dos fragmentos de 97 pb y 39 pb

- Genotipo C/T(heterocigoto Thronina/Metionina): Thrs fragmentos de 136, 97 y $39 \mathrm{pb}$ 
Mediante este procedimiento, se realizó el estudio de 95 pacientes y 95 controles. Como control de calidad, el análisis de cada muestra se hizo por duplicado.

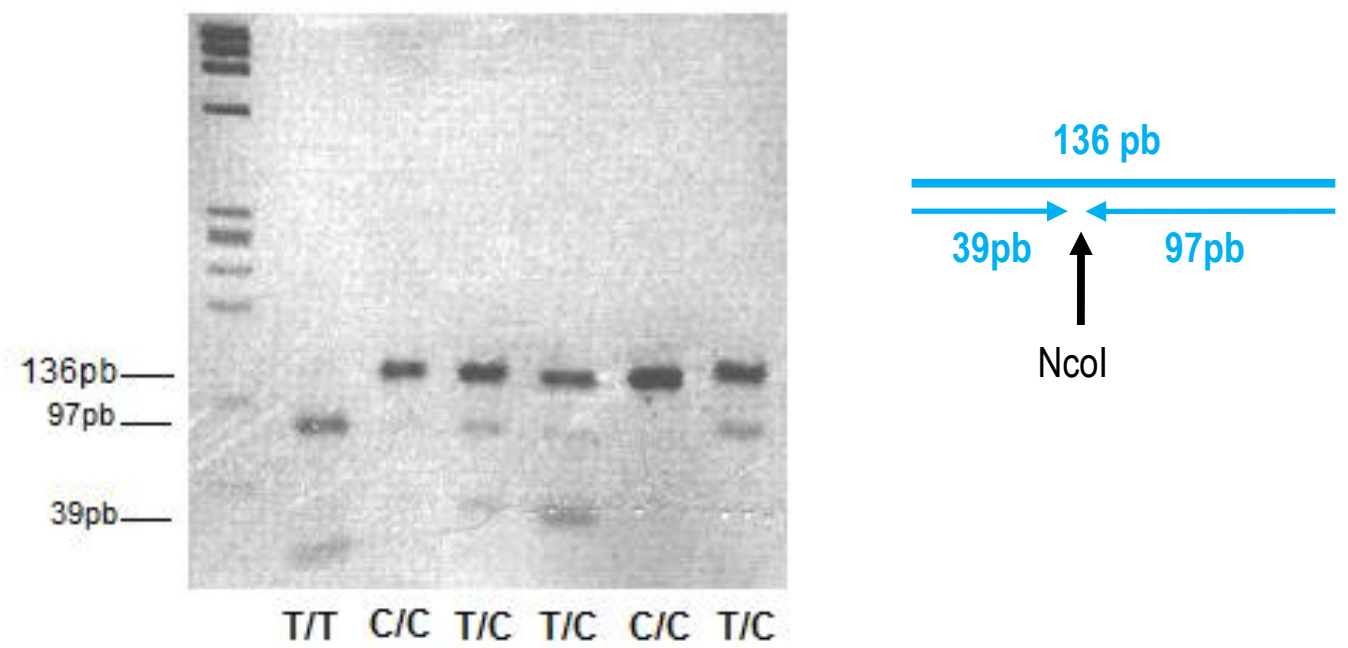

Figura 19. Diferenciación genotípica del polimorfismo en el exón 7 de XRCC3 tras la digestión con $\mathrm{N}_{c o} l$

\subsubsection{Análisis del polimorfismo Lys751Gln del gen XPD}

El polimorfismo Lys751GIn del gen XPD se localiza en el exón 23 y consiste en el cambio de una Adenina (A) por una Citosina (C), lo que implica el cambio del aminoácido Lisina por Glutamina. El fragmento que contiene la secuencia polimorfa se amplificó con los oligonucleótidos 5'-CTG CTC AGC CTG GAG CAG CTA GAA TCA GAG GAG ACG CTG-3' (sentido) y 5'-AAG ACC TTC TAG CAC CAC CG-3' (antisentido), en las siguientes condiciones:

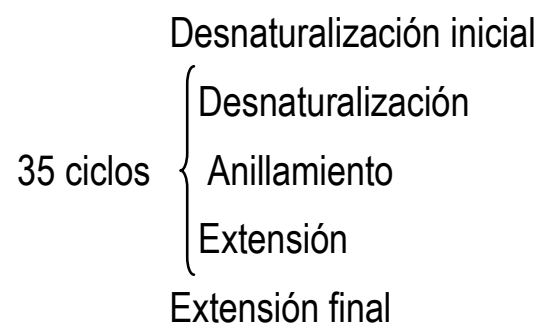

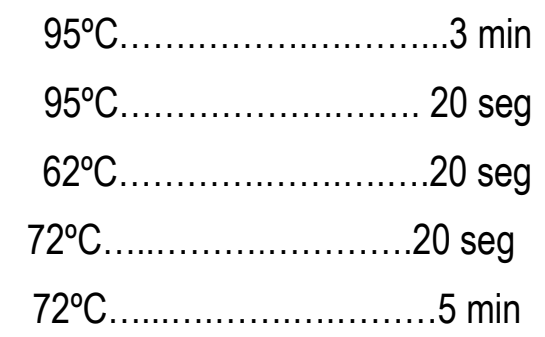


El producto de la PCR genera un fragmento de $161 \mathrm{pb}^{136}$ (Figura 20).

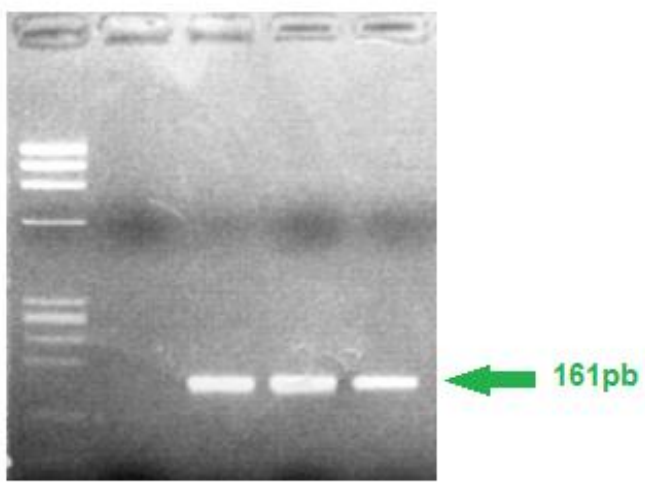

Figura 20: Amplificación por PCR del exón 23 de XPD

Se digirieron $10 \mu \mathrm{L}$ del producto de PCR con 10 unidades de la endonucleasa de restricción Pstl (Fermentas, Hanover, MD) a $37^{\circ} \mathrm{C}$ durante $5-6$ horas. El encima reconoce la secuencia $5^{\prime} \ldots \mathrm{CTGCA}^{*} \mathrm{G} \ldots 3^{\prime}$, presente únicamente en la forma mutada, donde se originan dos fragmentos de 120 y $41 \mathrm{pb}$, que fueron separadas y visualizadas mediante electroforesis en un gel de agarosa al 3\% (Figura 21)

Los posibles genotipos que se generan son:

- Genotipo A/A (homocigoto Lisina): un fragmento de $161 \mathrm{pb}$

- Genotipo C/C (homocigoto Glutamina): dos fragmentos de 120 pb y 41 pb

- Genotipo A/C (heterocigoto Lisina/glutamina): Thrs fragmentos de 161 pb, 120 y 41 pb 


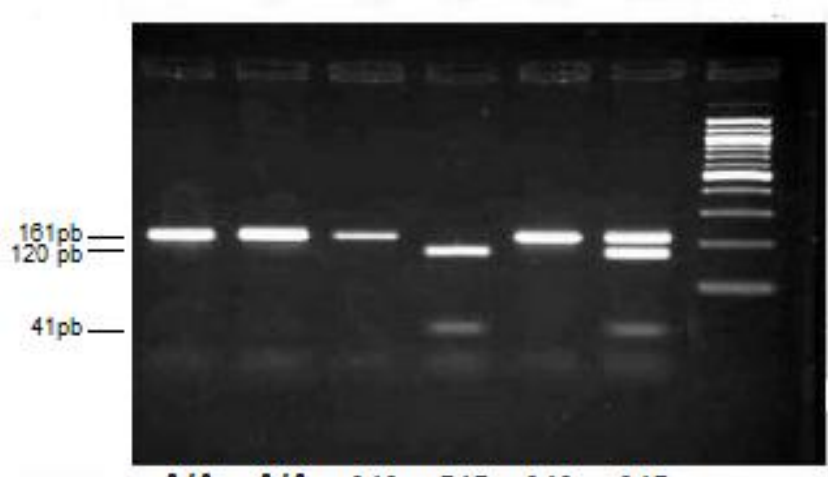

$\begin{array}{lllllllll}\text { A } / A & \text { A } / A & \text { A } / A & C / C & A / A & A / C\end{array}$
$161 \mathrm{pb}$

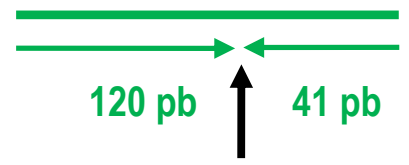

Pstl

Figura 21. Diferenciación genotípica del polimorfismo en el exón 23 de XPD tras la digestión con Pstl

Mediante este procedimiento se realizó la discriminación alélica en 95 pacientes y 95 controles. Como control de calidad, el análisis de cada muestra se hizo por duplicado.

\subsection{Discriminación alélica mediante qRT-PCR}

Higuchi describió en 1993 una técnica que permitía detectar los productos de la PCR a medida que se iban acumulando y la denominó Real Time-PCR (QRT-PCR) ${ }^{170}$. Esta técnica, sigue el mismo procedimiento de una PCR convencional, pero la amplificación tiene lugar en presencia de unos componentes capaces de emitir fluorescencia, lo que permite conocer y registrar la cinética de la amplificación en todo momento. Existen dos métodos principales para esta cuantificación: el primero consiste en la adicción de sustancias intercalantes del ADN como el bromuro de etidio, mientras que el otro emplea sondas que emiten fluorescencia al hibridar con la secuencia complementaria ${ }^{171}$. En este caso, se han empleado sondas TaqMan ${ }^{\circledR}$, marcadas con los fluorocromos VIC y FAM, uno para cada alelo de los genes estudiados. Estas sondas, complementarias para una secuencia específica, presentan un donador en el exThrmo $5^{\prime}$ y un aceptor (quencher) en el exThrmo 3' que absorbe la fluorescencia emitida por el donador cuando los exThrmos de la sonda están próximos, lo que sucede mientras la sonda está intacta (Figura 22) 
a)

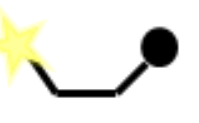

b)

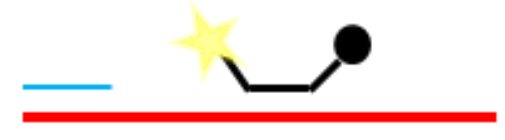

c)

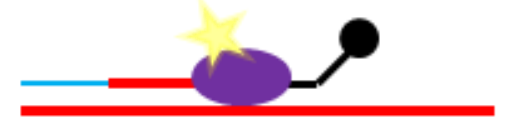

d)

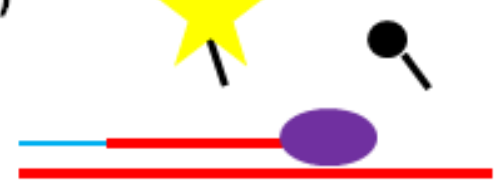

Figura 22: La fluorescencia emitida por el fluorocromo es absorbida por el aceptor (a) hasta que la sonda hibrida con su secuencia complementaria (b) y es hidrolizada por Taq pol $(c, d)^{169,170}$

Además de estas sondas, la QRT-PCR precisa de los mismos elementos que una PCR convencional (oligonucleótidos o primers, dNTPs, Taq polimerasa y solución tampón). Durante el anillamiento, tanto los oligonucleótidos como las sondas fluorescentes se unen a las cadenas de ADN. Taq polimerasa tiene además actividad 5'-3' exonucleasa de modo que si mientras realiza la extensión de una molécula de ADN a partir de un primer, encuentra una sonda unida a esa cadena, la hidroliza. Al separarse el flourocromo y el aceptor, la fluorescencia ya no es absorbida, de modo que la fluorescencia liberada tras la excitación de la muestra con un laser es detectada por el lector, y es proporcional al número de moléculas de doble cadena que se han formado como producto de la PCR ${ }^{170}$ (Figura 23) 


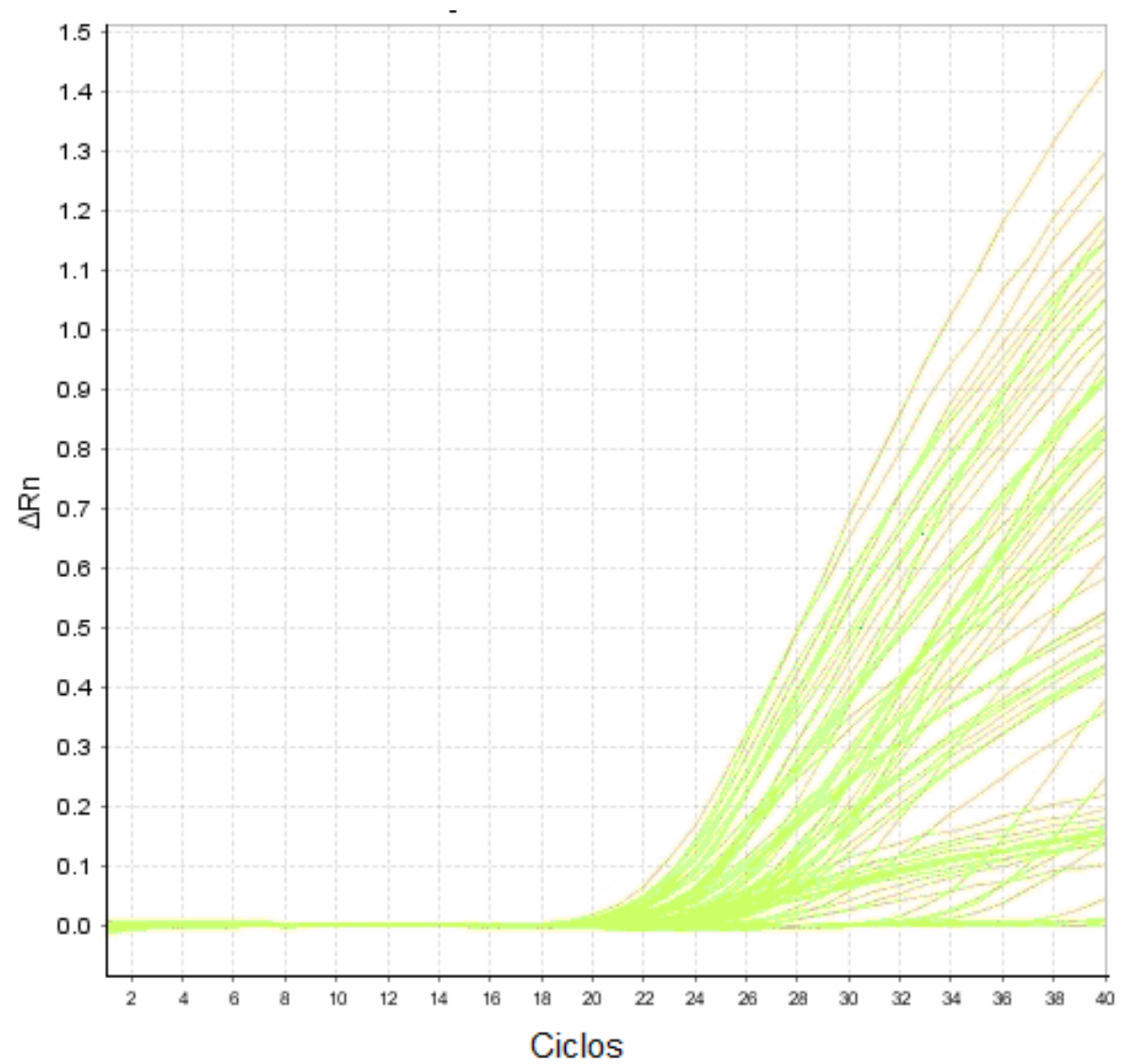

Figura 23: Emisión de fluorescencia en una QRT-PCR a medida que tienen lugar los ciclos de amplificación (StepOne®)

Al mismo tiempo, el sistema identifica cuál es el fluorocromo (VIC o FAM) que está emitiendo, y por lo tanto discrimina cuál es el SNP presente en cada una de las secuencias. En la figura 24 se muestran como ejemplo los resultados de discriminación alélicas de XRCC3. Cada uno de los puntos representa una muestra estudiada. En el caso de los individuos $\mathrm{C} / \mathrm{C}$, solo se une la sonda marcada con FAM (representado en azul), mientras que en el caso de los individuos T/T, solo se une la sonda marcada con VIC (rojo). El sistema representa en verde los genotipos C/T en el que se unen ambas sondas. Los cuadraditos negros representan las muestras sin ADN que se emplean como control. 


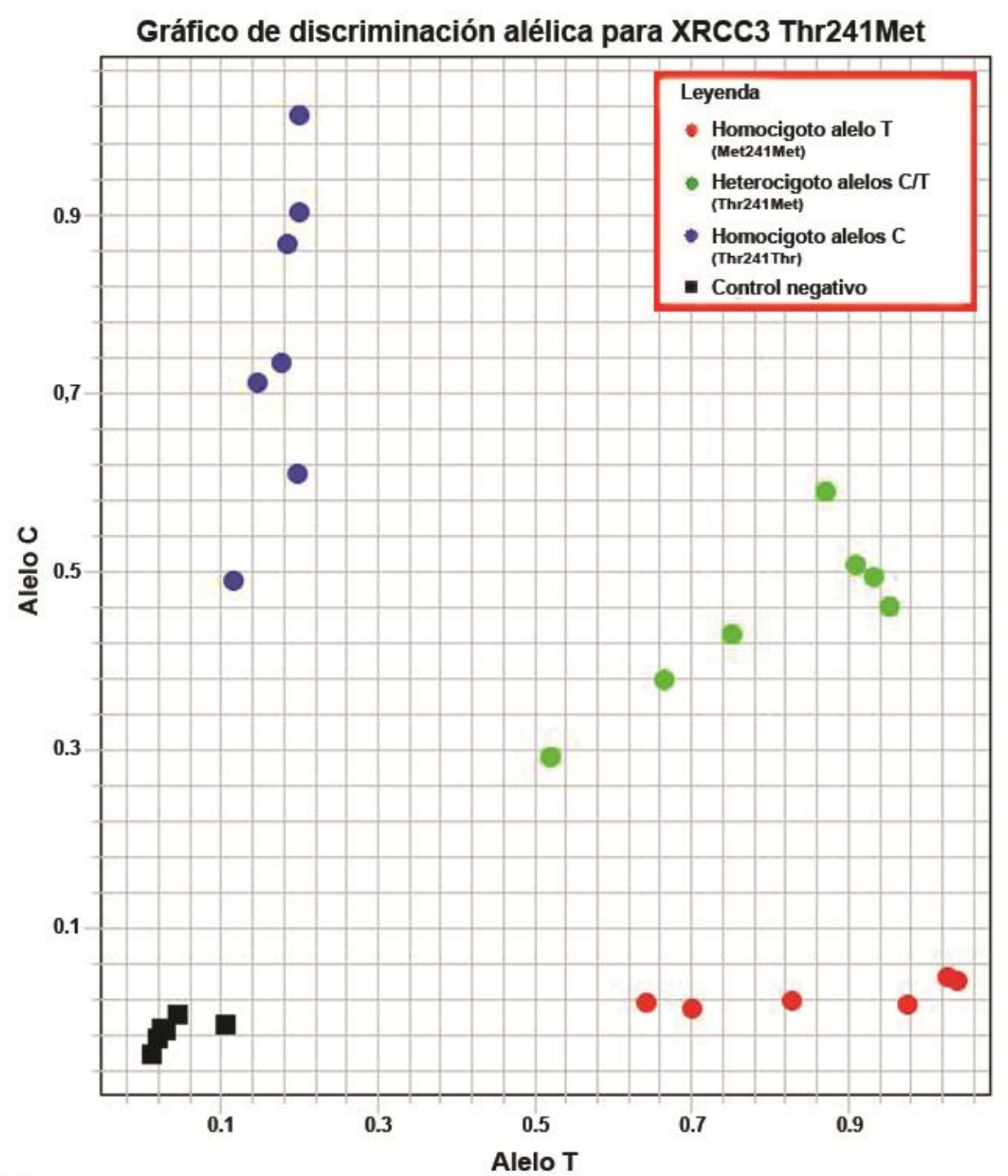

Figura 24: Discriminación alélica de XRCC3 Thr241Met (Allelic Discrimination Programme, Applied Biosystem) .

Las reacciones de PCR se realizaron con $5 \mu$ de los productos comerciales para QRTPCR TaqMan ${ }^{\circledR}$ Universal PCR Master Mix y TaqMan ${ }^{\circledR}$ Genotyping Mastermix ${ }^{\circledR}$ (Applied Biosystem, Foster City, CA). Se añadió $0.5 \mu \mathrm{l}$ del preparado comercial TaqMan® SNP Genotyping Assays, que contiene los primers con las sondas y $0.5 \mu \mathrm{l}$ de ADN y $4.25 \mu$ de $\mathrm{H}_{2} \mathrm{O}$, para un volumen final de 10 $\mu$ l. La tabla 9 recoge las secuencias de las sondas y los primers utilizados para el estudio de cada SNP. Se emplearon placas de 96 pocillos en las que a modo de control de una posible contaminación, se incluyeron preparaciones que contenían todos los reactivos citados, excepto los ADN problema. 
Tabla 9: Nombre comercial del ensayo, sondas y primers empleados para el estudio de cada uno de los SNPs.

\begin{tabular}{|lcrcl|}
\hline \multicolumn{1}{|c|}{ SNP } & Ensayo & Sondas TaqMan ${ }^{\circledR}$ (VIC/FAM) & \multicolumn{1}{c|}{$\begin{array}{c}\text { Primers } \\
\text { (Foward/Reverse) }\end{array}$} \\
\hline XRCC1 Arg399GIn & c_622564_10 & GGGTTGGCGTGTGAGGCCTTACCTG[CT]GGGAGGGCAGCCGCCGACGCATGCG & $\begin{array}{l}\text { Fw: GTGGGTGCTGGACTGTCA } \\
\text { Rv: GCAGGGTTGGCGTGTGA }\end{array}$ \\
\hline XRCC3 Thr241Met & c_890125_10 & GAAGGCACTGCTCAGCTCACGCAGCIAG]TGGCCCCCAGGGACTGCAGATGCCT & $\begin{array}{l}\text { Fw: CCAGGGCCAGGCATCTG } \\
\text { Rv: CAGCACAGGGCTCTGGAA }\end{array}$ \\
\hline XPD Lys751GIn & c_3145033_10 & TGCTGAGCAATCTGCTCTATCCTCT[G/T]CAGCGTCTCCTCTGATTCTAGCTGC & $\begin{array}{l}\text { Fw: CCCCCTCTCCCTTTCCTCTGTTC } \\
\text { Rv: GGACCTGAGCCCCCACTAACG }\end{array}$ \\
\hline
\end{tabular}

Una vez optimizadas para cada gen, las amplificaciones se llevaron a cabo en las siguientes condiciones:

\begin{tabular}{|c|c|c|}
\hline & Desnaturalización inicial & $10 \mathrm{~min}$ \\
\hline \multirow{3}{*}{40 ciclos } & Desnaturalización & ...............15 seg \\
\hline & Anillamiento & $60^{\circ} \mathrm{C} / 56^{\circ} \mathrm{C} \ldots \ldots \ldots \ldots .1 .15 \mathrm{~min}$ \\
\hline & Extensión & $60^{\circ} \mathrm{C}$. \\
\hline
\end{tabular}

La lectura de fluorescencia se realizó antes y después de la amplificación mediante el sistema StepOne ${ }^{\circledR}$ (Applied Biosystem,Foster City, CA) utilizando el software Allelic Discrimination Program (Applied Biosystem, Foster City, CA) para la determinación del alelo presente en cada una de las muestras.

Con este método, se realizó el estudio de XRCC1 Arg399GIn de 174 pacientes y 300 controles y de 79 pacientes y 205 controles para XRCC3 Thr241Met y XPD Lys751GIn. Para verificar los resultados, cada muestra se analizó por duplicado. Así mismo, se eligieron de forma aleatoria 20 pacientes y 20 controles en los que previamente se habían estudiado tanto XRCC3Thr241Met como XPDLys751GIn mediante PCR-RFLP. Puesto que los resultados fueron completamente reproductibles, se decidió no repetir mediante QRT-PCR el análisis de los casos y controles restantes. 


\section{ANÁLISIS ESTADÍSTICO}

El estudio se inició con el análisis descriptivo de todas aquellas variables demográficas y clínicas recogidas para el estudio tanto en la muestra de casos de cáncer de mama como en la muestra de controles sanos. Para variables categóricas nominales y ordinales se calculó la proporción de pacientes en cada categoría, y para las variables cuantitativas se calcularon la mediana, cuartiles y rango.

La comparación entre casos y controles de las frecuencias de cada una de las variantes de los polimorfismos del estudio se hizo mediante la prueba de Chi-cuadrado de Pearson. Así mismo, se analizaron las posibles diferencias en relación a la edad entre casos y controles en función de la variante polimórfica presente mediante pruebas no-paramétricas, concretamente, la prueba $K$ de Kruskal-Wallis.

Posteriormente, se estudiaron los posibles desequilibrios en la distribución de las diferentes variables demográficas y clínicas recogidas en función de los polimorfismos estudiados. Para ellos se utilizo la prueba de Chi-cuadrado de Pearson en variables categóricas nominales, prueba de Cochran-Armitage (o prueba Chi-cuadrado de tendencia lineal) para variables categóricas ordinales, y las pruebas no paramétricas $\mathrm{U}$ de Mann-Whitney o $\mathrm{K}$ de Kruskal-Wallis para variables continuas. En aquellos casos en los que se requirió la comprobación de hipótesis parciales mediante comparaciones múltiples se aplicó la corrección de Bonferroni.

Para posteriores análisis de supervivencia se definieron dos grupos de pacientes según su presentación: 1) pacientes con enfermedad temprana, y 2) pacientes con enfermedad metastásica. En el primer grupo se estudiaron la supervivencia libre de evento (SLE) y la supervivencia global (SG). La primera se define en este estudio como el tiempo transcurrido desde el tratamiento primario a la aparición del primer evento (recidiva local, tumor contra-lateral, recidiva metastásica 0 muerte por cáncer de mama). SG se define como el tiempo transcurrido desde el tratamiento primario a la muerte por cáncer de mama. Por último en el segundo grupo y en aquellas pacientes del primer grupo que presentaron metástasis durante el seguimiento, se analizó la supervivencia 
global desde la metástasis $\left(\mathrm{SG}_{\mathrm{M}}\right)$, siendo ésta el tiempo transcurrido desde el diagnóstico de la enfermedad metastásica a la muerte por cáncer de mama.

Previo al análisis de la supervivencia, se certificó la calidad de los datos del seguimiento, considerando como criterio de calidad para el análisis una proporción de casos perdidos menor del $15 \%$, así como la ausencia de una diferencia clínicamente significativa entre los tiempos de seguimiento de los casos no censurados y los censurados.

Aquellos pacientes con seguimientos completos pero sin aparición de evento o muerte, así como aquellos que presentaron muerte por otras causas competitivas fueron considerados casos censurados (censurados por la derecha), mientras aquellos casos en los que se desconoce el estado del paciente o se perdió el seguimiento, fueron considerados casos pérdidos (censurados por la izquierda). En todos estos casos sin evento o muerte por cáncer de mama, los tiempos se calcularon en función del último seguimiento reglado (o la fecha de muerte por otra causa competitiva cuando fuera aplicable).

Finalmente, se analizó el valor predictivo y pronóstico de los diferentes polimorfismos, los cuáles fueron agrupados para su transformación en variables binomiales de acuerdo con criterios de funcionalidad biológica. A continuación se utilizó el método de Kaplan-Meier para la derivación de las diferentes tablas, curvas y tiempos de supervivencia de cada polimorfismo (ya transformado en variable binomial), comparándose sus curvas mediante la prueba de mantel-Cox (Log-rank). De forma análoga, otras variables pronósticas conocidas fueron también agrupadas en función al conocimiento previo y su desviación de la situación normal o con mejor pronóstico. Aquellas variables continuas en las que no se encontró un valor de referencia establecido se clasificaron en función de su valor mediana. Todas las variables pronósticas o candidatas a estudio fueron introducidas individualmente en un modelo de Cox analizándose su significación mediante la razón de verosimilitud, al mismo tiempo se estimó el valor de su función de riesgo (o hazard ratio) en este modelo. Finalmente, se analizó el valor pronóstico independiente de cada polimorfismo mediante un modelo de riesgos proporcionales de Cox, donde se introdujeron todas aquellas variables con un valor $p \leq 0.05$. También se consideraron en este modelo inicial todos aquellos posibles factores de confusión, que pese a no cumplir el criterio $p$ antes citado, se les conoce un valor pronóstico ampliamente demostrado de forma prospectiva. Finalmente y debido a la posible 
repercusión del tratamiento en esta población con un largo seguimiento, se decidió realizar un análisis estratificado según las pacientes fueran tratadas con antraciclinas 0 sin antraciclinas inicialmente.

Todos los análisis estadísticos fueron realizados con el programa estadístico SPSS versión 15.0 (SPSS Inc, Chicago, IL, Estados Unidos). 
RESULTADOS 


\section{DESCRIPCIÓN DE LOS CASOS}

Tal y como se describió en el capítulo anterior (Material y Métodos), hemos estudiado 174 casos de cáncer de mama, con una mediana de edad de 62 años. En el momento del diagnóstico, la paciente más joven tenía 26.5 años, y la más anciana 91.5 . El $73 \%$ de las pacientes eran postmenopáusicas al diagnóstico.

Se seleccionaron casos de cáncer de mama esporádicos y se comprobó que en las pacientes diagnosticados antes de los 40 años se había llevado a cabo un estudio de los genes de alta penetrancia para cáncer de mama con resultado negativo. Esto permitió identificar a 2 portadoras de mutación en BRCA1 y 1 con alteración de BRCA2 que fueron excluidas del estudio.

\subsection{CARACTERISTICAS ANATOMOPATOLÓGICAS DE LOS TUMORES}

La tabla 10 resume las características anatomopatológicas de los tumores de nuestra muestra. El carcinoma ductal infiltrante (CDI) fue el más frecuente (84.5\%), la mayoría con un grado de diferenciación II O III (32.7\% y $47.2 \%$, respectivamente) y receptores hormonales (estrógenos+/- progestágenos) positivos (65\%). HER2 no estaba amplificado en el $45 \%$ de la muestra, aunque hay que reseñar que en casi el $30 \%$ de los casos, no se había determinado su expresión. De acuerdo con estas características, más de la mitad de los tumores (67.24\%), se corresponden con el fenotipo Luminal ${ }^{68}$, si bien, con los datos disponibles, no podemos distinguir entre los subgrupos luminal A y B. 
Tabla 10: Características anatomopatológicas de los tumores de la muestra

\begin{tabular}{|c|c|c|c|c|c|}
\hline $\begin{array}{c}\text { Tipo } \\
\text { Histológico }\end{array}$ & $\begin{array}{c}\text { Grado de } \\
\text { Diferenciación }\end{array}$ & $\begin{array}{l}\text { Receptor } \\
\text { Estrógenos }\end{array}$ & $\begin{array}{l}\text { Receptor } \\
\text { Progesterona }\end{array}$ & HER2 & $\begin{array}{l}\text { Subtipo } \\
\text { Molecular }\end{array}$ \\
\hline $\begin{array}{c}\text { CDI } \\
147(84.5 \%)\end{array}$ & $\begin{array}{l}\text { Grado I } \\
18(10.3 \%)\end{array}$ & $\begin{array}{l}\text { Positivo } \\
113(65 \%)\end{array}$ & $\begin{array}{l}\text { Positivo } \\
93(53.4 \%)\end{array}$ & $\begin{array}{c}\text { Positivo } \\
32(18.4 \%)\end{array}$ & $\begin{array}{c}\text { Luminal } \\
117(67.24 \%)\end{array}$ \\
\hline $\begin{array}{c}\text { CLI } \\
12(6.9 \%)\end{array}$ & $\begin{array}{c}\text { Grado II } \\
57(32.7 \%)\end{array}$ & $\begin{array}{l}\text { Negativo } \\
53(30.5 \%)\end{array}$ & $\begin{array}{l}\text { Negativo } \\
69(39.6 \%)\end{array}$ & $\begin{array}{l}\text { Negativo } \\
78(44.8 \%)\end{array}$ & $\begin{array}{l}\text { Triple negativo } \\
29(16.6 \%)\end{array}$ \\
\hline $\begin{array}{l}\text { Inflamatorio } \\
6(3.4 \%)\end{array}$ & $\begin{array}{l}\text { Grado III } \\
82(47.2 \%)\end{array}$ & $\begin{array}{c}\text { Desconocido } \\
8(4.5 \%)\end{array}$ & $\begin{array}{l}\text { Desconocido } \\
12(6.8 \%)\end{array}$ & $\begin{array}{c}\text { IHQ dudosa/no FISH } \\
17(9.8 \%)\end{array}$ & $\begin{array}{l}\text { HER2 } \\
17(9.7 \%)\end{array}$ \\
\hline $\begin{array}{l}\text { Otros } \\
9(5.2 \%)\end{array}$ & $\begin{array}{c}\text { Desconocido } \\
17(9.8 \%)\end{array}$ & & & $\begin{array}{l}\text { Desconocido } \\
47(27 \%)\end{array}$ & $\begin{array}{l}\text { No clasificable } \\
11 \quad 6.3 \%)\end{array}$ \\
\hline
\end{tabular}

\subsection{CLASIFICACION TNM DE LOS TUMORES DE LA MUESTRA}

En la tabla 11 se recogen las características del tamaño tumoral, afectación ganglionar y la presencia o no de metástasis (TNM) en la muestra.

El $86.2 \%$ de los casos presentó enfermedad localizada, de los que el 30\% presentaba enfermedad localmente avanzada. El tamaño del $54.6 \%$ de los tumores oscilaba entre 2 y $5 \mathrm{cms}$ de diámetro (T2) y en algo más de la mitad de los casos (58\%) el tumor había invadido los ganglios axilares, siendo lo más frecuente encontrar de 1 a 3 nódulos positivos (N1). El estadio II fue el más frecuente $(47.3 \%)$.

De los 14 casos con afectación metastásica inicial, el 64.3\% sólo presentaba afectación ósea, una paciente presentaba metástasis dérmicas $(7.1 \%)$, otra diseminación hepática $(7.1 \%)$ y en las tres restantes $(21.4 \%)$ la enfermedad se había extendido a dos o más órganos.

Los datos clínicos de otras 10 pacientes eran incompletos por lo que se incluyeron en el estudio de asociación de casos y controles, pero fueron excluídas del análisis de supervivencia. 
Tabla 11: Tamaño tumoral, afectación ganglionar y localización de las metástasis en la muestra.

\begin{tabular}{|c|c|c|c|c|c|}
\hline \multicolumn{4}{|c|}{ Pacientes no Metastásicas ( $n=150$ ) } & \multicolumn{2}{|c|}{ Pacientes Metastásicas ( $n=14$ ) } \\
\hline $\begin{array}{c}\text { Tamaño } \\
0-\leq 2 \\
>2-\leq 5 \\
>5\end{array}$ & $\begin{array}{c}\text { Frecuencia (\%) } \\
\qquad 54(36 \%) \\
82(54.6 \%) \\
14(9.3 \%)\end{array}$ & $\begin{array}{c}\text { Ganglios } \\
\text { Negativos } \\
\text { Positivos } \\
1-3 \mathrm{gl} \\
4-9 \mathrm{gl} \\
\geq 10\end{array}$ & $\begin{array}{c}\text { Frecuencia (\%) } \\
62(41.3 \%) \\
87(58 \%) \\
43(28.6 \%) \\
19(12.6 \%) \\
25(18.7 \%)\end{array}$ & $\begin{array}{l}\text { Localizacion } \\
\text { Óseas } \\
\text { Hepáticas } \\
\text { Dérmicas } \\
\geq 2 \text { localizaciones }\end{array}$ & $\begin{array}{r}\text { Frecuencia (\%) } \\
9(64.3 \%) \\
1(7.1 \%) \\
1(7.1 \%) \\
3(21.4 \%)\end{array}$ \\
\hline
\end{tabular}

Otros factores pronósticos conocidos, como la afectación ganglionar extracapsular, la invasión vascular linfática, la neofromación de vasos o el índice proliferativo no se han analizado por no estar recogidos en una gran proporción de las historias clínicas estudiadas, si bien por otra parte, en el Nottingham Prognostic Index, solamente la afectación ganglionar, el tamaño tumoral y el grado histológico, mostraron ser factores pronósticos independientes ${ }^{172}$.

\subsection{TRATAMIENTO}

\subsubsection{TRATAMIENTO LOCAL}

\subsubsection{Tratamiento Quirúrgico}

El tratamiento quirúrgico local se realizó mediante mastectomía en el $63.2 \%$ de los casos, mediante cuadrantectomía en el $10.3 \%$ y tumorectomía en el $21.8 \%$. En cuanto al tratamiento quirúrgico de la axila, solamente en 3 pacientes que habían tenido cirugía sobre la mama no se practicó ningún tipo de linfadenectomía axilar (1.8\%). En 24 pacientes, la biopsia del ganglio centinela (BGC) fue negativa. A 139 pacientes (83.4\%) se les practicó vaciamiento axilar con o sin BGC previa, no encontrándose infiltración ganglionar en 54 de ellas (38.8\%). Las tablas 12 y 13 recogen las pacientes que recibieron cada tipo de tratamiento. 
Resultados

Tabla 12: Frecuencia de los distintos tipos de cirugía local en nuestra muestra

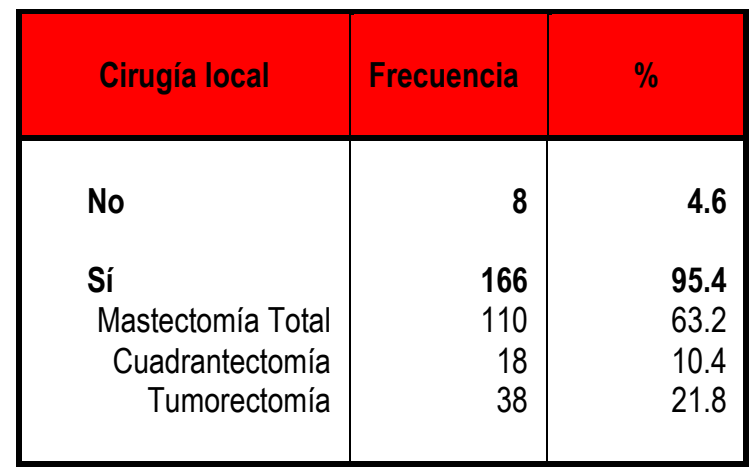

Tabla 13 : Frecuencia de los distintos tipos de cirugía sobre la axila en nuestra muestra

\begin{tabular}{|l|r|r|}
\hline Cirugía de la Axila & Frecuencia & \multicolumn{1}{|c|}{$\%$} \\
\hline No intervenida & 3 & 1.8 \\
BGC negativa & 24 & 14.4 \\
Vaciamiento Total & 139 & 83.8 \\
& 166 & 100 \\
\hline
\end{tabular}

En cuanto a la cirugía como tratamiento de la enfermedad metastásica, a ninguna de las pacientes de nuestra serie se le practicó exéresis de las metástasis, pero seis de ellas se trataron con cirugía local sobre la mama y la axila (mastectomía y vaciamiento axilar en todos los casos). Esto se debió a que, a menos que la paciente presentase algún signo o síntoma que hiciese sospechar que se había producido la diseminación tumoral, el estudio de extensión en nuestro hospital se realizaba muchas veces tras la cirugía, cuando la paciente era remitida al Servicio de Oncología Médica. Todas ellas presentaban enfermedad ósea como única afectación metastásica. 


\section{Resultados}

\subsubsection{Tratamiento radioterápico}

Siguiendo los protocolos del Hospital Universitario de Salamanca, acordes con las recomendaciones internacionales ${ }^{173}$, las pacientes que se intervinieron mediante cuadrantectomía o tumorectomía recibieron posteriormente radioterapia (RT) sobre el tejido mamario remanente. Se les administró una total de 50Gy con un fraccionamiento de 2Gy/sesión y una sobreimpresión del lecho tumoral de entre 10 y 20 Gy con electrones de alto fotovoltaje. También recibieron RT sobre la pared torácica (dosis total de 50 Gy con un fraccionamiento de 2Gy/sesión), aquellas mujeres tratadas mediante mastectomía radical que presentaban cuatro o más ganglios axilares positivos 0 tumores clasificados como T3-T4 o con infiltración de los bordes quirúrgicos, independientemente del estado ganglionar. La región supraclavicular se irradió en las pacientes con cuatro o más ganglios positivos 0 en aquellas que teniendo menos de cuatro ganglios infiltrados, se les había practicado una linfadenectomía axilar incompleta. De las 112 pacientes tratadas con RT postoperatoria, $25(22.3 \%)$ recibieron sobreimpresión axilar con electrones de alto fotovoltaje (dosis entre 5 y $15 \mathrm{~Gy}$ ). Todos los casos se trataron mediante RT externa. Ninguna de las pacientes que recibió tratamiento radioterápico presentaba metástasis al diagnóstico (Tabla 14).

Tabla 14: Pacientes que recibieron $\mathrm{RT}$ tras la cirugía

\begin{tabular}{|l|r|r|}
\hline \multicolumn{2}{|c|}{ Radioterapia } & \multicolumn{2}{|c|}{ Frecuencia } \\
\hline & 112 & 64.4 \\
Sí & 61 & 35.1 \\
No & 1 & 0.6 \\
Desconocido & 174 & 100 \\
Total & & \\
& & \\
\hline
\end{tabular}




\subsubsection{TRATAMIENTO SISTÉMICO}

\subsubsection{Tratamiento Quimioterápico}

Tal y como se recoge en la Tabla 15 , el $87.35 \%$ de las pacientes de nuestra serie recibieron tratamiento quimioterápico (QT). La mayoría (71.36\%) en adyuvancia tras la cirugía mientras que un $8 \%$ lo hizo previamente a la misma. Otro $8 \%$ lo recibió como tratamiento paliativo por presentar metástasis en el momento del diagnóstico.

Tabla 15: Distribución de las modalidades de QT

\begin{tabular}{|r|r|}
\cline { 2 - 2 } \multicolumn{1}{c|}{} & Frecuencia (\%) \\
\hline Pacientes tratadas SIN QT & $22(12.64)$ \\
Pacientes tratadas CON QT & $152(87.35)$ \\
Neoadyuvante & $14(8.04)$ \\
Adyuvante & $124(71.36)$ \\
Metastásica & $14(8.04)$ \\
\hline
\end{tabular}

Tabla 16: Distribución del tratamiento con y sin antraciclinas

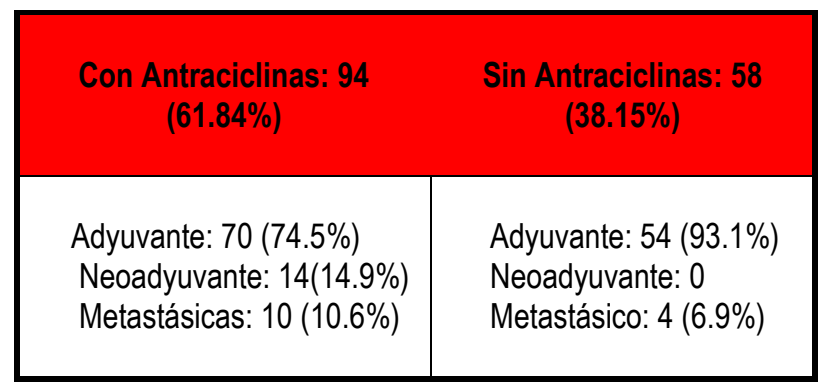

El 62\% de las pacientes que recibieron QT recibieron antraciclinas (tabla 16) según los diferentes esquemas recogidos en la tabla 17. De las pacientes tratadas con doxorrubicina, 17 recibieron una dosis acumulada de $360 \mathrm{mg} / \mathrm{m}^{2}, 49$ recibieron $300 \mathrm{mg} / \mathrm{m}^{2}$, en 5 casos la dosis fue de $240 \mathrm{mg} / \mathrm{m}^{2}$ y solamente una paciente recibió $200 \mathrm{mg} / \mathrm{m}^{2}$. De las 15 pacientes tratadas con epirrubicina, 4 recibieron $600 \mathrm{mg} / \mathrm{m}^{2}$, mientras que 5,3 y 3 recibieron $540 \mathrm{mg} / \mathrm{m}^{2}, 360 \mathrm{mg} / \mathrm{m}^{2}$ y $300 \mathrm{mg} / \mathrm{m}^{2}$ respectivamente.

El 38.15\% de las pacientes tratadas con QT no recibió antraciclinas debido a que fueron casos diagnosticados a comienzos de la década de los 90 , antes de los estudios que demostraron el beneficio de su uso en adyuvancia ${ }^{174,175}$. En los casos diagnosticados posteriormente, el uso de esquemas sin antraciclinas se debió a que las pacientes presentaban bajo riesgo de recaída, comorbilidad cardiaca o eran ancianas. 


\section{Resultados}

Tabla 17: Esquemas de tratamiento empleados en las pacientes de nuestro estudio

\begin{tabular}{|c|c|c|}
\hline \multicolumn{2}{|c|}{ Esquemas de tratamiento empleados } & № de pacientes \\
\hline $\begin{array}{l}\text { CMF } \\
\text { Ciclofosfamida } 600 \mathrm{mg} / \mathrm{m}^{2} \\
\text { Metrotexate } 40 \mathrm{mg} / \mathrm{m}^{2} \\
\text { 5-Fluoruracilo } 600 \mathrm{mg} / \mathrm{m}^{2}\end{array}$ & Cada 21 días x6 ciclos & 54 adyuvancia \\
\hline $\begin{array}{l}\mathrm{CAF}_{60} \\
\text { Ciclofosfamida } 600 \mathrm{mg} / \mathrm{m}^{2} \\
\text { Adriamicina } 60 \mathrm{mg} / \mathrm{m}^{2} \\
\text { 5-Fluoruracilo } 600 \mathrm{mg} / \mathrm{m}^{2}\end{array}$ & Cada 21 días x6 ciclos & $\begin{array}{l}13 \text { adyuvancia } \\
4 \text { neoadyuvancia }\end{array}$ \\
\hline $\begin{array}{l}\mathrm{CAF}_{50} \\
\quad \text { Ciclofosfamida } 500 \mathrm{mg} / \mathrm{m}^{2} \\
\text { Adriamicina } 50 \mathrm{mg} / \mathrm{m}^{2} \\
\text { 5-Fluoruracilo } 500 \mathrm{mg} / \mathrm{m}^{2}\end{array}$ & Cada 21 días $\times 6$ ciclos & $\begin{array}{l}40 \text { adyuvancia } \\
3 \text { adyuvancia }\end{array}$ \\
\hline $\begin{array}{l}\text { CAF }_{50} \rightarrow \text { Paclitaxel } \\
\quad \text { CAF } \times 4 \text { seguido de Paclitaxel } 10\end{array}$ & $\mathrm{~g} / \mathrm{m}^{2}, \mathrm{c} / 8 \mathrm{~d}$ x8 ciclos & 1 adyuvancia \\
\hline $\begin{array}{l}\mathrm{FEC}_{100} \\
5 \text {-Fluoruracilo } 600 \mathrm{mg} / \mathrm{m}^{2} \\
\text { Epirrubicina } 100 \mathrm{mg} / \mathrm{m}^{2} \\
\text { Ciclofosfamida } 600 \mathrm{mg} / \mathrm{m}^{2}\end{array}$ & Cada 21 días $\times 6$ ciclos & $\begin{array}{l}3 \text { adyuvancia } \\
1 \text { neoadyuvancia }\end{array}$ \\
\hline $\begin{array}{l}\text { FEC }_{100} \rightarrow \text { Docetaxel } \\
\quad \text { FEC } \times 3 \text { ciclos seguido de Doceta }\end{array}$ & $100 \mathrm{mg} / \mathrm{m}^{2} \mathrm{c} / 21 \mathrm{~d} \times 3$ ciclos & $\begin{array}{l}1 \text { adyuvancia } \\
2 \text { neoadyuvancia }\end{array}$ \\
\hline $\begin{array}{l}\text { AC Ciclofosfamida } 600 \mathrm{mg} / \mathrm{m}^{2} \\
\text { Adriamicina } 60 \mathrm{mg} / \mathrm{m}^{2}\end{array}$ & Cada 15 días x4 ciclos & 1 adyuvancia \\
\hline $\begin{array}{l}\text { AC } \rightarrow \text { Paclitaxel } \\
\quad \text { AC } \times 4 \text { ciclos seguido de Paclitax }\end{array}$ & $90 \mathrm{mg} / \mathrm{m}^{2}$ semanal x8 ciclos & 4 adyuvancia \\
\hline $\begin{array}{l}\text { TAC } \\
\text { Docetaxel } 75 \mathrm{mg} / \mathrm{m}^{2} \\
\text { Adriamicina } 50 \mathrm{mg} / \mathrm{m}^{2} \\
\text { Ciclofosfamida } 500 \mathrm{mg} / \mathrm{m}^{2}\end{array}$ & Cada 21 días $\times 6$ ciclos & 3 adyuvancia \\
\hline $\begin{array}{c}\text { Docetaxel + Epirrubicina } \\
\text { Docetaxel } 75 \mathrm{mg} / \mathrm{m}^{2} \\
\text { Epirrubicina } 90 \mathrm{mg} / \mathrm{m}^{2}\end{array}$ & Cada 21 días x6 ciclos & $\begin{array}{l}4 \text { adyuvancia } \\
1 \text { neoadyuvancia }\end{array}$ \\
\hline $\begin{array}{l}\text { ECx } 4 \rightarrow \text { Docetaxel } \\
\text { Epirrubicina } 90 \mathrm{mg} / \mathrm{m}^{2} \\
\text { Ciclofosfamida } 600 \mathrm{mg} / \mathrm{m}^{2} \\
\text { Seguido de Docetaxel } 100 \mathrm{mg} / \mathrm{m}^{2}\end{array}$ & $\begin{array}{l}\text { Cada } 21 \text { días } \times 4 \text { ciclos } \\
21 \mathrm{~d} \times 4 \text { ciclos }\end{array}$ & 3 neoadyuvancia \\
\hline Enfermedad Metastásica & & \\
\hline CMF & & 7 metastásicas \\
\hline $\begin{array}{l}\text { Gemcitabina } 1500-2000 \mathrm{mg} / \mathrm{m}^{2} \\
\text { Docetaxel } 50-60 \mathrm{mg} / \mathrm{m}^{2}\end{array}$ & Cada 15 días & 4 metastásicas \\
\hline $\begin{array}{l}\text { Gemcitabina } 1250 \mathrm{mg} / \mathrm{m}^{2} \\
\text { Vinorelbina } 25 \mathrm{mg} / \mathrm{m}^{2}\end{array}$ & Cada 15 días & 2 metastásicas \\
\hline $\begin{array}{l}\text { Paclitaxel } 80 \mathrm{mg} / \mathrm{m}^{2} \\
\text { Carboplatino AUC2 } \\
\text { Herceptín } 2 \mathrm{mg} / \mathrm{kg}\end{array}$ & $\begin{array}{l}\text { días } 1,8 \text { y } 15 \\
\text { días } 1,8 \text { y } 15 \\
\text { días } 1,8,15 \text { y } 22\end{array}$ & 1 metastásica \\
\hline
\end{tabular}




\section{Resultados}

\subsubsection{Hormonoterapia}

De acuerdo con las series publicadas, el $70 \%$ de los tumores expresan receptores de estrógenos (RE) y de progesterona (RP), siendo RE+/RP+ o RE+/RP-, entorno al $25 \%$ son $R E-$ /RP- y menos de un $5 \%$ de los casos son RE-/RP+. Dado que la expresión de los RP depende de la actividad de RE, algunos autores cuestionan la existencia de los tumores RE-/RP+ y consideran que son $\mathrm{RE}+$, pero que se ha producido un error bien durante la realización de la técnica inmunohistoquímica o bien durante su interpretación ${ }^{176,177}$. Por ello, en el subsiguiente análisis hemos considerado que los tumores que presentan RE+ y/o RP+ son Receptores Hormonales $(\mathrm{RH})$ positivos.

Tal como se refleja en la tabla 18 , el $61.8 \%$ de la premenopáusicas y el $69.3 \%$ de las postmenopáusicas presentaron tumores con receptores hormonales positivos, si bien se desconoce la expresión de estos receptores en el $4 \%$ de los casos.

Tabla 18: Expresión de RH en el tumor y status hormonal de las pacientes al diagnóstico.

\begin{tabular}{|c|c|c|c|}
\hline \multirow{2}{*}{$\begin{array}{l}\text { RECEPTORES } \\
\text { HORMONALES } \\
\text { (RH) }\end{array}$} & \multicolumn{2}{|c|}{ STATUS HORMONAL } & \multirow{2}{*}{ TOTAL } \\
\hline & PREMENOPAUSICAS & POSTMENOPAUSICAS & \\
\hline RH- & $14(29.8 \%)$ & $36(28.3 \%)$ & $50(28.8 \%)$ \\
\hline $\mathrm{RH}+$ & $29(61.8 \%)$ & $88(69.3 \%)$ & $117(67.2 \%)$ \\
\hline RH desconocido & $4(8.4 \%)$ & $3(2.4 \%)$ & $7(4 \%)$ \\
\hline Total & $47(100 \%)$ & $127(100 \%)$ & $174(100 \%)$ \\
\hline
\end{tabular}

139 pacientes $(79.8 \%)$ recibieron tratamiento hormonal, el 8\% como único tratamiento sistémico adyuvante a la cirugía, mientras que la mayoría (65.6\%) lo recibió tras la quimioterapia (tabla 19). 
Resultados

Tabla 19: Resumen del tratamiento hormonal

\begin{tabular}{|lrr|}
\hline \multicolumn{1}{|c}{ Hormonoterapia (HT) } & Frecuencia & $\%$ \\
\hline No HT ni QT & 5 & 2.8 \\
No HT (solo QT adyuvante) & 31 & 17.8 \\
HT como único tto adyuvante a la cirugía & 17 & 9.8 \\
HT como adyuvante tras QT & 114 & 65.5 \\
Metastásicas & 11 & 6.3 \\
Total & 174 & 100 \\
\hline
\end{tabular}

De las 35 de las mujeres premenopáusicas que recibieron hormonoterapia, 34 recibieron Tamoxifeno como primera línea, y 1 fue tratada con Inhibidores de la Aromatasa. Ninguna recibió análogos de LRHR (hormona liberadora de la gonadotropina) en combinación. En cuanto a las postmenopáusicas, 48 recibieron Tamoxifeno (37.8\%), 56 (44.1\%) recibieron un Inhibidor de Aromatasa, y el 18.1\% no recibió ningún tipo de hormonoterapia (Tabla 20).

Tabla 20: Tipo de HT recibida en $1^{\text {a }}$ línea y status hormonal de las pacientes al diagnóstico.

\begin{tabular}{|lrrr|}
\hline & \multicolumn{3}{c|}{} \\
HORMONOTERAPIA & \multicolumn{2}{c|}{ STATUS HORMONAL } \\
\cline { 2 - 3 } & PREMENOPAUSICAS & POSTMENOPAUSICAS & \\
\hline NO HT & $12(25.6 \%)$ & $23(18.1 \%)$ & $35(20.1 \%)$ \\
TAMOXIFENO & $34(72.3 \%)$ & $48(37.8 \%)$ & $82(47.1 \%)$ \\
INHIBIDORES & $1(2.1 \%)$ & $56(44.1 \%)$ & $57(32.8 \%)$ \\
AROMATASA & $47(100 \%)$ & $127(100 \%)$ & $174(100 \%)$ \\
\hline
\end{tabular}




\section{Resultados}

\section{ESTUDIO DE XPDLys751GIn, XRCC1Arg399GIn y XRCC3Thr241Met}

Las variantes XPD751GIn, XRCC1 399GIn y XRCC3Met se han asociado una menor capacidad de reparación en estudios funcionales, si bien la magnitud de su aportación al incremento de riesgo de diferentes tipos tumorales y entre ellos el cáncer de mama es muy controvertida. También se discute su papel en relación con la respuesta a quimioterápicos, especialmente a sales de platino y antraciclinas y con la mayor o menor sensibilidad a la aparición de efectos secundarios postradioterapia.

A continuación, se presenta el análisis de la frecuencia de estos polimorfismos en los grupos caso y control de nuestra muestra (apartado 2.1), su frecuencia en relación con los diferentes grupos de edad (apartado 2.2), en relación con el tratamiento radioterápico (apartado 2.3) y en relación con el tratamiento quimioterápico (apartado 3). Este último análisis se expone en un apartado independiente debido a su extensión.

\subsection{Estudio de XPDLys751GIn, XRCC1Arg399GIn y XRCC3Thr241Met en casos y controles}

La tabla 21 resume la distribución de los diferentes genotipos estudiados en los 174 casos y 174 controles pareados en función de la edad.

No hemos encontrado diferencias en la frecuencia de los diferentes genotipos de XPDLys751GIn entre casos y controles ( $p=0.944)$ ni en XRCC3Thr241Met ( $p=0.670)$. En cambio, la diferencia que se observan en XRCC1Arg399GIn sí es estadísticamente significativa $(p<0.007)$. Se repitió el análisis agrupando los diferentes genotipos según su significación biológica para establecer a cuál de ellos se debe la diferencia. Encontramos que Arg/Arg, con capacidad de reparación intacta, es más frecuente en el grupo control mientras que Gln/Gln y Gln/Arg son mas frecuentes entre los casos ( $p<0.002$, OR: 1.96, IC95\% 1.3-3), (Tabla 22). 
Tabla 21: Distribución de los diferentes genotipos XPDLys751Gln, XRCC1Arg399GIn y XRCC3Thr241Met en casos y controles

\begin{tabular}{|c|c|c|c|c|c|}
\hline & \multicolumn{2}{|c|}{ CASOS ( $n=174)$} & \multicolumn{2}{|c|}{ CONTROLES (n=174) } & \multirow{2}{*}{$p$-valor } \\
\hline & $\mathrm{N}$ & Porcentaje & $\mathrm{N}$ & Porcentaje & \\
\hline $\begin{array}{r}\text { XPDLys751GIn } \\
\text { Lys/Lys } \\
\text { Lys/GIn } \\
\text { GIn/GIn }\end{array}$ & $\begin{array}{l}75 \\
81 \\
18\end{array}$ & $\begin{array}{l}43.1 \% \\
46.6 \% \\
10.3 \%\end{array}$ & $\begin{array}{l}72 \\
84 \\
18\end{array}$ & $\begin{array}{l}41.4 \% \\
48.3 \% \\
10.3 \%\end{array}$ & 0.944 \\
\hline $\begin{array}{r}\text { XRCC1Arg399GIn } \\
\text { GIn/GIn } \\
\text { GIn/Arg } \\
\text { Arg/Arg }\end{array}$ & $\begin{array}{l}17 \\
87 \\
70\end{array}$ & $\begin{array}{r}9.8 \% \\
50 \% \\
40.2 \%\end{array}$ & $\begin{array}{l}10 \\
65 \\
99\end{array}$ & $\begin{array}{r}5.7 \% \\
37.4 \% \\
56.9 \%\end{array}$ & 0.007 \\
\hline $\begin{array}{r}\text { XRCC3Thr241Met } \\
\text { Thr/Thr } \\
\text { Thr/Met } \\
\text { Met/Met }\end{array}$ & $\begin{array}{l}65 \\
81 \\
28\end{array}$ & $\begin{array}{r}37.4 \% \\
64.6 \% \\
16 \%\end{array}$ & $\begin{array}{l}69 \\
73 \\
32\end{array}$ & $\begin{array}{r}39.6 \% \\
42 \% \\
18.4 \%\end{array}$ & 0.670 \\
\hline
\end{tabular}

Tabla 22: Distribución de los genotipos de XRCC1Arg399Gln

\begin{tabular}{|c|c|c|c|c|c|}
\hline \multirow{2}{*}{ XRCC1Arg399GIn } & \multicolumn{2}{|c|}{ CASOS } & \multicolumn{2}{|c|}{ CONTROLES } & \multirow{2}{*}{$p$-valor } \\
\hline & $\mathrm{N}$ & Porcentaje & $\mathrm{N}$ & Porcentaje & \\
\hline $\begin{array}{r}\mathrm{Gln} / \mathrm{G} \ln +\mathrm{Arg} / \mathrm{Gln} \\
\mathrm{Arg} / \mathrm{Arg}\end{array}$ & $\begin{array}{r}104 \\
70\end{array}$ & $\begin{array}{l}59.8 \% \\
40.2 \%\end{array}$ & $\begin{array}{l}75 \\
99\end{array}$ & $\begin{array}{l}43.1 \% \\
56.9 \%\end{array}$ & $\begin{array}{c}\mathrm{p}=0.002 \\
\text { OR: } 1.96 \\
\text { (IC95\%: } 1.3-3)\end{array}$ \\
\hline
\end{tabular}

\subsection{Estudio de XPDLys751GIn, XRCC1Arg399GIn y XRCC3Thr241Met en relación con la edad en los grupos caso y control}

A continuación, se presenta el análisis de la distribución de los diferentes genotipos de XPDLys751GIn, XRCC1Arg399GIn y XRCC3Thr241Met en función de la edad, en ambos grupos, caso y control. 


\subsubsection{Controles}

La tabla 23 muestra la frecuencia de las diferentes variables del estudio en los 300 controles de la muestra. No se encontró ninguna asociación entre los diferentes genotipos y la edad en el grupo de individuos sanos $(p=0.406, p=0.782$ y $p=0.667$ para XPDLys751GIn, XRCC1Arg399GIn y XRCC3Thr241Met, respectivamente).

Tabla 23: Distribución de los diferentes genotipos de XPDLys751, XRCC1Arg399GIn y XRCC3Thr241Met en el grupo control en función de la edad

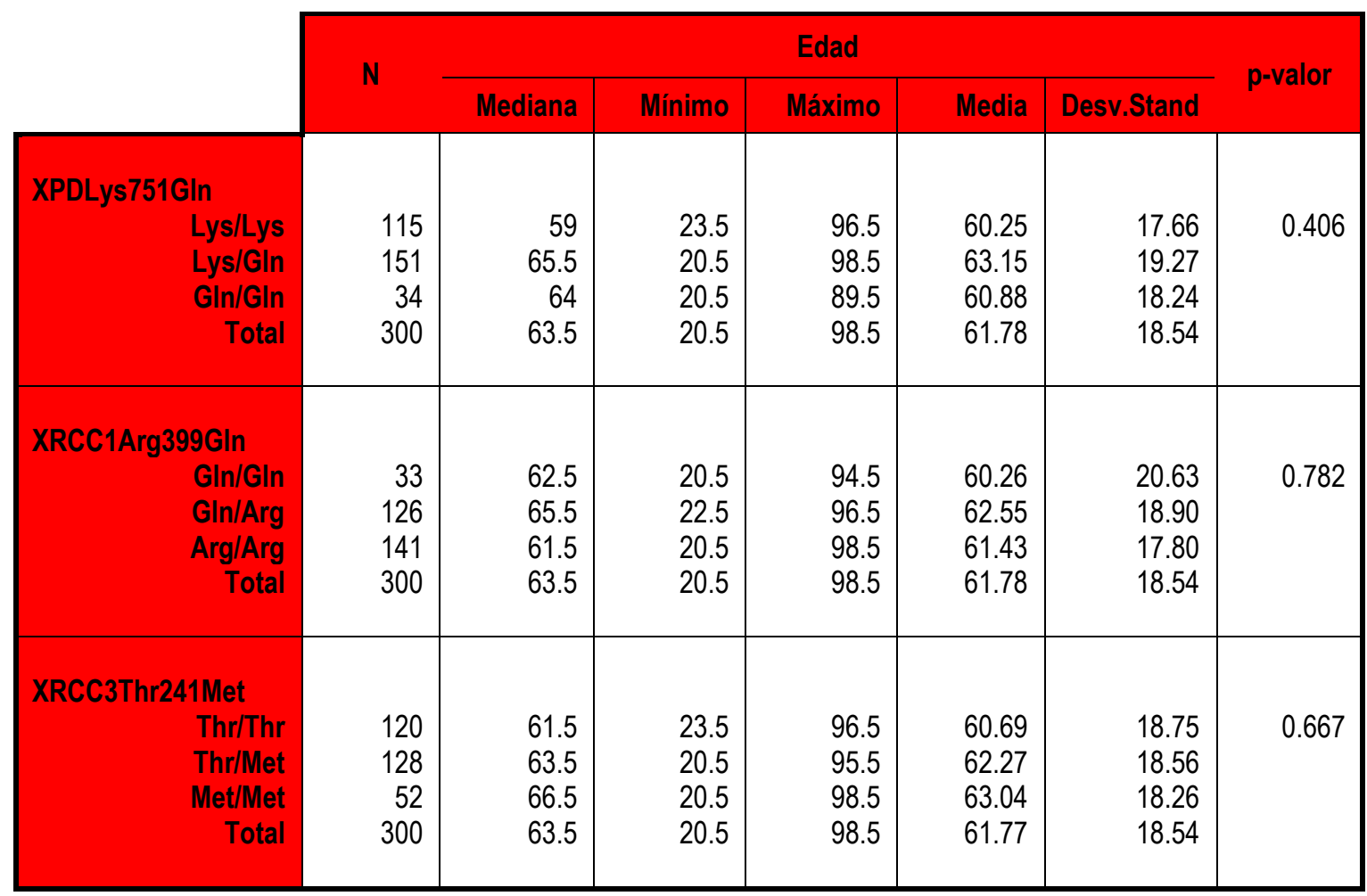

\subsubsection{Casos}

El estudio de los diferentes genotipos entre los casos (tabla 24) mostró que existe una diferencia en la distribución de las variantes de XRCC1Arg399GIn en relación con la edad. Tomando como punto de corte la mediana de edad de las pacientes (62 años), se observa que el genotipo Lys/Lys, asociado a una mayor capacidad de reparación del ADN, es más frecuente entre las mujeres que desarrollan cáncer de mama a edades más tardías $(p<0.001)$, OR: 3.52 (IC: 35.44) (Tabla 25). 


\section{Resultados}

Tabla 24: Distribución de los diferentes genotipos de XPDLys751Gln,

XRCC1Arg399GIn y XRCC3Thr241Met entre los casos en función de la edad.

\begin{tabular}{|c|c|c|c|c|c|c|c|}
\hline & \multirow{2}{*}{$\mathbf{N}$} & \multicolumn{5}{|c|}{ Edad } & \multirow{2}{*}{ p-valor } \\
\hline & & Mediana & Mínimo & Máximo & Media & Desv.Stan & \\
\hline $\begin{array}{r}\text { XPDLys751Gln } \\
\text { Lys/Lys } \\
\text { Lys/GIn } \\
\text { GIn/GIn } \\
\text { Total }\end{array}$ & $\begin{array}{r}75 \\
81 \\
18 \\
174\end{array}$ & $\begin{array}{r}65.5 \\
58.5 \\
58 \\
62\end{array}$ & $\begin{array}{l}29.5 \\
26.5 \\
33.5 \\
26.5\end{array}$ & $\begin{array}{l}86.5 \\
91.5 \\
67.5 \\
91.5\end{array}$ & $\begin{array}{l}63.71 \\
58.24 \\
53.78 \\
60.14\end{array}$ & $\begin{array}{l}12.55 \\
13.48 \\
11.34 \\
13.24\end{array}$ & 0.001 \\
\hline $\begin{array}{r}\text { XRCC1Arg399GIn } \\
\text { GIn/GIn } \\
\text { GIn/Arg } \\
\text { Arg/Arg } \\
\text { Total }\end{array}$ & $\begin{array}{r}17 \\
87 \\
70 \\
174\end{array}$ & $\begin{array}{r}59.5 \\
61.5 \\
62.5 \\
62\end{array}$ & $\begin{array}{l}33.5 \\
26.5 \\
33.5 \\
26.5\end{array}$ & $\begin{array}{l}79.5 \\
86.5 \\
91.5 \\
91.5\end{array}$ & $\begin{array}{l}57.51 \\
59.71 \\
61.31 \\
60.14\end{array}$ & $\begin{array}{l}14.74 \\
13.76 \\
12.26 \\
13.24\end{array}$ & 0.645 \\
\hline $\begin{array}{r}\text { XRCC3Thr241Met } \\
\text { Thr/Thr } \\
\text { Thr/Met } \\
\text { Met/Met } \\
\text { Total }\end{array}$ & $\begin{array}{r}65 \\
81 \\
28 \\
174\end{array}$ & $\begin{array}{r}62.5 \\
60.5 \\
58.5 \\
62\end{array}$ & $\begin{array}{l}26.5 \\
29.5 \\
33.5 \\
26.5\end{array}$ & $\begin{array}{l}82.5 \\
91.5 \\
86.5 \\
91.5\end{array}$ & $\begin{array}{l}61.47 \\
59.87 \\
57.82 \\
60.14\end{array}$ & $\begin{array}{l}13.11 \\
13.22 \\
13.72 \\
13.24\end{array}$ & 0.389 \\
\hline
\end{tabular}

Tabla 25: Distribución de los genotipos de XPDLys751GIn en relación con la mediana de edad de los casos

\begin{tabular}{|c|c|c|c|c|}
\hline \multirow{2}{*}{ XPD Lys751GIn } & \multicolumn{2}{|c|}{ Edad } & \multirow{2}{*}{ Total } & \multirow{2}{*}{$p$-valor } \\
\hline & $\leq 62$ años & $>62$ años & & \\
\hline $\begin{array}{r}\text { GIn/GIn +Lys/Gln } \\
\text { Lys/Lys } \\
\text { Total }\end{array}$ & $\begin{array}{r}60(69 \%) \\
21(31 \%) \\
87(100 \%)\end{array}$ & $\begin{array}{c}39(44.8 \%) \\
48(55.2 \%) \\
87(100 \%)\end{array}$ & $\begin{array}{l}99(56.9 \%) \\
75(43.1 \%) \\
174(100 \%)\end{array}$ & $\begin{array}{c}0.001 \\
\text { OR= } 3.52 \\
(I C: 3-5.44)\end{array}$ \\
\hline
\end{tabular}

Cuando se analiza la frecuencia de las diferentes variables de XPDlys751GIn atendiendo al status hormonal en el momento del diagnóstico, las diferencias se mantienen $(p=0.023)$ (Tabla 26) 
Tabla 26: Distribución de los genotipos de XPDLys7 entre los casos en función del status hormonal al diagnóstico

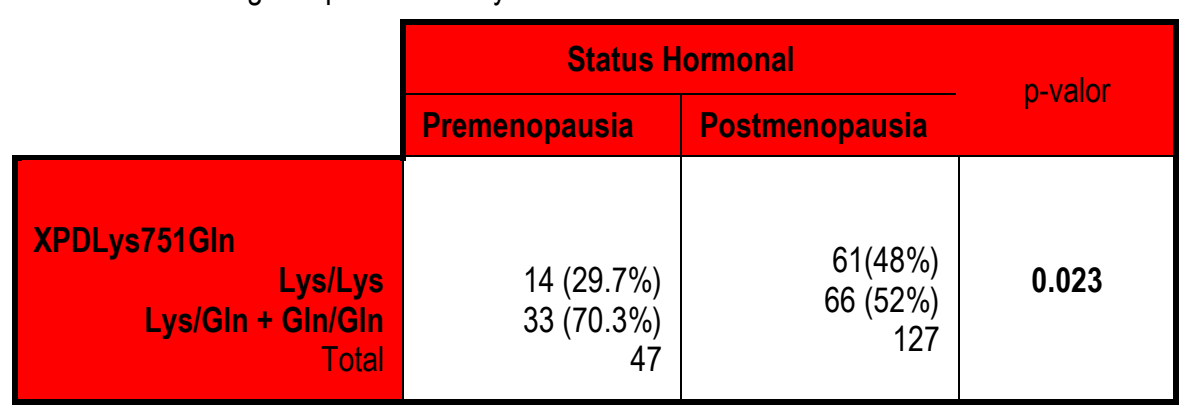

\subsection{Estudio de XPDLys751GIn, XRCC1Arg399GIn y XRCC3Thr241Met en relación con el tratamiento radioterápico}

La severidad del daño del tejido normal tras un tratamiento radioterápico está fundamentalmente relacionada con factores asociados a la exposición, pero éstos no son suficientes para explicar la variabilidad de la respuesta que se observa entre unos y otros pacientes. A este respecto, existen evidencias que indican que estas diferencias en los efectos secundarios dependen de factores asociados con el tratamiento, pero también del propio paciente, como la edad, el índice de masa corporal y factores genéticos que condicionarían la radiosensibilidad individual178,179.

Puesto que la radioterapia ejerce sus efectos citotóxicos a través del daño que induce en las células, proteínas y ADN, donde induce rotura de cadena simple pero también de doble cadena, la capacidad de cada individuo de reparar el ADN dañado podría modificar la respuesta del tejido normal a la radiación.

\subsubsection{Toxicidad cutánea aguda post-radioterapia}

La toxicidad cutánea postradioterapia es un hecho frecuente que habitualmente se presenta en sus formas más leves. Ciento doce de las pacientes de nuestro estudio recibieron tratamiento radioterápico sobre la mama, (en el caso de la cuadrantectomía o tumorectomía) o sobre el lecho de mastectomía. La toxicidad se recogió según los criterios de la RTOG (Radiation Therapy Oncology Group), (tabla 27). 
Resultados

Tabla 27: Toxicidad aguda cutánea post-radioterapia según criterios RTOG

Grado 0 Ningún cambio

Grado 1 Erupción maculo-papular o eritema aislado y asintomático

Grado 2 Erucpción máculo-papular o eritema con prurito u otros síntomas asociados

Grado 3 Erupción macular, papular o vesicular, generalizada y sintomática

Grado 4 Dermatitis exfoliativa o ulcerativa. Necrosis tisular.

Como se observa en la tabla 28, la toxicidad más frecuente en nuestra serie fue el eritema local acompañado o no de prurito (toxicidad grado 2 y 1 , respectivamente). Solamente se presentó el caso de una paciente con toxicidad grado 4 debido a dermatitis ulcerativa. En la historia clínica de 26 pacientes los datos de toxicidad aguda estaban incompletos, por lo que para el análisis la muestra se reduce a 86 pacientes.

Tabla 28: Frecuencia de los diferentes grados de toxicidad post-RT en la muestra

\begin{tabular}{|lrr|}
\hline $\begin{array}{c}\text { Toxicidad cutánea } \\
\text { aguda post RT }\end{array}$ & Frecuencia & $\%$ \\
\hline Grado 0 & 14 & 12.5 \\
Grado 1 & 27 & 24.1 \\
Grado 2 & 29 & 25.9 \\
Grado 3 & 15 & 13.4 \\
Grado 4 & 1 & 0.9 \\
Desconocido & 26 & 23.2 \\
Total & 112 & 100 \\
\hline
\end{tabular}


En la tabla 29 se recogen las frecuencias de las diferentes variables genotípicas en relación a la toxicidad cutánea aguda. Acorde con nuestros resultados no se puede establecer relación de dependencia entre ninguna de las variantes genéticas estudiadas y la aparición y severidad de toxicidad post-radioterapia.

Dado que la toxicidad aguda depende de la dosis total y del tiempo de administración, analizamos si la sobreimpresión axilar con electrones de alto fotovoltaje se asociaba a un incremento de la toxicidad cutánea. Solamente 23 de las 86 pacientes de las que se dispone de datos de toxicidad aguda postradioterapia, recibieron sobreimpresión axilar (Tabla 30). En estas pacientes, la toxicidad grado 3 y 4 fue más frecuente, aunque no se alcanzó la significación estadística $(p=0.088)$.

Tabla 29: Distribución de los diferentes grados de toxicidad aguda post-RT en relación con las variantes de XPDLys751GIn, XRCC1Arg399GIn y XRCC3Thr241Met

\begin{tabular}{|c|c|c|c|c|c|}
\hline & \multicolumn{3}{|c|}{ Toxicidad Aguda post-radioterapia } & \multirow[b]{2}{*}{ Total } & \multirow[b]{2}{*}{ p-valor } \\
\hline & $\begin{array}{l}\text { Ausente } \\
\text { (Grado 0) }\end{array}$ & $\begin{array}{c}\text { Leve } \\
\text { (Grado1-2) }\end{array}$ & $\begin{array}{c}\text { Severa } \\
\text { (Grado3-4) }\end{array}$ & & \\
\hline $\begin{array}{r}\text { XPDLys751GIn } \\
\text { Lys/Lys } \\
\text { Lys/Gln } \\
\text { GIn/GIn } \\
\text { Total }\end{array}$ & $\begin{array}{r}6(42.9 \%) \\
5(35.7 \%) \\
3(21.4 \%) \\
14\end{array}$ & $\begin{array}{r}19(33.9 \%) \\
31(55.4 \%) \\
6(10.7 \%) \\
56\end{array}$ & $\begin{array}{r}10(62.5 \%) \\
5(31.3 \%) \\
1(6.3 \%) \\
16\end{array}$ & $\begin{array}{l}35 \\
41 \\
10 \\
86\end{array}$ & 0.208 \\
\hline $\begin{array}{r}\text { XRCC1Arg399GIn } \\
\text { GIn/GIn } \\
\text { GIn/Arg } \\
\text { Arg/Arg } \\
\text { Total }\end{array}$ & $\begin{array}{r}2(14.3 \%) \\
6(42.9 \%) \\
6(42.9 \%) \\
14\end{array}$ & $\begin{array}{r}10(17.9 \%) \\
26(46.4 \%) \\
20(35.7 \%) \\
56\end{array}$ & $\begin{array}{r}1(6.3 \%) \\
7(43.8 \%) \\
8(50 \%) \\
16\end{array}$ & $\begin{array}{l}13 \\
39 \\
34 \\
86\end{array}$ & 0.728 \\
\hline $\begin{array}{r}\text { XRCC3Thr241Met } \\
\text { Thr/Thr } \\
\text { Thr/Met } \\
\text { Met/Met } \\
\text { Total }\end{array}$ & $\begin{array}{r}5(35.7 \%) \\
6(42.9 \%) \\
3(21.4 \%) \\
14\end{array}$ & $\begin{array}{r}16(28.6 \%) \\
29(51.8 \%) \\
11(19.6 \%) \\
56\end{array}$ & $\begin{array}{r}8(50 \%) \\
7(43.8 \%) \\
1(6.3 \%) \\
16\end{array}$ & $\begin{array}{l}29 \\
42 \\
15 \\
86\end{array}$ & 0.453 \\
\hline
\end{tabular}




\section{Resultados}

Tabla 30: Grados de toxicidad aguda post-RT en relación con la sobreimpresión axilar.

\begin{tabular}{|l|r|r|r|}
\hline \multirow{2}{*}{$\begin{array}{c}\text { Toxicidad aguda } \\
\text { postRT }\end{array}$} & \multicolumn{2}{|c|}{ Boost axilar } & p-valor \\
\cline { 2 - 3 } & \multicolumn{1}{|c|}{ Sí } & \\
\hline Grado 0-2 & $16(69 \%)$ & $54(85 \%)$ & 0.088 \\
Grado 3-4 & $7(30.43 \%)$ & $9(14.28 \%)$ & \\
Total & 23 & 63 & \\
\hline
\end{tabular}

\subsubsection{Toxicidad crónica post-radioterapia}

La toxicidad dérmica crónica post-radioterapia incluye fenómenos como fibrosis, alteraciones de la pigmentación cutánea o teleangiectasias. En la historia clínica de 21 pacientes (18.75\%) estos datos estaban incompletos, por lo que no se incluyeron en el análisis ( $n=91$ ). 32 mujeres que habían recibido RT presentaron datos de toxicidad crónica $(35.16 \%)$. La presencia de fibrosis fue el evento más frecuente, fenómeno que en el caso de la patología mamaria está también íntimamente relacionado con el tratamiento quirúrgico.

No hemos encontrado diferencias entre la frecuencia de las diferentes variables genotípicas y el desarrollo de toxicidad crónica (Tabla 31).

Tabla 31: Toxicidad crónica postRT en relación con los genotipos de XPDLys751GIn, XRCC1Arg399GIn y XRCC3Thr241Met

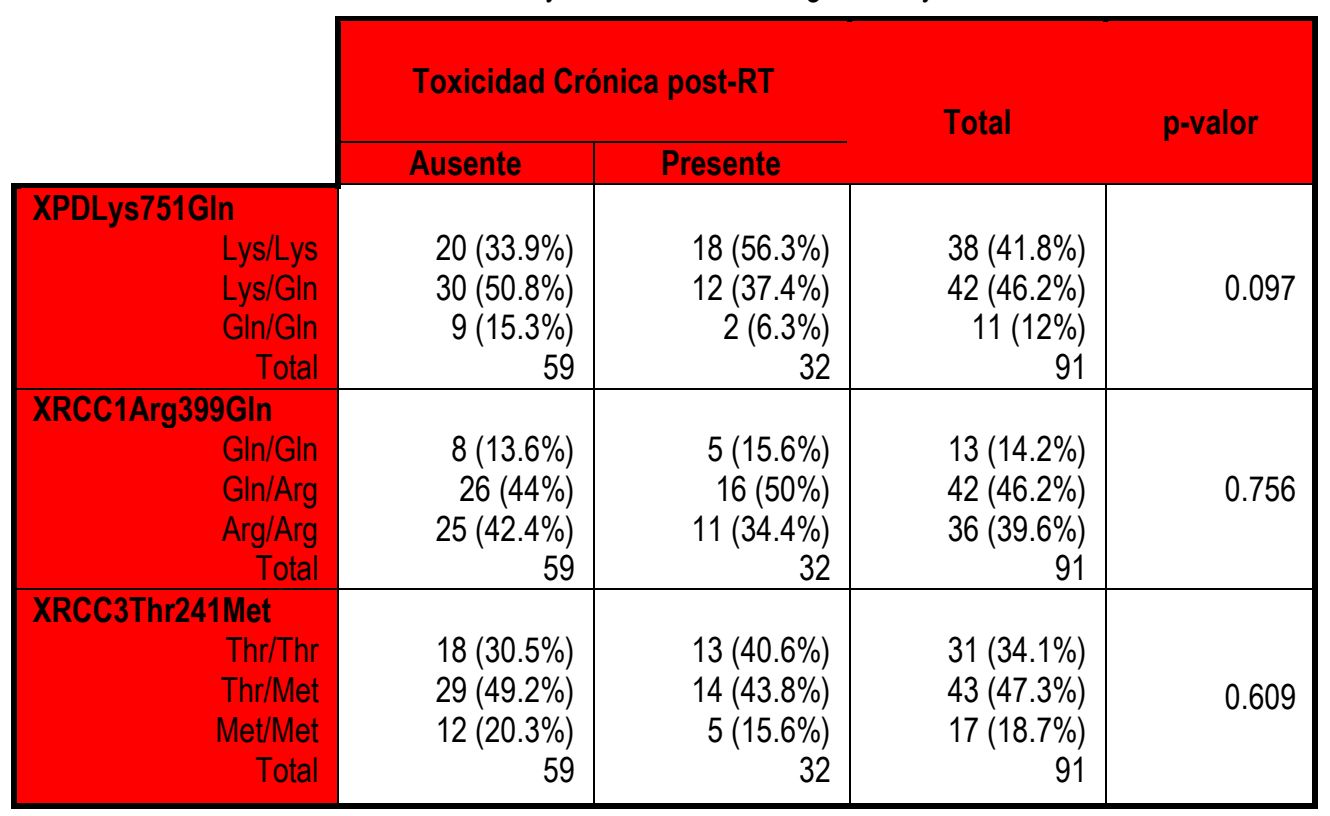


De las 91 pacientes de las que se tienen datos de toxicidad crónica postradioterapia, solamente 23 recibieron sobreimpresión axilar. En nuestra serie, no existe relación entre la sobreimpresión axilar y el desarrollo de toxicidad dérmica tardía (Tabla 32).

Tabla 32: Frecuencia de toxicidad crónica post-RT en relación con la sobreimpresión axilar.

\begin{tabular}{|c|r|r|r|}
\hline \multirow{2}{*}{$\begin{array}{c}\text { Toxicidad crónica } \\
\text { Post-RT }\end{array}$} & \multicolumn{1}{|c|}{ No } & p-valor \\
\cline { 2 - 3 } & & \multicolumn{1}{c|}{ Sí } & \\
\hline No & $47(70.14 \%)$ & $12(52.17 \%)$ & 0.118 \\
Sí & $20(29.85 \%)$ & $11(47.8 \%)$ & \\
Total & 67 & 23 & \\
\hline
\end{tabular}

\subsubsection{Recidiva local tras RT}

Con una mediana de seguimiento de 60 meses, 12 de las 112 pacientes tratadas mediante cirugía de la mama y RT (10.7\%), presentaron una recidiva local. Se observan algunas diferencias entre las pacientes que recayeron localmente y las que no en relación con XPDLys751GIn donde la variante Lys/Lys es menos frecuente entre las pacientes con recidiva (43\%vs8.3\%), pero la diferencia no alcanza la significación estadística ( $p=0.062$ ) (Tabla 33).

Tabla 33: Recaída local tras RT en relación con los diferentes SNPs de XPD, XRCC1 y XRCC3

\begin{tabular}{|c|c|c|c|c|}
\hline & \multicolumn{2}{|c|}{ Recidiva local } & \multirow{2}{*}{ Total } & \multirow{2}{*}{ p-valor } \\
\hline & No & Sí & & \\
\hline \multicolumn{5}{|l|}{ XPDLys751GIn } \\
\hline Lys/Lys & $43(43 \%)$ & $1(8.3 \%)$ & $44(39.28 \%)$ & \multirow{4}{*}{0.062} \\
\hline Lys/GIn & $44(44 \%)$ & $9(75 \%)$ & $53(47.32 \%)$ & \\
\hline $\mathrm{Gln} / \mathrm{Gln}$ & $13(13 \%)$ & $2(16.6 \%)$ & $15(13.39 \%)$ & \\
\hline Total & 100 & 12 & 112 & \\
\hline \multicolumn{4}{|l|}{ XRCC1Arg399GIn } & \multirow{5}{*}{0.673} \\
\hline$G \ln / G \ln$ & $13(13 \%)$ & $1(8.3 \%)$ & $14(12.5 \%)$ & \\
\hline GIn/Arg & $45(45 \%)$ & $7(58.3 \%)$ & $52(46.4 \%)$ & \\
\hline Arg/Arg & $42(42 \%)$ & $4(33.3 \%)$ & $46(41.1 \%)$ & \\
\hline Total & 100 & 12 & 112 & \\
\hline \multicolumn{4}{|l|}{ XRCC3Thr241Met } & \multirow{5}{*}{0.626} \\
\hline Thr/Thr & $38(38 \%)$ & $3(25 \%)$ & $41(36.6 \%)$ & \\
\hline Thr/Met & $45(45 \%)$ & $6(50 \%)$ & $51(45.5 \%)$ & \\
\hline Met/Met & $17(17 \%)$ & $3(25 \%)$ & $20(17.8 \%)$ & \\
\hline Total & 100 & 12 & 112 & \\
\hline
\end{tabular}




\section{ANÁLISIS DE SUPERVIVENCIA}

En la primera parte de este apartado, se presenta el estudio del valor pronóstico de las diferentes variantes polimórficas de XPDLys751GIn, XRCC1Arg399GIn y XRCC3Thr241Met en relación con la Superviviencia Global (SG) y Superviviencia Libre de Enfermedad (SLE) en el grupo de pacientes con estadios tempranos al diagnóstico. En este grupo de pacientes, también se analizó el valor pronóstico en nuestra serie de los factores pronósticos clásicos (tamaño tumoral, ganglios axilares, grado tumoral, receptores hormonales y HER2).

Para determinar el impacto de XPDLys751GIn, XRCC1Arg399GIn y XRCC3Thr241Met en el pronóstico de las pacientes que recibieron tratamientos quimioterápicos basados en antraciclinas, se analizaron por separado los datos de SG y SL del grupo de 84 pacientes que recibieron tratamiento adyuvante 0 neoadyuvante con estos citotóxicos. Dado que la administración de quimioterapia antes y después de la cirugía presentan tasas de SLE y SG similares ${ }^{180}$, se decidió incluir a todas estas pacientes en un mismo grupo para el análisis

En la segunda parte de este apartado, se analiza el valor pronóstico de estos polimorfismos en relación con la Supervivencia Global desde la Metástasis $\left(\mathrm{SG}_{\mathrm{M}}\right)$ en el grupo de pacientes que presentó diseminación metastásica de la enfermedad.

La mediana de seguimiento de nuestras pacientes ha sido de 62 meses (11-228), por lo que se presentan los datos de supervivencia a 5 años (60 meses). 


\subsection{PACIENTES CON ENFERMEDAD LOCAL}

\subsubsection{ANALISIS DE SUPERVIVENCIA LIBRE DE ENFERMEDAD (SLE)}

De las 150 pacientes no metástásicas al diagnóstico, 65 presentaron algún tipo de evento en los 60 meses siguientes al diagnóstico, con lo que la SLE a los 5 años fue del $69.9 \%$ (62.85\%$77,75 \%)$.

A continuación, se muestra el valor pronóstico para SLE de la afectación ganglionar, el tamaño y el grado tumoral, la expresión de receptores hormonales y HER2 y de las diferentes variantes de XPDLys751Gln, XRCC1Arg399GIn y XRCC3Thr241Met, en las pacientes de nuestra muestra.

\subsubsection{Afectación de ganglios axilares}

La presencia o no de metástasis en los ganglios de la axila es el factor pronóstico independiente más importante en el cáncer de mama intervenido, tanto para la SLE como para la SG $^{9,181}$.

De las 150 pacientes de nuestra serie con enfermedad localizada, 85 presentaban afectación ganglionar al diagnóstico. Solamente tres pacientes presentaron micrometástasis ganglionares $(<2 \mathrm{~mm})$, que a efectos pronósticos y de tratamiento fueron consideradas como ganglios negativos, por lo que en este análisis las incluimos en dicho grupo. En otros tres casos, se desconoce la afectación ganglionar, por lo que se asumieron como valores perdidos para el análisis estadístico.

Hubo 50 eventos entre los casos con ganglios positivos, con una SLE durante los primeros 60 meses del $59.5 \%$ y con una mediana de SLE de 78.5 meses (Tabla 34). La diferencia con las pacientes sin ganglios afectos es estadísticamente significativa $(p=0.002)$ 
Tabla 34: Impacto de la afectación ganglionar axilar en la SLE a 60 meses.

\begin{tabular}{|c|c|c|c|c|c|}
\hline Afectacion axilar & $N$ & Eventos & $\begin{array}{c}\text { SLE } \\
\text { a } 60 \text { meses }\end{array}$ & $\begin{array}{c}\text { Mediana SLE } \\
\text { (meses) }\end{array}$ & $p$-valor \\
\hline Ganglios - & 62 & 15 & $83.2 \%(73.6-92.8)$ & - & $\mathbf{p}=0.2$ \\
Ganglios + & 85 & 50 & $59.5 \%(48.7-70.3)$ & $78.5(63.8-93.2)$ & \\
\hline
\end{tabular}

No se dispone de los datos de afectación ganglionar axilar de 3 pacientes.

\subsubsection{Tamaño tumoral}

Después del estado ganglionar, el diámetro tumoral se considera el factor pronóstico más importante, tanto para la SLE como para SG ${ }^{182}$.

En nuestra muestra, a pesar de que la recaída a los 60 meses es mayor en los tumores mayores de $5 \mathrm{cms}$ que en los de menor tamaño $(76.8 \%, 68.7 \%$ y $53.8 \%)$, la diferencia no alcanza la significación estadística debido a la amplitud de los intervalos de confianza (Tabla 35).

Tabla 35: Impacto del tamaño tumoral en la SLE a 60 meses

\begin{tabular}{|c|c|c|c|c|c|}
\hline $\begin{array}{l}\text { Tamaño } \\
\text { Tumoral }\end{array}$ & $\mathrm{N}$ & Eventos & $\begin{array}{c}\text { SLE } \\
\text { a } 60 \text { meses }\end{array}$ & $\begin{array}{l}\text { Mediana SLE } \\
\text { (meses) }\end{array}$ & $p$-valor \\
\hline$\leq 2 \mathrm{cms}$ & 50 & 16 & $78.6 \%(66.6-90.6)$ & $94.5(75.4-113.6)$ & $p=0.537$ \\
\hline$>2-\leq 5 \mathrm{cms}$ & 81 & 37 & $68.7 \%(58.3-79.1)$ & $110.5(78.2-142.8)$ & \\
\hline$>5 \mathrm{cms}$ & 13 & 7 & $53.8 \%(26.8-80.8)$ & $86.5(0.5-184.8)$ & \\
\hline
\end{tabular}

No se dispone de los datos del tamaño tumoral de 6 pacientes 


\subsubsection{Grado tumoral}

El sistema más comúnmente empleado es el de Scarff-Bloom-Richardson ${ }^{183}$, que combina criterios histológicos (formación de túbulos) con los citológicos (pleomorfismo nuclear). Así, los tumores se clasifican en Grado I: Bien diferenciado, Grado II: Moderadamente diferenciado y Grado III: Pobremente diferenciado. Los tumores grado II y III se han asociado con un peor pronóstico ${ }^{184}$, resultado que también se observa en nuestra muestra, donde la SLE a 5 años en los tumores de grado I es del $100 \%$ y cae al $62.9 \%$ en los tumores grado III (Tabla 36 ).

Tabla 36: Impacto del grado tumoral en la SLE a 60 meses

\begin{tabular}{|c|c|c|c|c|c|}
\hline $\begin{array}{l}\text { Grado } \\
\text { Tumoral }\end{array}$ & $\mathrm{N}$ & Eventos & $\begin{array}{c}\text { SLE } \\
\text { a } 60 \text { meses }\end{array}$ & $\begin{array}{c}\text { Mediana SLE } \\
\text { (meses) }\end{array}$ & p-valor \\
\hline Grado I & 18 & 2 & $100 \%$ & - & \\
\hline Grado II & 51 & 14 & $78.1 \%(65.1-91.1)$ & 278.5 & $p=0.013$ \\
\hline Grado III & 74 & 34 & $62.9 \%(51.1-74.7)$ & $84.5(65-104)$ & \\
\hline
\end{tabular}

No se disponen de los datos de 22 pacientes

\subsubsection{Receptores hormonales}

La expresión de los receptores de estrógenos y de progestágenos tiene principalmente un valor predictivo de respuesta al tratamiento hormonal, aunque también poseen un significado pronóstico. Se ha observado que los tumores RH positivos poseen mayores tasas de SLE a corto plazo que el grupo $\mathrm{RH}$ negativos, si bien estas diferencias se diluyen en el seguimiento a largo plazo, y sin que se observen diferencias en la SG ${ }^{185,186}$. Por el contrario, en el análisis multivariante de Kollias et al, la expresión de receptores hormonales por parte del tumor no se confirmó como factor pronóstico independiente ${ }^{172}$. 


\section{Resultados}

En nuestro análisis, no hemos encontrado ninguna diferencia en la tasa de recaída a 60 meses en función de la expresión de receptores hormonales (Tabla 37). Todas las pacientes con expresión de RH habían recibido tratamiento hormonal adyuvante.

Tabla 37: Impacto de los receptores hormonales del tumor en la SLE a 60 meses

\begin{tabular}{|c|c|c|c|c|c|}
\hline $\begin{array}{c}\text { Receptores } \\
\text { Hormonales (RH) }\end{array}$ & N & Eventos & $\begin{array}{c}\text { SLE } \\
\text { a } 60 \text { meses }\end{array}$ & $\begin{array}{c}\text { Mediana SLE } \\
\text { (meses) }\end{array}$ & p-valor \\
\hline RH negativos & 47 & 19 & $70 \%(56.3-83.7)$ & 90.5 & \\
\hline RH positivos & 96 & 35 & $71.7 \%(61.9-81.5)$ & $111.5(81.1-141.9)$ & $p=0.818$ \\
\hline
\end{tabular}

No se dispone de los datos de $\mathrm{RH}$ de 7 pacientes

\subsubsection{HER2}

El gen HER2 forma parte de la familia de receptores del factor de crecimiento epidermoide (EGFR) y se encuentra amplificado en el $20 \%$ de los tumores de la mama ${ }^{187}$. Posee valor pronóstico en cuanto que la sobreexpresión de HER2 se ha asociado con formas de la enfermedad más agresivas, con SLE y SG más cortas ${ }^{188,189}$. Pero desde la aparición del anticuerpo monoclonal Trastuzumab, su papel principal es el de predictor de respuesta a los tratamientos anti- HER2.

En el momento del diagnóstico de las pacientes de nuestra serie (1990-2004) no se había aprobado la administración de Trastuzumab en adyuvancia, por lo que en algunas ocasiones no se realizaba la determinación de HER2. En total, son 43 las pacientes de las que no disponemos, incluidos 12 casos en los que la sobreexpresión de HER2 era dudosa y no fue confirmada mediante FISH, que han sido excluídos del análisis.

A pesar de que la muestra para este análisis se reduce a 106 pacientes, se observan diferencias en la supervivencia de aquellas con y sin sobreexpresión de HER2, lo que es acorde con la literatura ${ }^{188}$. El 48\% de las pacientes HER2 positivo recayeron antes de los 60 meses y la mediana de SLE (70.5 meses) es inferior a la que presentaron las pacientes HER2 negativas 
$(p=0.047)$ (Tabla 38). Ninguna de estas pacientes había recibido trastuzumab como tratamiento neoadyuvante 0 adyuvante.

Tabla 38: Efecto de la sobreexpresión de HER2 sobre la SLE a 60 meses

\begin{tabular}{|c|c|c|c|c|c|}
\hline HER2 & $\mathrm{N}$ & Eventos & $\begin{array}{c}\text { SLE } \\
\text { a } 60 \text { meses }\end{array}$ & $\begin{array}{c}\text { Mediana SLE } \\
\text { (meses) }\end{array}$ & p-valor \\
\hline HER2 negativo & 77 & 25 & $75.7 \%(65.9-85.5)$ & $90.5(47.9-133.1)$ & \\
HER2 positivo & 29 & 15 & $52.1 \%(32.9-12.3)$ & $70.5(32.9-108.1)$ & $\mathrm{p}=\mathbf{0 . 0 4 7}$ \\
\hline
\end{tabular}

Se desconocen los datos de sobreexpresión de HER2 en 43 pacientes

\subsubsection{Edad}

El impacto pronóstico de la edad y del estado menstrual han sido ampliamente discutidos, si bien parece que las pacientes que desarrollan cáncer de mama antes de los 35 años tienen mayor riesgo de recidiva local y a distancia.

En nuestra muestra, solamente 5 pacientes habían presentado la enfermedad antes de los 35 años y todas ellas habían desarrollado metástasis en el momento del diagnóstico.

\subsubsection{Otros}

Otros factores con implicaciones pronósticas como son la infiltración linfovascular o el índice de proliferación no han podido ser analizados ya que no fueron determinados en el diagnóstico histológico original. 


\subsubsection{Análisis de XRCC3Thr241Met, XRCC1Arg399GIn y XPDLys751GIn en relación con SLE en los estadios tempranos de cáncer de mama}

A continuación se analiza el impacto de los diferentes SNP de nuestro estudio sobre la SLE de las pacientes con cáncer de mama local. Como puede observarse en la tabla 39, las variantes XPD 751Lys, XRCC1 399Arg y XRCC3 241Met se asocian con menor número de eventos y mayor SLE, pero estas diferencias no alcanzan la significación estadística en el análisis univariante, motivo por el que no se continuó con el análisis.

Tabla 39: Frecuencia de las diferentes variables de XPDLys751GIn, XRCC1Arg399GIn y XRCC3Thr241Met en relación con la SLE en pacientes con cáncer de mama en estadios localizados

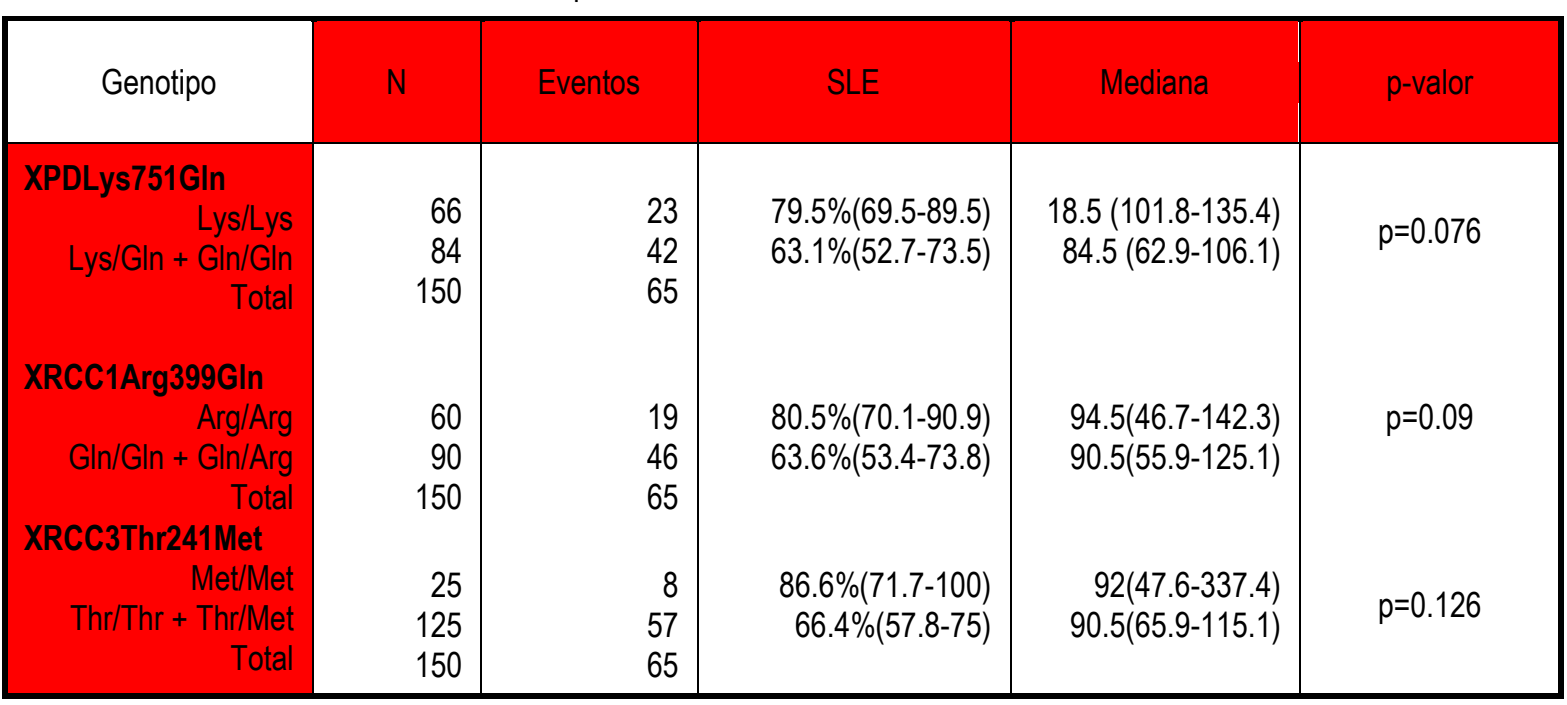

En nuestra muestra, por lo tanto, solamente la afectación de los ganglios axilares y el grado tumoral se mostraron como factores predictores de SLE en las pacientes con cáncer de mama en estadios tempranos. 


\subsubsection{SUPERVIVENCIA GLOBAL (SG)}

La supervivencia global a los 60 meses de las 150 pacientes con cáncer de mama en estadios tempranos en el momento del diagnóstico fue del 84.2\% (IC95\% 78.1 - 90.3). La SG mediana fue 140.5 meses (IC95\% 108-172.3).

\subsubsection{Afectación de ganglios axilares}

Tal y como se señaló anteriormente, la presencia o no de metástasis en los ganglios de la axila es el factor pronóstico independiente más importante en el cáncer de mama operado, tanto para la SLE como para SG.

Como se muestra en la tabla 40 , el $21.8 \%$ de las pacientes con afectación ganglionar axilar fallecieron en los 60 meses posteriores al diagnóstico, frente al 10\% en el caso de las pacientes sin metastatización axilar, diferencia que es estadísticamente significativa $(p=0.023)$

Tabla 40: Afectación ganglionar axilar y supervivencia global.

\begin{tabular}{|c|c|c|c|c|c|}
\hline Afectación axilar & $\mathrm{N}$ & Eventos & $\begin{array}{c}\text { SG } \\
\text { a } 60 \text { meses }\end{array}$ & $\begin{array}{c}\text { Mediana SG } \\
\text { (meses) }\end{array}$ & $p$-valor \\
\hline Ganglios - & 62 & 13 & $89.9 \%(82.3-97.5)$ & - & $\mathbf{p = 0 . 0 2 3}$ \\
\hline Ganglios + & 85 & 40 & $79.2 \%(70-88.4)$ & $124.5(114.4-154.6)$ & \\
\hline
\end{tabular}

No se dispone de los datos de afectación ganglionar axilar de 3 pacientes.

\subsubsection{Tamaño tumoral}

El tamaño tumoral es el segundo factor pronóstico más importante para la SG ${ }^{182}$. En nuestro análisis sin embargo, no se observa diferencia estadística en relación con este parámetro, a pesar de que el $40 \%$ de las pacientes diagnosticadas con tumores $>5 \mathrm{~cm}$ fallecieron antes de los 60 meses, y la mediana de supervivencia fue de 77.5 meses, frente al $85 \%$ de las pacientes 
diagnosticadas con tumores de menor tamaño que seguían vivas a los 5 años (Tabla 41). De nuevo, la amplitud de los intervalos de confianza impide que esta diferencia alcance la significación estadística $(p=0.085)$.

Tabla 41: Impacto del tamaño tumoral en la SG

\begin{tabular}{|c|c|c|c|c|c|}
\hline $\begin{array}{c}\text { Tamaño } \\
\text { Tumoral }\end{array}$ & $\mathrm{N}$ & $\begin{array}{c}\text { Fallecimientos } \\
\text { a } 60 \text { meses }\end{array}$ & $\begin{array}{c}\text { SG } \\
\text { a } 60 \text { meses }\end{array}$ & $\begin{array}{c}\text { Mediana SG } \\
\text { (meses) }\end{array}$ & $p$-valor \\
\hline$\leq 2 \mathrm{cms}$ & 50 & 16 & $85.2 \%(74-96.4)$ & $123.2(109.4-137.6)$ & $143.5(-)$ \\
$>2-\leq 5 \mathrm{cms}$ & 81 & 37 & $86.8 \%(79.2-94.4)$ & $\mathrm{p}=0.085$ \\
$>5 \mathrm{cms}$ & 13 & 7 & $58.6 \%(30.4-85)$ & $77.5(39.66-115.34)$ & \\
\hline
\end{tabular}

No se dispone de los datos del tamaño tumoral de 6 pacientes

\subsubsection{Grado tumoral}

La tabla 42 muestra la relación entre el grado de diferenciación de los tumores de nuestra muestra y la SG. La diferencia que se observa es estadísticamente significativa $(p=0.018)$. Cuando se realizan comparaciones parciales, se observa que esta diferencia en el pronóstico es atribuible a los tumores de grado III, mientras que los tumores grado I y II tienen un comportamiento similar $(p=0.196)$ (Tablas 42 y 43$)$

Tabla 42: Grados de diferenciación tumoral en relación con la SG.

\begin{tabular}{|c|c|c|c|c|c|}
\hline $\begin{array}{c}\text { Grado } \\
\text { Tumoral }\end{array}$ & N & Eventos & $\begin{array}{c}\text { SG } \\
\text { a } 60 \text { meses }\end{array}$ & $\begin{array}{c}\text { Mediana SG } \\
\text { (meses) }\end{array}$ & p-valor \\
\hline Grado I & 18 & 2 & $100 \%$ & $228.5(71-386)$ & $p=0.018$ \\
Grado II & 51 & 10 & $92.2 \%(83.6-100)$ & $140.5(115.3-165.7)$ & $p$ \\
Grado III & 74 & 29 & $73.4 \%(62.4-84.4)$ & $121.5(74.5-18.5)$ & \\
\hline
\end{tabular}

No se dispone del grado tumoral de 7 pacientes 
Tabla 43: Impacto del grado tumoral en la SG (Grado I y II agrupados)

\begin{tabular}{|c|c|c|c|c|c|}
\hline $\begin{array}{c}\text { Grado } \\
\text { Tumoral }\end{array}$ & $\mathrm{N}$ & Eventos & $\begin{array}{c}\text { SG } \\
\text { a } 60 \text { meses }\end{array}$ & $\begin{array}{c}\text { Mediana SG } \\
\text { (meses) }\end{array}$ & p-valor \\
\hline Grado I-II & 69 & 12 & $94 \%(87.7-100)$ & $228(71.9-385.1)$ & \\
Grado III & 74 & 29 & $73.4 \%(62.4-84.4)$ & $121.5(74.5-168.5)$ & $\mathbf{p = 0 . 0 0 7}$ \\
\hline
\end{tabular}

No se dispone del grado tumoral de 7 pacientes

\subsubsection{Receptores hormonales}

En nuestra muestra, la expresión de RH por parte del tumor, no afecta la SG a 60 meses de las pacientes con cáncer de mama en estadios tempranos (Tabla 44). Como se comentó anteriormente, todas las pacientes con expresión tumoral de RE, recibieron tratamiento hormonal adyuvante.

Tabla 44: Impacto de los receptores hormonales del tumor en la SG

\begin{tabular}{|c|c|c|c|c|c|}
\hline $\begin{array}{c}\text { Receptores } \\
\text { Hormonales } \\
(\mathrm{RH})\end{array}$ & $\mathrm{N}$ & Eventos & $\begin{array}{c}\text { SG } \\
\text { a } 60 \text { meses }\end{array}$ & $\begin{array}{c}\text { Mediana SG } \\
\text { (meses) }\end{array}$ & $\mathrm{p}$-valor \\
\hline RH negativos & 47 & 16 & $76.9 \%(64.4-89.4)$ & - & $\mathrm{p}=0.653$ \\
RH positivos & 96 & 29 & $89.1 \%(81.8-96.4)$ & $132.5(103.5-161.5)$ & \\
\hline
\end{tabular}

No se dispone de los datos de $\mathrm{RH}$ de 20 pacientes

\subsubsection{HER2}

La sobreexpresión tumoral de HER2 se muestra como un factor pronostico de SG, ya que el $86 \%$ de las pacientes con tumores HER2 negativo y el $71 \%$ de las pacientes con tumores que sobreexpresaban HER2 estaban vivas a los 60 meses $(p=0.016)$ (tabla 45). Ninguna de las pacientes con amplificación de HER2 recibió trastuzumab de forma adyuvante o neoadyuvante. 
Tabla 45: Efecto de la sobreexpresión de HER2 sobre la SG

\begin{tabular}{|c|c|c|c|c|c|}
\hline HER2 & N & Eventos & $\begin{array}{c}\text { SG } \\
\text { a } 60 \text { meses }\end{array}$ & $\begin{array}{c}\text { Mediana SG } \\
\text { (meses) }\end{array}$ & $p$-valor \\
\hline HER2 negativo & 77 & 18 & $86.3 \%(77.9-94.7)$ & $143(-)$ & $p=0.016$ \\
HER2 positivo & 29 & 13 & $71.1 \%(54.6-88.2)$ & $99.5(56.1-142.9)$ & \\
\hline
\end{tabular}

Se desconocen los datos de sobreexpresión de HER2 en 43 paciente

\subsubsection{XRCC3Thr241Met, XRCC1Arg399GIn y XPDLys751GIn en relación con SG}

En la tabla 46 se muestran los datos de SG en relación a la distribución de los diferentes genotipos de los SNP estudiados. Se observa que los individuos que portan la variable XRCC3Met241Met, presentan una SG a los 60 meses de $96.2 \%$ vs $81.4 \%$ en las pacientes homocigotas o heterocigotas para $\operatorname{Thr}(p=0.022)$

Tabla 46: SG en relación con las variantes de XPDLys751Gln, XRCC1Arg399GIn y XRCC3Thr241Met

\begin{tabular}{|c|c|c|c|c|c|}
\hline Genotipo & $\mathrm{N}$ & Eventos & SG a 60 meses & $\begin{array}{c}\text { Mediana de SG } \\
\text { ( a } 60 \text { meses) }\end{array}$ & p-valor \\
\hline $\begin{array}{r}\text { XPDLys751GIn } \\
\text { Lys/Lys } \\
\text { Lys/GIn + GIn/GIn } \\
\text { Total }\end{array}$ & $\begin{array}{r}66 \\
84 \\
150\end{array}$ & $\begin{array}{l}21 \\
32\end{array}$ & $\begin{array}{r}79.6 \%(69-90.2) \\
87.1 \%(79.5-94.7)\end{array}$ & $\begin{array}{l}143.5(107-180) \\
134(109-159.1)\end{array}$ & $p=0.902$ \\
\hline $\begin{array}{r}\text { XRCC1Arg399GIn } \\
\text { Arg/Arg } \\
\text { Gln/GIn + GIn/Arg } \\
\text { Total }\end{array}$ & $\begin{array}{r}60 \\
90 \\
150\end{array}$ & $\begin{array}{l}16 \\
37\end{array}$ & $\begin{array}{l}92.4 \%(85.2-99.6) \\
78.4 \%(69.4-87.4)\end{array}$ & $\begin{array}{r}146.5(124-168.8) \\
129.5(105.6-153.4)\end{array}$ & $p=0.268$ \\
\hline $\begin{array}{r}\text { XRCC3Thr241Met } \\
\text { Met/Met } \\
\text { Thr/Thr + Thr/Met } \\
\text { Total }\end{array}$ & $\begin{array}{r}26 \\
124 \\
150\end{array}$ & $\begin{array}{r}5 \\
48\end{array}$ & $\begin{array}{l}96.2 \%(88.8-100) \\
81.4 \%(74.1-88.7)\end{array}$ & 124.5(112.8-136.2) & $p=0.022$ \\
\hline
\end{tabular}


Por lo tanto, en el análisis univariante, solamente XRC3Met241Met, la afectación ganglionar axilar, el grado de diferenciación tumoral y la expresión de HER2 lograron la significación estadística, (XRCC3Thr241Met $p=0.022$, afectación ganglionar 0.023, grado tumoral $p=0.007$ y expresión de HER $2 p=0.016$ ).

El análisis multivariante se realizó mediante un modelo de Regresión de Cox, y en él sólo se incluyeron las variables con un valor de significación $p \leq 0.05$. Tras el análisis, solamente el grado histológico mantuvo la significación como variable pronóstica independiente $(p=0.022)$, aunque la afectación ganglionar axilar rozó la significación con un valor de p de 0.059 y XRCC3Thr241Met no se confirmó como variable independiente $(p=0.09)$. El Hazard Ratio para el grado de diferenciación tumoral III fue 2.26 (IC95\% 1.13 - 4.55).

\subsubsection{ANALISIS DE SUPERVIVENCIA EN PACIENTES TRATADAS CON ANTRACICLINAS EN ADYUVANCIA O NEOADUVANCIA}

Se han descrito múltiples actividades biológicas de las antraciclinas, entre las que destaca su capacidad para intercalarse entre los pares de bases adyacentes de ADN y fijarse con intensidad diversa. Esta acción modifica las propiedades del ADN, pero por sí misma no es suficiente para ejercer su acción citotóxica. Una de las actividades críticas es la inhibición de la Topoisomerasa II (Topo II). Esta encima, provoca cortes transitorios de una o de las dos cadenas de ADN, provocando el desenrrollamiento de la doble hélice y facilitando así los proceso de síntesis y transcripción del ADN. Las antraciclinas se fijan al complejo ADN-Topoll, estabilizándolo, lo que facilita la rotura tanto de las cadenas sencillas y dobles del ADN. Además, las antraciclinas forman radicales libres por reducción encimática, provocando nuevos daños en la cadena del ADN. Las antraciclinas también pueden alterar la membrana, inhibir la fosforilación oxidativa de las mitocondrias e inhibir diversas encimas reparadoras de ADN y ARN ${ }^{190}$.

La capacidad de reparación de estas lesiones por parte de la célula tumoral podría estar en relación con la resistencia y sensibilidad a este tipo de drogas. La presencia de determinadas variantes de los genes encargados de esta función, sobre todo de aquellos que intervienen en la reparación de roturas de ADN sencillas o de doble cadena, podrían influenciar la respuesta a estos fármacos. 
De las 150 pacientes con enfermedad local, 84 recibieron tratamiento con antraciclinas, 70 de forma adyuvante y 14 en neoadyuvancia. Los esquemas empleados se recogen en la tabla 17. La quimioterapia pre y postoperatoria presentan tasas de supervivencia comparables ${ }^{180}$, por lo que para el análisis de SLE y SG se han analizado de forma conjunta.

En nuestro estudio, hemos analizado tanto la supervivencia libre de enfermedad como la supervivencia global como marcadores de la efectividad de estos fármacos.

\subsubsection{SLE en pacientes tratadas con antraciclinas en adyuvancia o neoadyuvancia}

El 60.2\% (IC:49.4-71) de las 84 pacientes que recibieron tratamiento quimioterápico con esquemas basados en antraciclinas estaba libre de enfermedad a los 60 meses, con una mediana de SLE de 75.5 meses (IC: 54.2-96.8)

En la tabla 47 se refleja como las variantes XRCC1Arg399Arg y XRCC3Met241Met, se asocian con una mayor SLE.

Tabla 47: SLE en relación con las variantes de XPDLys751GIn, XRCC1Arg399GIn y XRCC3Thr241Met en pacientes no metastásicas tratadas con antraciclinas

\begin{tabular}{|c|c|c|c|c|c|}
\hline Genotipo & $\mathrm{N}$ & Eventos & SLE & $\begin{array}{c}\text { Mediana SLE } \\
\text { (60 meses) }\end{array}$ & $p$-valor \\
\hline \multicolumn{6}{|l|}{ XPDLys751GIn } \\
\hline Lys/Lys & 34 & 12 & $69 \%(52.9-85.1)$ & $111.5(50.5-164)$ & $n=0276$ \\
\hline Lys $/ G \ln +G \ln / G \ln$ & 50 & 27 & $54.4 \%(40.3-68.5)$ & $69.5(46-92.8)$ & $p=0.216$ \\
\hline Total & 84 & 39 & & & \\
\hline \multicolumn{6}{|l|}{ XRCC1Arg399GIn } \\
\hline Arg/Arg & 32 & 6 & $84 \%(71.1-92.9)$ & $84.5(64.7-103-5)$ & $n=0007$ \\
\hline $\mathrm{Gln} / \mathrm{Gln}+\mathrm{G} \ln / \mathrm{Arg}$ & 52 & 33 & $46.3 \%(32.2-60.4)$ & $48.5(19.1-77.9)$ & $p=0.001$ \\
\hline Total & 84 & 39 & & & \\
\hline \multicolumn{6}{|l|}{ XRCC3Thr241Met } \\
\hline Met/Met & 13 & 3 & $80.8 \%(56.1-100)$ & ـ & $\mathrm{p}=0.049$ \\
\hline Thr/Thr + Thr/Met & 71 & 36 & $56.3 \%(44.1-68.5)$ & $69.5(36.6-102.4)$ & \\
\hline Total & 84 & 39 & & & \\
\hline
\end{tabular}




\section{Resultados}

Para completar el análisis univariante, se se analizó el impacto de los factores pronósticos clásicos en la SLE de este grupo de pacientes (Tablas 48 a 52). En nuestra muestra, solamente la afectación ganglionar axilar y el tamaño tumoral tienen impacto sobre la supervivencia libre de progresión o evento. Ambas variables que fueron incluidas en el análisis multivariante para tratar de determinar si existía algún grado de interrelación entre los factores pronósticos clásicos y XRCC1Arg399Arg y XRCC3Thr241Met.

Tabla 48: Afectación ganglionar axilar y SLE en pacientes con enfermedad temprana tratadas con antracilinas

\begin{tabular}{|c|c|c|c|c|c|}
\hline Afectación axilar & N & Eventos & $\begin{array}{c}\text { SLE } \\
\text { a } 60 \text { meses }\end{array}$ & $\begin{array}{c}\text { Mediana SLE } \\
\text { (meses) }\end{array}$ & $p$-valor \\
\hline Ganglios - & 25 & 5 & $79.6 \%(63.5-95.7)$ & - & $\mathrm{p}=0.003$ \\
Ganglios + & 57 & 34 & $49.5 \%(35.5-63.5)$ & $50.5(22.3-78.7)$ & \\
\hline
\end{tabular}

No se dispone de los datos de afectación ganglionar axilar de 2 pacientes

Casi la mitad de las pacientes con afectación de los ganglios axilares presentaron progresión o evento en los 60 meses siguientes al diagnóstico, frente al $20 \%$ en las pacientes con ganglios negativos. Esta diferencia fue estadísticamente significativa $(p=0.003)$. (Tabla 48)

La SLE a 60 meses y la mediana de SLE son inversamente proporcionales al tamaño tumoral, tal y como se muestra en la tabla $49(p=0.001)$.

Tabla 49: Tamaño tumoral en relación con la SLE en pacientes con enfermedad temprana tratadas con antracilinas

\begin{tabular}{|c|c|c|c|c|c|}
\hline $\begin{array}{c}\text { Tamaño } \\
\text { Tumoral }\end{array}$ & N & Eventos & $\begin{array}{c}\text { SLE } \\
\text { a } 60 \text { meses }\end{array}$ & $\begin{array}{c}\text { Mediana SLE } \\
\text { (meses) }\end{array}$ & $p$-valor \\
\hline$\leq 2 \mathrm{cms}$ & 25 & 8 & $75 \%(57.6-92.4)$ & - & $\mathrm{p}=\mathbf{0 . 0 0 1}$ \\
$>2-\leq 5 \mathrm{cms}$ & 51 & 26 & $58.5 \%(43.6-73.4)$ & $69.5(48.1-90.9)$ & \\
$>5 \mathrm{cms}$ & 8 & 6 & $25 \%(0.5-55)$ & $18.5(14.5-25.5)$ & \\
\hline
\end{tabular}


Resultados

En cambio, no se observa ninguna diferencia en relación con el grado tumoral, o la expresión de receptores hormonales y HER2 por parte del tumor (Tablas 50, 51 y 52 respectivamente)

Tabla 50: Grado tumoral en relación con la SLE en pacientes no mestastásicas tratadas con antraciclinas

\begin{tabular}{|c|c|c|c|c|c|}
\hline $\begin{array}{c}\text { Diferenciación } \\
\text { tumoral }\end{array}$ & $\mathrm{N}$ & Eventos & $\begin{array}{c}\text { SLE } \\
\text { a } 60 \text { meses }\end{array}$ & $\begin{array}{c}\text { Mediana SLE } \\
\text { (meses) }\end{array}$ & $p$-valor \\
\hline Grado I-II & 32 & 10 & $68.4 \%(49-87.8)$ & - & $p=0.118$ \\
Grado III & 47 & 26 & $58.2 \%(43.5-72.9)$ & $69.5(36.1-102.9)$ & \\
\hline
\end{tabular}

Se desconocen los datos de grado tumoral de 5 pacientes

Tabla 51: RH en relación con SLE en pacientes no metastásicas tratadas con antraciclinas

\begin{tabular}{|c|c|c|c|c|c|}
\hline $\begin{array}{c}\text { Diferenciación } \\
\text { tumoral }\end{array}$ & $\mathrm{N}$ & Eventos & $\begin{array}{c}\text { SLE } \\
\text { a } 60 \text { meses }\end{array}$ & $\begin{array}{c}\text { Mediana SLE } \\
\text { (meses) }\end{array}$ & $\mathrm{p}$-valor \\
\hline RH negativo & 31 & 13 & $65.3 \%(47.9-82.7)$ & $70(38.4-102.6)$ & $\mathrm{p}=0.64$ \\
RH positivo & 50 & 21 & $62.7 \%(48-77.4)$ & $84.5(45.9-123.1)$ & \\
\hline
\end{tabular}

Tabla 52: Expresión de HER2 en relación con SLE en pacientes no metastásicas tratadas con antraciclinas

\begin{tabular}{|c|c|c|c|c|c|}
\hline $\begin{array}{c}\text { Expresión } \\
\text { de HER2 }\end{array}$ & $\mathrm{N}$ & Eventos & $\begin{array}{c}\text { SLE } \\
\text { a } 60 \text { meses }\end{array}$ & $\begin{array}{c}\text { Mediana SLE } \\
\text { (meses) }\end{array}$ & $p$-valor \\
\hline $\begin{array}{c}\text { HER2 } \\
\text { negativo }\end{array}$ & 51 & 20 & $69.2 \%(56.1-95.4)$ & $75.5(47-104)$ & $p=0.107$ \\
$\begin{array}{c}\text { HER2 } \\
\text { positivo }\end{array}$ & 20 & 10 & $51.1 \%(27.6-74.6)$ & $70.5(17.1-123.9)$ & \\
\hline
\end{tabular}


Para el análisis multivariante, realizado mediante un modelo de riesgos proporcionales de Cox, se consideraron únicamente las variables que habían alcanzado el valor de significación deseado a priori ( $p \leq 0.05)$, por lo que se incluyeron XRCC1Arg399Arg, XRCC3Met241Met, el tamaño tumoral y la afectación ganglionar axilar. Solamente XRCC1Arg399Arg y el tamaño tumoral mantienen la significación estadística ( $p=0.035$ y 0.002 , respectivamente). El Hazard Ratio para XRCC1Arg399Arg es 0.4 (IC95\% 0.2-0.9), y 2.5 para el tamaño tumoral $>5 \mathrm{cms}$ (IC95\% 1.41 4.43)

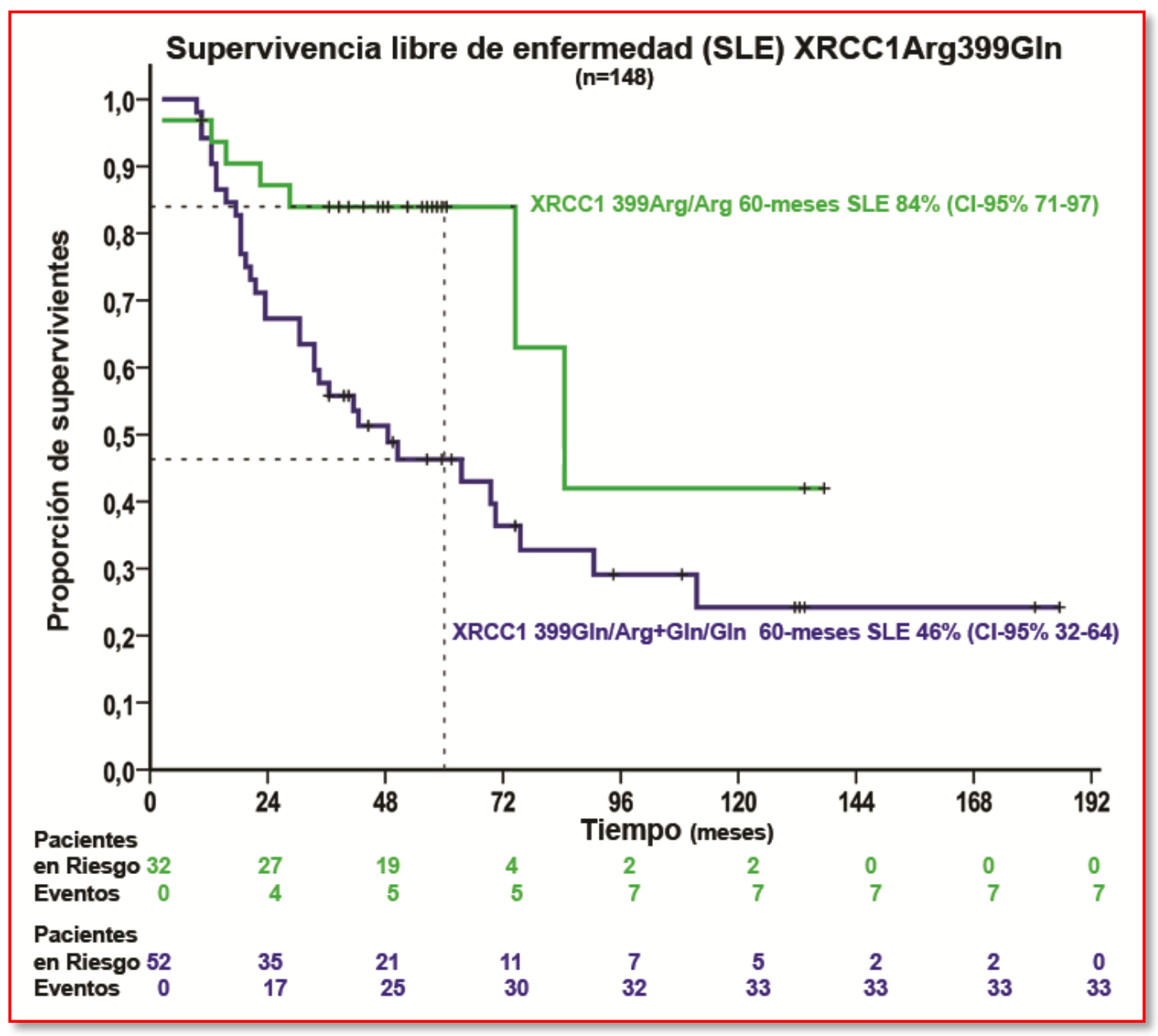

Figura 25: SLE en las pacientes que recibieron antraciclinas en adyuvancia en relación con XRCC1Arg399GIn 


\subsubsection{SG en las pacientes tratadas con antracilinas en adyuvancia o neoadyuvancia}

De las 84 pacientes que recibieron tratamiento adyuvante 0 neoadyuvante con antraciclinas, el 73.7\% (63.5-83.89) de ellas seguía con vida a los 60 meses. La mediana de SG fue 97.5 meses (IC: 53-141).

La tabla 53 muestra que las pacientes portadoras de XRCC3Met241Met presentan una SG más prolongada que aquellas que presentan las variantes Thr/Thr y Thr/Met $(p=0.027)$

Tabla 53: SG en relación con las variantes de XPDLys751GIn, XRCC1Arg399GIn y XRCC3Thr241Met en pacientes con enfermedad temprana tratadas con antraciclinas

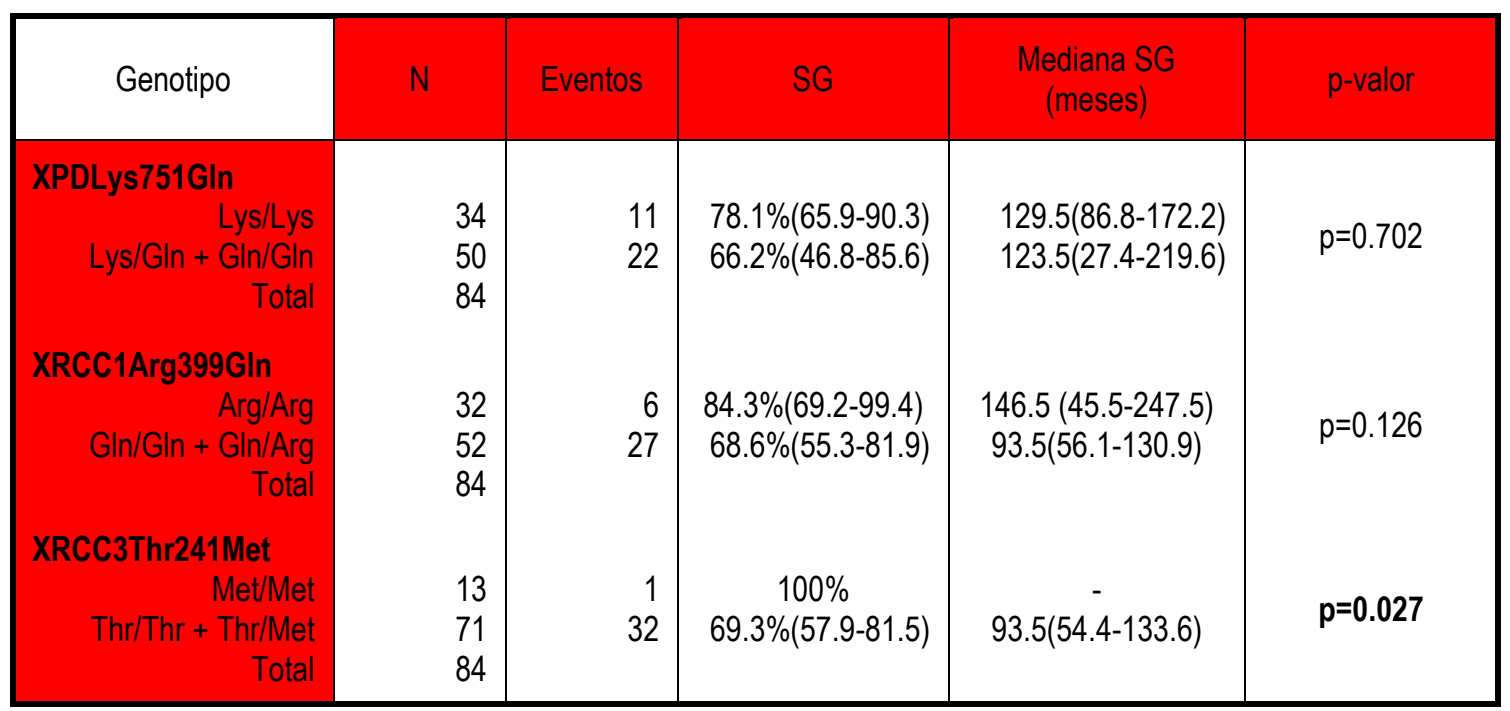

En las tablas 54 a 58 se muestra la relación entre la SG y los factores pronósticos clásicos. Solamente el tamaño tumoral y la expresión de HER2 tienen algún impacto en la SG en las pacientes de nuestra muestra $(p=0.005$ y 0.006 , respectivamente)

Tabla 54: Afectación ganglionar axilar en relación con la SG en las pacientes no metastásicastratadas con antracilinas

\begin{tabular}{|c|c|c|c|c|c|}
\hline $\begin{array}{c}\text { Afectación } \\
\text { axilar }\end{array}$ & N & Eventos & $\begin{array}{c}\text { SG } \\
\text { a } 60 \text { meses }\end{array}$ & $\begin{array}{c}\text { Mediana SG } \\
\text { (meses) }\end{array}$ & $p$-valor \\
\hline Ganglios - & 25 & 5 & $79.4 \%(63.3-95.5)$ & - & $p=0.161$ \\
Ganglios + & 57 & 28 & $71.4 \%(58.5-84.3)$ & $93.5(78.3-108.7)$ & \\
\hline
\end{tabular}

No se dispone de los datos de afectación ganglionar axilar de 2 pacientes 
Resultados

Tabla 55: Tamaño tumoral en relación con la SG en pacientes no metastásicas tratadas con antracilinas

\begin{tabular}{|c|c|c|c|c|c|}
\hline $\begin{array}{c}\text { Tamaño } \\
\text { Tumoral }\end{array}$ & $\mathrm{N}$ & Eventos & $\begin{array}{c}\text { SG } \\
\text { a } 60 \text { meses }\end{array}$ & $\begin{array}{c}\text { Mediana SG } \\
\text { (meses) }\end{array}$ & p-valor \\
\hline$\leq 2 \mathrm{cms}$ & 25 & 7 & $73.9 \%(53-94.8)$ & $123.5(-)$ & \\
\hline$>2-\leq 5 \mathrm{cms}$ & 51 & 19 & $78.6 \%(66.1-91.1)$ & $132.5(63.9-201)$ & $\mathbf{p}=\mathbf{0 . 0 0 5}$ \\
$>5 \mathrm{cms}$ & 8 & 6 & $45 \%(8.2-81.8)$ & $57.5(40.3-74.7)$ & \\
\hline
\end{tabular}

Tabla 56: Grado tumoral en relación con la SG en pacientes no mestastásicas tratadas con antraciclinas

\begin{tabular}{|c|c|c|c|c|c|}
\hline $\begin{array}{c}\text { Diferenciación } \\
\text { tumoral }\end{array}$ & $\mathrm{N}$ & Eventos & $\begin{array}{c}\text { SLE } \\
\text { a } 60 \text { meses }\end{array}$ & $\begin{array}{c}\text { Mediana SLE } \\
\text { (meses) }\end{array}$ & p-valor \\
\hline Grado I-II & 32 & 7 & $87 \%(72.7-100)$ & $123.5(93.1-153.9)$ & \\
Grado III & 47 & 21 & $67 \%(52.7-81.3)$ & $97.5(28-167)$ & $\mathrm{p}=0.270$ \\
\hline
\end{tabular}

Se desconocen los datos de grado tumoral de 10 pacientes

Tabla 57: RH en relación con SG en pacientes no metastásicas tratadas con antraciclinas

\begin{tabular}{|c|c|c|c|c|c|}
\hline $\begin{array}{c}\text { Receptores } \\
\text { Hormonales }\end{array}$ & $\mathrm{N}$ & Eventos & $\begin{array}{c}\text { SG } \\
\text { a } 60 \text { meses }\end{array}$ & $\begin{array}{c}\text { Mediana SG } \\
\text { (meses) }\end{array}$ & p-valor \\
\hline RH negativo & 31 & 12 & $71.5 \%(54.6-88.3)$ & $77.5(25.6-129.4)$ & $p=0.252$ \\
RH positivo & 50 & 17 & $81.2(68.3-94.1)$ & $132.5(78-186.9)$ & \\
\hline
\end{tabular}

Se desconocen los datos de receptores hormonales de 3 pacientes

Tabla 58: Expresión de HER2 en relación con SG en pacientes no metastásicas tratadas con antraciclinas

\begin{tabular}{|c|c|c|c|c|c|}
\hline $\begin{array}{c}\text { Expresión de } \\
\text { HER2 }\end{array}$ & $\mathrm{N}$ & Eventos & $\begin{array}{c}\text { SG } \\
\text { a } 60 \text { meses }\end{array}$ & $\begin{array}{c}\text { Mediana SLE } \\
\text { (meses) }\end{array}$ & p-valor \\
\hline $\begin{array}{c}\text { HER2 } \\
\text { negativo }\end{array}$ & 51 & 15 & $83.2 \%(71.64-94.76)$ & $132.5(84.9-180)$ & $\mathbf{p = 0 . 0 0 6}$ \\
$\begin{array}{c}\text { HER2 } \\
\text { positivo }\end{array}$ & 20 & 10 & $63 \%(41.1-84.9)$ & $71.5(47.6-95.3)$ & \\
\hline
\end{tabular}


En el análisis univariante, solamente XRCC3 Thr241Met, el tamaño tumoral y la expresión de HER2 alcanzaron un nivel de significación de $p<0.05$. Variables pronósticas como la afectación de los ganglios axilares, el grado tumoral o la expresión de receptores hormonales no alcanzaron la significación estadística, con valores de $p \geq 0.2$.

En el análisis multivariante, tanto XRCC3 Met241Met como el tamaño tumoral se mostraron como factores de riesgo independiente en nuestra serie $(p=0.05$ en el caso de XRCC3 Met241Met y $p=0.03$ para el tamaño tumoral).

El Hazard Ratio para XRCC3 Met241Met es 0.15 (IC95\% 0.02-0.99), mientras que para el tamaño tumoral $>5 \mathrm{cms}$ es de 1.8 (1.059 a 3.492)

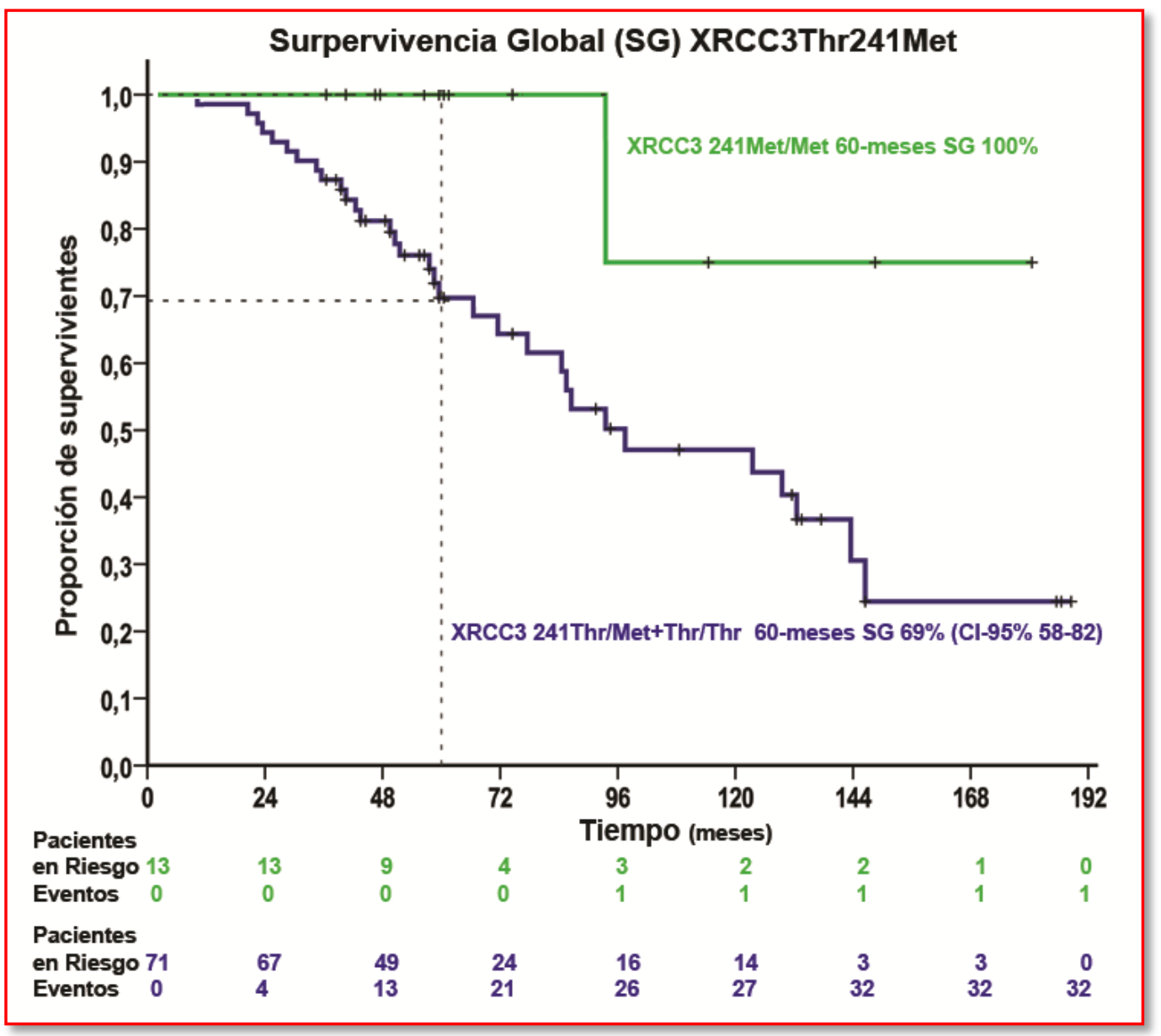

Figura 26: SG de las pacientes tratadas con antraciclinas en adyuvancia según las variantes de XRCC3Thr241Met 


\subsubsection{Pacientes tratadas con antraciclinas en adyuvancia y neoadyuvancia, excluyendo aquellas que recibieron taxanos.}

La adicion de taxanos, con diferentes pautas y secuencias, a los esquemas con antraciclinas, ha demostrado un beneficio adicional en la supervivencia de las pacientes con cancer de mama191,192. Para honmogeneizar la muestra y tener una idea más precisa de lo que podrían suponer las diferentes variables polimórficas del estudio en la respuesta a las antraciclinas, se realizó el análisis de supervivencia excluyendo las 19 pacientes que recibieron tratamiento adyuvante o neoadyuvante con derivados del tejo. El tamaño muestral se reduce con esto a 65 pacientes.

\subsection{Supervivencia Libre de Enfermedad}

El 55.8\% (IC 44.2-67.6\%) de las pacientes seguía libre de enfermedad a los 60 meses. La mediana de supervivencia fue de 69.5 meses (IC 44.5-94.45).

En la tabla 59 se presentan las diferentes variables de los polimorfismos del estudio en relación con la SLE de este grupo de pacientes. Únicamente XRCC1 mostró alguna asociación, presentando las pacientes Arg/Arg una SLE que prácticamente duplica la de las pacientes con las formas Arg/Gln o $\mathrm{Gln} / \mathrm{Gln}(\mathrm{p}=0.021)$.

Tabla 59: SLE en relación con XPDLys751GIn, XRCC1Arg399Gln y XRCC3Thr241Met en pacientes tratadas con antraciclinas y sin taxanos an adyuvancia y neoadyuvancia.

\begin{tabular}{|c|c|c|c|c|c|}
\hline Genotipo & $\mathrm{N}$ & Eventos & SLE & $\begin{array}{c}\text { Mediana SLE } \\
\text { (60 meses) }\end{array}$ & $p$-valor \\
\hline $\begin{array}{r}\text { XPDLys751GIn } \\
\text { Lys/Lys } \\
\text { Lys/GIn + Gln/GIn } \\
\text { Total }\end{array}$ & $\begin{array}{l}25 \\
40 \\
65\end{array}$ & $\begin{array}{l}11 \\
26 \\
37\end{array}$ & $\begin{array}{l}64.2 \%(47.1-81.3) \\
50.5 \%(35.5-65.5)\end{array}$ & $\begin{array}{r}111.5(43.29- \\
179.7) \\
63.5(30.7-96.3)\end{array}$ & $p=0.322$ \\
\hline $\begin{array}{r}\text { XRCC1Arg399GIn } \\
\text { Arg/Arg } \\
\text { GIn/GIn + GIn/Arg } \\
\text { Total } \\
\text { XRCC3Thr241Met } \\
\text { Met/Met } \\
\text { Thr/Thr + Thr/Met } \\
\text { Total }\end{array}$ & $\begin{array}{r}21 \\
44 \\
65 \\
\\
9 \\
56 \\
65\end{array}$ & $\begin{array}{r}6 \\
31 \\
37 \\
\\
3 \\
34 \\
37\end{array}$ & $\begin{array}{c}85.2 \%(69.7-96.5) \\
43.9 \%(29.2-58.6) \\
\\
78.8 \%(53.4-100) \\
51.7 \%(39-64.4)\end{array}$ & $\begin{array}{r}84.5(68.39-100.6) \\
42.5(22.3-62) \\
- \\
63.5(44.5-94.4)\end{array}$ & $p=0.021$ \\
\hline
\end{tabular}


Entre los factores pronósticos clásicos, solamente la afectación ganglionar axilar y el tamaño tumoral mayor de $5 \mathrm{cms}$ ( $p<0.0001$ en ambos casos) tienen impacto sobre la SLE en esta serie (Tablas 60 y 61). Las diferencias que se observan respecto al grado tumoral, y la expresión de receptores hormonales y de HER2 no alcanzan la significación estadística ( $p=0.327, p=0.311$, $p=0.721$, respectivamente).

Tabla 60: Afectación axilar en relación con SLE en pacientes tratadas en neo/adyuvnacia con antracilinas y sin taxanos

\begin{tabular}{|c|c|c|c|c|c|}
\hline $\begin{array}{c}\text { Afectación } \\
\text { axilar }\end{array}$ & N & Eventos & $\begin{array}{c}\text { SG } \\
\text { a } 60 \text { meses }\end{array}$ & $\begin{array}{c}\text { Mediana SG } \\
\text { (meses) }\end{array}$ & $p$-valor \\
\hline Ganglios - & 24 & 5 & $78.9 \%(62.5-95.3)$ & - & P<0.0001 \\
Ganglios + & 39 & 30 & $41.8 \%(26-57.7)$ & $41.5(18.9-64.1)$ & \\
\hline
\end{tabular}

No se dispone de los datos de afectación ganglionar axilar de 2 pacientes

Tabla 61: Tamaño tumoral en relación con SLE en pacientes tratadas en neo/adyuvnacia con antracilinas y sin taxanos

\begin{tabular}{|cr|r|c|c|c|}
\hline $\begin{array}{c}\text { Tamaño } \\
\text { Tumoral }\end{array}$ & N & \multicolumn{1}{|c|}{ Eventos } & $\begin{array}{c}\text { SG } \\
\text { a } 60 \text { meses }\end{array}$ & $\begin{array}{c}\text { Mediana SG } \\
\text { (meses) }\end{array}$ & p-valor \\
\hline$\leq 2 \mathrm{cms}$ & 21 & 8 & $68 \%(46.9-89.2)$ & - & \\
$>2-\leq 5 \mathrm{cms}$ & 39 & 22 & $58 \%(42.3-73.3)$ & $69.5(47.2-91.8)$ & $\mathbf{P}<0.0001$ \\
$>5 \mathrm{cms}$ & 5 & 5 & $0 \%$ & $10.5(0.5-20.95)$ & \\
\hline
\end{tabular}

En el análisis multivariante XRCC1Arg399GIn perdió la significación como factor pronóstico independiente $(\mathrm{p}=0.206)$ mientras que el tamaño tumoral y la afectación ganglionar la mantuvieron $(p=0.011, p=0.040)$. La Hazard Ratio para el tamaño tumoral $>5$ cms fue de 2.91 (IC95\% 1.26-6.3) y de 2.91 (IC 95\%: 1.05-8.05) para la positividad ganglionar, para XRCC1AGIn 399GIn fue de 2.24 (IC95\%: 0.65-7.91). 


\subsection{Supervivencia Global}

Durante los 60 meses del seguimiento, fallecieron 17 pacientes, con lo que la SG a 60 meses fue de 72.9\% (IC 62.1-83.7). La mediana de SG fueron 97.5 meses (IC 54.89-140.1)

En la tabla 62 se recogen los datos de SG en relación con los polimorfismos del estudio. El $100 \%$ de las pacientes con XRCC3Met241Met estaban vivas a los 5 años, frente al $68 \%$ de las que presentaban cualquiera de las otras dos variantes.

Tabla 62: SG en relación con XRCC3Thr241Met, XRCC1Arg399GIn y XPDLys751GIn en las pacientes tratadas en neo/adyuvnacia con antraciclinas y sin taxanos.

\begin{tabular}{|c|c|c|c|c|c|}
\hline Genotipo & $N$ & Eventos & $\begin{array}{c}\text { SG } \\
\%(I C 95 \%)\end{array}$ & $\begin{array}{c}\text { Mediana SG } \\
\text { (meses) }\end{array}$ & p-valor \\
\hline $\begin{array}{r}\text { XPDLys751GIn } \\
\text { Lys/Lys } \\
\text { Lys/GIn + GIn/GIn } \\
\text { Total }\end{array}$ & $\begin{array}{l}25 \\
40 \\
65\end{array}$ & $\begin{array}{l}11 \\
20 \\
31\end{array}$ & $\begin{array}{r}60.3 \%(39.6-81) \\
79.5 \%(64.8-94.2)\end{array}$ & $\begin{array}{l}123.5(46.6-200.3) \\
129.5(88.1-170.8)\end{array}$ & $p=0.404$ \\
\hline $\begin{array}{r}\text { XRCC1Arg399GIn } \\
\text { Arg/Arg } \\
\text { GIn/GIn + GIn/Arg } \\
\text { Total } \\
\text { XRCC3Thr241Met } \\
\text { Met/Met } \\
\text { Thr/Thr + Thr/Met } \\
\text { Total }\end{array}$ & $\begin{array}{l}21 \\
44 \\
65\end{array}$ & $\begin{array}{r}6 \\
25 \\
31\end{array}$ & $\begin{array}{c}78.5 \%(58.9-98.1) \\
70.2 \%(56.5-83.9) \\
100 \%(-) \\
69.3 \%(54.8-81.4)\end{array}$ & $\begin{array}{r}146.5(34.2-258.8) \\
93.5(49.1-137.8)\end{array}$ & $p=0.038$ \\
\hline
\end{tabular}

En cuanto a los factores pronósticos clásicos, solamente el tamaño tumoral y la sobreexpresión de HER2 demostraron una significación estadística ( $p=0.003$ y 0.03 , respectivamente) (tablas 63 y 64). La afectación ganglionar axilar que se había mostrado significativa par la SLE no lo es en cuanto a SG a 60 meses $(p=0.222)$. De nuevo, no se detectó ninguna diferencia en función del grado histológico y de la expresión de receptores hormonales del tumor $(p=0.726$ y $p=0.43)$. (Tabla 65) 
Resultados

Tabla 63: Tamaño tumoral y SG en pacientes tratadas con antracilinas y sin taxanos en esquemas neo/adyuvantes

\begin{tabular}{|c|c|c|c|c|c|}
\hline $\begin{array}{l}\text { Tamaño } \\
\text { Tumoral }\end{array}$ & $\mathrm{N}$ & Eventos & $\begin{array}{c}\text { SG } \\
\text { a } 60 \text { meses }\end{array}$ & $\begin{array}{c}\text { Mediana SG } \\
\text { (meses) }\end{array}$ & p-valor \\
\hline$\leq 2 \mathrm{cms}$ & 21 & 7 & $69.6 \%(46.3-92.9)$ & $123.5(47.7-199.3)$ & \\
\hline$>2-\leq 5 \mathrm{cms}$ & 39 & 16 & $80.1 \%(66.8-66.8)$ & $132.5(63.7-201.3)$ & $p=0.005$ \\
\hline$>5 \mathrm{cms}$ & 5 & 5 & $20 \%(0.5-55.1)$ & $50.5(18.3-82.7)$ & \\
\hline
\end{tabular}

No se dispone de los datos del diámetro tumoral en 6 pacientes

Tabla 64: Expresión de HER2 y SG en pacientes tratadas con antraciclinas y sin taxanos en esquemas neo/adyuvantes

\begin{tabular}{|cr|r|c|c|c|}
\hline $\begin{array}{c}\text { Expresión } \\
\text { deHER2 }\end{array}$ & N & Eventos & $\begin{array}{c}\text { SG } \\
\text { a } 60 \text { meses }\end{array}$ & $\begin{array}{c}\text { Mediana SG } \\
\text { (meses) }\end{array}$ & -valor \\
\hline HER2 negativo & 37 & 13 & $82 \%(68.7-95.3)$ & $132(85-179.8)$ & \\
HER2 positivo & 15 & 8 & $66.7 \%(42.8-90.6)$ & $71.5(47.5-95.5)$ & $\mathbf{p = 0 . 0 3 0}$ \\
\hline
\end{tabular}

Se desconocen los datos de HER2 en 13 pacientes

Tabla 65: Afectación axilar y SG en pacientes tratadas con antracilinas y sin taxanos en esquemas neo/adyuvantes

\begin{tabular}{|c|c|c|c|c|c|}
\hline $\begin{array}{l}\text { Afectación } \\
\text { axilar }\end{array}$ & N & Eventos & $\begin{array}{c}\text { SG } \\
\text { a } 60 \text { meses }\end{array}$ & $\begin{array}{c}\text { Mediana SG } \\
\text { (meses) }\end{array}$ & $p$-valor \\
\hline Ganglios - & 24 & 6 & $75.8 \%(59-92.6)$ & - & \\
Ganglios + & 39 & 24 & $70.5 \%(55.8-85.2)$ & $93.5(78.5-108.4)$ & \\
\hline
\end{tabular}

No se dispone de los datos de afectación ganglionar axilar de 2 pacientes

El análisis multivariante se realizó nuevamente mediante regresión de Cox. Todas las variables perdieron la significación estadística en este análisis, incluyendo XRCC3M ( $p=0.052)$. 


\subsection{PACIENTES CON ENFERMEDAD METASTÁSICA}

En 14 pacientes la enfermedad estaba ya diseminada en el momento del diagnóstico y otras 63 desarrollaron metástasis a lo largo del período de seguimiento. El 37\% de estas 77 pacientes seguía con vida a los 60 meses de ser diagnosticadas las metástasis (IC:25.6-48.4), por lo que la supervivencia global desde el diagnostico de las metástasis $\left(\mathrm{SG}_{\mathrm{M}}\right)$ fue de 49 meses (IC:38-60).

Se considera que las pacientes con metástasis de localización ósea, ganglionar, 0 dérmicas, que expresan receptores hormonales, son HER2 negativas y que se presentan con intervalo libre de enfermedad de al menos 2 años tienen mejor pronóstico ${ }^{9}$. En las tablas 66 a 69 se muestra el impacto de estos factores pronósticos en la $S_{G_{M}}$ de nuestra muestra.

Tabla 66: SGM a los 60 meses en relación con la localización de las metástasis

\begin{tabular}{|l|r|r|r|r|r|}
\hline $\begin{array}{l}\text { Localizacion de } \\
\text { metástasis }\end{array}$ & $\mathrm{N}$ & Eventos & $\begin{array}{c}\text { SGM } \\
\text { a } 60 \text { meses }\end{array}$ & $\begin{array}{c}\text { Mediana SGM } \\
\text { (meses) }\end{array}$ & $p$-valor \\
\hline $\begin{array}{l}\text { Óseas, dérmicas } \\
\text { o ganglionares }\end{array}$ & 44 & 32 & $34 \%(18.7-49.3)$ & $49(35.8-62.2)$ & \\
Otras \\
localizaciones
\end{tabular}

No hemos encontrado diferencia en la $\mathrm{SG}_{\mathrm{M}}$ de las pacientes que inicialmente presentaron metástasis óseas, dérmicas o ganglionares respecto a aquellas que las presentaron en otras localizaciones como hígado o pulmón (Tabla 66) 
Tabla 67: SGM a 60 meses en relación con el Intervalo Libre de Enfermedad (ILE) en pacientes metastásicas

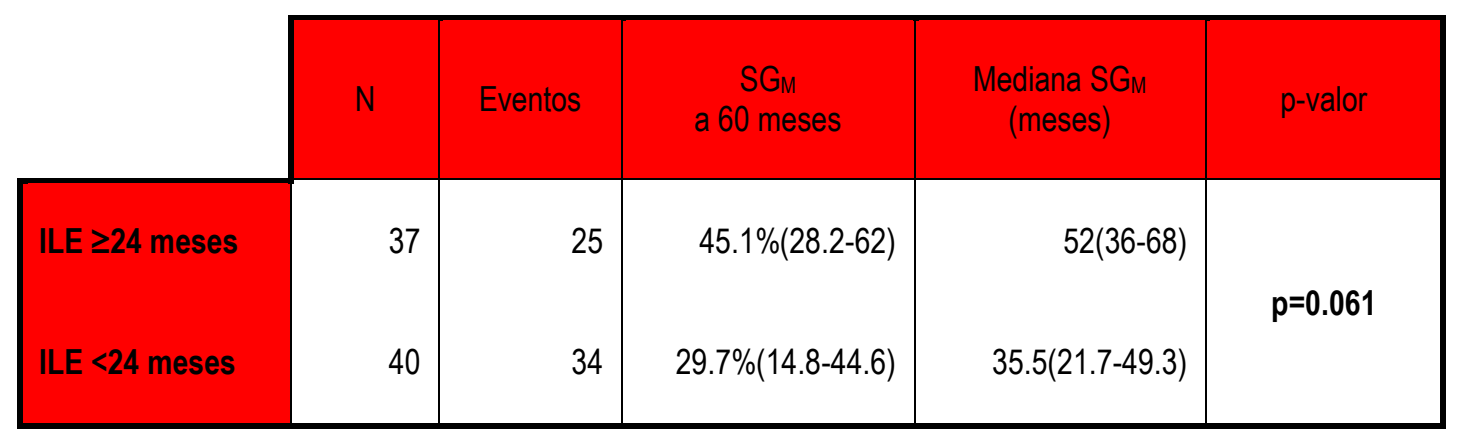

Aunque las pacientes que desarrollaron metástasis pasados dos años tienen mayor $\mathrm{SG}_{\mathrm{M}}$, la diferencia no alcanza la significación estadística, probablemente debido a la dispersión de los datos (Tabla 67)

Tabla 68: SGм a 60 meses en pacientes metastásicas en relación con la expresión tumoral de RH

\begin{tabular}{|c|r|r|r|r|r|}
\hline $\begin{array}{c}\text { Receptores } \\
\text { Hormonales } \\
\text { (RH) }\end{array}$ & N & Eventos & $\begin{array}{c}\text { SGM } \\
\text { a } 60 \text { meses }\end{array}$ & $\begin{array}{c}\text { Mediana SGM } \\
\text { (meses) }\end{array}$ & p-valor \\
\hline RH negativos & 26 & 15 & $31 \%(8-54)$ & $48(20.11-75.6)$ & \\
RH positivos & 47 & 34 & $42.3 \%(26.8-58)$ & $56.5(37.9-75.1)$ & $\mathrm{p}=0.335$ \\
\hline
\end{tabular}

Se desconocen los datos de expresión de $\mathrm{RH}$ de 4 pacientes

La tabla 68 recoge los datos de $S_{G}$ en relación a la expresión de receptores hormonales en el tumor primario. Aunque los tumores con $\mathrm{RH}$ positivos tienden a asociarse con una mayor supervivencia, la diferencia no alcanza la significación estadística $(p=0.035)$.

La $S_{M}$ a 60 meses en las pacientes con tumores HER2 negativos es mayor (38.4\% vs $30.9 \%$ ). La diferencia roza la significación estadística $(p=0.058)$, que nuevamente se ve afectada por la dispersión de los datos y por el hecho de que se desconocen los datos de expresión de HER2 en el $35.8 \%$ de los casos. 
Tabla 69: SG a 60 meses en pacientes metastásicas en relación con la expresión de HER2.

\begin{tabular}{|l|r|r|r|r|r|}
\hline $\begin{array}{c}\text { Expresion de } \\
\text { HER2 }\end{array}$ & $\mathrm{N}$ & Eventos & \multicolumn{1}{c|}{$\begin{array}{c}\mathrm{SG} \\
\text { a } 60 \text { meses }\end{array}$} & \multicolumn{1}{c|}{$\begin{array}{c}\text { Mediana } \mathrm{SG}_{M} \\
\text { (meses) }\end{array}$} & p-valor \\
\hline HER2 negativo & 34 & 22 & $38.4 \%(20.4-56.4)$ & $52(38-66)$ & $\mathbf{p}=\mathbf{0 . 0 5 8}$ \\
HER2 positivo & 18 & 14 & $30.9 \%(6.2-55.6)$ & $31(16.4-45.6)$ & \\
\hline
\end{tabular}

Se desconocen los datos de expresión de HER2 de 25 pacientes.

En la tabla 70 se muestran los datos de $S_{\mathrm{M}}$ en función de los polimorfismos XPDLys751GIn, XRCC1Arg399GIn y XRCC3Thr241Met.

Tabla 70: SGM a 60 meses en pacientes metastásicas en relación con los polimorfismos XPDLys751Gln, XRCC1Arg399Gln y XRCC3Thr241Met.

\begin{tabular}{|c|c|c|c|c|c|}
\hline Genotipo & $\mathrm{N}$ & Eventos & $\begin{array}{c}\mathrm{SG}_{\mathrm{M}} \text { a } 60 \\
\text { meses }\end{array}$ & $\begin{array}{c}\text { Mediana } \mathrm{SG}_{\mathrm{M}} \\
\text { (60 meses) }\end{array}$ & p-valor \\
\hline $\begin{array}{r}\text { XPDLys751GIn } \\
\text { Lys/Lys } \\
\text { Lys/GIn + GIn/Gln } \\
\text { Total }\end{array}$ & $\begin{array}{l}27 \\
50 \\
77\end{array}$ & $\begin{array}{l}21 \\
38\end{array}$ & $\begin{array}{r}15 \%(0-30.1) \\
48.3 \%(34.2- \\
62.4)\end{array}$ & $\begin{array}{r}47(31.9-62.1) \\
56.5(38.5-74.5)\end{array}$ & $p=0.051$ \\
\hline $\begin{array}{r}\text { XRCC1Arg399GIn } \\
\text { Arg/Arg } \\
\text { GIn/GIn + GIn/Arg } \\
\text { Total }\end{array}$ & $\begin{array}{l}23 \\
54 \\
77\end{array}$ & $\begin{array}{l}17 \\
42\end{array}$ & $\begin{array}{l}43.6 \%(22-65.2) \\
34.4(21.1-47.7)\end{array}$ & $\begin{array}{r}55(38.8-71.2) \\
43.5(25.9-61.1)\end{array}$ & $p=0.763$ \\
\hline $\begin{array}{r}\text { XRCC3Thr241Met } \\
\text { Met/Met } \\
\text { Thr/Thr + Thr/Met } \\
\text { Total }\end{array}$ & $\begin{array}{l}10 \\
67 \\
77\end{array}$ & $\begin{array}{r}7 \\
52\end{array}$ & $\begin{array}{r}56.3 \%(27.3- \\
85.3) \\
33 \%(20.8-45.2)\end{array}$ & $\begin{array}{r}48(32.8-63.2) \\
78.5(84-148.6)\end{array}$ & $p=0.073$ \\
\hline
\end{tabular}




\section{DISCUSIÓN}


XRCC3 Thr241Met, XRCC1 Arg399GIn, XPDLys751GIn son Thrs de los polimorfismos presentes en genes reparadores del ADN más ampliamente estudiados, debido a su frecuencia en la población general y a que inducen un cambio en la funcionalidad de la proteína. Si bien se han analizado en relación al riesgo de desarrollar numerosos tumores sólidos, hematológicos e incluso patologías no tumorales, su posible implicación en la respuesta individual al tratamiento es prácticamente desconocida.

En este trabajo, hemos pretendido analizar el papel de XRCC3 Thr241Met, XRCC1 Arg399Gln, XPDLys751Gln en el cáncer de mama, no solo en cuanto a su aportación al riesgo de desarrollar este tipo de tumores, sino también en cuanto a la posibilidad de que estos polimorfismos afecten a la edad de presentación de tumor, o a la respuesta al tratamiento habitual. Para ello lo hemos dividido en dos partes: la primera de ellas es un estudio de asociación en casos y controles, mientras que la segunda es un análisis radio y farmacogenómico en la cohorte de pacientes con cáncer de mama. 


\section{Discusión}

\section{ESTUDIOS DE ASOCIACIÓN EN CASOS Y CONTROLES}

Tal y como se ha señalado, en esta primera parte pretendemos analizar si existe alguna relación entre los polimorfismos de nuestro estudio y el riesgo de desarrollar cáncer de mama.

Existen varios mecanismos para "ratrear" los genes que subyacen a patologías frecuentes, y pueden recogerse en dos grandes grupos: los estudios de gen candidato y los que exploran todo el genoma, conocidos como estudios de genotipado masivo o GWAs (Genome Wide Association studies). Los estudios de asociación en casos y controles como el nuestro se incluyen dentro de la primera categoría, mientras que los mapas de ligamiento y los cada vez más utilizados GWAs se incluyen en la segunda ${ }^{193}$.

Los estudios de asociación en casos y controles comparan la frecuencia de los alelos 0 genotipos de un polimorfismo en ambos grupos. Tienen la ventaja de que son baratos y tienen poder estadístico suficiente para detectar a variantes de baja pentrancia, por lo que han sido y aún son la estrategia más empleada para caracterizar la aportación de uno o varios genes a una enfermedad. Estos estudios son adecuados cuando se tiene una hipótesis biológica o cuando se ha identificado un gen candidato mediante estudios de ligamiento. Se consideran un método de estudio eficaz para establecer las variantes genéticas que subyacen a las patologías complejas 0 poligénicas. Por otro lado, los avances tecnológicos han permitido que estos estudios cedan terreno en favor de los GWAs, en los que se rastrea todo el genoma buscando SNPs que puedan estar asociados a una patología dada, pero sin necesidad de una hipótesis biológica previa. ${ }^{193}$

La crítica que se hace a los estudios de asociación en casos y controles es que con frecuencia sus resultados no pueden ser replicados y las asociaciones que se observan son por lo tanto espúreas. Se ha señalado el pequeño tamaño muestral como la principal causa de esta discrepancias, dado que la mayoría de los estudios incluyen entre 100 y 500 sujetos, y por lo tanto, carecen de poder estadístico suficiente. Esto ha tratado de solventarse con la realización de metaanálisis que incluyen todos los estudios publicados para un determinado SNP, aumentando así el tamaño muestral y la consistencia de los resultados. Pero además, estos análisis sistemáticos han puesto de manifiesto, que los diferentes resultados vertidos por unos y otros estudios obedecen 


\section{Discusión}

en muchos casos a que se han realizado en individuos de etnias diferentes, sugiriendo que los polimorfismos que modifican el riesgo de un tipo de cáncer en un grupo étnico podrían carecer de significado en otro. También se ha observado que en muchos de estos estudios, los grupos caso y control no son comparables para factores que pueden ser muy relevantes en el desarrollo de una patología concreta, como la edad, sexo, raza, etcétera, de modo que las diferencias observadas entre uno y otro grupo no guardan relación con la enfermedad sino con estas otras variables, lo que hace que los estudios sean difícilmente reproductibles. Otra fuente de error, además de la realización de múltiples sub-análisis o de análisis de subgrupos, que pueden conducir a resultados falsamente positivos, es el sesgo de publicación, ya que los estudios con resultados negativos muchas veces no se publican 193 194,195.

Una vez expuestas las limitaciones de los estudios de asociación en general, señalaremos que nuestra muestra es homogénea en cuanto al grupo étnico y al sexo, ya que todos los individuos del estudio son mujeres caucásicas. La muestra para este análisis consta de 174 mujeres diagnosticadas de cáncer de mama y como grupo control, 300 mujeres que no habían presentado ninguna forma de cáncer en el momento en que fueron incluidas en el estudio. Además, las 174 pacientes fueren pareadas por edad ( \pm 3 años) con 174 controles, mientras que las 126 restantes, con edades comprendidas entre los 20 y los 98 años, están únicamente pareadas en función del sexo y la etnia. Sin embargo, es probable que el tamaño de nuestra muestra (174 casos y 300 controles) sea insuficiente para detectar algunas diferencias en las frecuencias de los alelos en ambos grupos.

Otra carencia de nuestro estudio es que a la hora de seleccionar los controles, no se tuvieron en cuenta variables que pueden interferir en el riesgo de desarrollar cáncer de mama, como la duración del periodo fértil, paridad, etc. Destacaremos sin embargo, que de todos las publicaciones revisadas en las que se analizan variantes polimórficas de los genes XRCC3, XPD y XRCC1 en relación con el cáncer de mama, solamente Shore et al196 estratificaron ambos grupos por edad, estado menstrual, menarquía, paridad, toma de anticonceptivos, terapia hormonal sustitutoria, ingesta de alcohol, BMl e historia familiar de cáncer de mama, factores de riesgo para el cáncer de mama. En el resto, casos y controles estaba únicamente pareados en función del sexo y la edad y/o estatus hormonal197-200. 


\section{Discusión}

\subsection{XRCC3 Thr241Met, XRCC1 Arg399GIn, XPDLys751GIn como modificadores del riesgo de cáncer de mama}

Los tres SNPs de nuestro estudio producen un cambio de aminóacido que conlleva una alteración en la función de la proteína, de modo que los individuos portadores de las variantes polimórficas presentan una capacidad de reparación del ADN disminuida. 134,136,151,152,164,166,201-206 XRCC3 Thr241Met, XRCC1 Arg399GIn, XPDLys751GIn han sido analizados en relación con muchos tumores sólidos y hematológicos, incluido el cáncer de mama, con resultados muchas veces contradictorios, debido, probablemente, a las limitaciones de los estudios de asociación anteriormente expuestas $155,198,207-220$. Pero también es posible que estos estudios no sean comparables debido a que los mecanismos de reparación presenten algún tipo de especificidad tisular, no elucidado hasta la fecha, con lo que los polimorfismos tendrían distinto significado en los distintos tumores, lo que explicaría la disparidad de los resultados.

XRCC1 es una proteína fundamental para la reparación mediante escisión de bases (BER). La interacción de XRCC1 y su sustrato facilita la unión del resto de factores de los complejos reparadores y regula la actividad de varias encimas, como la poli-ADPribosa polimerasa1 (PARP1) y la ligasa III. Por otro lado, el factor de transcripción E2F1 regula a XRCC1 y promueve la reparación del $A D N^{131}$. El polimorfismo Arg399GIn se localiza junto a la región BRCT1, lugar de unión de PARP1, y la sustitución de Arginina por Glutamina condiciona un cambio en la conformación tridimensional de la proteína ${ }^{134}$ lo que produce una disminución de su capacidad reparadora151,166,201-203, aunque no está claro si esta pérdida de función se debe a la incapacidad para unirse a PARP1 0 a otro mecanismo

Se ha realizado numerosos estudios de casos y controles para tratar de establecer una posible asociación entre XRCC1Arg399GIn y el cáncer de mama, pero los resultados han sido muy dispares, lo que no permitía extraer una conclusión definitiva. Recientemente se han publicado tres meta-análisis, en los que Gln/Gln se asocia mayor riesgo de cáncer de mama, mientras que Arg/Arg es más frecuente en el grupo control137,141,221. Estos tres estudios también coinciden en al demostrar que esta asociación es más fuerte en población asiática $\left(\mathrm{OR}=1.49^{137}, 1.59^{141}\right.$, y 1.26221 que en la población caucásica $(\mathrm{OR}=1.08)^{221}$. Nuestros resultados son consistentes con estos tres meta-análisis ya que encontramos que Arg/Arg es más frecuente en el grupo control mientras que 


\section{Discusión}

Arg/GIn y $G I n / G I n$ lo son en entre las pacientes con cáncer de mama $(p=0.002, O R=1.96, I C 95 \%$ 1.3-3). En nuestra serie, el alelo mutado se asocia a un aumento del riesgo de cáncer de mama.

XRCC3 Thr241Met supone el cambio de Treonina, un aminoácido hidrófilo con un grupo hidroxilo por uno hidrofóbico con un grupo metil-sulfuro, Metionina, ${ }^{222}$ lo que se traduce en una disminución de la función de la proteína y una merma en la capacidad celular de reparar los daños del ADN136,151,152,166,201,202,204,206.

En nuestra serie, no hemos encontrado ninguna diferencia en la frecuencia de los dos alelos de XRCC3 Thr241Met entre el grupo de casos y controles $(p=0.670)$.

Se han publicado múltiples estudios tratando de establecer una posible asociación entre XRCC3 Thr241Met y el riesgo de desarrollar cáncer de mama, nuevamente con resultados contrapuestos, por lo que una vez más, se recurrió al meta-análisis. En el que realizaron Han et al153 se incluyeron 48 estudios de casos y controles en los que se analizaba XRCC3Thr241Met en relación con el riesgo de desarrollar diferentes neoplasias. Se incluyeron 24975 individuos con cáncer, no sólo en la mama sino en cualquier localización y 34209 controles, encontrando que aquellos que homocigotos para el alelo Met, tenían más riesgo de desarrollar cualquier tipo de tumor ( $p=0.008, O R=1.07$ IC95\% 1.02-1.13) y particularmente, cáncer de mama $(p=0.0004$, $\mathrm{OR}=1.14$, IC95\% 1.06-1.23). Lee et al ${ }^{197}$ analizaron los datos de 12 estudios que comprendían en total 574 casos de cáncer de mama y 502 controles, encontrando que el alelo Met se asociaba a un incremento del riesgo, de modo que tanto Met/Met como Met/Thr se asociaban con mayor frecuencia a cáncer de mama ( $O R=1.08, I C 95 \%$ 1-1.17). Economopoulos et al223 realizaron un metaanálisis con 23 estudios donde se incluyeron 20791 pacientes con cáncer de mama y 22237 controles, encontrando que las mujeres Met/Met presentaban mayor riesgo de cáncer de mama (OR=1.073, IC95\% 1.010-1.140), aunque esta diferencia se observaba únicamente en las mujeres de origen no asiático.

XPD interviene en la reparación por escisión de nucleótidos y forma parte del complejo de transcripción BTF2-TFIIH. El cambio de Lisina por Glutamina en la posición 751, se traduce en un cambio conformacional de la proteína ${ }^{164}$ y una disminución de su capacidad reparadora $136,151,201,203$. 


\section{Discusión}

En nuestro estudio, no hemos encontrado ninguna relación entre la frecuencia de los alelos de XPDLys751GIn y cáncer de mama ( $p=0.944)$. De nuevo, los resultados de los estudios que analizan una posible relación entre XPDLys751GIn y cáncer de mama, son discodantes224-229. En un reciente metaanálisis para tratar de elucidar el papel de esta variante, Jiang et al230 incluyeron 21 estudios con un total de 11362 casos y 10622 controles. Encontraron que el alelo Gln se asociaba a un incremento del riesgo de cáncer de mama de 1.05 (IC95\% 1-1.11) en mujeres caucásicas, pero no en asiáticas o afroamericanas $(p=0.28)$.

Por lo tanto, los meta-análisis publicados hasta la fecha han encontrado que XRCC1 399Gln/GIn, XRCC3 241Met/Met y XPD751Gln/GIn se asocian a aumento del riesgo de cáncer de mama en mujeres caucásicas, si bien la magnitud de este impacto es pequeña $(O R=1.08,1.07$ y 1.07, respectivamente), y nuestro estudio no es capaz de detectarlo, excepto en el caso de XRCC1. Se trataría por lo tanto, de variantes de muy baja penetrancia que para incrementar el riesgo de cáncer de mama, precisan de la conjunción de otros factores con los que interactúan o a los que, posiblemente, modulen.

\subsection{XRCC3 Thr241Met, XRCC1 Arg399GIn, XPDLys751GIn en relación con la edad}

La acumulación progresiva de errores en el ADN y en los cromosomas conduce generalmente a la senescencia y muerte de la célula, pero también puede inducir la transformación tumoral y la inmortalidad celular206,231. En las células y en los organismos se observa una acumulación de lesiones en el ADN asociadas la pérdida gradual de funcionalidad y al envejecimiento ${ }^{232}$. Si bien las bases moleculares de este fenómeno no están del todo claras, estas lesiones podrían interferir con la transcripción y detener la replicación, lo cual desencadenaría la muerte 0 la senescencia celular, conduciendo al envejecimiento233,234. Al mismo tiempo, esta misma acumulación de errores en el ADN es también el origen y la característica principal de los tumores. El cancer y el envejecimiento son por lo tanto, las dos caras del daño al ADN235.

El aumento en la incidencia de cáncer que se produce a medida que envejecemos se relacionaría con el acúmulo de lesiones y la diminución o perdida de la capacidad reparadora intrínsecos al proceso de envejecimiento 206,236 . Pero dado que no todos los individuos al envejecer 


\section{Discusión}

desarrollan un cáncer, cabría pensar que aquellos individuos con mejor capacidad de reparar el ADN podrían ser más longevos y, en caso de desarrollar un tumor, hacerlo a edades más tardías.

\subsubsection{Grupo Control}

$\mathrm{Si}$, como hipotetizamos, los individuos con mejor capacidad de reparación alcanzan edades más avanzadas sin desarrollar tumores, cabría esperar que dentro del grupo control los alelos asociados a mejor capacidad de reparación fuesen más frecuentes en las ancianas que en las mujeres jóvenes. Aquellas mujeres con los alelos menos funcionales tendrían más posibilidades de desarrollar alguna forma de cáncer a lo largo de su vida y por lo tanto, abandonarían el grupo control. De este modo, el subgrupo de mujeres que alcanza las últimas décadas de la vida sin cáncer, estaría enriquecido con las variantes con mejor capacidad de reparación.

Con este propósito, junto a las 174 mujeres sanas pareadas por edad con los casos se incluyeron otras 126 , de entre 20 y 98 años, de modo que de las 300 mujeres del grupo control, 25 eran menores de 35 años (8.3\%) y 55 eran mayores de 80 años (18.3\%).

En nuestro estudio, encontramos que en el grupo control los alelos silvestre y mutado de los tres polimorfismos presentan frecuencias similares en todos los grupos de edad, sin que se observe ninguna diferencia entre jóvenes y ancianas, lo cual, anula nuestra hipótesis. El mismo resultado obtuvo Kazimirova ${ }^{204}$, que analizó varios polimorfismos en genes reparadores de ADN en dos poblaciones sanas, una entre los 20-25 años y la otra entre 60-70 encontrando que no había diferencia en la distribución de los polimorfismos, si bien, el grupo de mayor edad, presentaba mayor acumulo de aberraciones cromosómicas que los jóvenes. Esta acumulación de alteraciones genéticas en los individuos ancianos, incluso en aquellos que portan los alelos con mejor capacidad de reparación podría deberse, a que con la edad, se produjese un silenciamiento epigenético de los genes reparadores ${ }^{236,237}$. De ser así, el aumento de la incidencia de cáncer con la edad guardaría más relación con el propio fenómeno de envejecimiento que con la capacidad de reparación del $A D N$ que heredamos con el genotipo.

El hecho de que no haya diferencias en la frecuencia de los alelos entre las mujeres jóvenes y ancianas, indica que la mayoría de las portadoras de los alelos con peor capacidad de 


\section{Discusión}

reparación probablemente no desarrollaran ningún cáncer a lo largo de su vida, debido a la baja penetrancia de estos polimorfismos, tal y como se vio anteriormente.

\subsubsection{Casos}

En nuestro estudio encontramos que las pacientes portadoras de la variante XPD 751Lys/Lys habían sido diagnosticadas a edad más tardía que aquellas que portaban los alelos Lys/GIn o GIn/GIn (65.5 vs 58.5 y 58, respectivamente), p=0.001, OR=3.52 (IC95\% 3-5.44), diferencia que se mantiene cuando se analizan en función del estatus hormonal al diagnóstico, donde Lys/Lys es más frecuente entre las mujeres diagnosticadas con cáncer de mama tras la menopausia y $L y s / G l n+G \ln / G \ln$ entre las premenopáusicas.

Tal y como se ha expuesto previamente, XPD751GIn se asocia a una menor capacidad de reparación del ADN si bien, en nuestro estudio no hemos encontrado que se asocie con un mayor riesgo de cáncer de mama y el meta-análisis de Jiang et al230 mostró que esta variante se asociaba a un riesgo de cáncer de mama de 1.05. Pero si bien XPD751GIn no incrementa per se el riesgo de forma significativa, es posible que actúe modulando a otros factores lesivos al permitir que las células acumulen lesiones en su material genético que conduzcan al desarrollo de un tumor de una forma más temprana.

Esta hipótesis podría explicar también lo que observamos para XRCC1Arg399GIn y XRCC3Thr241Met. La mediana de edad de las pacientes portadoras de los alelos con mejor capacidad de reparación (XRCC1399 Arg y XRCC3 Thr) es superior, si bien, no se alcanza la significación estadística (XRCC1 399: Arg/Arg 62.5 años vs Gln/Gln59.5, p=0.645; XRCC3 241: Thr/Thr 62.5 vs Met/Met $58.5 p=0.389$ ).

Nuestros resultados para XPD751GIn contradicen los de otros autores que han analizado polimorfismos en los genes de reparación en relación con estatus hormonal y/o la edad de diagnóstico del cáncer de mama, siendo todos ellos negativos ${ }^{196-199,221}$. Solamente Han et al200 observaron, al igual que nosotros, que las mujeres que portadoras de una o más variantes de riesgo en los genes que intervienen en la reparación del $A D N$, tienen más riesgo de desarrollar cáncer de mama precoz, antes de la menopausia. Silva et al238 encontraron una asociación entre 


\section{Discusión}

cáncer de mama y XRCC1399GIn, pero solo entre aquellas mujeres que habían alcanzado la menopausia después de los 55 años.

El estudio de Silva et al es el único que estratifica a las mujeres en función de la edad en la que alcanzaron la menopausia, mientras que todos los demás dicotomizan la muestra atendiendo al estatus hormonal en el momento del diagnóstico, sin tener en cuenta a qué edad alcanzaron la menopausia. La acción carcinogénica de los estrógenos no solo se debe a inducción de la proliferación celular, sino también mediante daño directo al ADN y el tiempo de exposición a los mismos, se ha relacionado con la incidencia de cáncer de mama. Cuando los diferentes autores analizan la incidencia de cáncer de mama en pre o postmenopáusicas en relación con variantes de reparación del ADN generalmente tratan de establecer si esos polimorfismos reparan mejor o peor las lesiones secundarias a estrógenos. En tal caso, se debería hacer una recogida exhaustiva de todos aquellos factores que determinan la exposición a estas hormonas, tales como edad de la menarquía, menopausia, factores reproductivos, etc. La falta de estos datos, hace que las conclusiones de estos estudios deban tomarse con cautela. Sin el análisis de estas variables es posible que, cuando hablamos de cáncer en mujeres pre o postmenopáusicas, no estemos refiriéndonos a una medida del daño mediado por estas hormonas, sino estableciendo únicamente un punto de corte arbitrario, entorno a los 45-55 años para el análisis de todos aquellos factores que concurren con la exposición estrogénica, como los contaminantes ambientales, o el propio envejecimiento $204,206,237,239,240$. 


\section{ANALISIS RADIO Y FARMACOGENÓMICO DE LAS VARIANTES XRCC3Thr241Met, XRCC1Arg399GIn, XPDLys751GIn EN CÁNCER DE MAMA}

La segunda parte de este trabajo, es un estudio retrospectivo de la cohorte de enfermas con cáncer de mama en el que se analiza la asociación entre estos polimorfismos y la respuesta a los tratamientos radio y quimioterápicos, especialmente en relación con el tratamiento adyuvante basado en antraciclinas.

El tamaño muestral (150 pacientes, de las que 84 recibieron tratamiento con antraciclinas) puede ser insuficiente para extraer conclusiones definitivas, pero puede entenderse como un estudio exploratorio que sin duda debería seguirse de uno de mayor tamaño y, si fuera posible, prospectivo. Por otro lado, la mayoría de estudios publicados hasta la fecha que analizan estos polimorfismos en relación con la respuesta al tratamiento de diferentes tumores sólidos incluyen entre 55 y 175 pacientes.

Para nuestro estudio, se incluyeron pacientes que estaban siendo atendidas en nuestras consultas externas entre diciembre de 2003 y febrero de 2004 y que habían sido diagnosticadas con cáncer de mama entre enero de 1990 y febrero de 2004. Somos conscientes de que en el caso de las pacientes más antiguas existe un sesgo de selección, si bien la mayoría de las pacientes fueron diagnosticadas entre 2003 y 2004.

La mayoría de las pacientes de nuestra serie (70\%) presentaron un CDI, grado II-III, y fenotipo luminal. Debido al tamaño tumoral y a la afectación ganglionar, el 64\% fueron diagnosticadas con un estadio II. La SG de las pacientes no metastásicas fue del $84.2 \%$, con una mediana de 140.5 meses (IC95\% 108-172). La expresión de HER2 no se determinó en el 27\% de la muestra, debido sobre todo a los casos más antiguos, ya que a partir del año 2000 comenzó a estudiarse como factor pronóstico, pero no ha sido hasta la introducción del trastuzumab en la práctica clínica cuando su determinación se ha comenzado a hacerse en todos los casos de forma sistemática. 


\section{Discusión}

Hay que señalar también el alto porcentaje de pacientes mastectomizadas (63\%), de nuevo debido a la antigüedad de los casos, ya que no es hasta los estudios de Fisher y Veronesi en $2002^{241,242}$ que la cirugía conservadora seguida de radioterapia fue considerada práctica habitual por algunos profesionales.

54 pacientes de las 152 que recibieron tratamiento quimioterápico no recibieron antraciclinas, sino CMF (7 pacientes metastásicas y 47 en adyuvancia). La mayoría, habían sido diagnosticadas a principios de los años 90 , antes de los trabajos que demostraron el beneficio de las antraciclinas en adyuvancia ${ }^{174,175}$ pero en aquellas con un diagnóstico posterior se debe a que eran pacientes de bajo riesgo, presentaban comorbilidad cardiaca o edad avanzada.

\subsection{XRCC3Thr241Met, XRCC1Arg399GIn y XPDLys751GIn y radioterapia}

Ya sea sola o en combinación con cirugía y quimioterapia, la radioterapia constituye uno del los pilares del tratamiento oncológico. En el caso del cáncer de mama, es ampliamente utilizada tras la cirugía conservadora, dado que reduce el riesgo de recurrencia local y la combinación de ambas se ha mostrado tan efectiva como la mastectomía, en términos de superviviencia ${ }^{241}$. Su objetivo es el control local del tumor con el menor daño posible sobre el tejido sano circundante y en este sentido, se han producido grandes avances en el campo de la RT que han permitido que la gran mayoría de los pacientes la reciban sin demasiados efectos secundarios, a pesar de lo cual, todavía un $10 \%$ presentan secuelas graves, debidas probablemente a la susceptibilidad individual.

La variabilidad interindividual en el desarrollo de efectos adversos postRT es bien conocida. Existe evidencia de que junto a los factores relacionados con el paciente como la edad, el índice de masa corporal, el hábito tabáquico u otros estilos de vida, estas diferencia que se observan de paciente a paciente tienen también una base genética ${ }^{148,178,179,243-246}$. Las primeras observaciones se realizaron en individuos con mutaciones germinales heredadas en genes de reparación del ADN (Tabla 6). Estos pacientes, diagnosticados con Síndrome de Bloom, Síndrome de Nijmegen, Ataxia Teleangiectasia o Anemia de Fanconi, presentan una alta predisposición al cáncer, y con frecuencia desarrollan efectos secundarios severos tras $\mathrm{RT}^{247}$. Pero aunque estos casos nos dan una noción de la base molecular subyacente a la radiosensibilidad, la escasa 


\section{Discusión}

frecuencia de estas mutaciones $(<0.1 \%)$ no permite explicar lo que se observa en la clínica. Se pensó entonces que la sensibilidad a las radiaciones ionizantes podría estar en relación con la interacción de numerosos polimorfismos de baja penetrancia en genes participantes en diferentes vías celulares como la apoptosis, inflamación, o la reparación del ADN. La identificación de estos polimorfismos es importante porque podrían utilizarse como biomarcadores para predecir la respuesta del tejido normal al tratamiento radioterápico ${ }^{248,249}$.

La radiación ionizante ejerce su efecto citotóxico mediante el daño que induce en ADN, principalmente roturas de cadena doble y sencilla, pero también mediante las alteraciones que los radicales de oxígeno producen en las bases nitrogenadas. Por esta razón se cree que las vías de reparación del ADN deben ser uno de los mecanismos más importantes para defender a la célula de la radiación ionizante y los polimorfismos que alteran la capacidad funcional de estos genes pueden ser uno de los grandes determinantes de las diferencias interindividuales que se observan tanto en la respuesta al tratamiento como en el desarrollo de toxicidades. Puesto que las lesiones que este tipo de radiación produce en el ADN son muy diversas, todos los mecanismos de reparación (BER, NER, MMR y DSBR) han sido ampliamente estudiados en relación con esta modalidad de tratamiento.

Los efectos secundarios de RT se clasifican generalmente en agudos y tardíos. Los primeros son aquellos que se presentan durante 0 en los primeros 90 días desde el fin del tratamiento, mientras que los efectos tardíos son los que se presentan tras meses o incluso años después de finalizado el tratamiento. Los efectos secundarios agudos afectan generalmente a tejidos con un gran recambio celular, como es el caso de la piel o las mucosas, mientras que los efectos secundarios aparecen en tejidos con un turnover más lento. Los efectos agudos pueden ser limitantes de dosis y pueden obligar a suspender un tratamiento administrado con intención curativa. Las reacciones cutáneas agudas pueden variar desde eritema y descamación a necrosis y lesiones ulcerosas. Las lesiones cutáneas tardías que incluyen fibrosis, atrofia, alteraciones de la pigmentación y teleangiectasias, se consideran progresivas e irreversibles. Hay estudios que concluyen que las pacientes que presentan toxicidad aguda severa presentan mayor riesgo de toxicidad tardía250. 


\section{Discusión}

Nosotros no hemos encontrado relación entre el desarrollo de toxicidad aguda o crónica tras el tratamiento con radioterapia y XRCC3Thr241Met, XRCC1Arg399GIn o XPDLys751GIn.

Los estudios publicados hasta la fecha, presentan resultados muy dispares que no permiten extraer conclusiones claras sobre el impacto de estos SNPs en la toxicidad cutánea postradioterapia. En el caso de XPD Lys751GIn, no se ha encontrado ninguna asociación 247,251,252 mientras que para XRCC3Thr241Met, los resultados son más diversos ya que si bien ambos alelos han sido asociados a un mayor riesgo de fibrosis en algunos estudios $148,245,246,248$, otros no han encontrado ningún tipo de asociación $247,252,253$.

Tal y como se comento en la introducción, varios estudios funcionales han demostrado que las líneas celulares portadoras del alelo XRCC1 399GIn son más sensibles a la radiación ionizante ${ }^{135-138,140,254,255}$ que las portadoras del alelo Arg, por lo que este polimorfismo ha sido ampliamente estudiado en relación con la toxicidad secundaria a RT. Aunque la mayoría de los trabajos han sido negativos, ${ }^{247,252,256-258}$ existen otros con resultados totalmente contradictorios. Así, Andreassen et al248 encontraron asociación entre el alelo Arg y toxicidad cutánea tardía, mientras que Giotopulos 259 realizó la misma observación pero para el alelo Gln, en vez de Arg. Mullan et al mostraron que el alelo Gln se asociaba a mayor riesgo de toxicidad cutánea aguda, pero únicamente en combinación con otros SNPs ${ }^{260}$. Por el contrario, este mismo alelo se asoció con menor riesgo de toxicidad aguda en pacientes con índice de masa corporal (IMC) normal, pero no en aquellos con elevado IMC251

Los resultados de todos estos estudios, por lo tanto, no son los suficientemente consistentes como para concluir el posible papel de estos polimorfismos en la toxicidad por radioterapia. Una vez más, el principal motivo que se alega para estas discrepancias es el tamaño muestral. La mayoría de los estudios comprenden menos de 500 pacientes lo que hace que carezcan de poder estadístico para detectar el modesto impacto que estas variantes puedan tener en la sensibilidad individual a la radioterapia 261 . Actualmente está en marcha el proyecto GenPARE (Genetic Predictors of Adverse Radiotherapy Effects) que pretende caracterizar la aportación de polimorfismos en diferentes genes a la radiosensibilidad y por tanto optimizar e individualizar el tratamiento RT de cada paciente 262 . 
La negatividad de nuestros resultados puede deberse a que, efectivamente, no exista asociación entre estos SNPs y la toxicidad secundaria a RT, pero también puede deberse a que el tamaño muestral es pequeño. A pesar de que 112 paciente recibieron RT, para el análisis de la toxicidad aguda solo disponemos de los datos de 86, y de 91 en el caso de la toxicidad crónica. Aquellos casos en los que la toxicidad aguda o crónica no estaba recogida en la historia clínica no fueron considerados para el análisis. Se pone así de manifiesto otro problema: la subjetividad del observador y los múltiples observadores. Dado que las pacientes fueron atendidas por diferentes médicos, es posible que existieran diferencias en la recogida de datos, no solo en cuanto a la gradación de la toxicidad, sino en cuanto a dejar constancia de la misma en la historia clínica.

Otro aspecto que se analizó es si estos polimorfismos guardan alguna relación con el riesgo de recaída local tras radioterapia. Si las células tumorales mantienen el genotipo germinal para estos polimorfismos, es posible que aquellas mujeres portadoras de las variantes polimórficas desarrollasen tumores con una capacidad de reparación disminuida que no les permitiría reparar las lesiones al ADN inducidas por la RT y por tanto el riesgo de recaída local sería menor. Afortunadamente en nuestra serie sólo 12 de las 112 pacientes que recibieron RT recayeron localmente $(10.7 \%)$. No hemos encontrado asociación entre ninguno de los SNPs y la recaída local, pero es posible que debido al escaso número de eventos, aun existiendo una relación, nuestro estudio no sea capaz de detectarla. Por otro lado, no hemos encontrado en la literatura que ningún autor haya comunicado alguna asociación entre estos u otros SNPs en genes reparadores y recaída local.

\subsection{XRCC3Thr241Met, XRCC1Arg399GIn XPDLys751GIn en relación con el tratamiento con antraciclinas en pacientes con cáncer de mama temprano}

Las antraciclinas se aislaron de Streptomices peucetius en la década de 1960 y se han utilizado con éxito durante más de 40 años en el tratamiento de tumores sólidos, leucemias y linfomas. Su mecanismo de acción no está completamente elucidado y aunque parece que su acción citotóxica se debe, principalmente, a la inhibición de la Topoisomerasa II263 también se implican fenómenos como la formación de radicales libres y la peroxidación de los lípidos ${ }^{264-269}$, la unión al ADN, la formación de cross-links y aductos $265,270-272$ o la intercalación en el ADN impidiendo la replicación y transcripción del $\mathrm{ADN}^{273,274}$. La mayoría de estos procesos producen 


\section{Discusión}

roturas de doble cadena en el ADN que inducirían finalmente la muerte celular por apotosis $270,275,276$.

Las topoisomerasas son encimas capaces de modificar la topología de los ácidos nucleicos sin alterar su secuencia y estructura. Intervienen en múltiples procesos que tienen lugar en el núcleo como la replicación, transcripción, condensación/descondensación de los cromosomas remodelado de la cromatina, recombinación y reparación del ADN. Para que las proteínas que intervienen en estas funciones puedan acceder a la doble hélice es preciso que ésta esté desenrollada. Las topoisomerasas guían y catalizan este proceso de apertura, para lo que inducen una rotura transitoria del ADN que se repara una vez se ha desenrollado la doble hélice. Las antraciclinas estabilizan el paso intermedio en el que la cadena de ADN está cortada y covalentemente unida a la topoisomerasa II mediante residuos de tirosina, convirtiendo en permanentes las roturas transitorias del ADN277,278.

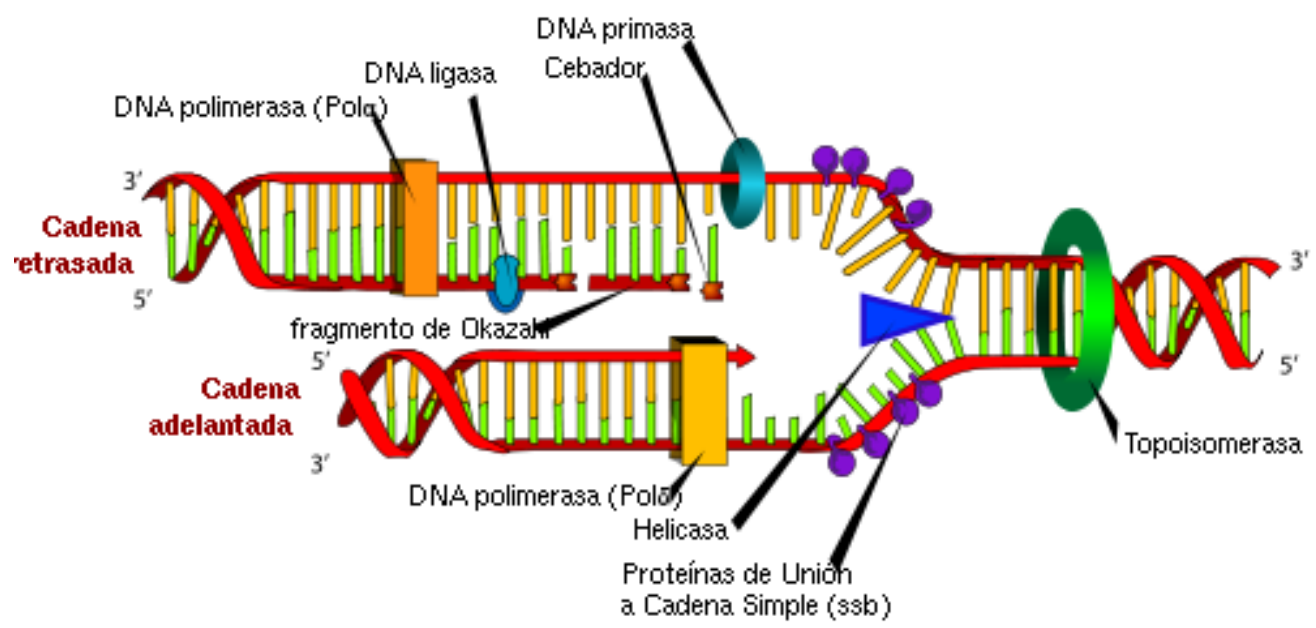

Figura 27: Mecanismo de acción de las topoisomerasas

A pesar del mejor conocimiento de los mecanismos de acción de las antraciciclinas y del desarrollo de nuevos derivados más activos y menos tóxicos, se han producido escasos avances en nuestra capacidad para seleccionar las pacientes con mayor capacidad de respuesta. En los últimos años se ha discutido mucho sobre la expresión tumoral de topoisomerasa II y la respuesta 


\section{Discusión}

a antraciclinas y aunque algunos estudios concluyen que la amplificación del gen de la topoisomerasa se asocia a un mayor beneficio en el tratamiento de pacientes de cáncer de mama con antraciclinas $279-282$, estudios recientes no han podido demostrar esta relación 283. Conceptualmente, es posible que la mayor expresión de Topoll se asocie con una mayor eficacia de las antraciclinas, ya que la droga tendría más sustrato sobre el que actuar, pero que las técnicas que se emplean para determinar la expresión no sean las más adecuadas y no se esté determinado correctamente la expresión de Topoll283.

Los mecanismos de reparación del ADN son imprescindibles para la supervivencia celular y la reparación del daño originado por los agentes citotóxicos, supondrían un mecanismo de resistencia a estos fármacos. Por el contrario, células deficientes en estos mecanismos de reparación serían más sensibles a estas drogas. La dificulta estriba en caracterizar el mecanismo de reparación implicado en las lesiones por antraciclinas.

$\mathrm{Si}$, como hemos visto, estos citotoxicos inducen principalmente roturas de doble cadena en el ADN, la recombinación homóloga tendría un papel clave en la sensibilidad a estos fármacos ${ }^{284}$. Spencer et al285 demostraron que las líneas celulares con déficit de XRCC3, y por tanto con capacidad de recombinación homóloga defectuosa, son 6 veces más sensibles a doxorrubicina, y hasta 100 veces más sensibles a su derivado, barminomicina que las células con los mecanismos de recombinación homóloga intactos. En cambio, no observaron ninguna diferencia entre las células deficientes en XRCC1 y las normales, lo cual tiene sentido dado que este gen interviene en la reparación por escisión de bases (BER), mecanismo que en principio, no repara ni roturas de doble cadena ni adductos de ADN, si bien, como se ha señalado anteriormente, estas vías están muy solapadas. Por otro lado, tanto Spencer como Saffi286 observaron que las células con déficit en XPD son más sensibles al tratamiento con antraciclinas, lo que confiere a NER un papel inesperado en la reparación del daño causado por antraciclinas.

Los estudios descritos se han realizado en líneas celulares con mutaciones deletéreas de XPD, XRCC3 y XRCC1, sin que existan hasta la fecha estudios de sensibilidad a antraciclinas en líneas celulares de cáncer de mama con las variantes XPD751Gln, XRCC3 241Met y XRCC1399GIn. Como se ha mencionado anteriormente, existen estudios funcionales y de conformación de proteínas ${ }^{134,151,164,166,201-203}$ que establecen que estas variantes presentan una 


\section{Discusión}

capacidad de reparación del ADN disminuída. A falta, por lo tanto, de un estudio funcional en líneas celulares, y con lo anteriormente expuesto, solo podemos hipotetizar que las células con una capacidad de reparación de la vía NER subóptima (XPD751GlnGln), pero, fundamentalmente un déficit en la capacidad de Recombinación Homóloga (XRCC3Thr241Met) serían más sensibles a tratamientos basados en antracilinas.

En nuestro trabajo, al igual que en todos los estudios discutidos a continuación, los polimorfismos de la línea germinal se han determinado a partir de ADN obtenido de linfocitos de sangre periférica, asumiendo que no se produce ningún cambio en el tumor.

Encontramos que las pacientes con enfermedad local portadoras de la variante XRCC3 241Met/Met, presentan mayor SG que aquellas que son Met/Thr o Thr/Thr. Cuando se analizan las 150 pacientes con enfermedad temprana, independientemente del esquema de tratamiento, la diferencia en $S G$ es significativa $(p=0.022)$, pero el polimorfismo no es una variable pronóstica independiente $(p=0.09)$. En cambio, cuando se estudia el grupo 84 pacientes que han recibido tratamiento con antraciclinas, la diferencia no solamente es significativa $(p=0.027)$, sino que en el análisis multivariante XRCC3Thr241Met se mantiene como factor pronóstico independiente (Log Rank $p=0.05$ ) HR 0.15 (IC95\% 0.02-0.9). En este grupo, Met/Met se asocia además a una mayor SLE ( $p=0.049$ ), en el análisis univariante, pero no en el multivariante.

Los taxanos en esquemas adyuvantes para pacientes con cáncer de mama en estadios iniciales han demostrado un incremento de la SLE y SG 191,192,287-289, por lo que a partir de los años 90, su uso ha sido cada vez más habitual. Son fármacos que llevan a cabo su acción citotóxica mediante la estabilización de los microtúbulos del huso mitótico y frente a lo cual no se ha descrito que los mecanismos de reparación del ADN en los que intervienen los genes de nuestro estudio tengan ningún papel. No obstante, para conseguir un grupo más homogéneo y eliminar el posible efecto de los taxanos sobre la supervivencia, se realizó un segundo análisis estratificando a las pacientes según hubiesen recibido o no estos fármacos. Esto redujo la muestra a 65 pacientes, con la consiguiente merma del poder estadístico, como demuestra la amplitud de los intervalos de confianza, de modo que aunque XRCC3Thr241Met se mostró nuevamente como factor pronóstico para SG en el análisis univariante, no pudo confirmarse en el multivariante. 


\section{Discusión}

Estos resultados, en los que la variante con capacidad de reparación disminuida (Met/Met) se asocia a mayor supervivencia son, como hemos visto, plausibles desde el punto de vista biológico.

En cuanto a XPDLys751GIn, en nuestro estudio no hemos observado ninguna relación entre este SNP y la SG o SLE en las pacientes con cáncer de mama temprano o metastásico.

De acuerdo con los mecanismos biológicos anteriormente expuestos, cabría esperar que tampoco se observase ninguna diferencia en la supervivencia en relación con XRCC1Arg399GIn, pero en nuestro estudio, observamos que las pacientes Arg/Arg con enfermedad local tratadas con antraciclinas, presentan una SLE más prolongada $(\mathrm{p}=0.022)$ y que este polimorfismo es además un factor pronóstico independiente (Log Rank p=0.035, HR 0.4, IC95\% 0.2-0.9). En el grupo de pacientes que recibieron tratamiento con antraciclinas, pero no con taxanos, Arg/Arg se asocia de nuevo a SLE más prolongada, pero ésta vez en el análisis multivariante, no se confirma como factor pronóstico independiente. Esto podría ser debido a que el menor tamaño muestral resta poder estadístico o a que la observación anterior es espúrea, pero Bewick ${ }^{157}$ obtuvo un resultado similar en pacientes con cáncer de mama metastásico tratadas con mitroxantrone. Así mismo, Yarosh et al 290 observaron que las células tumorales homocigotas para el alelo Gln eran más resistentes que aquellas que eran Arg/Gln o Arg/Arg a varios agentes alquilantes como el busulfán o las sales de platino.

Una vez revisada la bibliografía, no hemos encontrado ningún estudio que analice el posible impacto que XRCC3Thr24Met, XRCC1Arg399GIn o XPDLys751Gln puedan tener sobre pacientes con cáncer de mama en estadios precoces, tratadas con antracilinas. En el estudio arriba mencionado, Bewick et al $^{157}$ estudiaron el impacto sobre la supervivencia de XRCC3Thr24Met, XRCC1Arg399GIn en 95 pacientes con cáncer de mama metastásico tratadas con esquemas basados en mitroxantrone. Contrariamente a lo esperable, las variantes con capacidad de reparación deficiente XRCC1399GIn y XRCC3241Met se asociaban a una menor supervivencia, sin que los autores ofrezcan ninguna explicación o hipótesis.

Rodriguez et 291 al han publicado recientemente una firma de 69 genes relacionados con la reparación del ADN que predice la respuesta a antraciclinas en canceres de mama triple negativo. 


\section{Discusión}

Los tumores con una expresión disminuida de estos genes presentaron respuestas patológicas completas tras tratamientos neoadyuvantes con antraciclinas con mayor frecuencia que aquellos con una expresión normal. XRCC3, XRCC1 y XPD no han sido incluidos en el análisis.

Berwick et al292 estudiaron XRCC3Thr24Met, XRCC1Arg399Gln y XPDLys751GIn en relación con la respuesta a antraciclinas en pacientes diagnosticados de sarcoma de partes blandas. No encontraron ninguna asociación entre estas variantes y la supervivencia tras el tratamiento en los 120 pacientes analizados, si bien la muestra es muy heterogénea y junto a los pacientes tratados con antraciclinas se incluyen otros que recibieron radioterapia o fueron tratados únicamente con cirugía, sin que se haga ningún tipo de estratificación para el análisis de supervivencia.

No hemos encontrado ningún otro estudio que analice variantes polimórficas en genes de reparación del $A D N$ en relación con la respuesta a antraciclinas en cáncer de mama 0 de otras localizaciones. En cambio, existen varios trabajos que analizan estos polimorfismos en relación con esquemas a base de platinos. Estos fármacos producen también roturas de doble cadena y se ha sugerido que la reparación del ADN puede ser uno de los mecanismos de resistencia, por lo que sus resultados podrian, en cierta forma, servir de hipótesis para posteriores estudios en antraciclinas. Chew et al293 estudiaron el impacto sobre la supervivencia de XRCC3Thr241Met y XPDLys751GIn, en 54 pacientes con cáncer de mama metastásico tratadas con gemcitabina y cisplatino. XRCC3 241Met y XPD751GIn se asociaron a una menor supervivencia libre de progresión. Sin embargo, teniendo en cuenta que las pacientes habían recibido mútiples líneas previamente, el pequeño tamaño muestral, y el hecho de que el alelo Met, variante polimórfica de XRCC3 24,1 presente una prevalencia de 0.64 , doble de la que generalmente presenta en otras poblaciones y muy superior a la del alelo wild type (0.36), hace pensar en un posible error en el genotipado o en el recuento de los alelos, de modo que los resultados del estudio deban ser tomados con precaución.

Un estudio similar utilizando gemcitabina y cisplatino en 135 pacientes españoles con cáncer de pulmón de célula no pequeña (CPCNP) 294 , mostró que XRCC3 Thr241 Met es un factor predictor independiente y que los pacientes con el genotipo Met/Met presentaban una mayor SG. En el estudio de Kalikaki et al295 en población griega, 119 pacientes con CPCNP fueron tratados 


\section{Discusión}

con esquemas de quimioterapia con platinos, XRCC1 $399 \mathrm{GlnGln}$ se asoció a una mayor supervivencia, mientras que Sun et al296 no encontraron ninguna asociación entre este

polimorfismo y la respuesta a platinos en pacientes asiáticos con CPCNP estadio IV.

Quintela-Fandiño297 estudió de forma prospectiva los mismos polimorfismos de XRCC1 y XPD en 103 pacientes españoles con tumores de cabeza y cuello localmente avanzado tratados con quimioterapia de inducción basada en cisplatino. Encontró que las variantes polimórficas (XRCC1 399GInGIn y XPD GlnGIn) de ambos genes se asocian a mayor supervivencia y podrían condicionar la respuesta a cisplatinos en este tipo de tumores. Estudios en cultivos de líneas celulares de tumores de cabeza y cuello parecen confirmar que XRCC3Thr241Met y XPDLys751GIn median la sensibilidad a cisplatino ${ }^{158}$.

Ruzzo et al298 no encontraron que ninguno de los polimorfismos de nuestro estudio tuviese impacto sobre la superviviencia de pacientes con cáncer gástrico avanzado tratados cisplatino5FU, mientras que Vangsted et al299 encontraron que XPD751Gln y XRCC3241Met se asocia a mayor tiempo hasta el fallo del tratamiento en pacientes con trasplante autólogo por mieloma múltiple .

Son escasos los estudios farmacogenómicos realizados hasta la fecha con estos polimorfismos y aunque la mayoría apuntan que las variantes XPD751GIn, XRCC1399GIn y XRCC3241Met se asocian a una mejor respuesta a tratamientos que inducen doble rotura del ADN, existen resultados discrepantes. Estas diferencias pueden deberse una vez más al tamaño muestral o a las diferencias étnicas. Por otro lado, es posible que los distintos tejidos empleen diferentes mecanismos de reparación, y por lo tanto, aún tratándose del mismo fármaco, el mecanismo de resistencia de las células tumorales de la mama sean diferentes a las del sarcoma, con los que las conclusiones de los estudios no son extrapolables.

Nuestros resultados y los trabajos anteriormente expuestos sugieren que XRCC3Tre241Met, XRCC1Arg399GIn y XPDLys751GIn podrían estar asociados con la respuesta a agentes quimioterápicos que inducen lesiones de doble cadena en el DNA. Pero estos trabajos están limitados por el tamaño muestral y por el hecho de que en ninguno de ellos se administraron platinos o antraciclinas como agente único, sino siempre en combinación, lo que puede 
enmascarar el efecto real de estas variantes genéticas. La confirmación de la implicación farmacogenómica de estos polimorfismos precisa tanto de estudios funcionales in vitro y/o in vivo, como de estudios prospectivos adecuadamente diseñados ${ }^{300}$. 
CONCLUSIONES 


\section{Conclusiones}

1. El alelo GIn del polimorfismo XRCC1 Arg399GIn es más frecuente en el grupo de pacientes con cáncer de mama que en los controles de nuestra serie, lo que sugiere que la presencia de este alelo podría ser un factor de riesgo para el desarrollo de este tipo de tumores.

2. En nuestra serie, el genotipo Lys/Lys del polimorfismo XPDLys751GIn se asocia con el desarrollo de cáncer de mama a edades más tardías que en las portadoras de las otras dos variantes (Lys/Gln y GLn/Gln). Es posible que XPDLys751Lys module a otros factores de riesgo, retrasando la aparición del cáncer de mama.

3. Ninguno de los polimorfismos estudiados se ha asociado con el riesgo de desarrollar toxicidad cutánea aguda o tardía tras el tratamiento radioterápico.

4. En nuestra serie, las variantes de XRCC3Thr241Met y XRCC1Arg399GIn se asocian con diferente pronóstico, probablemente en relación con la capacidad de reparar las lesiones de doble cadena del ADN inducidas por antraciclinas. Esto podría tener implicaciones farmacogenómicas al seleccionar el tratamiento más adecuado para las pacientes con cáncer de mama en estadios tempranos. 
SUMMARY 


\section{INTRODUCTION}

\subsection{Epidemiology}

Breast cancer is the most common cancer among women in the Western world. Incidence and mortality varies from one country to another, with the greatest incidence observed in North America, Australia, Scandinavia, Western Europe and Argentina. Data presented by the European Union Directorate General for Health and Consumers in 2010 demonstrate breast cancer is the commonest form of cancer among European women, as it represents $30 \%$ of all the new cases of cancer in women and it is also the main cause of cancer-related death among women younger than 75 years across the European Union. In Spain, 16000 new cases are diagnosed every year, affecting one in thirteen women, and causes 6000 deaths a year. Breast cancer represents, with no doubt, one of the majors concerns of public health.

Since the 1990s profound changes have taken place in the clinical presentation and management of breast cancer due to mammography screening, and the implementation of effective treatments, including advances in surgery, radiotherapy, chemotherapy and lately biologically targeted therapies. All these innovations have contributed to improve breast cancer survival in the developed countries. Nevertheless, a better understanding of the risk factors and the identification of biological mechanisms that confer sensitivity to those treatments, particularly to chemotherapy, could help to tailor the most adequate therapies to each patient.

\subsection{Genetic Susceptibility to Breast Cancer}

Breast cancer, like other common cancers, tends to cluster in families, with the disease being approximately twofold more common in women whose first-degree relatives have been diagnosed with breast cancer than in women without such a family history. The higher rate of most breast cancers in monozygotic twins of case patients than in dizygotic twins or siblings suggests that most familial clustering is the result of inherited genetic factors rather than lifestyle or environmental factors. Some of this familial aggregation can be explained by mutations in genes that confer high 
risk of disease (high penetrance genes). However, such susceptibility alleles are rare in the population. For example, highly penetrant variants in the breast cancer susceptibility genes BRCA1 and $B R C A 2$, account for less than $20 \%$ of the total genetic risk of breast cancer, and other rarer high penetrance genes such as P53 and PTEN account for less of $5 \%$ of the risk. It is likely that much of the unexplained familial risk is due to alleles of low to moderate penetrance. In other words, the greater part of inherited predisposition to breast cancer and therefore perhaps of other common cancers, may be due to the effect of the combination of genetics variants at several different loci.

Up to date, the main strategy to identify low-penetrance cancer susceptibility genes has been through the analysis of polymorphisms with association studies either with candidate loci or with Genome Wide Association studies (GWAs).

Polymorphisms have been historically classified as commonly occurring $(>1 \%)$ genetic variations in the general population, whereas the rare variants with obvious functional consequences on the protein have been classified as mutations. When a polymorphism involves only a single nucleotide is called Single Nucleotide Polymorphism (SNP), and it has been estimated that more than 10 million SNPs exist in the genome. Compared to mutations, SNPs have been perceived as functionally insignificant, but current evidence emphasizes that many of them affect the intrinsic properties and the function of the proteins to a variable degree. Even those variants that do not cause an amino acid change may also have an impact on the DNA repair phenotype, because they may lie in introns that regulate splicing, may cause RNA instability, or may be linked to genetic changes in other unknown genes.

Although the effect of an individual SNP is generally small, the genetic effect of combinations of functionally relevant SNPs may additively or synergistically contribute to breast cancer risk. This gene-gene interaction is likely to be a ubiquitous component of the genetic architecture of common diseases, such as breast cancer.

Predisposition by combinations of weak genetic variants may be of much greater significance to public health than the marked individual risk seen in the inherited cancer syndromes. 
The identification of these low penetrance variants could allow us to stratify women according to genetic risk, improving the efficiency of screening programs, but, they could also be implicated in the response to chemotherapy and radiotherapy, and their characterization would help us for better clinical decisions.

\subsection{Polymorphisms in DNA repair genes and breast cancer}

DNA repair and cell cycle control mechanisms maintain genomic stability. When DNA damage occurs, DNA repair pathways, cell cycle arrest and apoptosis may be activated. Decrease in this DNA repair ability has been associated with an increased risk of different types of cancer.

Radiation therapy and treatment with chemotherapeutic drugs, such as alkylanting agents (e.g. anthracyclines and platins) can damage DNA directly, through intercalation and also by inducting by-products, such as reactive oxygen species. While DNA repair mechanisms are vital for cell survival and normal functioning, repair of chemotherapy DNA damage is a major contributor to drug resistance in cells. Hence, cellular repair can reduce the effectiveness of chemotherapeutic agents, while cells with down regulated of deficient repair systems display increased sensitivity to many DNA-damaging agents. In vitro and in vivo studies have shown associations between alterations in DNA repair genes and sensitivity to a broad range of drugs and patients survival. In addition, SNPs in genes involved in DNA repair can affect repair efficiency and significantly alter patient responses to cancer treatments.

Among all SNPs in DNA repair genes, we have chosen XRCC3Thr241Met, XRCC1Arg399GIn and XPDLys751GIn because their biological implications have been well characterize and the minor alleles are very frequent in the general population $(>20 \%)$.

\subsubsection{XRCC1 Arg399GIn}

XRCC1 (X-ray repair cross complementation group 1) is a $33 \mathrm{~kb}$ gene located on chromosome 19q13.2-13.3 that encodes a 663 amino acid protein that interacts with many other 
proteins and is also a phosphorilation site for CK2, even though the protein has not enzymatic activity. XRCC1 is involved in the repair of DNA base damage and single strand break (BER) by binding DNA ligase III (LIG3) at its carboxyl domain and by binding DNA polymerase $\beta$ (DNA pol $\beta$ ) at the site of damaged DNA. Therefore, XRCC1 plays an essential role in removing endogenous and exogenous DNA damage.

In vitro, Chinese hamster ovary and breast cancer cells lacking functional XRCC1 protein are hypersensitive to a broad range of DNA damaging agents, and XRCC1 transcript levels correlate positively with cisplatin chemoresistance and hypersensibility to ionizing radiation in cancer cell lines.

More than 60 SNPs have been identified in XRCC1, but probably the most studied one is Arg399GIn, in exon 10, consisting in a nucleotide substitution of $G$ to $A$ that once translated results in an arginine (Arg) to glutamine (Gln) amino acid change at codon 399. It produces significant conformational changes in the protein, including the loss of secondary structural features such as alpha helices that may be critical for protein-protein interactions, altering the ability of XRCC1 to coordinate BER.

Different studies have estimated the Gln variant to be present in $23-36 \%$ of the general population. This allele has been associated with different cancer types, manly in smokers.

\subsubsection{XRCC3 Thr251Met}

XRCC3 (X-ray repair cross complementation group 3) is located on chromosome $14 q 32.3$ and is structurally related to RAD51, with who interacts. XRCC3 is involved in homologous recombinational repair of DNA double strand breaks and crosslinks. XRCC3 deficient cells do not form Rad51 foci after radiation damage, they exhibit genetic instability and increased sensitivity to DNA-damaging agents, such us ultraviolet light.

XRCC3 has a SNP consisting in a substitution of $C$ to $T$ at position 18067 (exon 7) that results in a Thr to Met amino acid change at codon 241. It seems to remove a phosphorilation site 
and thus affect $X R C C 3$ interaction with other proteins involved in homologous recombination that results in a decrease in the cellular capacity to repair DNA.

The T allele is present in 22 to $44 \%$ of general population and has been associated to an increased risk of various malignancies but is also related with the response to various drugs, mainly, alkylanting agents.

\subsubsection{XPD Lys $751 \mathrm{Gln}$}

The 54.3kb XPD gene codes for an evolutionary conserved helicase, a subunit of TFIIH that is essential for transcription and nucleotide excision repair (NER) though the transcriptioncoupled repair mechanisms. Mutations in XPD decrease the helicase activity and prevent the protein form interacting with other factors, resulting in a defect in the repair capacity.

The C-terminal domain of XPD has been implicated in interactions with other components of the TFIIH complex, and it is also the site of a common SNP consisting in a substitution of adenine $(A)$ to cytosine $(C)$ that once translated, results in a Lysine (Lys) to Glutamine (GIn) amino acid change. The substitution produces a significant conformational change immediately terminal to the site of the polymorphism. Functional studies have shown that cells with the $\mathrm{Gln} / \mathrm{Gln}$ variant present with higher levels of chromatid aberrations than the homozygous wild type after ionizing radiation.

According to the previous studies the $C$ allele is present in $30-40 \%$ of the general population, and, has also been associated with an increased risk of different types of cancer, but also with the response to alkylating drugs, such as platin salts or anthracyclines. 


\section{OBJECTIVES}

In this study, we will analyze the association between polymorphisms in DNA repair genes and the development of sporadic breast cancer, as well as the effect of these genetic variants in the patient response to cancer treatments. Therefore, we have established the following objectives:

1. To determine and compare the alleles and genotypes distribution of polymorphisms XRCC1Arg399GIn, XRCC3Thr241Met and XPDLys751GIn in breast cancer patients and controls, in order to establish a possible relation between the different genotypes and breast cancer.

2. To determine the alleles and genotypes distribution of polymorphisms XRCC1Arg399GIn, XRCC3Thr241Met and XPDLys751GIn by age, in breast cancer patients and controls.

3. To analyze the alleles and genotypes distribution of XRCC1Arg399GIn, XRCC3Thr241Met and XPDLys751GIn in breast cancer patients treated with RT to asses a possible asociation with acute and late toxicity.

4. To analyze the potential prognostic value of XRCC1 Arg399GLn, XRCC3Thr241Met y XPDLys751GIn in breast cancer patients.

\section{MATERIAL AND METHODS}

XRCC1Arg399GIn, XRCC3Thr241Met and XPDLys751GIn have been widely studied because their biological significance has been well characterized and the minor alleles are present with relatively high frequency in the general population. We have analyzed the role of these SNPS in breast cancer risk, but we have also explored the possibility that these polymorphisms could affect the age of diagnosis, or the response and sensitivity to breast cancer treatments. Hence, the study has been divided into two parts: the first one is a case-control association study, while the second one is a radio and farmacogenomic study in a cohort of breast cancer patients. 


\subsection{Cases}

Eligible patients were women 18 years or older, diagnosed with breast cancer and treated at Hospital Universitario de Salamanca between 1990 and 2004. Patients were recruited among those who attended the outpatients clinic of the Medical Oncology Department between December 2003 and April 2004 for treatment of follow up.

200 cases were recruited and a data base was created with the clinical data retrospectively collected for each patient. These clinical variants included: Histopathological characteristics of the tumour (type, differentiation grade, hormonal receptors and HER2 amplification); TNM stage; age and hormonal status at diagnosis; treatment characteristics (surgery, radiotherapy, and hormonal therapy and chemotherapy schemes) and follow up data (local relapse, distant metastasis, secondary tumours, disease free survival, overall survival)

Three patients who were find to carry a mutation in the BRCA1 gene during the follow up and other 2 who received high dose chemotherapy with PBPCT (peripheral blood progenitor cells transplantation) were excluded together with another 16 cases whose clinical data were uncompleted and other 5 due to insufficient DNA. Finally, 174 breast cancer patients were included in the study. The youngest was 26.5 years old at diagnosis and the oldest 82.5 (median 62 years).

Majority of cases $(86.2 \%)$ presented with localized breast cancer, being $30 \%$ of them locally advanced. $54.6 \%$ of tumours were $\mathrm{T} 2(2-5 \mathrm{cms})$ and the tumour had spread to the axillary lymphatic nodes in $58 \%$ cases. At the time of diagnosis, 14 cases were already metastatic (8\%).The commonest TNM stage was II. Breast cancer cases and treatments are summarized in tables 71 and 72 . Chemotherapy schemes are detailed in table 17.10 patients were excluded from the survival analysis due to missing some relevant clinical data, but were included in the association study. 
Table 71: Characteristics of breast cancer patients included in the study

\begin{tabular}{|c|c|c|}
\hline Characteristic & No of $\mathrm{Pa}$ & $\begin{array}{c}\text { Percentage } \\
(\%)\end{array}$ \\
\hline $\begin{array}{l}\text { Age (years) } \\
\text { Median } \\
\text { Range }\end{array}$ & \multicolumn{2}{|c|}{$\begin{array}{c}62 \\
26.5-82.5\end{array}$} \\
\hline $\begin{array}{l}\text { Hormonal Status } \\
\text { Premenopausal } \\
\text { Postmenopausal }\end{array}$ & $\begin{array}{c}47 \\
127\end{array}$ & $\begin{array}{l}27 \\
73\end{array}$ \\
\hline $\begin{array}{l}\text { Histotype } \\
\text { Invasive ductal carcinoma (IDC) } \\
\text { Invasive lobulillar carcinoma (ILC) } \\
\text { Inflammatory cancer } \\
\text { Other subtypes }\end{array}$ & $\begin{array}{c}147 \\
12 \\
6 \\
9\end{array}$ & $\begin{array}{l}84.5 \\
6.9 \\
3.4 \\
5.2\end{array}$ \\
\hline $\begin{array}{l}\text { Grade } \\
\text { I } \\
\text { II } \\
\text { III } \\
\text { Unknown }\end{array}$ & $\begin{array}{l}18 \\
57 \\
82 \\
17\end{array}$ & $\begin{array}{c}10.6 \\
32.7 \\
47.2 \\
9.8\end{array}$ \\
\hline $\begin{array}{l}\text { Estrogens Receptor } \\
\text { Positive } \\
\text { Negative } \\
\text { Unknown }\end{array}$ & $\begin{array}{c}113 \\
53 \\
8\end{array}$ & $\begin{array}{c}65 \\
30.5 \\
4.5\end{array}$ \\
\hline $\begin{array}{l}\text { Progesterone Receptor } \\
\text { Positive } \\
\text { Negative } \\
\text { Unknown }\end{array}$ & $\begin{array}{l}93 \\
69 \\
12\end{array}$ & $\begin{array}{l}53.4 \\
9.7 \\
6.9\end{array}$ \\
\hline $\begin{array}{l}\text { HER2 } \\
\text { Positive } \\
\text { Negative } \\
\text { Unknown }\end{array}$ & $\begin{array}{l}32 \\
78 \\
64\end{array}$ & $\begin{array}{l}18.4 \\
44.8 \\
36.8\end{array}$ \\
\hline $\begin{array}{l}\text { Subtype } \\
\quad \text { Luminal } \\
\text { Triple Negative } \\
\text { HER2 } \\
\text { Unknown }\end{array}$ & $\begin{array}{l}117 \\
29 \\
17 \\
11\end{array}$ & $\begin{array}{l}67.3 \\
16.7 \\
9.7 \\
6.3\end{array}$ \\
\hline $\begin{array}{l}\text { Pathological Stage (Local disease) } \\
\text { Tumor Size } \\
0-\leq 2 \mathrm{cms} \\
2-\leq 5 \mathrm{cms} \\
>5 \mathrm{cms}\end{array}$ & $\begin{array}{l}54 \\
82 \\
14\end{array}$ & $\begin{array}{c}36 \\
54.6 \\
9.3\end{array}$ \\
\hline $\begin{array}{l}\text { Lymphatic Nodes (Local disease) } \\
\text { Negative } \\
\text { Positive } \\
1-3 \\
4-9 \\
\geq 10\end{array}$ & $\begin{array}{l}62 \\
87 \\
43 \\
19 \\
25\end{array}$ & $\begin{array}{c}41.4 \\
58 \\
28.6 \\
12.6 \\
18.7\end{array}$ \\
\hline $\begin{array}{l}\text { Metastasis at diagnosis } \\
1 \text { site } \\
\text { Bone } \\
\text { Liver } \\
\text { Skin } \\
\geq 2 \text { sites }\end{array}$ & $\begin{array}{l}11 \\
9 \\
1 \\
1 \\
3\end{array}$ & $\begin{array}{c}78.6 \\
64.3 \\
7.1 \\
7.1 \\
21.4\end{array}$ \\
\hline
\end{tabular}


Table 72: Treatments administered to the breast cancer patients in the study

\begin{tabular}{|c|c|c|}
\hline Type of treatment & No of Patients & Percentage (\%) \\
\hline $\begin{array}{l}\text { Surgical treatment } \\
\text { No surgery } \\
\text { Mastectomy } \\
\text { Quadrantectomy } \\
\text { Tumorectomy } \\
\text { Axillary dissection } \\
\text { No } \\
\text { Sentinel lymph node negative } \\
\text { Axillary lymph node dissection }\end{array}$ & $\begin{array}{c}8 \\
110 \\
18 \\
38 \\
\\
3 \\
24 \\
139\end{array}$ & $\begin{array}{c}4.6 \\
63.2 \\
10.3 \\
21.8 \\
\\
1.8 \\
14.5 \\
83.7\end{array}$ \\
\hline $\begin{array}{l}\text { Radiotherapy } \\
\text { Yes } \\
\text { Axillary boost } \\
\text { No }\end{array}$ & $\begin{array}{c}112 \\
25 \\
61\end{array}$ & $\begin{array}{l}64.4 \\
22.3 \\
35.1\end{array}$ \\
\hline $\begin{array}{l}\text { Hormonal Treatment } \\
\text { No } \\
\text { Tamoxifen } \\
\text { Aromatase inhibitors }\end{array}$ & $\begin{array}{l}35 \\
82 \\
57\end{array}$ & $\begin{array}{l}20.1 \\
47.1 \\
32.8\end{array}$ \\
\hline $\begin{array}{l}\text { Adjuvant treatment } \\
\text { No adjuvant chemotherapy } \\
\text { Schemes containing anthracyclines } \\
\text { Schemes without anthracyclines }\end{array}$ & $\begin{array}{l}12 \\
84 \\
54\end{array}$ & $\begin{array}{c}8 \\
56 \\
36\end{array}$ \\
\hline $\begin{array}{l}\text { Adjuvant taxanes } \\
\text { Schemes with taxanes }\end{array}$ & 19 & 12.7 \\
\hline
\end{tabular}

\subsection{Controls}

Eligible controls were women, 18 years or older with no previous or concurrent malignant disease. 310 controls were recruited between June 2004 and June 2005 in the Accident \& Emergency Department at Hospital Universitario de Salamanca.

174 controls were matched with cases for age ( \pm 3 years) and menstrual status. Median age was 61.5 (range 26.5-91.5). The difference with the case group is not statistically significant $(p=0.996)$.

Another 126 women with age between 20.5 and 98.5 were included in order to enrich the control group with women of every age. Thus, the control group includes 300 women, 25 of which were younger than 35 years old (8.3\%), 55 were older than $80(18.3 \%)$ and the remaining $73.3 \%$ (220) was between 35 and 80 years old (Table 7). 


\subsection{SNPs genotyping}

Blood samples of all patients and controls were collected into $10 \mathrm{ml}$ heparinised tubes. Germline DNA was extracted using the alkaline lyses method and frozen at $-20^{\circ} \mathrm{C}$ until the assay was performed.

At the time the study was started we did not have the required infrastructure to perform RTPCR assays, and the gene polymorphisms were determined by PCR-RFLP. When a RT-PCR system was acquired, the study was finally completed with this technique.

\subsubsection{PCR-RFLP}

For XRCC3Thr241Met, a PCR product of $136 \mathrm{pb}$ was obtained with the following primers ( forward/reverse): 5'-GCC TGG TGG TCA TCG ACT C-3'; 5'-ACA GGG CTC TGG AAG GCA CTG CTC AGC TCA CGC ACC-3'. PCR reactions were carried out in a total volume of $25 \mu$ containing 20ng of genomic DNA. PCR amplifications consisted of an initial denaturing step of $95^{\circ} \mathrm{C}$ for $3 \mathrm{~min}$ and 35 cycles of denaturalization at $95^{\circ} \mathrm{C}(20 \mathrm{sec})$, annealing $\left(60^{\circ} \mathrm{C}, 20 \mathrm{sec}\right)$ and extension $\left(72^{\circ} \mathrm{C}\right.$, $20 \mathrm{sec}$ ). A final extension at $72^{\circ} \mathrm{C}(\mathrm{min})$ was also included. $10 \mu$ l of PCR product was incubated with the restriction enzyme $\mathrm{Ncol}$ (Fermentas, Hanover, $\mathrm{MD}$ ) at $37^{\circ} \mathrm{C}$ for 6 hours. Products were resolved on $3 \%$ agarose gels and stained with ethidium bromide. Three fragments (136, 97 and $39 \mathrm{pb})$ were generated. A $136 \mathrm{pb}$ band corresponded to the CC genotype, two bands of 97 and $39 \mathrm{pb}$, corresponded to the TT genotype, and three bands of 136, 97 and $39 \mathrm{pb}$ corresponded to the TC genotype.

For XPDLys751GIn a PCR product of $161 \mathrm{pb}$ was obtained with the following primers: (forward/reverse) 5'-CTG CTC AGC CTG GAG CAG CTA GAA TCA GAG GAG ACG CTG-3'; 5'AAG ACC TTC TAG CAC CAC CG-3'. The conditions were the same as described above, but the annealing temperature was $62^{\circ} \mathrm{C}$. $10 \mu \mathrm{l}$ of PCR product was incubated with the restriction enzyme 
Pstl (Fermentas, Hanover, MD) at $37^{\circ} \mathrm{C}$ for 6 hours obtaining three fragments of 161,120 and 41 pb. A $161 \mathrm{pb}$ band corresponded to the AA genotype and two bands of 120 and $41 \mathrm{pb}$ corresponded to the CC genotype, whilst three bands of 136,97 and $39 \mathrm{pb}$ corresponded to the heterozygous phenotype.

Ninety five cases and ninety five controls were genotyped with PCR-RFLP. All the samples were genotyped twice for quality control purposes.

\subsubsection{RT-PCR}

The TaqMan assays (Applied Biosystems, Foster City, CA) consists of two primers for PCR of the sequence of interest and two allele specific fluorescent probes. TaqMan probes and primers for each SNP are described in table 9.

PCR reactions were carried out in a total volume of $25 \mu$ l containing $15 \mathrm{ng}$ of genomic DNA. PCR amplifications consisted of an initial denaturing step of $95^{\circ} \mathrm{C}$ for $10 \mathrm{~min}$ and 40 cycles of denaturalization at $92^{\circ} \mathrm{C}(15 \mathrm{sec})$ and annealing $\left(60^{\circ} \mathrm{C} / 56^{\circ}, 1.15 \mathrm{~min}\right)$. A final extension at $60^{\circ} \mathrm{C}$ for 1 min was added.

Genotyping was conducted in StepOne system ${ }^{\circledR}$ (Applied Biosystems, Foster City, CA). Allelic Discrimination Program ${ }^{\circledR}$ software (Applied Biosystems, Foster City, CA), was used to determine the alleles in each sample. For quality control purposes, each sample was processed by duplicate.

XRCC1Arg399GIn allelic discrimination was performed using RT-PCR in the whole sample (174 patients and 300 controls). The same method was used to genotype XRCC3Thr241Met and XPDLys751 in 79 and 205 controls. In addition, another 20 cases and 20 controls previously genotyped with PCR-RFLP were randomly selected to be repeated with RT-PCR. The concordance was $100 \%$ so it was decided not to repeat the entire sample previously genotyped. 


\subsubsection{Statistical Methods}

Descriptive parameters of demographic and clinical variables were described separately for cases and controls. Allelic distribution frequencies in each group were compared with Chi-square test. Median age and distribution was calculated for each allelic subgroup in both cases and controls and later compared using Kruskal-Wallis $\mathrm{K}$ tests.

Chi-square, Cochran-Armitage, Mann-Withnney $\mathrm{U}$ and Kruskal-Wallis $\mathrm{K}$ tests were used when appropriate to analyze the differences in demographic and clinical variables according to the polymorphisms distribution.

Breast cancer patient outcomes were also analyzed. For survival analysis, cases were classified into two subgroups: 1) patients with early breast cancer and 2) patients with metastatic disease. In the first group, Disease Free Survival (DFS) and Overall Survival (OS) were analyzed. OS from Metastasis $\left(O S_{M}\right)$ was analyzed in those patients who presented with metastasic disease at diagnosis and in those who developed metastasis during the follow up.

Disease Free Survival (DFS) was defined as the time elapsed from date of initial surgical treatment until a disease related event occurred (either local or metastatic relapse, contralateral breast cancer or disease related death). Overall Survival (OS) was estimated until death. Overall Survival from Metastasis $\left(O S_{M}\right)$ was defined as the time elapsed since the metastases were diagnosed until death. Data collection cut-off for this analysis was December 2009, when median follow-up was 62 months (range 11-228).

Survival rates and their 95\% confident interval were estimated using the Kaplan-Meier Method. Survival curves plotted with the Kaplan-Meier Method were compared by Cox log-rank test. Survival Hazard Ratio were obtained using a Cox regression model in which all significant variables $(p \leq 0.05)$ in the univariate analysis and those acting as potential confounding factors were introduced.

Statistical analysis was performed with SPSS version 15 (SPSS, Inc, Chicago, IL). 


\section{RESULTS}

\subsection{Genotypes distribution in cases and controls}

We have not found any difference between cases and controls for XPDLys751GIn $(p=0.944)$ and XRCC3Thr241Met ( $p=0.670)$, but the difference observed for the Arg and Gln alleles of XRCC1Arg399GIn is statistically significant (Table 21). Gln/Gln and Gln/Arg are more frequent in cases, while the Arg/Arg genotype is more common in controls [p<0.002; OR 1.96 (CI95\% 1.3-3)].

\subsection{Genotypes distribution in cases and controls by age}

\subsubsection{Controls:}

Alelles and genotypes distribution by age in the control group is shown in table 23. No difference was found in the distribution of those SNP according to age in this group $(p=0.406$, $p=0.782$ and $p=0.667$, XPDLys751 GIn, XRCC1Arg399GIn and XRCC3Thr241Met, respectively).

\subsubsection{Cases:}

Median age of cases carrying the XPDArg751Lys/Lys genotype was 65 years (range: 29.586.5), and 58.5 (26.5-91.5) and 58 (33.5-67.5) for those with the Lys/GIn and GIn/GIn genotypes, respectively. This difference is significant ( $p<0.001)$, OR: 3.52 (IC: 3-5.44) (Tables 24 and 25). When patients were stratified by menstrual status at diagnosis, the Lys/Lys genotype remained more frequent among postmenopausal women ( $p=0.023$ ) (Table 26).

\subsection{Genotype distribution and cutaneous toxicity following radiotherapy}

\subsubsection{Acute toxicity:}

Acute toxicity data were incomplete in 26 cases that were excluded for this analysis. Majority of cases with acute toxicity following RT developed grade 1 or 2 cutaneous toxicity $(24.1 \%$ and $25.9 \%$, respectively) and only one patient presented with grade 4 toxicity (Table 28 ). No association 
was seen in our study between the genetic variants and acute cutaneos toxicity following RT (Table 29) even when axillary boost was administered (Table 30).

\subsubsection{Late toxicity:}

Late cutaneous toxicity was present in 32 of the 91 patients included in the analysis $(35.16 \%)$ Fibrosis was the commonest event, which is also related with surgery. In our sample, no association was seen between any SNPs and late cutaneos toxicity (Table 31). This toxicity is not associated with axilar boost either (Table 32).

\subsubsection{Local relapse after RT:}

After 62 months median follow up, 12 patients out of 112 (10.7\%), who received RT presented local relapse. The XPD751 Lys/Lys was less common among the patients with local relapse (43\% vs $8.3 \%)$, but the difference was not statistically significant. ( $p=0.062)$ (Table 33$)$.

\subsection{SURVIVAL ANALYSIS}

Median follow up was 62 months (11-228), therefore survival analysis was done at 5 years. Considering the whole sample, 5-years DFS was 69.9\% (CI95\% 62.8-77.7) and 5-years OS was $84.2 \%$ (CI95\% 78.1-90.3).

\subsubsection{Early breast cancer}

\subsubsection{Disease Free Survival (DFS)}

65 patients out of 150 with early breast cancer presented with an event in the 60 months after diagnosis, therefore 5-years DFS was 69.9 (CI95\% 62.85\%-77,75\%). Classical prognostic factors for breast cancer were analyzed (tables 34 to 38). In our series, axillary node metastasis, high tumour grade, and HER2 amplification were associated with worse outcome $(p=0.002$, $p=0.013$ and $p=0.047$, respectively), whilst tumour size and hormone receptors expression were not $(p=0.537$ and $p=0.818$, respectively). None of the genetic variants analyzed was associated with DFS in these patients (table 39). 


\subsubsection{Overall Survival}

$84.2 \%$ of patients with early breast cancer were alive 5 years after diagnosis (CI95\% 78.190.3). Median Overall Survival was 140.5 months (IC95\% 108-172.3). Axillary nodes metastasis $(p=0.023)$, tumor grade $(p=0.007)$ and HER2 expression $(p=0.016)$, XRCC3241Met/Met $(p=0.022)$ were associated to 5 -years $\mathrm{OS}$ (table 40 to 46$)$. Tumor grade $(p=0.022)$ and axillary node metastasis $(p=0.05)$ remained to be independent prognostic factors in the multivariate analysis, whilst XRCC3241Met/Met failed ( $p=0.09)$.

\subsubsection{Patients with early breast cancer treated with anthracyclines}

\subsection{Disease Free Survival}

84 out 150 patients with early breast cancer were treated with chemotherapy regimens containing anthracyclines (14 neoadjuvant and 70 adjuvant treatments).

In this subgroup of patients, XRCC1 399Arg/Arg (84\% vs 46.3\%, p=0.007) and XRCC3241Met/Met ( $80.8 \%$ vs 56.3\%, p=0.049) were associated to more prolonged DFS (table 47), as well as axillary nodes $(p=0.003)$, and tumor size $(p=0.001)$ (tables 48 to 52$)$. Multivariate analyses showed XRCC1 399Arg/Arg and tumor size $\geq 5 \mathrm{cms}$ as independent prognostic factors $[(p=0.035 ; \mathrm{HR}=0.4,(\mathrm{Cl} 95 \% 0.2-0.9)$ and $\mathrm{p}=0.002, \mathrm{HR}=2.5,(\mathrm{Cl} 95 \% 1.41-4.43)$, respectively]

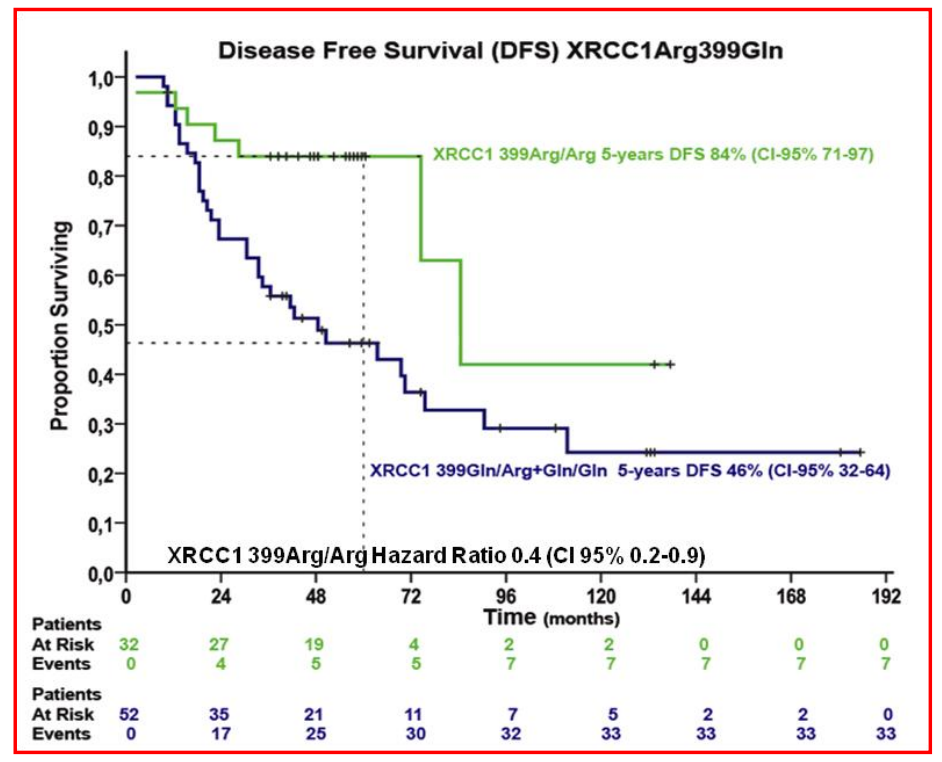

Figure 25: DFS in early breast cancer patients treated with antracyclines and XRCCArg1399GIn genotypes 


\subsection{Overall Survival}

In the subgroup of patients treated with anthracyclines, median OS was 97.5 months (CI95\% 53-141) and 73.7\% (65-83.89) were alive five years after diagnosis.

Patients with the XRCC3 241Met/Met genotype, presented with a longer 5-years OS (100\%) than those with the Thr/Thr and Met/Thr genotypes (69.3\%, IC95\% 57.9-81.5) ( $p=0.027)$ (Table 53). Tumor size and Her2 expression were also positively associated to 5 -years OS ( $p=0.005$ and $p=0.006$, respectively) (table 54 to 58 ). Multivariate analysis reported XRCC3 241 Met/Met and tumor size $\geq 5 \mathrm{cms}$ as independent prognostic factors [ $(\mathrm{p}=0.05, \mathrm{HR}=0.15$ (IC95\% 0.02-0.99), and $p=0.03, H R=1.8(1.059-3.492)$ respectively].

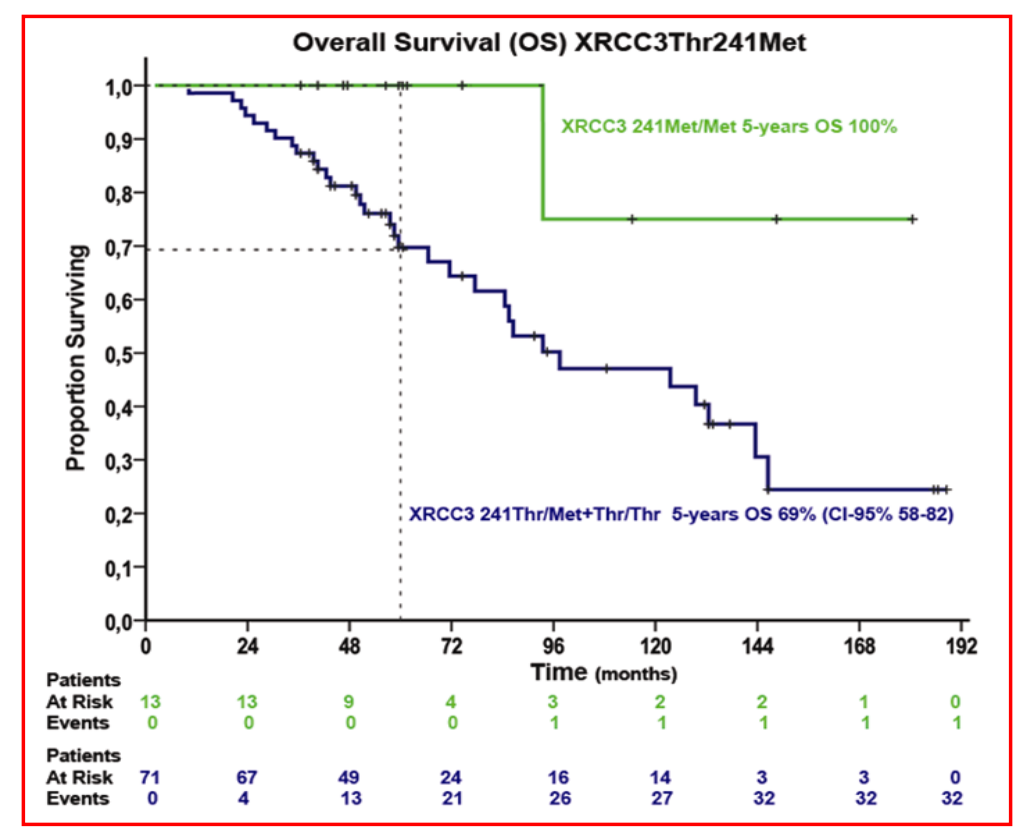

Figura 26: OS in early breast cancer patients treated with anthracyclines and XRCC3Thr241 genotypes

In order to avoid as many confounding factors as possible when evaluating the effect of anthracyclines in early breast cancer outcome, the analysis was repeated without the 19 patients who also received taxanes. In this subgroup of 65 patients, 5 -years DFS was $55.8 \%$ (Cl95\% 44.2$67.6 \%$ ) and median 5 years-DFS was 69.5 months (CI95\% 44.5-94.45). Patients carrying the XRCC1 399Arg/Arg genotype presented prolonged 5years-DFS than those with the Arg/Gln and 
$\mathrm{GIn} / \mathrm{G} \ln$ genotypes $(p=0.021$ ). Once again, axillary node metastasis and tumor size $\geq 5 \mathrm{cms}$ were also related with outcome ( $p<0.0001$ in both cases). The multivariate analysis did not support XRCC1Arg399GIn as independent prognosis factor $(p=0.206)$.

5 years-OS in this group was $72.9 \%$ (CI95\% 62.1-83.7), and median OS was 97.5 months (Cl 54.89-140.1). $100 \%$ of patients carrying the XRCC3 241Met/Met genotype and $68.1 \%$ of those carrying the Met/Thr and Thr/Thr genotypes were alive 60 months after diagnosis $(p=0.034)$, but this SNP failed as independent prognostic factor in the multivariate analysis $(p=0.052)$

\subsubsection{Metastatic breast cancer patients}

14 patients presented with metastasis at the time of diagnosis and in another 63 the diseases spread during the follow up. OSM was 49 months (CI95\% 38-60), and 37\% of patients were alive 5 years after the diagnosis of metastasis (C195\% 25.6-48.4).

None of the factors previously reported as prognostic in metastatic breast cancer patients, such as DFS $\geq 24$ months metastasis localization, hormone receptors expression or HER 2 amplification) were associated with $0 S_{M}$ in our series $(p=0.061, p=0.816, p=0.031, p=0.052$, respectively.) Neither were any of the genetic variants: XRCC1Arg399GIn ( $p=0.763)$, XRCC3Thr241Met $(p=0.073)$ XPDLys751GIn $(p=0.051)$. This subgroup was not stratified according to chemotherapy treatment. 


\section{DISCUSSION}

\subsection{CASE-CONTOL ASSOCIATION STUDY}

The sample for this analysis consisted of 174 breast cancer patients and 174 controls matched on age ( \pm 3 years), sex and ethnicity. The control group was enriched with 126 individuals between 20 to 98 years old.

We recognize that the sample size might be small to detect some differences in the allele frequency. Another limitation is that some risk factors for breast cancer, such as parity or the length of the fertile period were not taken in account when cases and controls were enrolled. On the other hand, it is remarkable that after an exhaustive review of the literature analyzing polymorphic variants of XRCC3, XPD and XRCC1, we found that majority of authors only matched cases and controls on age, sex and hormonal status at diagnosis. Only Shore et al, stratified cases and controls according to age, menstrual status, menarche, parity, contraceptives, hormonal replacement therapy, alcohol intake, body mass index and family history of breast cancer.

\subsubsection{XRCC3Thr241Met, XRCC1Arg399GIn and XPDLys751GIn and breast cancer risk}

In our series XRCC1399Arg/Arg is more frequent in the control group and the $\mathrm{Arg} / \mathrm{Gln}$ and $\mathrm{Gln} / \mathrm{Gln}$ genotypes are more common in cases ( $p=0.002, \mathrm{OR} 1,96, \mathrm{Cl} 95 \%$ 1.3-3). Our results are consistent with three published meta-analysis that found the $\mathrm{Gln} / \mathrm{Gln}$ genotype to be associated to breast cancer. The association seems to be stronger in Asian than in Caucasian populations. Gln allele presented a decreased DNA repair ability in functional studies.

We have not found any association between XRCC3Thr241Met and XPDLys751Gln and breast cancer ( $p=0.670$ and $p=0.944$ ) while some meta-analysis have reported the minor alleles (Met and $\mathrm{Gln}$, respectively) to be associated with the disease ( $O R=1.07$ and 1.05 , respectively). These are very low penetrance genes, which would require the presence of many other factors, such as tobacco or other genetic variants, to increase the risk of breast cancer. Due to the modest 
effect of these variants, a bigger sample than ours might be required to detect any difference in the allele distribution in cases and controls.

\subsubsection{XRCC3Thr241Met, XRCC1Arg399GIn and XPDLys751GIn and age}

Time-dependent accumulation of damage in cells and organs is associated with a gradual functional decline and aging. The molecular basis of this phenomenon remains unclear, whereas also in cancer, DNA alterations are the major culprit. Therefore, cancer and aging are two sides of the same DNA-damage problem. There is an increased incidence of cancer with age due to this intrinsic DNA repair decreased ability and the consequent DNA damage accumulation. But obviously, not all individuals develop cancer when getting older and we hypothesize that this could be in relation with their DNA repair ability.

\subsubsection{Control Group}

If, as we propose, individuals with a better DNA repair ability reach the last decades of life without developing cancer, it is reasonable to expect that the alleles associated with a better DNA repair ability would be more common among the older controls. Young individuals carrying the risk alleles or genotypes would have more chances of developing cancer along their lives and, consequently, would leave the control group.

All controls $(n=300)$ were included for this analysis, so 25 of them were younger than 35 years $(8.3 \%), 55$ were older than 80 years $(18.3 \%)$ and 120 were 35 to 79 years old.

In our series, the allelic distribution is very similar in all groups of age, without any difference between the younger and the elder women. Similar results were reported by Kazimirova, who demonstrated older individuals to accumulate more DNA aberrations than younger, even when de allelic distribution in both groups of age did not differed. In that case, the increased cancer incidence observed in the last decades of life could not be not only conditioned by the inherited 
DNA ability, but by the ageing process itself, which could implicate epigenetic silencing of repairing genes.

\subsubsection{Cases Group}

In our study, women carrying the XPD751Lys/Lys genotype have been diagnosed with breast cancer later than those with the Lys/Gln o Gln/Gln genotypes (65.5 vs 58.5 and 58, respectively), $p=0.001, \mathrm{OR}=3.52$ (CI95\% 3-5.44). When stratified by menstrual status, Lys/Lys is more frequent in the women diagnosed in the menopause while Lys/Gln and $G \ln / G \ln$ is more common in premenopausal patients $(p=0.023)$. Previous studies have demonstrated that XP751GIn presents a decreased DNA repair ability, but increases breast cancer risk very modestly $(O R=1.05)$. It is possible that XPD751GIn enhance other damaging factors by not contributing to repair the lesions these could cause and so, many other elements have to concur to observe an increment in breast cancer risk associated to XP751Gln. The same reasoning is applicable to XRCC1399Arg and XRCC3241Thr, as in our sample these alleles are more frequent in the patients with a later diagnosis, but the difference is not statistically significant.

To our knowledge, this is the first study comparing DNA repair genes allelic distribution according to the age of breast cancer diagnosis and contradicts some of the previous studies that analyze the allelic distribution according to the menstrual status at diagnosis. Nevertheless, Silva et al have taken in account the length of the fertile period while the others only dichotomize the patients in pre or postmenopausal, in spite of using a term that refers to estrogens presence and effect. As they do not take in consideration the period of exposition to estrogens, they are only setting an arbitrary cut-off for the analysis around 45-55 years, when the menopause usually occurs. Many factors that affect breast cancer risk concur with the estrogens exposition, including the aging process itself. Hence, we think that unless all these risk and confounding factors are considered for the analysis, it could be more accurate to compare the median age at diagnosis for each allele instead of comparing the allelic distribution in pre and postmenopausal patients. 


\subsection{XRCC3Thr241Met, XRCC1Arg399GIn and XPDLys751GIn in the cohort of breast cancer patients}

This second part is a retrospective cohort study of outcome following radiotherapy and chemotherapy (anthracycline based) in breast cancer patients.

We are aware of our study weaknesses, such as the sample size, a possible selection bias in the case group, and the lack of some clinical data (e.g. HER2 amplification in $27 \%$ of patients). We neither compared the germline with the tumor genotype, but to our knowledge, but majority of reviewed farmacogenomic studies have not done it either. Even though the statistical power of our study could be insufficient to obtain definitive conclusions, it could be considered an exploratory one.

\subsubsection{XRCC3Thr241Met, XRCC1Arg399GIn and XPDLys751GIn and radiotherapy}

Therapeutic exposure to ionising radiation can induce normal tissue side effects that differ among individuals. Age, body mass index, breast size or tobacco, are some of the factors related to skin toxicity following RT, but a genetic predisposition has also been reported. Persons with very compromised DNA repair capacity, have increased mutation rates, genomic instability and an increased risk of cancer, but in some cases, they also present with an increased sensitivity to RT. Nevertheless, even healthy individuals differ in intrinsic capacity to DNA damage repair, and this variation could be a result of polymorphic variations in genes involved in repair pathways. In fact, several common variants in these genes have been reported to significantly contribute to the amount of unrepaired DNA damage that result in an increase of genetic aberrations and clinical outcomes, such as side toxicity.

Nowadays, radiogenomics is one of the emerging fields of research that focuses on the study of genetic variations as an explanation of interindividual differences in response to accidental and therapeutic radiation exposure. Even when major advances have been introduced in RT treatments to decrease toxicity, $10 \%$ of patients who receive it still develop severe side effects. The identification of genetic variants associated with decreased DNA repair is important as they could 
be used as biomarkers to predict the normal tissue response to radiotherapy and avoid, or at least decrease, RT side effects.

We have not found any significant association of XRCC1Arg399GIn, XRCC3Thr241Met and XPDLys751GIn with the occurrence of RT induced acute and late cutaneous side effects, which is in consonance with other authors. Up to date, no association of XPDLys751GIn with RT side effects has been reported, while both alleles of XRCC3Thr241Met have been related to fibrosis, although majority of studies were negative. On the other hand, many functional studies have shown that cells with the XRCC1 399GIn allele are more sensitive to ionising radiation than those with the Arg allele, and for that reason, this polymorphism has widely been studied in relation to RT side effects. Reported results are inconclusive as many studies have been negative, two have associated the Gln variant with an increased risk of side effects and another one has reported the Arg allele as the risk allele.

We also failed in reporting any association between these polymorphisms and local relapse after RT treatment. In our series, only 12 out of 112 patients treated with RT developed a local relapse $(10.7 \%)$ and is possible that our study lacks of statistical power to detect a difference, if any. On the other hand, up to date, no polymorphism in DNA repair genes has been associated with local relapse after breast cancer treatment.

\subsubsection{XRCC3Thr241Met, XRCC1Arg399GIn and XPDLys751GIn in early breast cancer treated with anthracyclines}

Anthracyclines were isolated from Streptomices peucetius in the 1960's and have been used for more than 40 years to treat different types of solid tumours, lymphoma and leukaemia. Its mechanisms of action have not been completely elucidated but include topoisomerasa II inhibition, lipid peroxidation, reactive oxygen species generation, DNA intercalation and formation of crosslinks and adducts. Majority of these processes led to DNA double strand break and consequently, induce apoptosis. DNA repair is substantial for cells survival, but repair of lesions produced by citotoxic agents could be a mechanism of resistance to these drugs. On the contrary, cells with deficient DNA repair systems could be more sensible to certain forms of chemotherapy. 
Identification of the specific mechanisms that repairs the lesions induced by different chemotherapy drugs could be very helpful for tailoring treatments.

As anthracyclines induce double strand break, Homologous Recombination should be principal in determining sensitivity to these drugs. Spencer and Saffi reported that XRCC3 deficient cells are 6 times more sensible to doxorrubicine and 100 times more sensible to barminomicine. They also reported a similar result in those cells with a XPD deficiency. This was unexpected, as XPD is involved in NER but had not been reported to take part in DSB repair. No difference was seen for cells with a XRCC1 deficiency. These studies were conducted in cells with deleterious mutations of XRCC3, XRCC1 and XPD, but have not been repeated in cells carrying different alleles of polymorphic variants.

In our sample, early breast cancer patients carrying the XRCC3 241 Met/Met genotype presented better outcome that those with the Met/Thr or Thr/Thr genotypes. When the group of 150 patients is analyzed without stratifying by type of chemotherapy, a difference in OS is observed $(p=0.002)$ but XRCC3Thr241Met fails as an independent prognostic factor in the multivariate analysis $(p=0.09)$. On the contrary, when patients are stratified by treatment and only those who received anthracyclines are included, the difference in OS is statistically significant $(p=0.027)$ and XRCC3Thr241Met remains as an independent prognostic factor in the multivariate analysis (Log Rank $p=0.05, H R=0.15$ (CI95\% 0.02-0.9). In this subgroup of patients, XRCC3 241Met/Met was also associated to better DFS in the univariate analysis $(p=0.049)$, but failed in the multivariate. When patients who also received taxanes were excluded $(n=65)$, those with the Met/Met genotype presented again with better OS $(p=0.038)$, but the polymorphism was not confirmed as independent prognostic factor in the multivariate analysis. In summary, XRCC3 Thr241Met could be an independent prognostic factor for anthracyclines based chemotherapy in early breast cancer.

We have not observed any association between XPDLys751GIn and OS or DFS in early breast cancer patient. On the contrary, we have found that early breast cancer patients who received anthracyclines and carried the XRCC1399Arg/Arg genotype presented a more prolonged DFS than those with the other genotypes $(p=0.022)$. XRCC1Arg299Gln was confirmed as an independent prognostic factor in the multivariate analysis (Log Rank $p=0.035, \mathrm{HR}$ 0.4, CI95\% 0.2$0.9)$, but not when the patients treated with taxanes are excluded. These different results could be 
due to the sample size reduction in the second analysis. It is also possible that the first result is mistaken, as the functional studies in culture cells do not support it either, but Bewick et al reported similar results in metastatic breast cancer patients treated with mitroxantrone.

We have exhaustively reviewed the literature, and we could not find any study analyzing XRCC3 Thr241Met, XRCC1 Arg399GIn and XPD Lys750GIn in early breast cancer patients treated with anthracyclines. Only Bewick et al analyzed these variants in 95 metastatic breast cancer patients who received mitroxantrone. They reported that XRCC3 241Met and XRCC1 399Gln, the alleles with decreased DNA repair ability, were associated with worse outcome. They do not offer any explanation or hypothesis, even when these results are opposite to those expected.

Rodriguez et al has recently reported a gene expression signature of DNA repair genes that predicts tumor response to anthracyclines in triple negative breast cancer. Tumors with decreased expression of these DNA repair genes presented a higher rate of pathological complete responses after neoadjuvant treatment with anthracyclines than those with normal expression. Nevertheless, XRCC3, XRCC1 and XPD have not been included in this signature.

There is only one more study analyzing these polymorphisms in patients treated with anthracyclines based chemotherapy. Berwick et al failed to report any association in 120 soft tissue sarcoma cases, although these results must be cautiously considerer as some patients received treatment with anthracyclines while others received only local treatment with surgery $\pm R T$ and there was no stratification by treatment for the survival analysis.

Many authors have studied these genetic variations in lung and head and neck cancer patients treated with platine salts. Platins also produce double strand break and those patients with XRCC3 241Met/Met, XRCC1 399GIn/GIn or XPD751Gln/GIn might be more sensitive to these drugs and present better outcome than those with other genotypes. XRCC3Thr241Met has already been found to be and independent determinant of favourable survival in Non Small Lung Cancer and Head and Neck patients treated with cisplatin.

These studies and our current data further support the urgent need for incorporating DNA repair farmacogenomic studies in order to better tailoring breast cancer treatment strategies. 


\section{CONCLUSIONS}

1. XRCC1 $399 \mathrm{GIn} / \mathrm{Gln}$ and Agl/Arg genotypes are more frequent in breast cancer patients than in controls, suggesting that the Gln allele might be associated to an increased risk of breast cancer.

2. In breast cancer patients, XPD751Lys/Lys is associated with older age at diagnosis than in those with the Lys/GIn and GIn/GIn genotypes. This difference could be related with a proficient DNA repair ability, but it is also possible that XPD751Lys modulates other risk factors.

3. In our series, XRCC1Arg399GIn, XRCC3Thr241Met and XPDLys751GIn are not associated with acute or late cutaneos toxicity following radiotherapy treatment for breast cancer.

4. In our series, XRCC3Thr241Met y XRCC1Arg399GIn are associated to different outcome in early breast cancer patients, probably in relation with the ability to repair DNA double strand breaks secondary to anthracyclines. These polymorphisms might be predictive of survival outcome and could have farmacogenomic implications to better choose the most adequate treatment for breast cancer patients in early stages. 
BIBLIOGRAFÍA 
1. Ferlay J, Boniol M, Heanue M, Colombert M, Boyle P. Estimates of the cancer incidence and mortality in Europe in 2006. Annals of Oncoly 18:581-92. 2007

2. Parkin DM WS, Ferlay J, Suarez B: Cancer Incidence in Five Continents. IARC CancerBase N07, 2005

3. Thümmler K, Kirch W: Data and Information on Women's Health in the European Union. Germany, Directorate General for Health and Consumers, 2010

4. López-Avente G, Pollán M., Aragonés N., et al: La situación del cáncer en España, Centro Nacional de Epidemiología. Ministerio de Sanidad y Consumo, 2009

5. Ferlay J BF, Pisani P, Parkin DM. Globocan 2002: Cancer Incidence, Mortality and Prevalnece Worldwide. IARC CancerBase N05. Version 2.0, 2004

6. Botha JL BF, Sankila R, Parkin DM. Breast cancer incidence and mortality trends in 16 European countries. Eur J Cancer 39:1718-19, 2003

7. Verdecchia A, Brenner $\mathrm{H}$, et al. Recent cancer survival in Europe: a 2000-2002 period analisys of EUROCARE-4 data. Lancet Oncol 8:784-96, 2007

8. Autier $\mathrm{P}$, Boniol M, LaVecchia $\mathrm{C}$, et al. Disparities in breast cancer mortality trends between 30 European countries: retrospective trend analysis of $\mathrm{WHO}$ mortality database. Bmj $341: 03620$

9. de Vita V, Rosenberg S et al. Cancer: Principles and practice of Oncology (ed 8th ). Philadelphia, Lippincott Williams \& Wilkins, 2008

10. Liehr JG. Dual role of oestrogens as hormones and pro-carcinogens: tumour initiation by metabolic activation of oestrogens. European Journal Cancer Prevention 6:3-10, 1997

11. Raftogianis R. CC, and Weinshilboum R. Estrogen metabolism by conjugation. Journal of the National Cancer Institute Monographs 27:113-124, 2000

12. Ross J. HG, et al: Molecular oncology of breast cancer. Sudbury, Mayo, 2005

13. Brinton LA, Williams RR, Hoover RN, et al. Breast cancer risk factors among screening program participants. J Natl Cancer Inst 62:37-44, 1979

14. Lambe M, Hsieh $C$, Trichopoulos D, et al. Transient increase in the risk of breast cancer after giving birth. N Engl J Med 331:5-9, 1994

15. Dumitrescu RG. Understanding breast cancer risk -- where do we stand in 2005? NJournal Cellular and Molecular Medicine 9:208-21, 2005

16. Newcomb PA, Storer BE, Longnecker MP, et al: Lactation and a reduced risk of premenopausal breast cancer. N Engl J Med 330:81-7, 1994

17. Beral V. Breast cancer and hormone-replacement therapy in the Million Women Study. Lancet 362:419-27, 2003

18. Brinton LA, Richesson D, Leitzmann MF, et al. Menopausal hormone therapy and breast cancer risk in the NIH-AARP Diet and Health Study Cohort. Cancer Epidemiol Biomarkers Prev 17:3150-60, 2008

19. Marchbanks PA, Wilson $\mathrm{HG}$ et al. Oral contraceptives and the risk of breast cancer. New England of Journal Medicine 346:2025-32, 2002 
20. McTiernan A. Behavioral risk factors in breast cancer: Can risk be modified? The Oncologist 8:326-334, 2003

21. Key TJ, Appleby PN, Reeves GK, et al. Insulin-like growth factor 1 (IGF1), IGF binding protein 3 (IGFBP3), and breast cancer risk: pooled individual data analysis of 17 prospective studies. Lancet Oncol 11:530-42

22. Amstrong D. Enviromental factors and cancer incidence and mortality in different countries, with special reference to dietary practices. Interantional Journal of Cancer 15:617-631, 1975

23. Willet W. Diet and Cancer. The Oncologist 5:393-404, 2000

24. Hunter DJ, Adami HO, et al. Cohort studies of fat intake and the risk of breast cancer-a pooled analysis. New England Journal of Medicine 334:356-361, 1996

25. Fung TT, Hu FB, Holmes MD, et al. Dietary patterns and the risk of postmenopausal breast cancer. Int J Cancer 116:116-21, 2005

26. Agurs-Collins T, Rosenberg L, Makambi K, et al. Dietary patterns and breast cancer risk in women participating in the Black Women's Health Study. Am J Clin Nutr 90:621-8, 2009

27. Cho E, Spiegelman D, Hunter DJ, et al. Premenopausal dietary carbohydrate, glycemic index, glycemic load, and fiber in relation to risk of breast cancer. Cancer Epidemiol Biomarkers Prev 12:1153-8, 2003

28. Horn-Ross PL, Canchola AJ, West DW, et al. Patterns of alcohol consumption and breast cancer risk in the California Teachers Study cohort. Cancer Epidemiol Biomarkers Prev 13:405-11, 2004

29. Band RP, Fang R, Deschamps M. Carcinogenic and endocrine disrupting of cigarette smoke and risk of breast cancer. Lancet 360:1044-49., 2002

30. Cruz Hernández JJ. Cáncer de mama, in Sidonia N (ed): Lecciones de Oncología Clínica (ed $\left.2^{\mathrm{a}}\right)$. Madrid, 2004

31. Boyd NF, Jong RA, et al. Quantitative classification of mammographic densities and breast cancer risk: results from the Canadian National Breast Screening Study Journal of National Cancer Institute 87:670-675, 1995

32. Harvey JA. Quantitative assessment of mamographic breast density: relationship with breast cancer risk. Radiology 230:29-41, 2004

33. Cummings SR, Tice JA, Bauer $\mathrm{S}$, et al. Prevention of breast cancer in postmenopausal women: approaches to estimating and reducing risk. J Natl Cancer Inst 101:384-98, 2009

34. Brisson J, Sadowsky NL et al. Mamogrphic features of the breast and breast cancer risk. American Journal of Epidemiology 115:428-437, 1982

35. Collaborative group on hormonal factors in breast cancer. Familial breast cancer: collaborative reanalysis of individual data from 52 epidemiological studies including 58,209 women with breast cancer and 101,986 women without the disease. The Lancet 358:138999, 2001

36. Ronckers CM, Land CE. Radiation and breast cancer: a review of the current evidence. Breast Cancer Research 7:21-32, 2005

37. Brody JG. MK, Humblet O, et al. Environmental pollutants and breast cnacer: epidemiologic studies. Cancer 109:2667-711, 2007 
38. Clapp RW, Jacobs MM, Loechler EL: Environmental and occupational causes of cancer: new evidence 2005-2007. Rev Environ Health 23:1-37, 2008

39. Broca P. Traite des tumeurs. Paris, Asselin, 1866

40. Claus EB, Thompson WD. Autosomal dominant inheritance of early-onset breast cancer. Implications for risk prediction. Cancer 73:643-51, 1994

41. Haites N. Overview of the clinical genetics of breast cancer, in Morrison P. HS, and Haites N (ed): Familial breast and ovarian cancer. Cambridge, Cambridge University Press, 2002, pp 6-21

42. Hodgson S, Eng C, and Maher E. Reproductive system, in Hodgson S (ed): A practical guide to human cancer genetics. Cambridge, Cambridge University Press, 2007, pp 67-85

43. Penrose LS, Karn MN. A genetic study of human mamary cancer. Annals of Eugenics 14:234-266, 1948

44. Miki $Y$, Swensen J, Shattuck-Eidens $D$, et al. A strong candidate for the breast and ovarian cancer susceptibility gene BRCA1. Science 266:66-71, 1994

45. Wooster R, Bignell G, Lancaster J, et al. Identification of the breast cancer susceptibility gene BRCA2. Nature 378:789-92, 1995

46. Balmain A. GJ, and Ponder B. The genetics and genomics of cancer. Nature Genetics 33:238-244, 2003

47. Lichtenstein P, Holm NV, Verkasalo PK, et al. Environmental and heritable factors in the causation of cancer--analyses of cohorts of twins from Sweden, Denmark, and Finland. N Engl J Med 343:78-85, 2000

48. Pharoah PD, Bobrow M, et al. Polygenic susceptibility to breast cancer and implications for prevention. Nature Genetics 31:33-36, 2002

49. Peto J. Breast cancer susceptibility-A new look at an old model. Cancer Cell 1:411-2, 2002

50. Gail MH, Brinton LA, Byar DP, et al. Projecting individualized probabilities of developing breast cancer for white females who are being examined annually. J Natl Cancer Inst 81:1879-86, 1989

51. Tyrer J, Duffy SW, Cuzick J. A breast cancer prediction model incorporating familial and personal risk factors. Stat Med 23:1111-30, 2004

52. Costantino JP, Gail MH, Pee D, et al. Validation studies for models projecting the risk of invasive and total breast cancer incidence. J Natl Cancer Inst 91:1541-8, 1999

53. Rockhill B, Spiegelman D, Byrne C, et al. Validation of the Gail et al. model of breast cancer risk prediction and implications for chemoprevention. J Natl Cancer Inst 93:358-66, 2001

54. Gail MH. Value of adding single-nucleotide polymorphism genotypes to a breast cancer risk model. J Natl Cancer Inst 101:959-63, 2009

55. Gail MH, Mai PL. Comparing breast cancer risk assessment models. J Natl Cancer Inst 102:665-8

56. Jacobi $\mathrm{CE}$, de Bock $\mathrm{GH}$, Siegerink $\mathrm{B}$, et al. Differences and similarities in breast cancer risk assessment models in clinical practice: which model to choose? Breast Cancer Res Treat 115:381-90, 2009 
57. Claus EB, Risch NJ, Thompson WD. Age at onset as an indicator of familial risk of breast cancer. Am J Epidemiol 131:961-72, 1990

58. Parmigiani G, Berry $D$, Aguilar $O$. Determining carrier probabilities for breast cancersusceptibility genes BRCA1 and BRCA2. Am J Hum Genet 62:145-58, 1998

59. Antoniou AC, Pharoah PP, Smith $P$, et al. The BOADICEA model of genetic susceptibility to breast and ovarian cancer. Br J Cancer 91:1580-90, 2004

60. Boughey JC, Hartmann LC, Anderson SS, et al. Evaluation of the Tyrer-Cuzick (International Breast Cancer Intervention Study) model for breast cancer risk prediction in women with atypical hyperplasia. J Clin Oncol 28:3591-6

61. Alberts B, Bray D, Lwis J, Raff M, Roberts K, Watson JD. El núcleo celular, in Omega (ed): Biología Molecular de la célula (ed 3ª). Barcelona, 1996, pp 258-265

62. Perou CM, Sorlie T, Eisen MB, et al. Molecular portraits of human breast tumours. Nature 406:747-52, 2000

63. Castro E, Bellido L. Tumores Basal-Like. Mucho más que triple Negativo. Translational Oncology Reviews 4:16-25, 2008

64. Reis-Filho JS, Tutt AN. Triple negative tumours. a critical review. Histopathology 52:108-18, 2008

65. Rakha E, Ellis I, Reis-Filho J. Are triple-negative and basal-like breast cancer synonymous? Clin Cancer Res 14:618; author reply 618-9, 2008

66. Rakha EA, Reis-Filho JS, Ellis IO. Basal-like breast cancer: a critical review. J Clin Oncol 26:2568-81, 2008

67. Irvin WJ, Jr., Carey LA. What is triple-negative breast cancer? Eur J Cancer 44:2799-805, 2008

68. Nielsen TO, Hsu FD, Jensen K, et al. Immunohistochemical and clinical characterization of the basal-like subtype of invasive breast carcinoma. Clin Cancer Res 10:5367-74, 2004

69. van de Vijver MJ, He YD, van't Veer LJ, et al: A gene-expression signature as a predictor of survival in breast cancer. N Engl J Med 347:1999-2009, 2002

70. Livasy CA, Karaca G, Nanda R, et al: Phenotypic evaluation of the basal-like subtype of invasive breast carcinoma. Mod Pathol 19:264-71, 2006

71. Savage K, Lambros MB, Robertson D, et al: Caveolin 1 is overexpressed and amplified in a subset of basal-like and metaplastic breast carcinomas: a morphologic, ultrastructural, immunohistochemical, and in situ hybridization analysis. Clin Cancer Res 13:90-101, 2007

72. Rodriguez-Pinilla SM, Sarrio D, Moreno-Bueno G, et al. Sox2: a possible driver of the basallike phenotype in sporadic breast cancer. Mod Pathol 20:474-81, 2007

73. Rodriguez-Pinilla SM, Sarrio D, Honrado $E$, et al. Vimentin and laminin expression is associated with basal-like phenotype in both sporadic and BRCA1-associated breast carcinomas. J Clin Pathol 60:1006-12, 2007

74. Charafe-Jauffret E, Ginestier C, Monville F, et al. Gene expression profiling of breast cell lines identifies potential new basal markers. Oncogene 25:2273-84, 2006 
75. Weigelt B, Glas AM, Wessels LF, et al. Gene expression profiles of primary breast tumors maintained in distant metastases. Proc Natl Acad Sci U S A 100:15901-5, 2003

76. Bueno-de-Mesquita JM, Linn SC, Keijzer R, et al. Validation of 70-gene prognosis signature in node-negative breast cancer. Breast Cancer Res Treat 117:483-95, 2009

77. Sotiriou C, Neo SY, McShane LM, et al. Breast cancer classification and prognosis based on gene expression profiles from a population-based study. Proc Natl Acad Sci U S A 100:10393-8, 2003

78. Rakha EA, El-Sayed ME, Green AR, et al. Prognostic markers in triple-negative breast cancer. Cancer 109:25-32, 2007

79. Hanahan D. The hallmarks of cancer. Cell 100:57-70, 2000

80. Osborne C., Tripathy D. Oncogenes and tumor suppressor genes in breast cancer. Potential diagnostic and therapeutic applications. The Oncologist 9:361-377, 2004

81. Knowles M. Oncogenes, in Selby Ka (ed): Cellular and molecular biology of cancer (ed 4). Oxford, Oxford University Press, 2005, pp 117-134

82. Laín S. Tumour supressor genes, in P. Kmas (ed): Cellular and molecular biology of cancer (ed 4). Oxford, Oxford University Press, 2005, pp 135-155

83. Hodgson S, Eng C, and Maher E. Genetic couselling in a familial cancer clinic, in Hodgson S, Eng $\mathrm{C}$, and Maher $\mathrm{E}$ (eds): A practical guide to human cancer genetics. Cambridge, Cambridge University Press, 2007, pp 3-9

84. Lallo F. How to evaluate a family history, Risk assessment and management in cancer genetics (ed 1st). Oxford, Oxford University Press, 2005

85. Wooster R, Lancaster $\mathrm{J}$, et al. Identification of the breast cancer susceptibility gene BRCA2. Nature 378:789-792, 1995

86. Haites N. Overview of the clinical genetics of breast cancer, in Morrison P. HS, and Haites N., (ed): Familial breast and ovarian cancer. Cambridge, Cambridge University Press, 2002, pp 6-21

87. Ford $D$, Easton DF, Stratton $M$, et al. Genetic heterogeneity and penetrance analysis of the BRCA1 and BRCA2 genes in breast cancer families. The Breast Cancer Linkage Consortium. Am J Hum Genet 62:676-89, 1998

88. Milne RL, Osorio A, Cajal TR. The average cumulative risks of breast and ovarian cancer for carriers of mutations in BRCA1 and BRCA2 attending genetic counseling units in Spain. Clinical Cancer Research 14:2861-9, 2008

89. Wang X, Pankratz VS, Fredericksen Z, et al. Common variants associated with breast cancer in genome-wide association studies are modifiers of breast cancer risk in BRCA1 and BRCA2 mutation carriers. Hum Mol Genet

90. Houlston RS, Tomlinson IP. Detecting low penetrance genes in cancer: the way ahead. J Med Genet 37:161-7, 2000

91. Eeles R. Genetic predisposition to cancer, (ed 2nd). London, Arnold, 2004

92. Easton D, Dunning A, et al. Genome-wide association study identifies novel breast cancer susceptibility loci. Nature 447:1087-1093, 2007 
93. Smith $\mathrm{T}$, Freimanis $\mathrm{R}$, et al. Poligenic model of DNA repair genetic polymorphisms in human breast cancer risk. Carcinogenesis 29:2132-2138, 2008

94. Balmain A, Gray J, and Ponder B. The genetics and genomics of cancer. Nature Genetics 33:238-244, 2003

95. Pharoah PD, Easton D, et al. Polygenes, risk prediction and targeted prevention of Breast Cancer. New England Journal of Medicine 358:2796-803, 2008

96. Easton DF, Eeles RA. Genome-wide association studies in cancer. Hum Mol Genet 17:R109-15, 2008

97. Wacholder S, Hartge P, Prentice R, et al. Performance of common genetic variants in breastcancer risk models. N Engl J Med 362:986-93

98. Kruglyak $L$ and Nickerson DA. Variations is the spice of life. Nature Genetics 27:234-236, 2001

99. Strachan T. Human Molecular Genetics. Oxford, BIOS scientific, 1996

100. Newton-Cheh C, Hischhorn J. Genetic association studies of complex traits: design and analysis issues. Mutation Research 573:54-69, 2005

101. Wooster R, Lancaster J, et al. Identification of the breast cancer susceptibility gene BRCA2. Nature 378:789-792, 1995

102. Shen MR, Mohrenweiser H. Nonconsevative Amino Acid Substitution Variants Exist at Polymorphic Frequency in DNA Repair Genes in Healthy Humans. Cancer Research 58:604608, 1998

103. Gonzalez-Neira AR, Osorio A, et al. Genomewide high-density SNP linkage analysis of non BRCA1/2 breast cancer identifies various candidate regions and has greater power than microsatellite studies. BMC Genomics 8:299, 2007

104. Milne RL, Ribas G, et al. Evaluating new candidate SNPs as low penetrance risk factors in sporadic breast cancer: A two-stage Spanish case-control study. Gynecological oncology 112:210-214, 2009

105. Friedberg E. How Nucleotide excision repair protects against Cancer. Nature reviews in Cancer. 1:22-23, 2001

106. Ford BN, Kyle VL, Brackley ME, Glickman BW. Identification of single nucleotide polymorphisms in human DNA repair genes. Carcinogénesis 21:1977-1981., 2000

107. Wood RD, Sgouros J, and Lindahl T. Human DNA repair genes. Science. 291:1284-1289., 2001

108. Hoeijmakers J. Genome maintenance mechanisms for preventing cancer. Nature 411:366374,2001

109. Kolodner R. Eukaryotic DNA mismatch repair. Current Opinion in Genetics \& Development. 9:89-96, 1999

110. Hanawalt PC, Ford JM, Lloyd DR. Funtional characterization of global genomic DNA repair and its implications for cancer. . Mutation Reserch 544:107-114, 2003

111. Karran P. DNA double strand break repair in mammalian cells. Current Opinion in Genetics \& Development 10:144-150, 2000 
112. Modrich P. Strand-specific mismatch Repair in Mammalian Cells. The Journal of Biological Chemistry. 272:24727-24730, 1997

113. Hsieh P. Molecular mechanisms of DNA mismatch repair. Mutation Research 486:71-87, 2001

114. Bronner CE, Morrison PT, et al. Mutation in th DNA mismatch repair gene homologue hMLH1 is associated with hereditary nonpolyposic colon cancer. Nature 368:258-261, 1994

115. Eshleman JR, Marcowitz SD. Microsatellite inestability in inherited and sporadic neoplasms. Current Opinion in Oncology 7:83-89, 1996

116. Li G. DNA Mistmach Repair: Biological functions and molecular mechanisms, in Wei $Q$, and Chen D, (ed): DNA repair, genetic inestability and cancer. London, World Scientific, 2007, pp $87-117$

117. Lindahl T, Wood RD. DNA excision repair pathways. Current Opinion in Genetics \& Development. 7:158-169, 1997

118. Lindahl T. Quality control by DNA Repair. Science 286, 1999

119. Haber J. Partners and Pathways repairing a double-strand break. Trends in Genetics 16:259264,2000

120. Sonoda E, Saberi A, Taniguchi Y, and Takeda S. Differential usage of non-homologous endjoining and homologous recombination in double strand break repair. DNA repair 5:10211029, 2006

121. Shen Z, Nickoloff J. Mammalian homologous recombination repair and cancer intervention, in Wei Q, Chen D (ed): DNA repair, genetic instability and cancer London, World Scientific, 2007, pp 119-156

122. Mimitou EP, Symington LS. DNA end resection: many nucleases make light work. DNA Repair (Amst) 8:983-95, 2009

123. Jackson S. Sensing and repairing DNA double-strand breaks. Carcinogenesis 23:687-696, 2002

124. San Filippo J, Sung P, Klein H. Mechanism of eukaryotic homologous recombination. Annu Rev Biochem 77:229-57, 2008

125. Li L. Nucleotide Excision Repair, in Wei Q, Chen D (ed): DNA repair, genetic instability and cancer. London, World Scientific, 2007, pp 63-85

126. Hoeijmakers JH. TFHIIH: a key component in multiple DNA transactions. Current Opinion in Genetics \& Development 6: 26-33, 1996

127. Laat WL, and Hoejimakers J. Molecular mechanism of nucleotide excision repair. . Genes and development 13:768-785, 1999

128. De Boer J, Hoeijmakers J. Nucleotide excision repair and human syndroms. Carcinogenesis 21:453-360, 2000

129. Hang B. Base Excision Repair, in Wei Q. LL, and Chen D., (ed): DNA repair, genetic instability and cancer. London, World Science, 2007, pp 23-64

130. Ladiges WC. Mouse models of XRCC1 DNA repair polymorphisms and cancer. Oncogene 25:1612-1619, 2006 
131. Chen D, Yu Z, Zhu Z, et al. E2F1 regulates the base excision repair gene XRCC1 and promotes DNA repair. J Biol Chem 283:15381-9, 2008

132. Tebbs RS, Flannery ML, Meneses JJ, et al. Requirement for the Xrcc1 DNA base excision repair gene during early mouse development. Dev Biol 208:513-29, 1999

133. Shen MR, Zdzienicka MZ, Mohrenweiser H, et al. Mutations in hamster single-strand break repair gene XRCC1 causing defective DNA repair. Nucleic Acids Res 26:1032-7, 1998

134. Monaco R, Rosal R, Dolan MA, et al. Conformational effects of a common codon 399 polymorphism on the BRCT1 domain of the XRCC1 protein. Protein J 26:541-6, 2007

135. Duell EJ, Cheng TJ, Varkonvi A, Zuo ZF, Ashok TD, Mark EJ, Wain JC, Cristiani DC, Kelse KT. Polymorphims in the DNA repair genes XRCC1 and ERCC2 and biomarkers of DNA damage in human blood mononuclear cells. Carcinogenesis 21:965-971, 2000

136. Matullo G, Palli D, Peluso M, et al. XRCC1, XRCC3, XPD gene polymorphisms, smoking and (32)P-DNA adducts in a sample of healthy subjects. Carcinogenesis 22:1437-45, 2001

137. Saadat M, Ansari-Lari M. Polymorphism of XRCC1 (at codon 399) and susceptibility to breast cancer, a meta-analysis of the literatures. Breast Cancer Res Treat 115:137-44, 2009

138. Saadat M, Kohan L, Omidvari S. Genetic polymorphisms of XRCC1 (codon 399) and susceptibility to breast cancer in Iranian women, a case-control study. Breast Cancer Res Treat 111:549-53, 2008

139. Hu Z, Ma H, Chen F, et al. XRCC1 polymorphisms and cancer risk: a meta-analysis of 38 case-control studies. Cancer Epidemiol Biomarkers Prev 14:1810-8, 2005

140. Hu JJ, Smith TR, Miller MS, et al: Genetic regulation of ionizing radiation sensitivity and breast cancer risk. Environ Mol Mutagen 39:208-15, 2002

141. Li H, Ha TC, Tai BC: XRCC1 gene polymorphisms and breast cancer risk in different populations: a meta-analysis. Breast 18:183-91, 2009

142. Liu N, Lamerdin JE, Tebbs RS, et al: XRCC2 and XRCC3, new human Rad51-family members, promote chromosome stability and protect against DNA cross-links and other damages. Mol Cell 1:783-93, 1998

143. Brenneman MA, Weiss AE, Nickoloff JA, et al: XRCC3 is required for efficient repair of chromosome breaks by homologous recombination. Mutat Res 459:89-97, 2000

144. Schild D, Lio YC, Collins DW, et al: Evidence for simultaneous protein interactions between human Rad51 paralogs. J Biol Chem 275:16443-9, 2000

145. Henry-Mowatt J, Jackson D, Masson JY, et al: XRCC3 and Rad51 modulate replication fork progression on damaged vertebrate chromosomes. Mol Cell 11:1109-17, 2003

146. Nagaraju G, Hartlerode A, Kwok A, et al: XRCC2 and XRCC3 regulate the balance between short- and long-tract gene conversions between sister chromatids. Mol Cell Biol 29:4283-94, 2009

147. Xu ZY, Loignon M, Han FY, et al: Xrcc3 induces cisplatin resistance by stimulation of Rad51related recombinational repair, S-phase checkpoint activation, and reduced apoptosis. J Pharmacol Exp Ther 314:495-505, 2005 
148. Alsbeih G, El-Sebaie M, Al-Harbi N, et al: Radiosensitivity of human fibroblasts is associated with amino acid substitution variants in susceptible genes and correlates with the number of risk alleles. Int J Radiat Oncol Biol Phys 68:229-35, 2007

149. Griffin CS: Aneuploidy, centrosome activity and chromosome instability in cells deficient in homologous recombination repair. Mutat Res 504:149-55, 2002

150. Tebbs RS, Zhao Y, Tucker JD, et al: Correction of chromosomal instability and sensitivity to diverse mutagens by a cloned cDNA of the XRCC3 DNA repair gene. Proc Natl Acad Sci U S A 92:6354-8, 1995

151. Au WW, Salama SA, Sierra-Torres $\mathrm{CH}$ : Functional characterization of polymorphisms in DNA repair genes using cytogenetic challenge assays. Environ Health Perspect 111:1843-50, 2003

152. Krupa R, Synowiec E, Pawlowska E, et al: Polymorphism of the homologous recombination repair genes RAD51 and XRCC3 in breast cancer. Exp Mol Pathol 87:32-5, 2009

153. Han S, Zhang HT, Wang Z, et al: DNA repair gene XRCC3 polymorphisms and cancer risk: a meta-analysis of 48 case-control studies. Eur J Hum Genet 14:1136-44, 2006

154. Manuguerra M, Karagas $M$, et al. XRCC3 and XPD/ERCC2 single nucleotide Polymorphims and the risk of cancer: a HuGe review. American Journal of Epidemiology 164:297-302, 2006

155. Garcia-Closas M, Newcomb P, et al. Polymorphisms in DNA double-strand break repair genes and risk of breast cancer: two population-based studies in USA and Poland and metaanalyses. Human Genetics, 2006

156. de las Penas R. S-RM, Alberola V, et al. Polymorphisms in DNA repair genes modulate survival in cisplatine/gemcitabine treated non-small cell lung cancer patients. Annals of Oncology 17:668-675, 2006

157. Bewick MA, Conlon MS, Lafrenie RM: Polymorphisms in XRCC1, XRCC3, and CCND1 and survival after treatment for metastatic breast cancer. J Clin Oncol 24:5645-51, 2006

158. Farnebo $L$, Jedlinski $A$, Ansell $A$, et al: Proteins and single nucleotide polymorphisms involved in apoptosis, growth control, and DNA repair predict cisplatin sensitivity in head and neck cancer cell lines. Int J Mol Med 24:549-56, 2009

159. Schaeffer L, Moncollin V, Roy R, et al: The ERCC2/DNA repair protein is associated with the class II BTF2/TFIIH transcription factor. Embo J 13:2388-92, 1994

160. Andreassen $\mathrm{J}$, Wit $\mathrm{J}$, et al. An Xpd mouse model for the combined xeroderma pigmentosum/Cockayne syndrome exhibiting both cancer predisposition and segmental progeria. Cancer Cell 10:121-132, 2006

161. Lehmann AR. DNA repair-deficient diseases, xeroderma pigmentosum, Cockayne syndrome and trichothiodystrophy. Biochimie 85:1101-11, 2003

162. Clarkson SG, Wood RD. Polymorphisms in the human XPD (ERCC2) gene, DNA repair capacity and cancer susceptibility: an appraisal. DNA Repair (Amst) 4:1068-74, 2005

163. Broughton BC, Steingrimsdottir H, Lehmann AR. Five polymorphisms in the coding sequence of the xeroderma pigmentosum group D gene. Mutat Res 362:209-11, 1996 
164. Monaco R, Rosal R, Dolan MA, et al. Conformational effects of a common codon 751 polymorphism on the C-terminal domain of the xeroderma pigmentosum $\mathrm{D}$ protein. $\mathrm{J}$ Carcinog 8:12, 2009

165. Lunn R, Parsahd R, Umbach D, Harris E, Sanford K, Bell A. XPD polymorphisms: effects on DNA repair proficency. Carcinogenesis 4:551-555, 2000

166. Vodicka $\mathrm{P}$, Kumar $\mathrm{R}$, Stetina $\mathrm{R}$, et al. Genetic polymorphisms in DNA repair genes and possible links with DNA repair rates, chromosomal aberrations and single-strand breaks in DNA. Carcinogenesis 25:757-63, 2004

167. Saiki RK, Scharf S, Faloona F, et al. Enzymatic amplification of beta-globin genomic sequences and restriction site analysis for diagnosis of sickle cell anemia. Science 230:1350-4, 1985

168. Mullis KB, Faloona FA. Specific synthesis of DNA in vitro via a polymerase-catalyzed chain reaction. Methods Enzymol 155:335-50, 1987

169. Kubista M, Bengtsson M, et al. The real time polymerase chain reaction. Molecular aspeccts of medicine 27:95-125, 2006

170. Higuchi R, Dollinge G, Watson R. PCR-analysis: real time monitoring of DNA amplification reactions. Biotechnology (NY) 11:1026-1030, 1993

171. Ma H, Chen G, Quiao T, Chuang M. Application of real-time polymerase chain reaction. The Jouranl of American Science 2:1-15, 2006

172. Kollias J, Elston CW, Ellis IO, et al. Early-onset breast cancer--histopathological and prognostic considerations. Br J Cancer 75:1318-23, 1997

173. Kataja V, Castiglione M. Primary breast cancer: ESMO clinical recommendations for diagnosis, treatment and follow-up. Ann Oncol 20 Suppl 4:10-4, 2009

174. Fisher B, Anderson S, Tan-Chiu E, et al. Tamoxifen and chemotherapy for axillary nodenegative, estrogen receptor-negative breast cancer: findings from National Surgical Adjuvant Breast and Bowel Project B-23. J Clin Oncol 19:931-42, 2001

175. Levine MN, Bramwell VH, Pritchard KI, et al. Randomized trial of intensive cyclophosphamide, epirubicin, and fluorouracil chemotherapy compared with cyclophosphamide, methotrexate, and fluorouracil in premenopausal women with nodepositive breast cancer. National Cancer Institute of Canada Clinical Trials Group. J Clin Oncol 16:2651-8, 1998

176. Nadji M, Gomez-Fernandez C, Ganjei-Azar P, et al: Immunohistochemistry of estrogen and progesterone receptors reconsidered: experience with 5,993 breast cancers. Am J Clin Pathol 123:21-7, 2005

177. De Maeyer L, Van Limbergen E, De Nys K, et al: Does estrogen receptor negative/progesterone receptor positive breast carcinoma exist? J Clin Oncol 26:335-6; author reply 336-8, 2008

178. Alapetite $C$, Thirion $P$, de la Rochefordiere $A$, et al: Analysis by alkaline comet assay of cancer patients with severe reactions to radiotherapy: defective rejoining of radioinduced DNA strand breaks in lymphocytes of breast cancer patients. Int J Cancer 83:83-90, 1999

179. Gatti RA: The inherited basis of human radiosensitivity. Acta Oncol 40:702-11, 2001 
180. Wolmark N, Wang J, Mamounas E, et al: Preoperative chemotherapy in patients with operable breast cancer: nine-year results from National Surgical Adjuvant Breast and Bowel Project B-18. J Natl Cancer Inst Monogr:96-102, 2001

181. Valagussa P, Bonadonna G, Veronesi U: Patterns of relapse and survival following radical mastectomy. Analysis of 716 consecutive patients. Cancer 41:1170-8, 1978

182. Rosen PP, Groshen S, Kinne DW, et al: Factors influencing prognosis in node-negative breast carcinoma: analysis of 767 T1NOMO/T2NOMO patients with long-term follow-up. J Clin Oncol 11:2090-100, 1993

183. Bloom HJ, Richardson WW: Histological grading and prognosis in breast cancer; a study of 1409 cases of which 359 have been followed for 15 years. Br J Cancer 11:359-77, 1957

184. Le Doussal V, Tubiana-Hulin M, Friedman S, et al: Prognostic value of histologic grade nuclear components of Scarff-Bloom-Richardson (SBR). An improved score modification based on a multivariate analysis of 1262 invasive ductal breast carcinomas. Cancer 64:191421, 1989

185. Fisher B, Redmond C, Fisher ER, et al: Relative worth of estrogen or progesterone receptor and pathologic characteristics of differentiation as indicators of prognosis in node negative breast cancer patients: findings from National Surgical Adjuvant Breast and Bowel Project Protocol B-06. J Clin Oncol 6:1076-87, 1988

186. Crowe JP, Hubay CA, Pearson $\mathrm{OH}$, et al: Estrogen receptor status as a prognostic indicator for stage I breast cancer patients. Breast Cancer Res Treat 2:171-6, 1982

187. Slamon DJ, Godolphin W, Jones LA, et al: Studies of the HER-2/neu proto-oncogene in human breast and ovarian cancer. Science 244:707-12, 1989

188. Allred DC, Clark GM, Tandon AK, et al: HER-2/neu in node-negative breast cancer: prognostic significance of overexpression influenced by the presence of in situ carcinoma. $\mathrm{J}$ Clin Oncol 10:599-605, 1992

189. Andrulis IL, Bull SB, Blackstein ME, et al: neu/erbB-2 amplification identifies a poorprognosis group of women with node-negative breast cancer. Toronto Breast Cancer Study Group. J Clin Oncol 16:1340-9, 1998

190. Florez: Farmacologia Humana (ed 3). Barcelona, 1999

191. Martin M, Pienkowski T, Mackey J, et al: Adjuvant docetaxel for node-positive breast cancer. N Engl J Med 352:2302-13, 2005

192. Mamounas EP, Bryant J, Lembersky B, et al: Paclitaxel after doxorubicin plus cyclophosphamide as adjuvant chemotherapy for node-positive breast cancer: results from NSABP B-28. J Clin Oncol 23:3686-96, 2005

193. Hirschhorn JN, Daly MJ: Genome-wide association studies for common diseases and complex traits. Nat Rev Genet 6:95-108, 2005

194. Ioannidis JP, Ntzani EE, Trikalinos TA, et al: Replication validity of genetic association studies. Nat Genet 29:306-9, 2001

195. Cardon LR, Bell Jl: Association study designs for complex diseases. Nat Rev Genet 2:91-9, 2001 
196. Shore RE, Zeleniuch-Jacquotte A, Currie D, et al: Polymorphisms in XPC and ERCC2 genes, smoking and breast cancer risk. Int J Cancer 122:2101-5, 2008

197. Lee SA, Lee KM, Park SK, et al: Genetic polymorphism of XRCC3 Thr241Met and breast cancer risk: case-control study in Korean women and meta-analysis of 12 studies. Breast Cancer Res Treat 103:71-6, 2007

198. Debniak T, Scott RJ, Huzarski T, et al: XPD common variants and their association with melanoma and breast cancer risk. Breast Cancer Res Treat 98:209-15, 2006

199. Patel AV, Calle EE, Pavluck AL, et al: A prospective study of XRCC1 (X-ray crosscomplementing group 1) polymorphisms and breast cancer risk. Breast Cancer Res 7:R1168-73, 2005

200. Han J, Haiman C, Niu T, et al: Genetic variation in DNA repair pathway genes and premenopausal breast cancer risk. Breast Cancer Res Treat 115:613-22, 2009

201. Au WW, Navasumrit $P$, Ruchirawat M: Use of biomarkers to characterize functions of polymorphic DNA repair genotypes. Int J Hyg Environ Health 207:301-13, 2004

202. Vodicka P, Stetina R, Polakova V, et al: Association of DNA repair polymorphisms with DNA repair functional outcomes in healthy human subjects. Carcinogenesis 28:657-64, 2007

203. Synowiec E, Stefanska J, Morawiec Z, et al: Association between DNA damage, DNA repair genes variability and clinical characteristics in breast cancer patients. Mutat Res 648:65-72, 2008

204. Kazimirova A, Barancokova M, Dzupinkova Z, et al: Micronuclei and chromosomal aberrations, important markers of ageing: possible association with XPC and XPD polymorphisms. Mutat Res 661:35-40, 2009

205. Weng $\mathrm{H}$, Morimoto $\mathrm{K}$ : Differential responses to mutagens among human lymphocyte subpopulations. Mutat Res 672:1-9, 2009

206. Weng H, Weng Z, Lu Y, et al: Effects of cigarette smoking, XRCC1 genetic polymorphisms, and age on basal DNA damage in human blood mononuclear cells. Mutat Res 679:59-64, 2009

207. Millikan RC, Player JS, Decotret AR, et al: Polymorphisms in DNA repair genes, medical exposure to ionizing radiation, and breast cancer risk. Cancer Epidemiol Biomarkers Prev 14:2326-34, 2005

208. Figueiredo JC, Knight JA, Briollais L, et al: Polymorphisms XRCC1-R399Q and XRCC3$\mathrm{T} 241 \mathrm{M}$ and the risk of breast cancer at the Ontario site of the Breast Cancer Family Registry. Cancer Epidemiol Biomarkers Prev 13:583-91, 2004

209. Han J, Hankinson SE, Ranu H, et al: Polymorphisms in DNA double-strand break repair genes and breast cancer risk in the Nurses' Health Study. Carcinogenesis 25:189-95, 2004

210. Jacobsen NR, Nexo BA, Olsen A, et al: No association between the DNA repair gene XRCC3 T241M polymorphism and risk of skin cancer and breast cancer. Cancer Epidemiol Biomarkers Prev 12:584-5, 2003

211. Matullo G, Dunning AM, Guarrera S, et al: DNA repair polymorphisms and cancer risk in nonsmokers in a cohort study. Carcinogenesis 27:997-1007, 2006 
212. Harms C, Salama SA, Sierra-Torres $\mathrm{CH}$, et al: Polymorphisms in DNA repair genes, chromosome aberrations, and lung cancer. Environ Mol Mutagen 44:74-82, 2004

213. Butkiewicz D, Rusin M, Enewold L, et al: Genetic polymorphisms in DNA repair genes and risk of lung cancer. Carcinogenesis 22:593-7, 2001

214. Ye W, Kumar R, Bacova G, et al: The XPD 751 Gln allele is associated with an increased risk for esophageal adenocarcinoma: a population-based case-control study in Sweden. Carcinogenesis 27:1835-41, 2006

215. Huang WY, Berndt SI, Kang D, et al: Nucleotide excision repair gene polymorphisms and risk of advanced colorectal adenoma: XPC polymorphisms modify smoking-related risk. Cancer Epidemiol Biomarkers Prev 15:306-11, 2006

216. Seedhouse C, Bainton R, Lewis M, et al: The genotype distribution of the XRCC1 gene indicates a role for base excision repair in the development of therapy-related acute myeloblastic leukemia. Blood 100:3761-6, 2002

217. Moreno V, Gemignani F, Landi S, et al: Polymorphisms in genes of nucleotide and base excision repair: risk and prognosis of colorectal cancer. Clin Cancer Res 12:2101-8, 2006

218. Jiang J, Zhang $X$, Yang $H$, et al: Polymorphisms of DNA repair genes: ADPRT, XRCC1, and XPD and cancer risk in genetic epidemiology. Methods Mol Biol 471:305-33, 2009

219. Li C, Jiang Z, Liu X: XPD Lys(751)GIn and Asp (312)Asn polymorphisms and bladder cancer risk: a meta-analysis. Mol Biol Rep 37:301-9

220. Le Morvan V, Longy M, Bonaiti-Pellie C, et al: Genetic polymorphisms of the XPG and XPD nucleotide excision repair genes in sarcoma patients. Int J Cancer 119:1732-5, 2006

221. Huang Y, Li L, Yu L: XRCC1 Arg399GIn, Arg194Trp and Arg280His polymorphisms in breast cancer risk: a meta-analysis. Mutagenesis 24:331-9, 2009

222. Kuschel B. AA, McBride S., Novik L., Antoniou A., Lipscombe J., Day N., Easton D., Ponder B., Pharoah P., and Dunning A., : Variants in DNA double-strand break repair genes and breast cancer susceptibility. . Human Molecular Genetics 11, 2002

223. Economopoulos KP, Sergentanis TN: XRCC3 Thr241Met polymorphism and breast cancer risk: a meta-analysis. Breast Cancer Res Treat 121:439-43

224. Kuschel B, Chenevix-Trench G, Spurdle AB, et al: Common polymorphisms in ERCC2 (Xeroderma pigmentosum $\mathrm{D}$ ) are not associated with breast cancer risk. Cancer Epidemiol Biomarkers Prev 14:1828-31, 2005

225. Brewster AM, Jorgensen TJ, Ruczinski I, et al: Polymorphisms of the DNA repair genes XPD (Lys751GIn) and XRCC1 (Arg399GIn and Arg194Trp): relationship to breast cancer risk and familial predisposition to breast cancer. Breast Cancer Res Treat 95:73-80, 2006

226. Shen J, Desai M, Agrawal M, et al: Polymorphisms in nucleotide excision repair genes and DNA repair capacity phenotype in sisters discordant for breast cancer. Cancer Epidemiol Biomarkers Prev 15:1614-9, 2006

227. Costa S, Pinto D, Pereira D, et al: XRCC1 Arg399GIn and RAD51 5'UTR G135C polymorphisms and their outcome in tumor aggressiveness and survival of Portuguese breast cancer patients. Breast Cancer Res Treat 109:183-5, 2008 
228. Jorgensen TJ, Visvanathan K, Ruczinski I, et al: Breast cancer risk is not associated with polymorphic forms of xeroderma pigmentosum genes in a cohort of women from Washington County, Maryland. Breast Cancer Res Treat 101:65-71, 2007

229. Rajaraman $P$, Bhatti $P$, Doody MM, et al: Nucleotide excision repair polymorphisms may modify ionizing radiation-related breast cancer risk in US radiologic technologists. Int $\mathrm{J}$ Cancer 123:2713-6, 2008

230. Jiang Z, Li C, Xu Y, et al: Associations between XPD polymorphisms and risk of breast cancer: a meta-analysis. Breast Cancer Res Treat

231. Andressoo JO, Hoeijmakers JH, Mitchell JR: Nucleotide excision repair disorders and the balance between cancer and aging. Cell Cycle 5:2886-8, 2006

232. Kirkwood TB: Understanding the odd science of aging. Cell 120:437-47, 2005

233. Hughes KA, Reynolds RM: Evolutionary and mechanistic theories of aging. Annu Rev Entomol 50:421-45, 2005

234. Martin GM: Modalities of gene action predicted by the classical evolutionary biological theory of aging. Ann N Y Acad Sci 1100:14-20, 2007

235. Hoeijmakers JH: DNA damage, aging, and cancer. N Engl J Med 361:1475-85, 2009

236. Arai T, Sawabe M, Hosoi T, et al: Role of DNA repair systems in malignant tumor development in the elderly. Geriatr Gerontol Int 8:65-72, 2008

237. Polosak J, Roszkowska-Gancarz M, Kurylowicz A, et al: Decreased expression and the Lys751GIn polymorphism of the XPD gene are associated with extreme longevity. Biogerontology 11:287-97

238. Silva SN, Moita R, Azevedo AP, et al: Menopausal age and XRCC1 gene polymorphisms: role in breast cancer risk. Cancer Detect Prev 31:303-9, 2007

239. Sram RJ, Beskid O, Binkova B, et al: Chromosomal aberrations in environmentally exposed population in relation to metabolic and DNA repair genes polymorphisms. Mutat Res 620:2233, 2007

240. Perez-Cadahia B, Laffon B, Valdiglesias V, et al: Cytogenetic effects induced by Prestige oil on human populations: the role of polymorphisms in genes involved in metabolism and DNA repair. Mutat Res 653:117-23, 2008

241. Fisher B, Anderson S, Bryant J, et al: Twenty-year follow-up of a randomized trial comparing total mastectomy, lumpectomy, and lumpectomy plus irradiation for the treatment of invasive breast cancer. N Engl J Med 347:1233-41, 2002

242. Veronesi U, Cascinelli N, Mariani L, et al: Twenty-year follow-up of a randomized study comparing breast-conserving surgery with radical mastectomy for early breast cancer. $\mathrm{N}$ Engl J Med 347:1227-32, 2002

243. Twardella D, Popanda O, Helmbold I, et al: Personal characteristics, therapy modalities and individual DNA repair capacity as predictive factors of acute skin toxicity in an unselected cohort of breast cancer patients receiving radiotherapy. Radiother Oncol 69:145-53, 2003

244. Popanda O, Ebbeler R, Twardella D, et al: Radiation-induced DNA damage and repair in lymphocytes from breast cancer patients and their correlation with acute skin reactions to radiotherapy. Int J Radiat Oncol Biol Phys 55:1216-25, 2003 
245. Alsbeih G, Al-Harbi N, Al-Buhairi M, et al: Association between TP53 codon 72 singlenucleotide polymorphism and radiation sensitivity of human fibroblasts. Radiat Res 167:53540, 2007

246. Alsbeih G, Torres M, Al-Harbi N, et al: Evidence that individual variations in TP53 and CDKN1A protein responsiveness are related to inherent radiation sensitivity. Radiat Res 167:58-65, 2007

247. Popanda O, Marquardt JU, Chang-Claude J, et al: Genetic variation in normal tissue toxicity induced by ionizing radiation. Mutat Res 667:58-69, 2009

248. Andreassen $\mathrm{CN}$, Alsner J, Overgaard $\mathrm{M}$, et al: Prediction of normal tissue radiosensitivity from polymorphisms in candidate genes. Radiother Oncol 69:127-35, 2003

249. Andreassen $\mathrm{CN}$ : Can risk of radiotherapy-induced normal tissue complications be predicted from genetic profiles? Acta Oncol 44:801-15, 2005

250. Lilla C, Ambrosone CB, Kropp S, et al: Predictive factors for late normal tissue complications following radiotherapy for breast cancer. Breast Cancer Res Treat 106:143-50, 2007

251. Chang-Claude J, Popanda O, Tan XL, et al: Association between polymorphisms in the DNA repair genes, XRCC1, APE1, and XPD and acute side effects of radiotherapy in breast cancer patients. Clin Cancer Res 11:4802-9, 2005

252. Chang-Claude J, Ambrosone CB, Lilla C, et al: Genetic polymorphisms in DNA repair and damage response genes and late normal tissue complications of radiotherapy for breast cancer. Br J Cancer 100:1680-6, 2009

253. Popanda O, Tan XL, Ambrosone CB, et al: Genetic polymorphisms in the DNA double-strand break repair genes XRCC3, XRCC2, and NBS1 are not associated with acute side effects of radiotherapy in breast cancer patients. Cancer Epidemiol Biomarkers Prev 15:1048-50, 2006

254. Sterpone S, Cozzi R: Influence of XRCC1 Genetic Polymorphisms on lonizing RadiationInduced DNA Damage and Repair. J Nucleic Acids 2010

255. Sterpone S, Cornetta T, Padua L, et al: DNA repair capacity and acute radiotherapy adverse effects in Italian breast cancer patients. Mutat Res 684:43-8

256. Andreassen CN, Overgaard J, Alsner J, et al: ATM sequence variants and risk of radiationinduced subcutaneous fibrosis after postmastectomy radiotherapy. Int J Radiat Oncol Biol Phys 64:776-83, 2006

257. Andreassen CN, Alsner J, Overgaard J, et al: TGFB1 polymorphisms are associated with risk of late normal tissue complications in the breast after radiotherapy for early breast cancer. Radiother Oncol 75:18-21, 2005

258. Suga T, Ishikawa A, Kohda M, et al: Haplotype-based analysis of genes associated with risk of adverse skin reactions after radiotherapy in breast cancer patients. Int J Radiat Oncol Biol Phys 69:685-93, 2007

259. Giotopoulos G, Symonds RP, Foweraker K, et al: The late radiotherapy normal tissue injury phenotypes of telangiectasia, fibrosis and atrophy in breast cancer patients have distinct genotype-dependent causes. Br J Cancer 96:1001-7, 2007

260. Moullan N, Cox DG, Angele S, et al: Polymorphisms in the DNA repair gene XRCC1, breast cancer risk, and response to radiotherapy. Cancer Epidemiol Biomarkers Prev 12:1168-74, 2003 
261. Andreassen $\mathrm{CN}$, Alsner J: Genetic variants and normal tissue toxicity after radiotherapy: a systematic review. Radiother Oncol 92:299-309, 2009

262. Ho AY, Atencio DP, Peters S, et al: Genetic predictors of adverse radiotherapy effects: the Gene-PARE project. Int J Radiat Oncol Biol Phys 65:646-55, 2006

263. Tewey KM, Rowe TC, Yang L, et al: Adriamycin-induced DNA damage mediated by mammalian DNA topoisomerase II. Science 226:466-8, 1984

264. Gutteridge JM, Quinlan GJ: Free radical damage to deoxyribose by anthracycline, aureolic acid and aminoquinone antitumour antibiotics. An essential requirement for iron, semiquinones and hydrogen peroxide. Biochem Pharmacol 34:4099-103, 1985

265. Sinha BK, Mimnaugh EG, Rajagopalan S, et al: Adriamycin activation and oxygen free radical formation in human breast tumor cells: protective role of glutathione peroxidase in adriamycin resistance. Cancer Res 49:3844-8, 1989

266. Bustamante J, Galleano M, Medrano EE, et al: Adriamycin effects on hydroperoxide metabolism and growth of human breast tumor cells. Breast Cancer Res Treat 17:145-53, 1990

267. Feinstein E, Canaani E, Weiner LM: Dependence of nucleic acid degradation on in situ freeradical production by adriamycin. Biochemistry 32:13156-61, 1993

268. Griffin-Green EA, Zaleska MM, Erecinska M: Adriamycin-induced lipid peroxidation in mitochondria and microsomes. Biochem Pharmacol 37:3071-7, 1988

269. Fukuda $F$, Kitada M, Horie $T$, et al: Evaluation of adriamycin-induced lipid peroxidation. Biochem Pharmacol 44:755-60, 1992

270. Skladanowski A, Konopa J: Relevance of interstrand DNA crosslinking induced by anthracyclines for their biological activity. Biochem Pharmacol 47:2279-87, 1994

271. Skladanowski A, Konopa J: Interstrand DNA crosslinking induced by anthracyclines in tumour cells. Biochem Pharmacol 47:2269-78, 1994

272. Zeman SM, Phillips DR, Crothers DM: Characterization of covalent adriamycin-DNA adducts. Proc Natl Acad Sci U S A 95:11561-5, 1998

273. Di Marco A, Silvestrini R, Di Marco S, et al: Inhibiting effect of the new cytotoxic antibiotic daunomycin on nucleic acids and mitotic activity of HeLa cells. J Cell Biol 27:545-50, 1965

274. Zunino F, Gambetta R, Di Marco A, et al: A comparison of the effects of daunomycin and adriamycin on various DNA polymerases. Cancer Res 35:754-60, 1975

275. Gewirtz DA: A critical evaluation of the mechanisms of action proposed for the antitumor effects of the anthracycline antibiotics adriamycin and daunorubicin. Biochem Pharmacol $57: 727-41,1999$

276. Swift LP, Rephaeli A, Nudelman A, et al: Doxorubicin-DNA adducts induce a nontopoisomerase II-mediated form of cell death. Cancer Res 66:4863-71, 2006

277. Patel S, Sprung AU, Keller BA, et al: Identification of yeast DNA topoisomerase II mutants resistant to the antitumor drug doxorubicin: implications for the mechanisms of doxorubicin action and cytotoxicity. Mol Pharmacol 52:658-66, 1997

278. Moro S, Beretta GL, Dal Ben D, et al: Interaction model for anthracycline activity against DNA topoisomerase II. Biochemistry 43:7503-13, 2004 
279. Harris LN, Yang L, Liotcheva V, et al: Induction of topoisomerase II activity after ErbB2 activation is associated with a differential response to breast cancer chemotherapy. Clin Cancer Res 7:1497-504, 2001

280. Knoop AS, Knudsen $H$, Balslev $E$, et al: retrospective analysis of topoisomerase Ila amplifications and deletions as predictive markers in primary breast cancer patients randomly assigned to cyclophosphamide, methotrexate, and fluorouracil or cyclophosphamide, epirubicin, and fluorouracil: Danish Breast Cancer Cooperative Group. J Clin Oncol 23:7483-90, 2005

281. Tanner M, Isola J, Wiklund $\mathrm{T}$, et al: Topoisomerase llalpha gene amplification predicts favorable treatment response to tailored and dose-escalated anthracycline-based adjuvant chemotherapy in HER-2/neu-amplified breast cancer: Scandinavian Breast Group Trial 9401. J Clin Oncol 24:2428-36, 2006

282. Di Leo A, Gancberg D, Larsimont D, et al: HER-2 amplification and topoisomerase llalpha gene aberrations as predictive markers in node-positive breast cancer patients randomly treated either with an anthracycline-based therapy or with cyclophosphamide, methotrexate, and 5-fluorouracil. Clin Cancer Res 8:1107-16, 2002

283. Harris LN, Broadwater G, Abu-Khalaf M, et al: Topoisomerase II\{alpha\} amplification does not predict benefit from dose-intense cyclophosphamide, doxorubicin, and fluorouracil therapy in HER2-amplified early breast cancer: results of CALGB 8541/150013. J Clin Oncol 27:3430-6, 2009

284. Jackson SP, Bartek J: The DNA-damage response in human biology and disease. Nature 461:1071-8, 2009

285. Spencer DM, Bilardi RA, Koch $\mathrm{TH}$, et al: DNA repair in response to anthracycline-DNA adducts: a role for both homologous recombination and nucleotide excision repair. Mutat Res 638:110-21, 2008

286. Saffi J, Agnoletto MH, Guecheva TN, et al: Effect of the anti-neoplastic drug doxorubicin on XPD-mutated DNA repair-deficient human cells. DNA Repair (Amst) 9:40-7

287. De Laurentiis M, Cancello G, D'Agostino D, et al: Taxane-based combinations as adjuvant chemotherapy of early breast cancer: a meta-analysis of randomized trials. J Clin Oncol 26:44-53, 2008

288. Jones SE, Savin MA, Holmes FA, et al: Phase III trial comparing doxorubicin plus cyclophosphamide with docetaxel plus cyclophosphamide as adjuvant therapy for operable breast cancer. J Clin Oncol 24:5381-7, 2006

289. Roche H, Fumoleau $P$, Spielmann $M$, et al: Sequential adjuvant epirubicin-based and docetaxel chemotherapy for node-positive breast cancer patients: the FNCLCC PACS 01 Trial. J Clin Oncol 24:5664-71, 2006

290. Yarosh DB, Pena A, Brown DA: DNA repair gene polymorphisms affect cytotoxicity in the National Cancer Institute Human Tumour Cell Line Screening Panel. Biomarkers 10:188-202, 2005

291. Rodriguez AA, Makris A, Wu MF, et al: DNA repair signature is associated with anthracycline response in triple negative breast cancer patients. Breast Cancer Res Treat 123:189-96

292. Berwick M, Matullo G, Song YS, et al: Association between aryl hydrocarbon receptor genotype and survival in soft tissue sarcoma. J Clin Oncol 22:3997-4001, 2004 
293. Chew HK, Doroshow JH, Frankel P, et al: Phase II studies of gemcitabine and cisplatin in heavily and minimally pretreated metastatic breast cancer. J Clin Oncol 27:2163-9, 2009

294. de las Penas R, Sanchez-Ronco M, Alberola V, et al: Polymorphisms in DNA repair genes modulate survival in cisplatin/gemcitabine-treated non-small-cell lung cancer patients. Ann Oncol 17:668-75, 2006

295. Kalikaki A, Kanaki M, Vassalou $\mathrm{H}$, et al: DNA repair gene polymorphisms predict favorable clinical outcome in advanced non-small-cell lung cancer. Clin Lung Cancer 10:118-23, 2009

296. Sun X, Li F, Sun N, et al: Polymorphisms in XRCC1 and XPG and response to platinumbased chemotherapy in advanced non-small cell lung cancer patients. Lung Cancer 65:2306, 2009

297. Quintela-Fandino M, Hitt R, Medina PP, et al: DNA-repair gene polymorphisms predict favorable clinical outcome among patients with advanced squamous cell carcinoma of the head and neck treated with cisplatin-based induction chemotherapy. J Clin Oncol 24:4333-9, 2006

298. Ruzzo A, Graziano F, Kawakami K, et al: Pharmacogenetic profiling and clinical outcome of patients with advanced gastric cancer treated with palliative chemotherapy. J Clin Oncol 24:1883-91, 2006

299. Vangsted A, Gimsing P, Klausen TW, et al: Polymorphisms in the genes ERCC2, XRCC3 and CD3EAP influence treatment outcome in multiple myeloma patients undergoing autologous bone marrow transplantation. Int J Cancer 120:1036-45, 2007 
Bibliografía 